\title{
Options for Wastewater Management in Harare, Zimbabwe
}

\author{
DISSERTATION \\ Submitted in fulfilment of the requirements of \\ the Academic Board of Wageningen University and \\ the Academic Board of the UNESCO-IHE Institute for Water Education \\ for the Degree of DOCTOR \\ to be defended in public \\ on Tuesday, 18 May 2004 at 15:00 h in Delft, The Netherlands
}

by

INNOCENT NHAPI

born in Chegutu District, Zimbabwe 
Promoter:

Prof. Dr. H.J. Gijzen

Professor of Environmental Biotechnology

UNESCO-IHE Institute for Water Education, The Netherlands

Co-promoter: $\quad$ Dr. M.A. Siebel, P.E.

Associate Professor in Environmental Biotechnology

UNESCO-IHE Institute for Water Education, The Netherlands

Awarding Committee: Prof. Dr. D. Huisingh

University of Tennessee, United States of America

Prof. Dr. ir. C.J.N. Buisman

Wageningen University, The Netherlands

Prof. Dr. P. Marjanovic

UNESCO-IHE Institute for Water Education, The Netherlands

Prof. Dr. B.E. Marshall

University of Zimbabwe, Zimbabwe

Prof. Dr. ir. H.H.G. Savenije

UNESCO-IHE Institute for Water Education, The Netherlands

Copyright (C) 2004 Taylor \& Francis Group plc, London, UK

All rights reserved. No part of this publication or the information contained herein may be reproduced, stored in a retrieval system, or transmitted in any form or by any means, electronic, mechanical, by photocopying, recording or otherwise, without written prior permission from the publisher.

Although all care is taken to ensure the integrity and quality of this publication and the information herein, no responsibility is assumed by the publishers nor the authors for any damage to property or persons as a result of operation or use of this publication and/or the information contained herein.

Published by A.A. Balkema Publishers, a member of Taylor \& Francis Group plc. www.balkema.nl and www.tandf.co.uk

ISBN 9058096971 (Taylor \& Francis Group)

ISBN 9058040442 (Wageningen University) 


\title{
NN08201,3584
}

\author{
Propositjons \\ Belonging to the thesis: \\ "Options for Wastewater Management in Harare, Zimbabwe" \\ by Innocent Nhapi, 18 May 2004
}

The effective management of wastewater in urban areas requires different solutions for different landuses, i.e., industrial, commercial, and residential areas.

The management of wastewater for environmental protection requires a systematic approach that ensures progressive filtering out of nutrients starting with pollution prevention/reduction measures at the point of generation, up to offsite treatment focusing on recovery and reuse of wastewater components (water, nutrients, and biogas).

A poor or incomplete institutional framework could prevent satisfactory performance of any sanitation technology, even when this technology is technically sound and properly designed, and constructed.

The standards for effluent disposal could have a significant influence on project feasibility. Realistic standards are required to safeguard public health and protection against adverse environmental impacts.

The custodianship of water and wastewater treatment plants in many developing countries needs to be clearly defined and a command structure established. At present there are confusions and conflicts between civil, electrical, and mechanical engineers on one hand, and chemists on the other.

The decentralised wastewater management concept offers a framework for the development of wastewater systems that a re more financially a ffordable, $m$ ore socially responsible, and more environmentally benign than conventional centralised systems.

Wealth protects the rich; poverty destroys the poor.

Giving land to the poor could be a good starting point in fighting poverty. However, it is the availability and access to water that will ensure the productive use of that land; thus empowering the poor. 
To my father, who died in the final stages of the preparation of this thesis on 24/06/03: Paidamoyo 


\section{CONTENTS}

Acknowledgements vii

Abstract viii

Chapter 1 Introduction $\quad 1$

Chapter 2 Inventory of Existing Water Management Practices in Harare, Zimbabwe 22

Chapter 3 Impact of Urbanisation on Water Quality of Lake Chivero, Zimbabwe 40

Chapter 4 A Strategic Framework for Managing Wastewater: A Case Study of Harare, 57 Zimbabwe

Chapter 5 Options for Onsite Management of Wastewater in Harare, Zimbabwe 77

Chapter 6 Options for Decentralised Management of Wastewater in Harare, Zimbabwe 96

Chapter 7 Centralised Management of Wastewater in Harare, Zimbabwe: Current Practice 115 and Future Options

Chapter 8 Effluent Polishing via Pasture Irrigation in Harare, Zimbabwe 133

Chapter 9 Proposal for the Sustainable Management of Wastewater in Harare, Zimbabwe $\quad 148$

$\begin{array}{ll}\text { Summary (in English) } & 167\end{array}$

$\begin{array}{ll}\text { Summary (in Dutch) } & 173\end{array}$

Curriculum Vitae 


\section{ACKNOWLEDGEMENTS}

The author is very grateful to all those who have generously contributed their time in the production of this thesis. In particular, I feel greatly indebted to my Promoter, Professor H.J. Gijzen of UNESCO-JHE Institute for Water Education, together with my Mentor, Assoc. Professor M.A. Siebel, for their guidance, criticisms and valued advice. Special thanks also to Dr. Pieter van der Zaag and Eng. E. Kaseke for their administrative and supporting roles. I would also like to extend my gratitude to Dr G.G. O'loughlin of Sydney, Australia, for encouragement, and University of Zimbabwe staff from various departments, especially Professors B.E. Marshall and M.F. Zaranyika, and the laboratory staff of the Civil Engineering Department. Part of the work that was carried out and published in conjunction with MSc students - Eng. Misery Mawere and Mrs. Sithabile Tirivarombo - is gratefully acknowledged. Also of special mention is the assistance I received from Eng. Zvikomborero Hoko, Dr. Jerry Ndamba, and Mr. Job Dalu, which resuited in joint publications with each of them.

I would like to acknowledge financial support that made my study possible: SAlL Project (Netherlands Government), SIDAVAREC fund at the University of Zimbabwe, and the Water Research Fund for Southern Africa. I would also like to pay special tribute to all professionals who have contributed to a large body of knowledge in urban wastewater management. The use of their material is acknowledged with thanks. Last, but certainly not least, I would aiso like to extend my sincere appreciation to my wife and family members for their patience and endurance throughout my studies. 


\section{ABSTRACT}

The capital city of Zimbabwe, Harare, has adopted an urban water cycle that is geared towards high level service provision. Water supply and sewerage/sanitation coverage amounts to over $98 \%$, which makes Harare one of the cities in Africa with the highest coverage. The city's high volume of water abstraction from its main water resource, Lake Chivero, however, can no longer be sustained. The lake has been seriously polluted by large volumes of (partially) treated effluents from wastewater treatment plants in Harare and the neighbouring town of Chitungwiza. It also receives pollution from agricultural, solid waste, industrial, and natural sources. Most of the wastewater treatment plants in the lake's catchment are overloaded and they experience frequent breakdowns. This situation has been worsened by repeated years of drought, resulting in the accumulation of nitrogen and phosphorous in the lake. The negative impacts of this have been reflected in periodic fish kills, proliferation of algae and water hyacinth, and the reduction in biological diversity. Other related problems are difficulties in potable water treatment and clogging of irrigation pipes.

There is now an urgent need to control pollution loads and to remove contaminants that have accumulated in Lake Chivero over many years. A great deal could be achieved through rational management of the urban water system and the associated nutrient cycle. This should be based on an integrated approach that includes reduction of water consumption, and the wise use of water through pollution prevention/reduction measures. On the water supply side, available options include reduction of water losses (now at $\pm 30 \%$ ), water-saving installations (in households, commerce, and industry), direct reuse (e.g., greywater), and alternative water resources (e.g., rainwater harvesting and groundwater). On the wastewater side, options available include onsite, decentralised and centralised treatment plus reuse.

The general objectives of this research were to assess the contribution of wastewater from Harare to the nitrogen and phosphorous inflows into Lake Chivero and, based on this assessment, to formulate feasible sanitary engineering solutions to the problem of excessive nutrient inflows into the lake. The research specifically targeted nutrients because these are the major problem parameters. BOD is largely taken care of via current wastewater treatment and river self-purification processes. The general strategy was to intervene at various levels; i.e., property, decentralised and centralised levels, with various options aimed at reducing water use and limiting wastewater production and reusing or recycling water and nutrients. This strategy would reduce nitrogen and phosphorous flows to the lake, whilst increasing water availability. 
An extensive water quality and quantity monitoring study in the Chivero catchment was carried out from June 2000 to December 2001 to assess the current situation in terms of water use, treatment and reuse levels, and flow balances. In addition, current contributions of wastewater discharges to nutrient flows in the rivers and Lake Chivero were assessed. Intervention strategies were developed based on an approach, referred to as the "3-Step Strategic Approach" to wastewater management. The steps include: 1) pollution prevention/reduction at source, 2) treatment in the direction of reuse, and 3) disposal with stimulation of self-purification capacity of the receiving water body. The three steps should be considered in this chronological order. Options considered include source control by the users (residents, industries, etc) using various strategies such as greywater separation and reuse, implementation of toilets with urine separation, and other ecological methods of wastewater management. Other possible options are invoking better behaviour through fees and information, and user responsibility through education, legislative changes and stricter controls over industry. Options for boosting the selfpurification capacity of water bodies include introducing wetlands into the river system via natural overflow, land irrigation, reducing retention time in the lake, etc. Flexible and differential solutions were developed for each landuse category (commercial, industrial and residential).

The results of this study confirmed that wastewater plays a major role in the pollution of Lake Chivero. Wastewater contributed over $50 \%$ of the annual water flows in the major inflow rivers of Marimba and Mukuvisi. Water quality was found to be an urgent problem that requires immediate action whilst water scarcity was considered a medium-term problem. The river water quality for points upstream and downstream of wastewater discharge points were far above the $0.03 \mathrm{mg} / \mathrm{TP}$ required for avoiding excessive plant growth in rivers. The lake nutrient concentrations were $2.0 \pm 1.3 \mathrm{mg} / \mathrm{TN}$ and $0.6 \pm 3 \mathrm{mg} / \mathrm{lP}$ ( \pm standard deviation), reflecting a hypertrophic status. Nearly $70 \%$ of the annual phosphorus infiows were retained within the lake, which had a hydraulic retention time of $1.6 \pm 1.1$ years based on rainfall years 1981/2 to 2000/1. However, for the monitoring period, the hydraulic retention time reduced to 0.4 years due to the heavy rains received in that period. Besides the need to substantially reduce nutrient inflows in Lake Chivero, adequate water inflows are also essential for the flushing out of nutrients from the lake, especially phosphorus. The continued accumulation of phosphorus in the lake sediments leads to an internal phosphorus cycle, further complicating remedial measures.

The effective reduction of nutrient inflows into Lake Chivero hinges on solutions related to wastewater management. It is in this context that the "3-Step Strategic Approach" was applied, focusing on wastewater treatment and reuse options at onsite, decentralised, and centralised 
levels. An aggregation of these options led to the development of short-term, medium-term, and long-term solutions. It was estimated that significant improvements in the lake water quality (to about $0.4 \mathrm{mg} / \mathrm{TN}$ and $0.07 \mathrm{mg} / \mathrm{TP}$ in the medium-term) could be achieved by applying the measures suggested in this dissertation. In addition, the treatment of part of the effluent to tertiary standard and subsequent discharge into Lake Chivero could also reduce the lake hydraulic retention time to below 0.5 years, thereby enhancing the flushing out of nutrients. It was concluded that both water quality and quantity problems in the Chivero catchment could be significantly reduced via improvements in wastewater management in combination with the control of other point and non-point sources of pollution. 


\section{Chapter 1}

\section{Introduction}

Parts of this Chapter were submitted as:

Nhapi, I. and Gijzen, H.J. (2004) Wastewater Management in Zimbabwe in the Context of Sustainability, paper accepted for publication in the Water Policy Journal, January 2004. 


\section{Introduction}

\section{Developments in Water Management}

There is now almost universal acceptance of the basic principle that water resources need to be managed in an integrated manner (ICWE, 1992; Cosgrove and Rijsberman, 2000). The relationship between water quality, safe water supply, appropriate sanitation, pollution prevention/control, and the need to feed increasing populations is particularly important in this era of frequent droughts, floods and disease outbreaks. Drought forecasting and mitigation, water security assessment, and water demand management are areas that are receiving attention more than before at both local and international conferences. Related areas are water end-use efficiency, system efficiency, rainwater harvesting, storage and recharge innovations, and reuse strategies. In the $21^{\text {st }}$ century, the philosophy behind water management is most likely going to be driven by the Dublin Principles, the World Water Vision, and the Millennium Development Goals (MDG) (Cosgrove and Rijsberman, 2000; United Nations, 2003). The MDG include commitments to halve, by the year 2015 , the proportion of people who are unable to reach or afford safe drinking water and those who do not have access to basic sanitation. Much of the focus will be on efficient drinking water supply, low-cost wastewater management, and effective water quality management as the key to improved water resources management, linking the three to water availability and protein production.

\section{The Dublin Principles}

In early 1992 an International Conference on Water and the Environment (ICWE) held in Dublin, Ireland, adopted what is now called the Dublin Principles. These were presented to the world leaders at the United Nations Conference on Environment and Development (UNCED) in Rio de Janeiro in June 1992. The Dublin Conference proposed concerted action to reverse overconsumption, pollution, and rising threats from drought and floods. The Dublin Statement recognised freshwater as a finite and vulnerable resource, essential to sustain life, development and the environment. The effective management of water resources demands a holistic approach, linking social and economic development with the protection of natural ecosystems. It also recognised that water has an economic value in all its competing uses and therefore should be recognised as an economic good. Past failure to recognise the economic value of water has led to wasteful and environmentally damaging uses of water (ICWE, 1992). 
The potential implications of these recommendations on water conservation (industry, domestic and agriculture) and reuse are very important. Recycling could reduce water consumption of many industries with a potential benefit of reduced pollution. The application of the "polluter pays" principle and realistic water pricing would encourage conservation and reuse. Better water management could significantly increase agriculture, industry and domestic water supplies, significantly defer investment in costly new water resource development and wastewater treatment facilities, and have an enormous impact on the sustainability of future supplies.

\section{World Water Vision}

In recognition of the unsustainable way water has been managed by society so far, the World Water Council developed the World Water Vision. The idea to develop a Long Term Vision for Water, Life and Environment in the $21^{\text {st }}$ Century - or in short, the World Water Vision - was introduced during the first World Water Forum in Marakech, Morocco, in 1997. The process was co-ordinated by the World Water Council and the results were presented during the second World Water Forum in March 2000 in The Hague (Cosgrove and Rijsberman, 2000). There was no consensus on important conclusions as two groups of opinion, referred to as the globalisation and the anti-globalisation groups, emerged from the conference. However, the two groups supported the Vision21 document, the 'Water for People' component, in part, because this document was prepared in a clear bottom-up participatory process. The perception was that the anti-globalisation camp favoured human rights, pluralism and democratic accountability, while those in favour of globalisation supported privatisation, economic valuation of water and the power of the global market.

\section{Vision21}

Vision21 represents the 'Water for People' component in the overall World Water Vision. It is aimed at achieving by 2025 a world in which each person knows the importance of hygiene, and enjoys safe and adequate water and sanitation services. To achieve these ambitious goals, it will be necessary to deal with the shortcomings of the current concept of urban water management (too much, too high or too low quality, too little reuse). The realisation of Vision21 will only be possible through the re-formulation of the current practices and the development of new concepts and approaches for sustainable urban water management. These include the establishment of effective water institutions, water demand management, the development of low water usage facilities and low cost sanitation systems, rainwater harvesting, and the extensive use of resource recovery and re-use approaches for wastewater. A holistic approach is therefore required in which wastewater is seen as a resource, and its management is linked to that of water resources and of nutrients. In fact, resource recovery and re-use approaches 
could, in addition to water savings, create financial incentives that could be used to cover part of the cost of wastewater treatment.

The above considerations have been further developed by the Environmental Sanitation Group of the Water Supply and Sanitation Collaborative Council (WSSCC) and have led to the so called 'Household Centred Approach' (King, 2000). This and other emerging approaches emphasize the household as the target unit for waste containment methods such as cleaner production techniques, and treatment geared to resource recovery and reuse (Gijzen, 2001). In addition to this, there is a need to analyse the water and nutrient cycles and develop appropriate intervention measures at each stage of the cycles.

\section{Urban water management}

Urban water management includes abstraction, treatment, storage, transmission and distribution to consumers and the subsequent collection and processing of the generated wastewater. It is now realised that urban wastewater is a vital component of water resources and nutrient management, and that it is crucial for sustainability in the water sector. Here, sustainability amounts to maintaining the abundance and quality of water resources to sustain ecosystems and support future human needs while also meeting current household and commercial/industrial water requirements. An emerging new school of thought believes that the traditional or conventional sanitation approach is very expensive and inefficient in terms of money, resources and energy. Its proponents are calling for radical changes, focusing more on pollution prevention, resource recovery (nutrients, biogas, and water) and reuse (Frijns and Jansen, 1996; Parr, 1996; Jeffrey et al., 1997; Otterpohl et al., 1997; Gijzen, 1998; King, 2000). According to these authors, sustainable solutions could only be found by considering:

i. the entire urban water cycle (not focusing just on components);

ii. the way in which other material cycles interact with the urban water cycle $(N, P, \ldots)$;

iii. that these cycles are closed via shorter loops (e.g. wastewater to be treated to level of water resource before discharge, ammonia nitrogen to be reused in stead of denitrified).

\section{Problems of the conventional wastewater management approach}

A typical traditional wastewater management approach uses "end-of-pipe" and centralised treatment technoiogies with river discharge of effluent (Fig 1.1). This approach focuses on solving short-term problems instead of avoiding them by using appropriate approaches. It results in unrestricted usage of water, fossil nutrients and energy, thereby suppressing the development of systems with source control. In the current approach, which originates from the 
$19^{\text {th }}$ century (Gijzen, 1998), water from a nearby water resource is treated to drinking water quality and subsequently used only once for a wide range of uses, many of these not requiring such high quality. Subsequently, and often without treatment, wastewater is discharged back to the same water resource. The effective treatment of wastewater worldwide is very low (estimates suggest below 10\% (WHO, 2000)) because of the prohibitive costs of current sewerage and centralised treatment systems. Most of these systems also do not provide a complete solution, as only COD and TSS are targeted, while nutrients and pathogens are usually discharged without any form of treatment. As a result, eutrophication and frequent outbreaks of water borne disease are reported worldwide (UNEP, 2000).

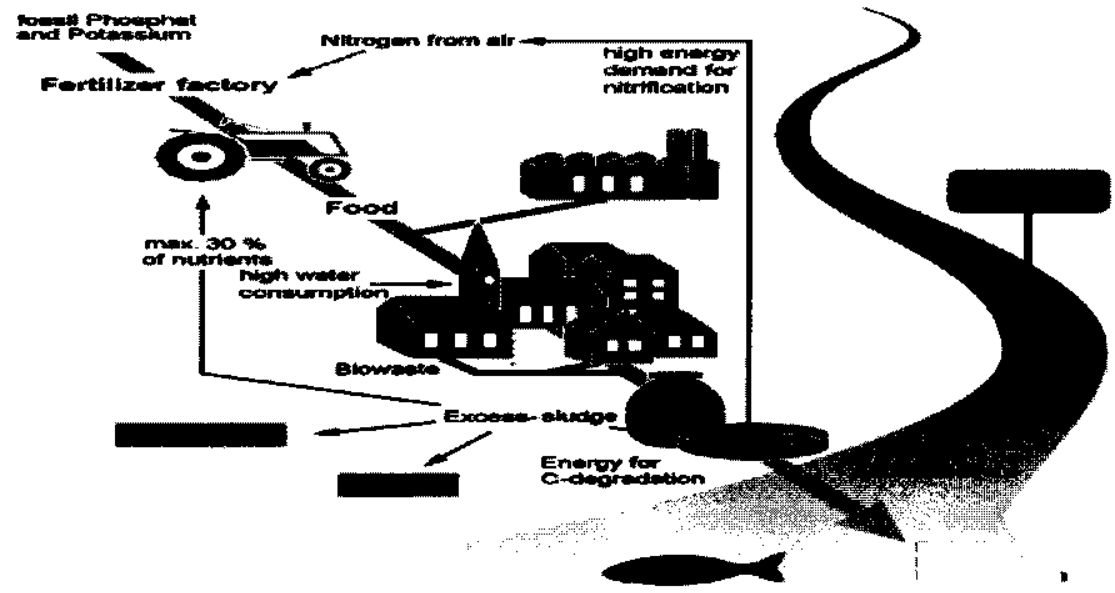

Figure 1.1: Linear mass fluxes in the traditional urban sanitation approach (Source: Otterpohl et al., 1998)

Some disadvantages of this "mix, dilute, and disperse" conventional sewerage system are: health problems in receiving downstream waters; trace contaminants of dissolved matter; nutrient losses to the atmosphere and the seas; and ignoring responsibilities for maintaining fertile topsoil (Otterpohl et al., 1998). Other problems include high energy demand for the degradation of organic and nitrogen compounds; mixing of different wastewater qualities which reduces reuse opportunities; high failure risk; mobilisation of metals; reduced production of humus (carbon-storing); high operation and rehabilitation costs, and negatively affecting the water quality of downstream water users.

The traditional approach to wastewater management mainly focuses on the control of waterborne diseases and preventing the degradation of the urban environment and surface waters. This approach is characterised by high water consumption and large central treatment 
works. The design of treatment facilities is normally based on the removal of suspended solids and biological treatment with hydraulics largely determining the sizing of holding tanks (Khouri et al., 1994). Water consumption, therefore, has a huge bearing on capital costs. Traditional sanitation systems also require highly skilled labour, imported spare parts, consume a lot of energy and are costly to maintain (Veenstra et al., 1997). Plants are normally built larger than required to allow for upsets and uncertainties in their ability to treat the water adequately.

The irrational use of water has serious implications on wastewater treatment. Water of drinking quality is used for non-potable uses, including the transportation of waste (flush toilets), gardening, cleaning floors, and washing cars. One may wonder why 150-300 litres of potable water per capita is used when only 1-2 litres per day are needed for drinking. Is it sensible to dilute the compact volumes of human excreta with large quantities of water simply to transport this waste to another location? The term "drinking water" seems misleading as more than $99 \%$ of the product carrying this name is for purposes other than drinking. Water is erroneously assumed to be an infinite resource when, in fact, it is limited in terms of quality and location. The use of one litre of water will result in an almost equal volume of wastewater, and one litre of wastewater is generally more expensive to treat than a similar volume of drinking water (Gunnerson and French, 1996; Gijzen, 2001). As a result, attempts to copy the expensive and inefficient urban water cycle as used in 'western' countries, have resulted in a large proportion of the population in developing regions being left without safe water supply and sanitation services.

Not only is the current urban water cycle not sustainable, but it is also coupled to nonsustainable nutrient cycles. For example, the current anthropogenic influx of nitrogen into the biosphere via fertiliser production amounts to some $37 \%$ of natural nitrogen fixation (Gijzen and Mulder, 2001). Balancing the $\mathrm{N}$-cycle would require the large-scale introduction of biological nitrogen removal, which, under current technical and economic conditions, is only feasible for a small fraction of the world wastewater production. Probably less than $2 \%$ of all nitrogen in wastewater is treated for $\mathrm{N}$-removal (denitrification) and this will lead to a further built up of nitrogen in the environment and in water resources resulting in widespread eutrophication and other problems. It is therefore irrational to spend energy and money fixing nitrogen, and to spend energy and money again for denitrification. The same applies to phosphorus, which is essential for agricultural production. Mineral reserves of phosphorus will last for only about 100 150 years (Otterpohl et al., 1996), and for this reason, it should not be wasted to receiving waters, where it will end up in sediments. A solution to this is reuse and short cycling of nitrogen and phosphorus by coupling water and nutrient cycles with resource recovery and reuse. 
Methane is another valuable by-product of wastewater. When organic matter is treated anaerobically about 375 I of methane gas can be expected from each kilogram of BOD digested material. Assuming an almost complete conversion of organic matter into biogas, a daily production of $25-451$ of methane per capita can be expected (Gijzen, 1998). The gas could be used as energy to power treatment plants or for pumping wastewater to irrigation areas.

\section{A new approach}

It is obvious that the current approach adopted for urban water does not provide sustainable solutions for the majority of the world population, notably in developing regions. There is therefore a strong case for designers and policymakers to challenge the conventional approach and explore alternatives before committing themselves to a central, mechanised wastewater system. These alternatives should focus on basic needs for dignity and quality of life and should balance these with the needs of the environment. The resource value of wastewater should be recognised and its management should be holistic and form part of an integrated process of managing water resources, nutrient flows and wastes. This requires rationalisation of the food and water cycles to avoid a net accumulation of nutrients and other pollutants in water bodies. The water and food cycles, indeed, are intimately interconnected but they could be improved further via shorter cycles. This entails a cyclical (loop) approach to water and nutrient management (Fig 1.2) as opposed to the conventional, linear flow (Fig 1.1). Thus, problems are avoided instead of wasting resources in solving them.

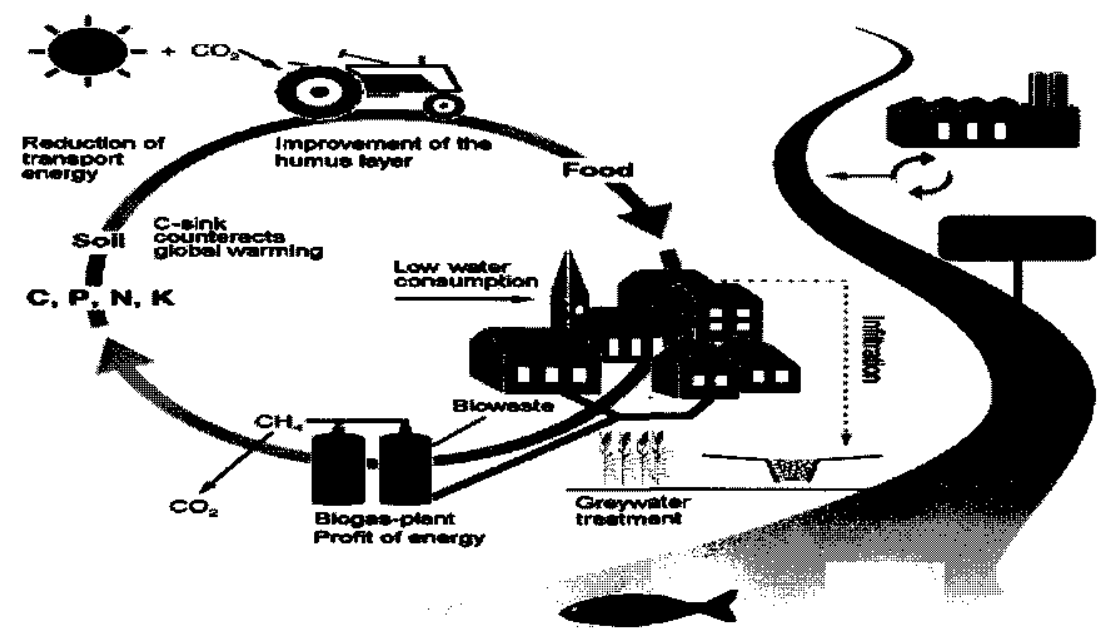

Figure 1.2: Mass fluxes in a sustainable urban sanitation approach (Source: Otterpohl et al., 1998) 


\section{Wastewater management in Zimbabwe}

Zimbabwe is one of the few African countries that have been able to provide water and sanitation to over $90 \%$ of its urban population (WHO/UNICEF, 2001). By law, all households are compelled to have an acceptable sanitation system before an occupation certificate is issued (Urban Councils Act, Chapter 29.15; Regional Town and Country Planning Act, Chapter 29.6). Onsite systems like bucket systems and pit latrines are not allowed in urban areas of Zimbabwe (Taylor and Mudege, 1997) and only flushing toilets with either septic tanks or conventional sewerage are permitted. Smaller urban centres use mostly septic tanks but few towns have vacuum tankers to periodically empty them. It is estimated that more than $92 \%$ of urban households are connected to the sewerage system (Table 1.1).

Urban councils are the water authorities in Zimbabwe, and this includes responsibilities for sanitation services according to the Urban Councils Act. Recent strict effluent treatment standards (Government of Zimbabwe, Statutory Instrument 274 of 2000) have increased financial pressures on councils by prescribing tougher effluent standards and high penalties for non-compliance; a situation that encourages tertiary treatment instead of reuse. All effluent and waste discharges require a permit. This has led to increased tariffs for users who are already faced with an ailing economy, abnormally high inflation, escalating prices and soaring unemployment rates. Problems relating to serious water pollution are more pronounced in Harare, the capital city, located in the Lake Chivero catchment area (Thornton and Nduku, 1982; Moyo, 1997).

Table 1.1: Number of Zimbabwean urban households using each sanitation technology by Province (Source: Taylor and Mudege, 1997)

\begin{tabular}{|c|c|c|c|c|c|c|c|}
\hline \multirow[t]{2}{*}{ Province } & \multicolumn{6}{|c|}{ TECHNOLOGY } & \multirow[b]{2}{*}{ No. of Households } \\
\hline & Flush & Blair & Pit & Bucket & None & No data & \\
\hline Manicaland & 96.6 & 1.48 & 1.66 & 0 & 0.25 & 0.01 & 43,587 \\
\hline Mashonaland Central & 85.37 & 7.73 & 4.97 & 0.15 & 1.74 & 0.04 & 15,684 \\
\hline Mashonaland east & 87.94 & 4.88 & 3.69 & 0 & 3.14 & 0.05 & 15,160 \\
\hline Mashonaland West & 90.43 & 1.9 & 4.8 & 0 & 2.87 & 0 & 60.767 \\
\hline Matabeleland North & 91.44 & 1.33 & 5.53 & 0 & 1.64 & 0.01 & 16,719 \\
\hline Matabeleland South & 88.37 & 3.86 & 5.08 & 0.08 & 2.57 & 0.03 & 11,964 \\
\hline Midlands & 94.4 & 1.37 & 2.23 & 0 & 2.01 & 0.01 & 70,196 \\
\hline Masvingo & 97.01 & 1.04 & 0.93 & 0 & 1.03 & 0 & 24,181 \\
\hline Harare & 93.94 & 1.71 & 4.19 & 0 & 0.13 & 0.04 & 359,216 \\
\hline Bulawayo & 98.41 & 0.51 & 0.65 & 0 & 0.42 & 0.01 & 145,962 \\
\hline National average & 92.4 & 2.6 & 3.4 & 0.0 & 1.6 & 0.0 & \\
\hline Total \#households & 720,450 & 12,536 & 24,302 & 33 & 5,924 & 189 & 763,436 \\
\hline
\end{tabular}

"Blair toilets are commonly referred to as Ventilated Improved Pit (VIP) latrines. 


\section{(Waste)water management and pollution in the Chivero Basin}

The location of Harare in Zimbabwe is shown in Fig 1.3 and that of Lake Chivero relative to Harare is shown in Fig 1.4. Lake Chivero has a storage capacity of $247,181,000 \mathrm{~m}^{3}$, a surface area of $26.3 \mathrm{~km}^{2}$, maximum depth of $27.43 \mathrm{~m}$, and an average depth of $9.3 \mathrm{~m}$ (Thornton and Nduku, 1982; JICA, 1996; Marshall, 1997;). The lake was created in 1952 and is located 35 km south-west and downstream of Harare. It is the major water source for the city (providing over $70 \%$ of its needs) and the neighbouring towns of Epworth, Norton, Chitungwiza and Ruwa. The mean annual rainfall is $830 \mathrm{~mm}$ (JICA, 1996; Luxemburg, 1996) and the mean annual runoff is about $140 \mathrm{~mm}$ (Department of Water Development, 1995).

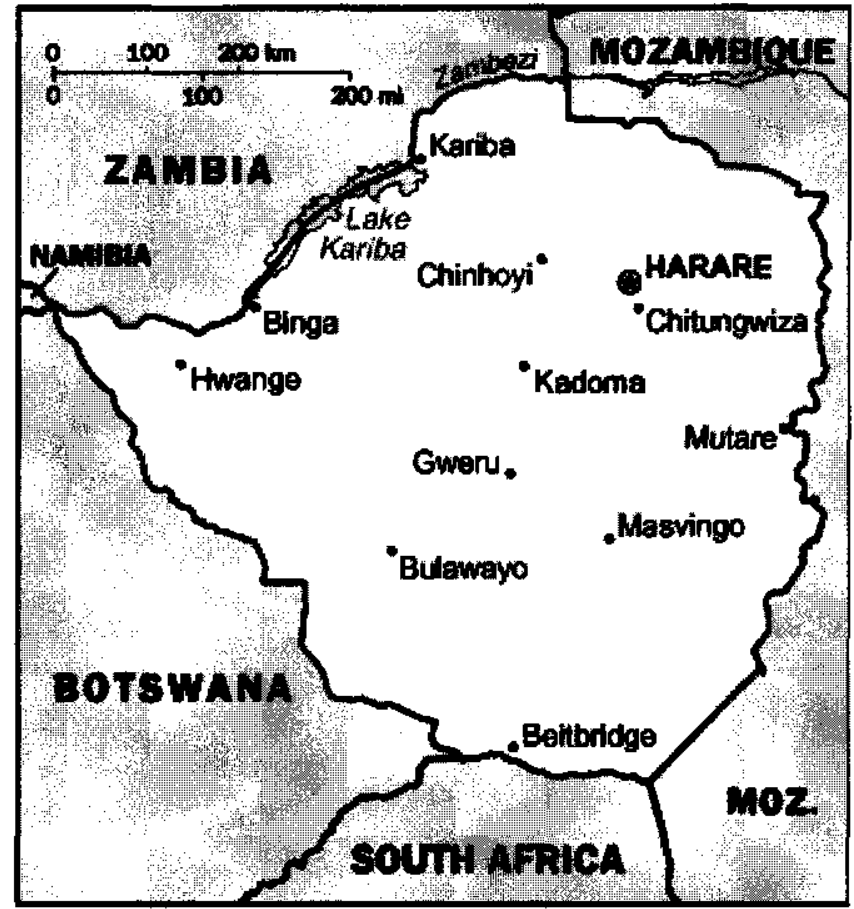

Figure 1.3: Map showing the location of Harare in Zimbabwe

(Source: http://uww.lib.utexas.edu/maps/cia02/zimbabwe_sm02.gif)

The preliminary results of the 2002 census $(C S O, 2002)$ estimated that the population in the Harare metropolitan area was about $1,900,000$. Water consumption in Harare averages $430,000 \mathrm{~m}^{3} / \mathrm{d}$ and $304,000 \mathrm{~m}^{3} / \mathrm{d}$ (or $70 \%$ of it) is collected as wastewater. Only $23,800 \mathrm{~m}^{3} / \mathrm{d}$ of wastewater is treated onsite and two main wastewater treatment plants (WTP) serve the city. These are the Firle (capacity $144,000 \mathrm{~m}^{3} / \mathrm{d}$ ) and the Crowborough $\left(54,000 \mathrm{~m}^{3} / \mathrm{d}\right.$ ) wastewater 
treatment plants. Treatment is mainly by trickling filters (TF) and activated sludge systems incorporating Biological Nutrient Removal (BNR). About $70 \%$ of this effluent is reused for pasture irrigation whilst the rest is discharged into the Mukuvisi and Marimba Rivers (JICA, 1996). There are also two waste stabilisation pond systems in Marlborough and Donnybrook with combined treatment capacity of $7,500 \mathrm{~m}^{3} / \mathrm{d}$ and a new extended aeration plant in Hatcliffe with a capacity of $2,500 \mathrm{~m}^{3} / \mathrm{d}$. Overloading and maintenance problems plague all the plants and the quality of the final effluent flowing into rivers is very poor.

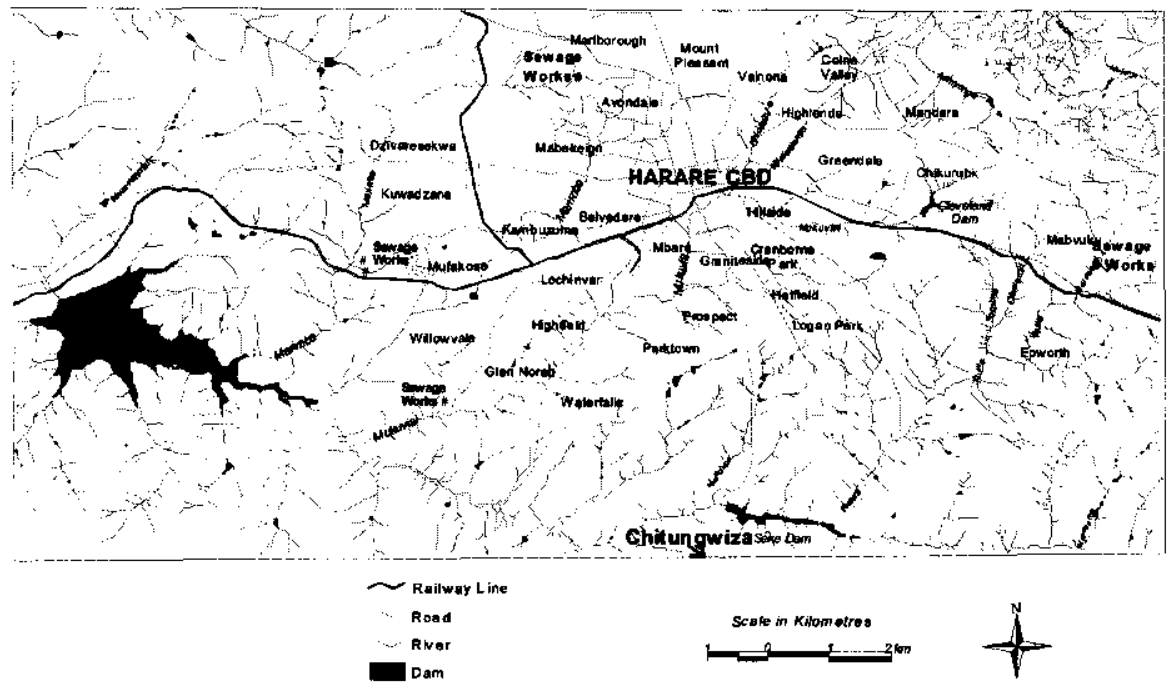

Figure 1.4: Map of study area showing the location of Lake Chivero in relation to Harare and Chitungwiza

Because of the poor quality of the WTP effluent discharges, runoff and seepage intrusions from pasture irrigation, and other upstream point and non-point sources of pollution, Lake Chivero is heavily polluted. Previous research focusing on the lake found it to be eutrophic (Robarts and Southall, 1977; Thornton and Nduku, 1982; JICA, 1996; Magadza, 1997; Marshall, 1997). Many of these researchers report that wastewater is the major problem. Research focusing on Mukuvisi River (Zaranyika, 1997; Moyo and Worster, 1997; Machena, 1997; Kamudyariwa, 2000 ) revealed numerous sources and causes of pollution like industrial discharges, solid waste dumps and WTP effluent. In studies on the Marimba River by JICA (1996), Mathuthu et al., (1997), and Manjonjo (1999), heavy metals and nutrients in the river frequently exceeded WHO limits. It has been recommended that industrial effluents and wastewater discharges be tightly controlled if water quality in the rivers and Lake Chivero is to be managed effectively (Moyo, 1997; Bethune and Roberts, 1999). 
In 1996 the mean concentrations of total nitrogen (TN) and total phosphorus (TP) in Lake Chivero were 0.51 and $0.27 \mathrm{mg} / /$ respectively (JICA, 1996). Two decades ago, nitrogen and phosphorous were identified as the main nutrients limiting phytoplankton growth (Robarts and Southall, 1977; Watts, 1982). In the past few years, a number of planned developments such as the expansion of Crowborough and Firle wastewater treatment plants have failed to take place. A harsh economic environment, characterised by lack of foreign currency and electric power cuts also affects the proper functioning of these plants.

\section{Lake Chivero under a "business as usual" scenario}

The water quality problems in the Chivero catchment are likely to be exacerbated by rapid industrialisation and high population growth rates in urban areas (Zanamwe, 1997; CSO, 2002). Using the annual average inter-censal (1992 - 2002) growth rate of $2.5 \%$ (CSO, 2002), the population in the Chivero catchment area is expected to increase to approximately $2,050,000$ by 2005 , and to $2,620,000$ by 2015 . This will lead to increased water consumption, resulting in larger water abstractions from Lake Chivero. It will also result in an increased volume of wastewater discharges, whilst natural river flows will increase marginally because of an increase in impervious areas caused by urban construction. The current rainfall trend suggests more frequent drought years (Luxemburg, 1996) and this means that rivers would increasingly be carrying more WTP effluent than natural flows. Lake spillages would decrease with the lake increasingly becoming a major pollutant sink, leading to serious water quality problems. Figure 1.5 , derived from the 1996 monitoring data from JICA, shows that there was already a net accumulation of phosphorous and nitrogen in the lake, resulting in a stressed system that needs urgent action.

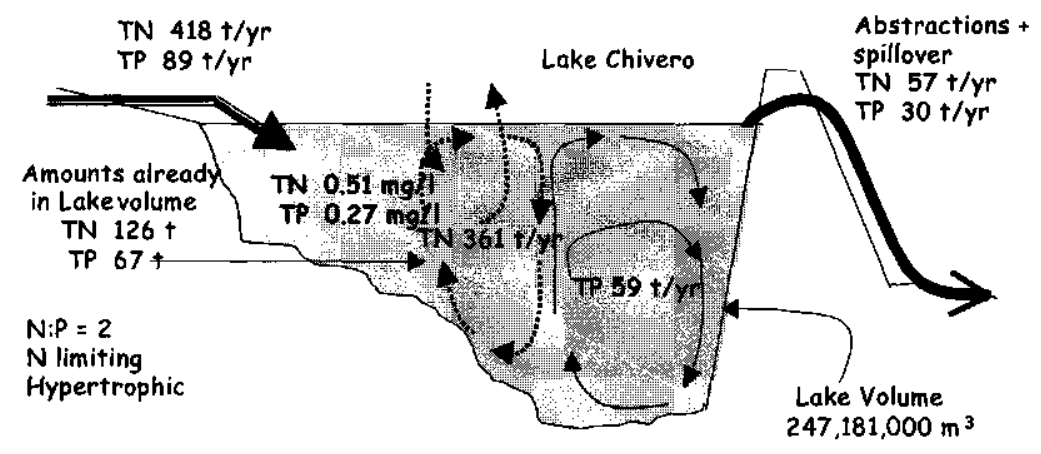

Figure 1.5: Nitrogen and phosphorous fluxes and concentrations in Lake Chivero for 1996 (derived from JICA (1996) and Zimbabwe National Water Authority (ZINWA) database) 
Increased wastewater discharges will reduce hydraulic retention times and the self-purification capacities of receiving rivers (Machena, 1997) impacting on water quality in the rivers. The major wastewater treatment plants (Crowborough and Firle) are close to the Lake, so there will be insufficient time for natural purification to play a significant role in the current set up. The water balance of Lake Chivero (Fig. 1.6) is affected by periodic droughts when flows over the spillway of the dam are very low (or do not occur) and the accumulation of pollutants in the lake increases.

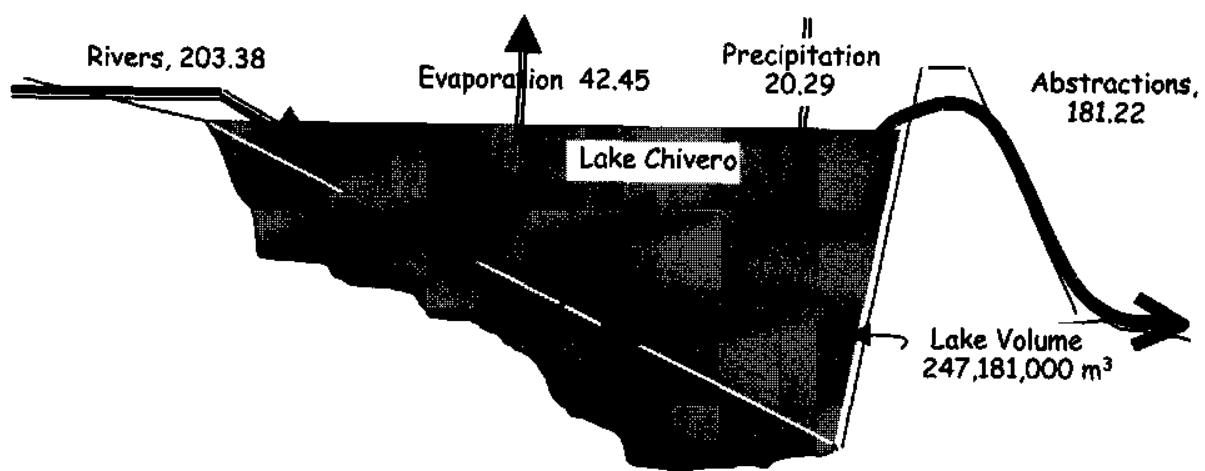

Figure 1.6: The 1996 annual water budget for Lake Chivero, excluding groundwater flows; flows expressed as $10^{6} \mathrm{~m}^{3} / \mathrm{yr}$ (Derived from JICA (1996) and ZINWA database)

The hydraulic retention time of 403 days in Lake Chivero (Fig 1.6) is not adequate for the flushing out of phosphorus, a process that is more effective in lakes with retention times of less than six months (Thornton, 1980). The water quality problems of excessive algae and water hyacinth (Eichhornia crassispes) growth, clogging of irrigation pipes, impaired boating and fishing activities, occasional fish kills, and water treatment difficulties (frequent filter backwash, odours, taste) are likely to worsen if no action is taken. The City of Harare will face increased problems in ensuring safe and sufficient water supply especially in the dry season when urban water demand, water evaporation from the lake surface, and lake productivity (hyacinth and algae blooms) is at its highest.

The disposal of effluent and sludge on pastures in Harare is already showing limitations in removing nutrients and pollutants such as heavy metals (McKendrick, 1982; Nyamangara and Mzezewa, 1999; Manjonjo, 1999). Sustainable nutrient removal via pasture irrigation requires more land, a resource that is now becoming both scarce and too costly for this purpose Furthermore, the efficiency of the land treatment of effluent decreases during wet weather (McKendrick, 1982). Urban agriculture, and its consequences on water quality is also likely to 
continue unhindered into the future (Mbiba, 1995; Zanamwe, 1997), with chemical and fertiliser applications probably higher than in normal farming (ENDA-Zimbabwe, 1996). The cumulative loading of chemicals and fertilisers on the soils and groundwater, and subsequent leaching into the lake, will be a problem in the future but urban agriculture could have positive effects by reusing nutrients and water if organised differently.

If no intervention measures are put in place, the present problems retated to effluent disposal and downstream pollution in Harare will continue and increase in magnitude. The lake will become more eutrophic and the quality and quantity of urban water supplies will be adversely affected as will other uses of the lake, e.g. recreation and fishing. This research project was therefore motivated by the need to seek effective ways of managing water resources and pollution in the Harare sub-catchment area of Lake Chivero. Emphasis is put on wastewater management, especially the control of water, nitrogen and phosphorus flows. The philosophy driving the research dictates smallest cycles for nutrients and water (not only the end of the pipe).

\section{Specific research problem}

The main water management problem in Harare is that wastewater discharges contribute significantly to eutrophication in Lake Chivero, although the current extent is not known. The problem is compounded by the fact that water release from the lake does not takes place in years of low rainfall as the dam's floodgates are permanently closed. Spillway discharges normally take place only from January to April, meaning that the lake acts as a sink for pollutants for most of the year. As the population increases, the lake will increasingly receive a higher fraction of WTP effiuent whilst raw water abstraction will also increase, posing a water quality and quantity problem. Nutrient concentrations in the lake are higher than the allowable limits of $<0.3 \mathrm{mg} / \mathrm{IN}$ and $<0.01 \mathrm{mg} / \mathrm{TP}$ for drinking water taken from lakes (Mandaville, 2000). This has led to excessive primary productivity and related problems in the lake. Nitrogen and phosphorous inputs need to be controlled to avoid further deterioration in water quality. Research is required to understand the current flows of water and nutrients into and out of the catchment so that corrective measures can be based on a better understanding of the system.

\section{Research objectives}

The aims of the research described in this thesis were to assess the present and future contributions of wastewater discharges from Harare to the nitrogen and phosphorus loading of 
Lake Chivero and, based on this assessment, to formulate feasible sanitary engineering solutions to ensure sustainable use of the resources in the lake.

The specific objectives of this research were:

i. to quantify the contribution of wastewater discharges to the water, nitrogen and phosphorus loading of Lake Chivero,

ii. to monitor the actual levels of nitrogen and phosphorus in Lake Chivero, and

iii. to formulate strategies of managing water and nutrient flows in the catchment with a view to ensure sustainable use of the water resource in the lake.

\section{Research scope}

The research focused on two aspects. The first was the collection of background and current information on water quality and quantity in the Harare sub-catchment area of Lake Chivero. This was used to validate available information and to assess the current state of the problem. The lake was taken as a reference point for the development of sustainable measures, which meant that the impacts of recommended measures on the water quality of the lake were assessed. The second aspect dealt with the formulation of intervention measures based on the control of nitrogen, phosphorus and water flows, beginning at the lowest (property) level and up to the city or central level were developed. This control could be achieved through a systematic and strategic approach that includes cleaner production approaches, treatment, reuse, and recycling.

\section{Relevance of the research}

Some research has been done on the effects of WTP effluent on Lake Chivero and the rivers flowing into it (Mathuthu et al., 1997; Moyo, 1997; Moyo and Worster, 1997). Studies done elsewhere (ESCWA, 1985; Chenje and Johnson, 1996; Haarhoff and Van der Merwe, 1996; Asano and Levine, 1996) have demonstrated that the reuse of WTP effluents for potable water supply, directly or indirectly, is technically feasible. Harare presents a peculiar situation in that Lake Chivero, situated downstream, is not refreshed in drought years leading to a build-up of pollutants. This is worsened by the ever-increasing wastewater discharges. An assessment of the long-term sustainability of this practice needs further analysis but research in Zimbabwe has focused mainly on the impacts of effluents on the rivers and the lake. A broad study of the pollution situation in the catchment was done by JICA (1996) but it was too general for this purpose as it covered a much broader perspective. There is a need for a more focused 
approach within Harare itself so that the cause and effect relationships are known. Generally, the amount and quality of data available does not seem consistent and sufficient for the quantification of the problem, the trends and future projections, and does not permit the development of concrete remedial measures. The current data cover different segments of the catchment at different times, often using different parameters. Reliable data are required to define a correct water and nutrient balance of Lake Chivero. Once the current situation is understood, projections to the future could be made. From this, solutions could be developed that would lead to a desirable balance that avoids water quality deterioration now and in the future. The nature and sources of the pollution, reuse and recycling options, and long-term sustainability of these options all need to be understood in order to arrive at feasible intervention measures.

This research will take into account the above considerations and contribute to:

i. the provision of additional and reliable data (extensively collected over a long time and based on total nitrogen and total phosphorus, and in combination with flow measurements) to define annual trends, water budgets and nutrient balances in the catchment.

ii. a better understanding of the problem in terms of the current situation, required interventions and time scale.

iii. an increased focus on the application of cleaner production principles to urban water management, and wastewater resource recovery and reuse as tools for sustainable environmental management.

\section{Thesis outline}

The structure of this dissertation is shown in Fig 1.7 whilst details of each Chapter are given in Table 1.2. The current Chapter gives a background to the dissertation, including the problem statement, the objectives to be addressed, and the scope. Chapter 2 covers an inventory of the existing wastewater management practices, focusing on Harare and the Lake Chivero. A detailed monitoring of water quality and the pollution situation in the Chivero catchment area, including the contribution of wastewater discharges, and current nutrient balances, are covered in Chapter 3. A conceptual framework for the sustainable management of wastewater in Harare based on the so-called "3-Step Strategic Approach" is presented in Chapter 4. Chapters 5, 6, and 7 are based on this strategic approach and look in detail into options for managing wastewater at various stages of onsite, decentralised and centralised levels, with the overall aim of reducing the generation of wastewater and to recover and reuse nutrients. 


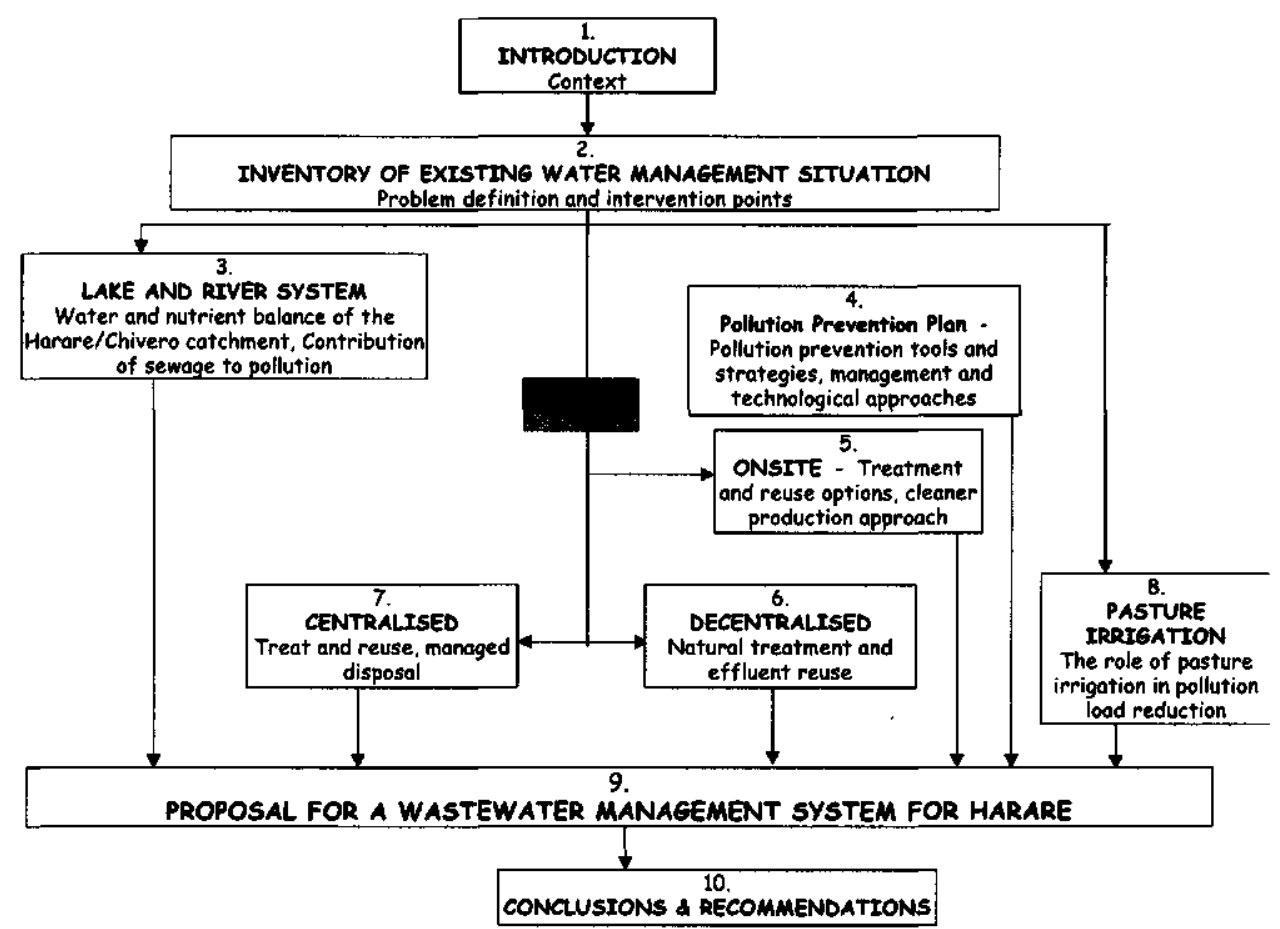

Figure 1.7: A schematic outline of the thesis

Chapter 5 verifies nutrient and wastewater production figures and assesses how wastewater could be managed onsite. Options considered include source separation and reuse, combined treatment and onsite reuse, and hybrid systems that combine partial onsite treatment and secondary/tertiary offsite polishing and reuse. Options for pollution reduction and prevention are considered as a first step for reducing water consumption, wastewater generation, and phosphorus use. Chapter 6 explores the decentralised concept of wastewater management and how it could be applied to Harare. Besides giving the conceptual framework, it also presents case studies on how decentralised wastewater treatment systems could be applied in Zimbabwe and the relevant institutional/regulatory considerations. Chapter 7 looks at the centralised management of wastewater in Harare focusing first on the current situation and its limitations. Alternative solutions based on treatment and reuse, and on disposal with stimulation of river self-purification capacity are offered. A detailed case study on pasture irrigation was carried out (Chapter 8 ) to understand the extent to which nutrients may be removed via land irrigation. Chapter 9 synthesised the findings in previous chapters and presents an integrated approach aimed at reducing nutrient flows into Lake Chivero and an improved water supply for Harare. 
Table 1.2: A detailed overview of the structure of this thesis

\begin{tabular}{|c|c|c|}
\hline Chapter No. and Titte & Specific Objectives & Outtine \\
\hline $\begin{array}{l}1 . \\
\text { Introduction }\end{array}$ & $\begin{array}{l}\text { To introduce the thesis subject in } \\
\text { terms of global and local settings } \\
\text { and trends, including the research } \\
\text { objectives, scope, and thesis } \\
\text { outline }\end{array}$ & $\begin{array}{l}\text { Literature review. Critical review of global } \\
\text { approaches, water and nutrient cycles, new } \\
\text { approaches and sustainability of sanitation systems, } \\
\text { study area, problem definition, aims and objectives, } \\
\text { approach and relevance, thesis outline }\end{array}$ \\
\hline $\begin{array}{l}2 . \\
\text { Inventory of Existing } \\
\text { Water Management } \\
\text { Practices in Harare }\end{array}$ & $\begin{array}{l}\text { To identify water and nutrient } \\
\text { sources and assess the extent of } \\
\text { the problem } \\
\text { To assess quality of available data } \\
\text { and identify gaps }\end{array}$ & $\begin{array}{l}\text { Descriptive analysis of the Chivero catchment, } \\
\text { installed systems } \\
\text { - Critical review of previous research and findings } \\
\text { - Water supply, sewerage infrastructure, rainfall and } \\
\text { runoff, water quality, future projections }\end{array}$ \\
\hline $\begin{array}{l}\text { Impact of Urbanisation } \\
\text { on Water Quality of Lake } \\
\text { Chivero }\end{array}$ & $\begin{array}{l}\text { To assess the current status of } \\
\text { pollution in the Chivero catchment } \\
\text { through a water quality monitoring } \\
\text { program } \\
\text { To update water and nutrient } \\
\text { balances }\end{array}$ & $\begin{array}{l}\text { Nutrient concentrations in Lake Chivero inflow rivers, } \\
\text { including the contribution of wastewater to pollution } \\
\text { in these rivers } \\
\text { - Nutrient concentrations in Lake Chivero; spatial } \\
\text { distribution and physical assessment of water quality } \\
\text { using secchi disc measurements } \\
\text { Updated water and nutrient balance of Lake Chivero } \\
\text { basin and predictions to the future }\end{array}$ \\
\hline $\begin{array}{l}\text { A Strategic Framework } \\
\text { for Managing } \\
\text { Wastewater in Harare }\end{array}$ & $\begin{array}{l}\text { To develop a conceptual } \\
\text { framework for controlling nutrient } \\
\text { inflows and outflows from Lake } \\
\text { Chivero and also to reduce water } \\
\text { consumption, and, hence, reduce } \\
\text { wastewater production }\end{array}$ & $\begin{array}{l}\text { Global approaches to urban water management, the } \\
\text { Dublin Principles, Vision21, Bellagio Statement, } \\
\text { household-centred sanitation } \\
\text { Strategy formulation and rationale: household } \\
\text { interventions and cleaner production approaches } \\
\text { (commerce, household and industries) } \\
\text { Pollution prevention using a 3-step approach: } \\
\text { prevention (demand management), treat and reuse, } \\
\text { safe disposal, - brief examples }\end{array}$ \\
\hline $\begin{array}{l}5 . \\
\text { Options for Onsite } \\
\text { Management of } \\
\text { Wastewater in Harare }\end{array}$ & $\begin{array}{l}\text { To quantify wastewater volume } \\
\text { that can be feasibly managed } \\
\text { onsite } \\
\text { To formulate strategies for } \\
\text { handling this amount } \\
\text { To assess the impacts of such } \\
\text { strategies on the overall pollution } \\
\text { regime in Harare }\end{array}$ & $\begin{array}{l}\text { - Household water use and wastewater production } \\
\text { Strategic plan for onsite management of wastewater: } \\
\text { poliution prevention (cleaner production approaches, } \\
\text { household centred approaches), reuse, source } \\
\text { separation and reuse, convert and reuse } \\
\text { - Strategy application in the case of Harare } \\
\text { - Treatment and disposal options in the context of the } \\
\text { strategy and potential impacts }\end{array}$ \\
\hline $\begin{array}{l}6 . \\
\text { Options for the } \\
\text { Decentralised } \\
\text { Management of } \\
\text { Wastewater in Harare }\end{array}$ & $\begin{array}{l}\text { - To assess the potential of the } \\
\text { decentralised management of } \\
\text { wastewater in Harare in the } \\
\text { context of the 3-step strategic } \\
\text { approach }\end{array}$ & $\begin{array}{l}\text { The need and benefits of decentralised wastewater } \\
\text { management } \\
\text { Strategic plan for the decentralised management of } \\
\text { wastewater: nutrient recovery and reuse, convert } \\
\text { and reuse } \\
\text { Treatment and disposal alternatives in the context of } \\
\text { the strategy } \\
\text { Strategy application in the case of Harare and } \\
\text { potential impacts }\end{array}$ \\
\hline
\end{tabular}


Table 1.2: A detailed overview of the structure of this thesis (continued)

\begin{tabular}{|c|c|c|}
\hline Chapter No. and Titte & Speciffc Objectives & Oufline \\
\hline $\begin{array}{l}7 . \\
\text { Options for Centralised } \\
\text { Management of } \\
\text { Wastewater in Harare }\end{array}$ & $\begin{array}{l}\text { To assess the potential of the } \\
\text { centralised management of } \\
\text { wastewater in Harare in the } \\
\text { context of the 3-step strategic } \\
\text { approach }\end{array}$ & $\begin{array}{l}\text { The future of central treatment of wastewaler, } \\
\text { benefits and limitations in Harare } \\
\text { Strategic plan for centralised management of } \\
\text { wastewater: prevention, treat and reuse, discharge. } \\
\text { Treatment and disposal alternatives in the context of } \\
\text { the strategy } \\
\text { Strategy application in the case of Harare and } \\
\text { potential impacts }\end{array}$ \\
\hline $\begin{array}{l}8 . \\
\text { Assessment of Effluent } \\
\text { Polishing via Pasture } \\
\text { Irrigation in Harare }\end{array}$ & $\begin{array}{l}\text { To present a detailed illustration of } \\
\text { the discharge option } \\
\text { To assess the current role of } \\
\text { pastures in effluent polishing and } \\
\text { hence the sustainability of the } \\
\text { system } \\
\text { To explore alternative scenarios of } \\
\text { improving the system }\end{array}$ & $\begin{array}{l}\text { Characterisation of effluent and sludge pumped to } \\
\text { the pastures } \\
\text { - Water and nutrient balance of the pastures } \\
\text { - Management and sustainability of the system } \\
\text { Optimisation of variables that would improve } \\
\text { verformance, alternative cropping, economic } \\
\text { viabilty, and extrapolation for wider usage }\end{array}$ \\
\hline $\begin{array}{l}9 . \\
\text { Proposal for a } \\
\text { Wastewater } \\
\text { Management System for } \\
\text { Harare }\end{array}$ & $\begin{array}{l}\text { To investigate how the different } \\
\text { approaches can be integrated into } \\
\text { a differentiated and staged plan for } \\
\text { the overall benefit of water quality } \\
\text { management in the Chivero basin }\end{array}$ & $\begin{array}{l}\text { - Summary of current water management problems in } \\
\text { Harare } \\
\text { - Opportunities and threats to water management in } \\
\text { Harare } \\
\text { - A strategy for managing wastewater in Harare } \\
\text { - Strategy application, scenarios, and implications on } \\
\text { the Chivero system: short, medium, and long-term } \\
\text { measures }\end{array}$ \\
\hline
\end{tabular}

\section{References}

Asano T. and Levine, A.D. (1996) Wastewater Reclamation, Recycling and Reuse: Past, Present and Future, IAWQ Wat. Sci. Tech. Vol. 33(10-11), p1-14.

Bethune, S. and Roberts, K. (1999) Water Weeds and Hyacinth Control, paper presented to the Seminar on Water Resources Management in Southern Africa: Enhancing Environmental Sustainability, Harare, October 1999.

Chenje, M. and Johnson, P. (1996) Water in Southem Africa, SADC/IUCN/SARDC Communicating the Environment Programme, Harare, Zimbabwe.

Cosgrove, W.J. and Rijsberman, F.R. (2000) World Water Vision: Making Water Evenybody's Business, World Water Council, London, UK.

CSO (Central Statistical Office) (2002) Census 2002: Zimbabwe, Preliminary Report, Central Census Office, Government of Zimbabwe, Harare, Zimbabwe.

Department of Water Development (1995) Assessment of Surface Water Resources in the Manyame Catchment - Zimbabwe; Streamflow Gauging and Conceptual Hydrological Modelling, SMHI Hydrology No. 60, 1995. 
ENDA - Zimbabwe (1996) Urban Agriculture in Zimbabwe: Realities and Prospects, Proceedings of a workshop organised by ETC International and ENDA - Zimbabwe, Mandel Training Centre, Harare June 1996.

ESCWA (Economic and Social Commission for Western Asia) (1985) Wastewater Reuse and its Applications in Western Asia, United Nations Publication E/ESCWA/NR/84/2/Rev.1.

Frijns, J. and Jansen, M. (1996) Institutional Requirements for Appropriate Wastewater Treatment Systems, in Proceeding of the Worksop on Sustainable Municipal Waste Water Treatment, Leusdan the Netherlands, 12-14 November 1996, pp54-66.

Gijzen, H.J. (1998) Sustainable Wastewater Management Via Reuse: Turning Waste into Wealth, in Proc. Aqua 98, Water and Sustainability, 1 - 4 June 1998, Cali, Colombia, pp 211-224.

Gijzen, H.J. (2001). Anaerobes, Aerobes and Phototrophs - A Winning Team for Wastewater Management, IWA Wat. Sci: Tech. Vol. 44(8), p121-132.

Gijzen, H.J., Mulder, A. (2001). The Nitrogen Cycle out of Balance. Water21, August 2001, p38-40.

Government of Zimbabwe (2000) Statutory Instrument (S.I.) 274 of 2000, Water (Waste and Effluent Disposal) Regulations, Government Printers, Harare, Zimbabwe.

Gunnerson, C.G. and French, J.A. (1996). Wastewater Management for Coastal Cities - The Ocean Disposal Option. Sringer Verlag, Berlin, 340p.

Haarhoff., J. and Van der Merwe, B. (1996) Twenty Five Years of Wastewater Reclamation in Windhoek, Namibia, IAWQ Wat. Sci: Tech. Vol. 33(10-11), p25-35.

ICWE (International Conference on Water and Environment) (1992) The Dublin Statement and Record of the Conference, World Meteorological Organisation, Geneva, Switzerland.

JICA Report (1996) The Study of Water Pollution Control in Upper Manyame River Basin in the Republic of Zimbabwe, MLGRUD, Nippon Jogeduido Sekkei Co. Ltd., Nippon Koei Co. Ltd, September 1996.

Jeffrey, P., Seaton, R., Parsons, S. and Stephenson, T. (1997) Evaluation Methods for the Design of Adaptive Water Supply Systems in Urban Environments, in IWA Wat. Sci. Tech. Vol. 35(9).

Kamudyariwa, C. (2000) Seasonal Variation of Water Quality with Respect to Anthropogenic Activities Along Mukuvisi River, Harare, Zimbabwe, MSc. Thesis, IHE Delit, The Netherlands.

Khouri, N., Kalbermatten, J.M. and Bartone, C.R. (1994) Reuse of Wastewater in Agriculture: A Guide for Planners, UNBWB Water and Sanitation Program, Washington, USA.

King, N (2000) New Strategies for Environmental Sanitation, in Water21, Magazine of the International Water Association, April 2000, London, UK, p11-12.

Luxemburg, W. (1996) Yield Analysis Using Simulation Models for the Chivero, Manyame and Biri Dam System, Department of Water Resources, Ministry of Lands and Water Resources, Harare, Zimbabwe.

Machena, C. (1997) The Pollution and Self-Purification Capacity of the Mukuvisi River, in Moyo, N.A.G.

(Ed.) Lake Chivero: A Polluted Lake, University of Zimbabwe Publications, Harare, Zimbabwe.

Magadza C.H.D. (1997) Water Pollution and Catchment Management in Lake Chivero, in Moyo, N.A.G.

(Ed.) Lake Chivero: A Polluted Lake, University of Zimbabwe Publications, Harare, Zimbabwe. 
Mandaville, S.M. (2000) Lake Data of Relatively Undisturbed Lakes within Nova Scotia; Provincial Averages; CCME, Health and Welfare Canada, and OME Guidelines, Internet Site: htto://uww.chebucto.ns.ca/Science/SWCS/SWCS.html.

Manjonjo, M. (1999) Land Disposal of Sludge and Pond Effluent on Crowborough Farm: Its Efficiency and Influence on Marimba River, MSc WREM Thesis, University of Zimbabwe, Harare, Zimbabwe.

Marshall, B.E. (1997) Lake Chivero After Forty Years: The Impact of Eutrophication, in Moyo, N.A.G. (Ed.) Lake Chivero: A Polluted Lake, University of Zimbabwe Publications, Harare, Zimbabwe.

Mathuthu, A.S., Mwanga, K. and Simoro, A. (1997) Impact Assessment of Industrial and Sewage Effluents on Water Quality of the Receiving Marimba River in Harare, in Moyo, N.A.G. (Ed.) Lake Chivero: A Polluted Lake, University of Zimbabwe Publications, Harare, Zimbabwe.

Mbiba, B. (1995) Urban Agriculture in Zimbabwe - Implications for Urban Management and Poverty, Ashgate Publishing Ltd, Avebury, UK.

Mckendrick, J. (1982) Water Supply and Sewage Treatment in Relation to Water Quality in Lake Mcllwaine in Thornton,J A and Nduku,W K (eds.) Lake Mcllwaine; The Eutrophication and Recovery of a Tropical African Man-Made Lake, Dr W Junk Publishers, The Hague, The Netherlands, p 202217.

Moyo, N.A.G. (Ed.) (1997) Lake Chivero: A Polluted Lake, University of Zimbabwe Publications, Harare, Zimbabwe.

Moyo, N.A.G. and Worster, K. (1997) The Effects of Organic Pollution on the Mukuvisi River, Harare, Zimbabwe, in Moyo, N.A.G. (Ed.) Lake Chivero: A Polluted Lake, University of Zimbabwe Publications, Harare, Zimbabwe.

Nyamangara, J. and Mzezewa J. (1999). The Effect of Long-term Sewage Sludge Application on $\mathrm{Zn}$, $\mathrm{Cu}, \mathrm{Ni}$ and $\mathrm{Pb}$ levels in a Clay Loam Soil under Pasture Grass in Zimbabwe in Agriculture, Ecosystems and Environment 73, p199-204.

Otterpohl, R, Albold, A and Grottker, M (1996) Integrating Sanitation into Natural Cycles: A New Concept for Cities, in Staudemann, J, Schonborn, A and Etnier, C (Eds.) Recycling the Resource Ecological Engineering for Wastewater Treatment, Transtec Publications Ltd, Switzerland.

Otterpohl, R., Grottker, M. and Lange, J (1997) Sustainable Water and Wastewater Management in Urban Areas, in IWA Wat. Sci. Tech., Vol 35(9).

Otterpohl, R., Abold, A. and Oldenburg, M. (1998) Differentiating Management of Water Resources and Waste in Urban Areas - Proceedings of the Internet Conference on Integrated Bio-Systems, Lübeck, Germany: Internet Site hitp://www.soc.titech.ac.jp/uem/waste/oldenburg.html.

Parr, $J$ (1996) Towards Effective Wastewater Management in Developing Countries: Some Issues, in Workshop on Sustainable Municipal Waste Water Treatment - ETC - WASTE.

Robarts R.D. and Southall, G.C. (1977) Nutrient Limitation of Phytoplankton Growth in Seven Tropical Man-Made Lakes, with Specific Reference to Lake Mcllwaine, Rhodesia, in Arch, Hydrobiologia. 79(1), p1-35.

Taylor, P. and Mudege, N.R. (1997) Unban Sanitation in Zimbabwe and the Relation to Environmental Pollution, Institute of Water and sanitation Development, Harare, Zimbabwe. 
Thornton, J.A. (1980) A Comparison of the Summer Phosphorous Loading to Three Zimbabwean Water-

Supply Reservoirs of Varying Trophic States, Water SA Vol. 64, October 1980, p163-170.

Thornton, J.A. and Nduku, W.K. (eds.) (1982) Lake Mcllwaine - The Eutrophication and Recovery of a

Tropical Man-made Lake, Dr. W. Junk Publishers, The Hague, The Netherlands.

UNEP (United Nations Environment Programme) (2000) Where Nutrients Come from and how they

Cause Eutrophication, Internet: http://www.unep.or.jp/ietc/publications/short series/lakereservoirs3/index.asp.

United Nations (2003) Millennium Indicator Database, Department of Economic and Social Affairs, Internet Site: http://unstats.un.org/unsd/mi/mi_goals.asp, Accessed: July 2003.

Veenstra S., Alaerts G., Bijlsma M. (1997) Technology Selection. In: Water Pollution Control. Eds. R Helmer and I. Hespanol. E\&FN Spon, London, UK.

Watts, C.J. (1982) An Examination of Phytoplankton Nutrient Limitation in Lake Mcllwaine and Hunyani River System, in Thornton, J.A. and Nduku, W.K. (eds.) Lake Mcllwaine - The Eutrophication and Recovery of a Tropical Man-made Lake, Dr. W. Junk Publishers, The Hague, The Netherlands, p117-133.

WHO (2000) Global Water Supply and Sanitation Assessment 2000 Report, World Health Organisation, Geneva, Switzerland.

WHO/UNICEF (2001) Access to Improved Sanitation: WHO/UNICEF Joint Monitoring Programme for Water Supply and Sanitation Coverage Estimates 1980-2000, Internet: http://www.childinfo.org/eddb/sani/africa/zimbabwe sanitation1.pdf.

Zanamwe, L. (1997) Population Growth and Land Use in the Manyame Catchment Area, in Moyo, N.A.G.

(Ed.) Lake Chivero: A Polluted Lake, University of Zimbabwe Publications, Harare, Zimbabwe.

Zaranyika, M.F. (1997) Sources and Levels of Pollution Along Mukuvisi River: A Review, in Moyo, N.A.G.

(Ed.) Lake Chivero: A Polluted Lake, University of Zimbabwe Publications, Harare, Zimbabwe. 


\section{Chapter 2}

\section{Inventory of Existing Water Management Practices in Harare, Zimbabwe}

Submitted as:

Nhapi, I., Siebel, M.A. and Gijzen, H.J. (2002) An inventory of existing water management practices in Harare, Zimbabwe, Joumal of Uiban Water 


\title{
Inventory of Existing Water Management Practices in Harare, Zimbabwe
}

\begin{abstract}
Lake Chivero, in Zimbabwe, is the major water supply source for the greater Harare area. This paper looks at the sustainability of current practices of the urban water cycle in relation to water quantity and quality management in the Chivero catchment. Data on population, water supply, water and wastewater treatment and river flows were obtained from urban councils and government departments. The data were used to assess water consumption, wastewater generation, treatment and disposal practices, river flow trends, raw water abstractions, and water demand patterns. The results showed that the current situation is not sustainable as water quantity in the catchment will soon be a problem at current levels of consumption whilst water quality already is a problem, especially with regards to nutrient levels. Water and nutrient management strategies, which include water use efficiency, treatment and water recycling, and nutrient reuse in controlled urban agriculture are recommended as matters of urgency.
\end{abstract}

Keywords: Lake Chivero, nutrients, pollution, wastewater, water management, water quality, water scarcity

\section{Introduction}

The functional and economic effectiveness of conventional urban water management methods in fulfilling environmental, quality of life, and other objectives is now being questioned (Pinkham, 1999). Urban water management (UWM) involves the qualitative (hygienic) and quantitative aspects of all water in urban settings (Siebel and Gijzen, 2002). The conventional methods of urban water management mainly focus on the control of waterborne diseases and preventing the degradation of the urban environment and surface waters. This system is characterised by high water consumption and large central treatment works. The conventional methods are supply-driven and suit an era of abundance (Wright, 1997). Fresh water as a resource is renewable and therefore unlimited in quantity but it is limited in terms of quality and flow. Water demand will continue to increase worldwide because of population growth, increased irrigation requirements and industrialisation. The availability of an adequate water supply (i.e. in the required quantity and quality) is crucial for economic development and to sustain ecosystems. 
In Zimbabwe, the question of water scarcity is not well-defined. Zimbabwe has a population of about 12 million people and a land area of $390,580 \mathrm{~km}^{2}$ (CSO, 2002). Assuming that $8-10 \%$ of the annual rainfall ( $675 \mathrm{~mm} / \mathrm{yr}$ ) appears as river flow (Department of Water Development, 1995), the available renewable fresh water resources amount to $1,980 \mathrm{~m}^{3} / \mathrm{cap}$.yr. With an annual population growth of about $1.1 \%$ (CSO, 2002), this figure will drop to about $1.590 \mathrm{~m}^{3} / \mathrm{cap}$.yr by the year 2025. Considering the per capita requirements for renewable fresh water as defined by Gardner-Outlaw and Engelman (1997), and Engelman and LeRoy (1993), by the year 2025 the country will be further experiencing water scarcity problems $\left(1,500-1,700 \mathrm{~m}^{3} / \mathrm{cap} . \mathrm{yr}\right)$. The situation could be worse if the effects of the Aids scourge on population growth are removed via the discovery of an Aids cure.

Harare, the capital city of Zimbabwe, is one of the areas where water quantity and quality issues are receiving increased attention. Harare is located upstream of Lake Chivero and the lake's catchment area also includes the towns of Chitungwiza, Epworth, and Ruwa. The lake receives large amounts of wastewater effluent and pollution discharges from urban and agricultural runoffs (McKendrick, 1982; Moyo, 1997; Nhapi and Tirivarombo, 2004). Lake Chivero has been eutrophic since 1960 when the first algal blooms appeared and its condition continues to deteriorate (Munro, 1966; McKendrick and Williams, 1968; Robarts and Southall, 1977; Jarvis et al., 1982; Marshall, 1995; JICA, 1996; Nhapi et al., 2001). The rapid increase of population in the lake's catchment area and a shortage of funds to extend and rehabilitate the water supply and wastewater treatment infrastructure threaten Harare's water supply in terms of both quality and quantity. A number of studies have been carried out recently on different sections of the Chivero system (JICA, 1996; Moyo, 1997; Manjonjo, 1999; Mawere, 2001; Kamudyariwa, 2000; Chidavaenzi, 2001; Nhapi and Tirivarombo, 2004). It is now essential to correlate the results of these studies to produce an integrated picture of water issues (quantity and quality) in the catchment.

The present Chapter forms part of a broader study on the management of water quality and quantity in the Chivero catchment. It describes various components of the urban water cycle and systematically reviews their contribution to potential problems in the lake now or in the near future. The components are water abstraction, treatment and distribution, wastewater production and its management, and river flows. The extent to which these individual components can be influenced in order to arrive at a sustainable situation needs further study. 


\section{Materials and methods}

\section{The study area}

The main study area is the city of Harare, the largest town in the Lake Chivero catchment (Fig. 2.1) although some others are also considered. The Chivero catchment has an estimated population of about 2.4 million people (Table 2.1) and has a surface area of about $2,220 \mathrm{~km}^{2}$ (Department of Water Development records), consisting of approximately $10 \%$ urban and $90 \%$ rural developments. The latter consists of communal and commercial farming lands in nearly equal proportions (Magadza, 1997). The lake, created by a dam constructed in 1952, is located about $35 \mathrm{~km}$ south-west and downstream of Harare. It has a full capacity surface area of 26.449 $\mathrm{km}^{2}$, a volume of $247,181,000 \mathrm{~m}^{3}$, and a mean depth of $9.3 \mathrm{~m}$, with the deepest point measuring about $27 \mathrm{~m}$. Its full supply level is $1,368 \mathrm{~m}$ above mean sea level. It receives water from the Manyame, Mukuvisi and Marimba Rivers. The Ruwa and Nyatsime Rivers feed into the Manyame and they drain the towns of Ruwa and Chitungwiza, respectively. The Marimba and Mukuvisi Rivers drain most parts of Harare. Five wastewater treatment works and two water treatment works are found in the catchment (Fig 2.1).

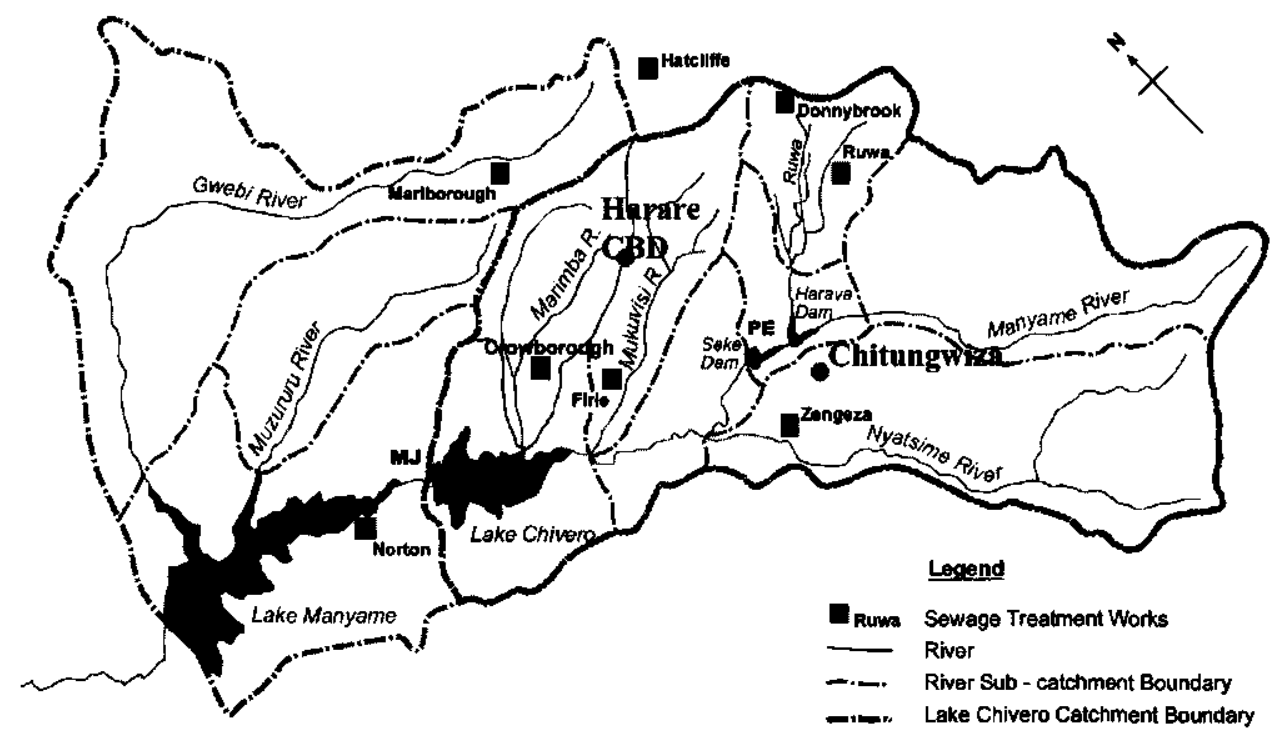

Figure 2.1: Map showing the catchment areas of Lakes Chivero and Manyame, and the location of water treatment works, wastewater treatment plants, and major rivers (MJ = Morton Jaffray waterworks, PE = Prince Edward waterworks) 
Table 2.1: The population of towns in the Chivero Catchment, 1969-2002 (Source: Central Statistical Office; JICA, 1996; Magadza, 1997; Taylor and Mudege, 1997; Zimbabwe Factbook, 1998)

\begin{tabular}{|c|c|c|c|c|c|}
\hline Urban Area & Area $(\mathrm{km})^{2}$ & 1969 & 1982 & 1992 & $2002^{\star}$ \\
\hline Harare City & 447.1 & 386,000 & 658,000 & $1,189,103$ & $1,862,000$ \\
\hline Chitungwiza Town & 42.0 & 15,000 & 172,000 & 274,912 & 388,000 \\
\hline Epworth Local Board & 11.1 & & & 62,630 & 88,000 \\
\hline Ruwa Local Board & 31.4 & & & $1, \mathbf{4 4 7}$ & 56,000 \\
\hline Total & 531.6 & 401,000 & 830,000 & $1,548,092$ & 2,394000 \\
\hline$\%$ of national population & $0.14^{* *}$ & 8 & 11 & 15 & $19^{* * *}$ \\
\hline
\end{tabular}

\section{Approach, data collection and analysis}

For the purpose of analysis, four existing components of the urban water cycle in the Chivero system were identified. These are: 1) the water resource (rainfall and runoff, dams), 2) water treatment plants and water supply system, 3) wastewater generation, collection and treatment, 4) wastewater disposal systems (river discharge, pasture irrigation). However, the nutrient flow is strongly interconnected with the urban water cycle, so urban agriculture is also discussed as a major user and source of nutrients. The study considered mainly quantitative data, focusing on water security and technologies used. On urban agriculture, the study dealt with the possibility of channelling water and nutrients present in wastewater to food production. This would be an alternative to the current practice of discharging it into the river and pasture irrigation. Surface water quality is assessed and discussed on the basis of available data in the literature. A detailed assessment of water quality will be dealt with in a subsequent study (Chapter 3 - Nhapi et al., 2004). The current Chapter shows the impact of existing water and nutrient management practices on the environment, and on various water uses, especially the impacts on Lake Chivero as a major source of water supply. The question of sustainability is discussed in the context of water scarcity and water quality, now and in the future.

Data were collected from the City of Harare, the Meteorological Office, and the Zimbabwe National Water Authority (ZINWA) and they included the volume of raw water abstracted and treated, the volume of wastewater produced and treated, rainfall, and river flows. Population data were obtained from the Central Statistical Office and city planning reports. The water quality situation is based on literature data. 


\section{Results}

\section{Water Resources}

Rainfall, runoff and rivers. Rainfall over the Chivero catchment varies in time and in space (Fig 2.2a), with an average precipitation of around $830 \mathrm{~mm}$ /annum for the 18 gauging stations in the catchment. The Marimba and Mukuvisi rivers, with sub-catchments of $189 \mathrm{~km}^{2}$ and $231 \mathrm{~km}^{2}$ respectively, have fairly similar flow patterns and magnitudes (Fig 2.2b) and they receive runoff and wastewater discharged from the city of Harare. The catchment area of the Manyame River is $1,510 \mathrm{~km}^{2}$ and about $290 \mathrm{~km}^{2}$ of the catchment area is not gauged. The mean area runoff is $175 \mathrm{~mm} / \mathrm{annum}$ for the Mukuvisi and Marimba sub-catchments, and $102 \mathrm{~mm} / \mathrm{annum}$ for the Manyame. Runoff in the Marimba and Mukuvisi Rivers is increased by effluent discharged from Crowborough and Firle wastewater treatment plants. The value for Manyame reflects upstream water losses via abstractions for irrigation and urban water supply and evaporation, especially from the Seke and Harava dams.
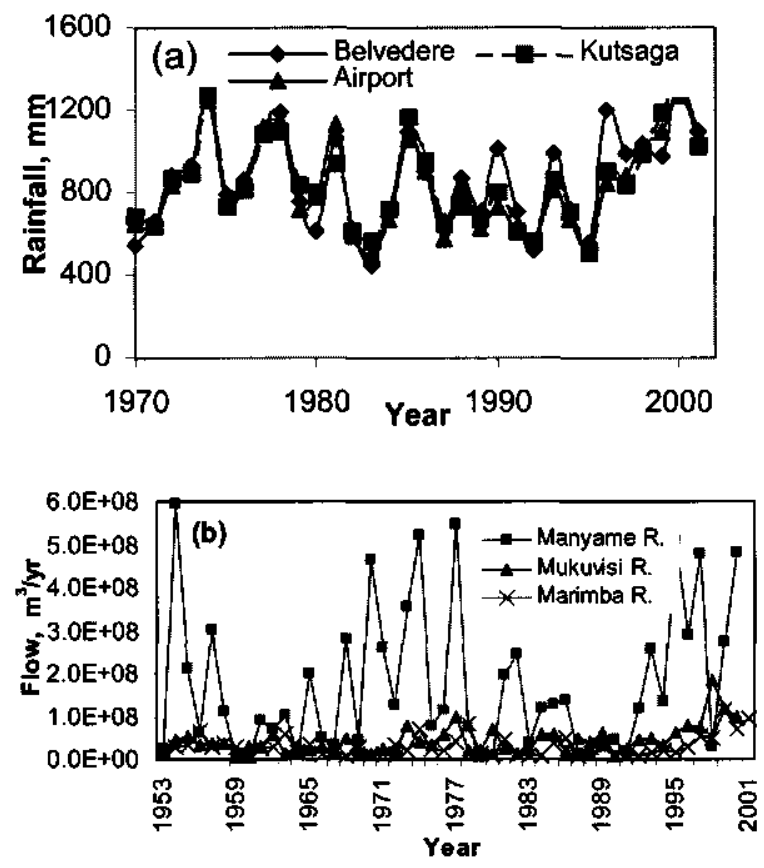

Figure 2.2: (a) Annual rainfall for three weather stations in Harare, $1970-2001$ and (b) river flows at three main gauging stations before L. Chivero; 1953 - 2001 (Data sources: ZINWA)

Dams. Water rarely flows over the spillway at Lake Chivero in the dry months of July to November (Fig 2.3a) while water flows into the lake throughout the year. There are no regulated outflows from Lake Chivero into the Manyame River as the floodgates are permanently closed 
and water is no longer abstracted for irrigation directly from the lake. Human activities, mostly boating clubs, lodges and National Parks premises, around the lake are not significant consumers of water and have no impact on its quantity and quality. The lake's inflow and outflow mainly dictates seasonal water quality and, to some extent, the self-purification capacity of feeding rivers and of the lake itself. In severe periods of droughts, e.g. years 1985 and 1995, the useful volume of the lake below which no abstraction is allowed $\left(167,000 \mathrm{~m}^{3}\right.$, according to ZINWA records) may be exhausted (Fig 2.3b).
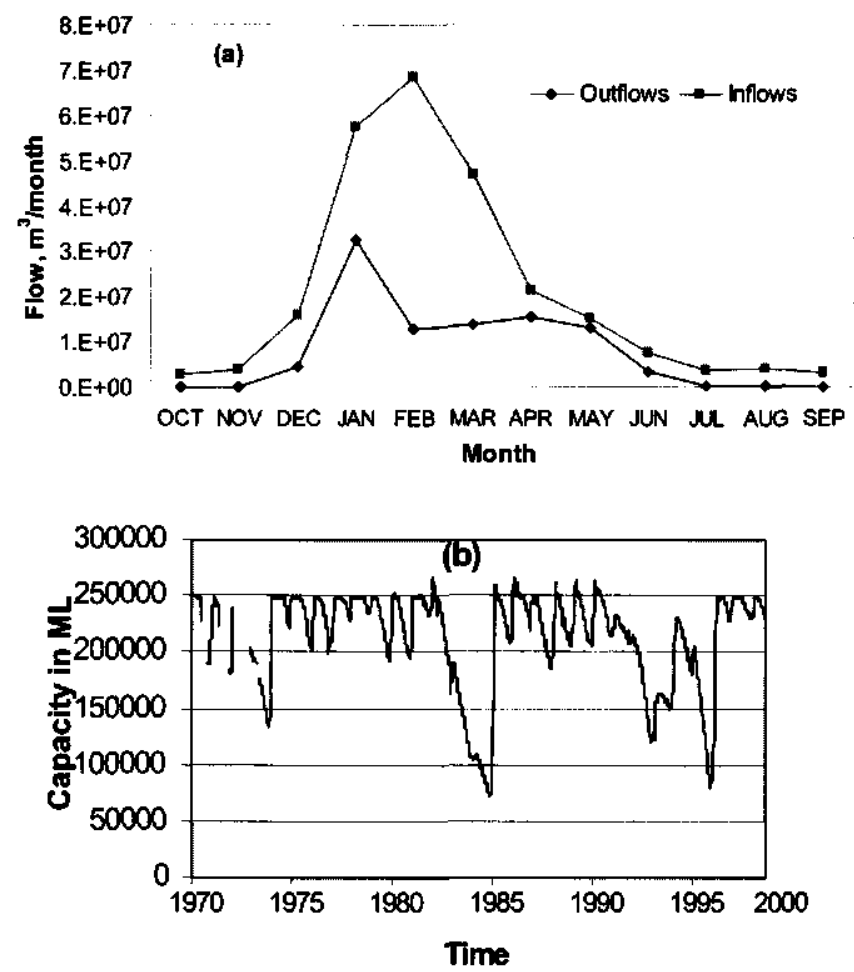

Figure 2.3: (a) The average monthly flow over the spillway, Lake Chivero (1990 - 2000), and (b) the variation in the lake's capacity from 1970 to 2000 (Data source: ZINWA).

The level of Lake Chivero water volume falls considerably during years of low rainfall (Fig 2.3b). A water balance analysis showed that the lake could sustain the provision of about 421,000 $\mathrm{m}^{3} / \mathrm{d}$ of raw water without drawing down the lake level. The current abstraction rate of 416,000 $\mathrm{m}^{3} / \mathrm{d}$ means that the abstraction limit has now been reached and this is evidenced by rapid declines in the water level in the dry season (Fig 2.3a). Water conservation measures in the catchment should be increased coupled with increased abstractions from Lake Manyame, which 
is much larger than Chivero, with a volume of $480,236,000 \mathrm{~m}^{3}$. The combined storage capacity of the Chivero/Manyame lakes is $727,417,000 \mathrm{~m}^{3}$. In fact, less and less water is being abstracted from Lake Manyame over the years and no satisfactory explanation for this could be obtained from the City of Harare.

\section{Water treatment and water supply system}

The water supply scheme for Harare is shown in Fig 2.4. The Prince Edward and Morton Jaffray Water Treatment Works (WTWs) supply the Harare metropolitan area and have design capacities of $90,000 \mathrm{~m}^{3} / \mathrm{d}$ and $614,000 \mathrm{~m}^{3} / \mathrm{d}$, respectively (JICA, 1996). Lake Chivero, although receiving the bulk of urban contamination, supplies $416,000 \mathrm{~m}^{3} / \mathrm{d}(73 \%)$ out of the total 544,000 $\mathrm{m}^{3} / \mathrm{d}$ of the raw water currently abstracted for the Harare metropolitan area (Fig. 2.5). On the other hand, Lake Manyame (which receives little urban contamination) supplies only $\mathbf{8 4 , 0 0 0}$ $\mathrm{m}^{3} / \mathrm{d}$ and Seke dam $44,000 \mathrm{~m}^{3} / \mathrm{d}$. Harare suffers water losses of more than $30 \%$ in the distribution/reticulation system (City of Harare, 1996), because of the ageing reticulation network. Water losses within the water treatment works for the study period were $7 \pm 3 \%$ for Prince Edward and $11 \pm 6 \%$ for Morton Jaffray (Fig 2.6) but have been going down recently. This is because of renovations and improved maintenance at the plants. Losses are attributed to the high levels of algae in the raw water, which necessitates frequent back-washing of filters. The generated wastage (sludge) is either discharged into the river through a retention tank or pumped to farmland for irrigation use. Extrapolation from Fig $2.5 \mathrm{~b}$ shows that the full capacity of Morton Jaffray waterworks will be reached in $\mathbf{2 0 0 8}$ while that for Prince Edward waterworks will be reached in 2012.

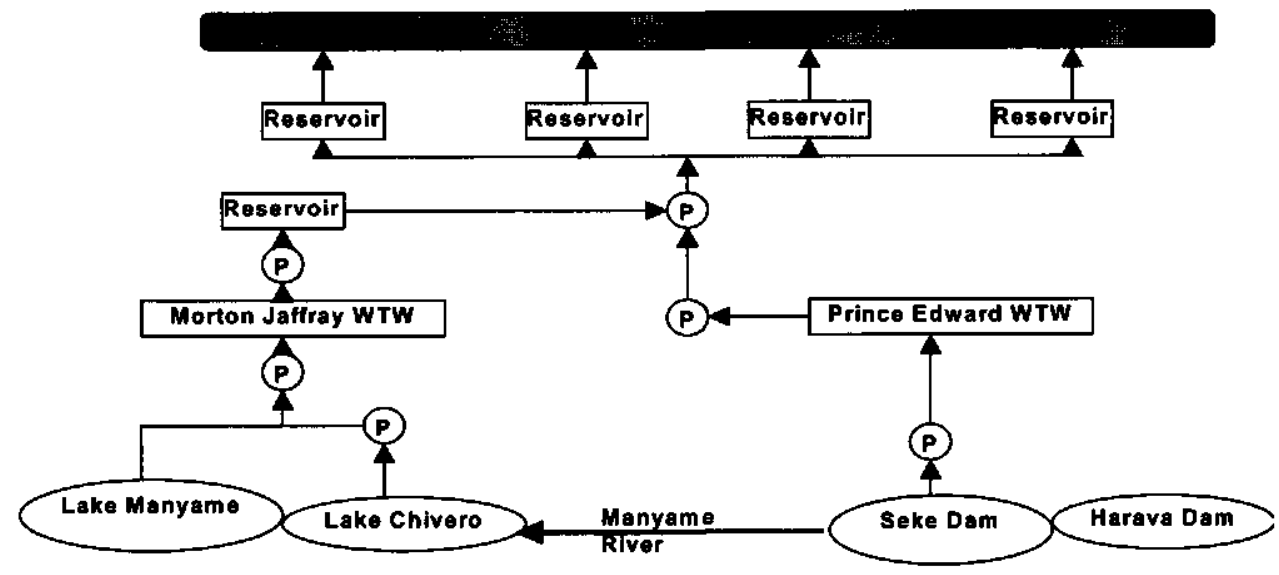

Figure 2.4: Schematic layout of Water Supply System for the Harare metropolitan area $(P=$ pump, and $W T W=$ water treatment works $)$. 

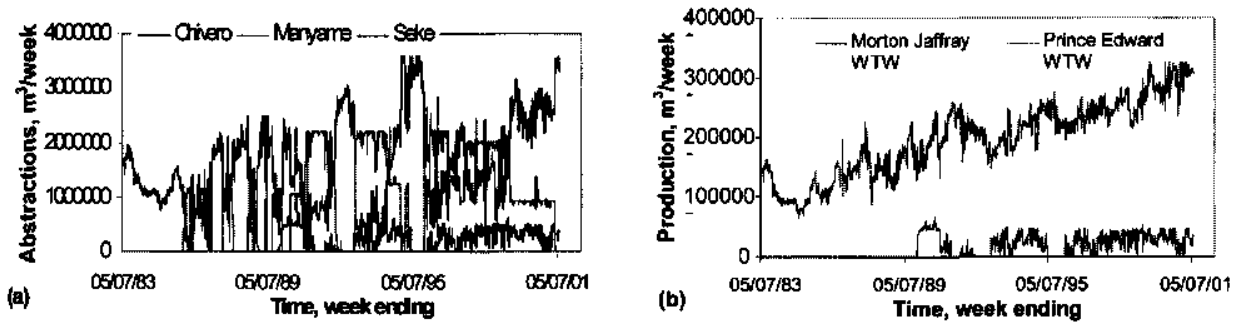

Fig 2.5: Water supply for the Harare metropolitan area (a) raw water abstractions from Chivero, Manyame and Seke dams, and (b) potable water production from Morton Jaffray and Prince Edward waterworks (Data source: City of Harare)

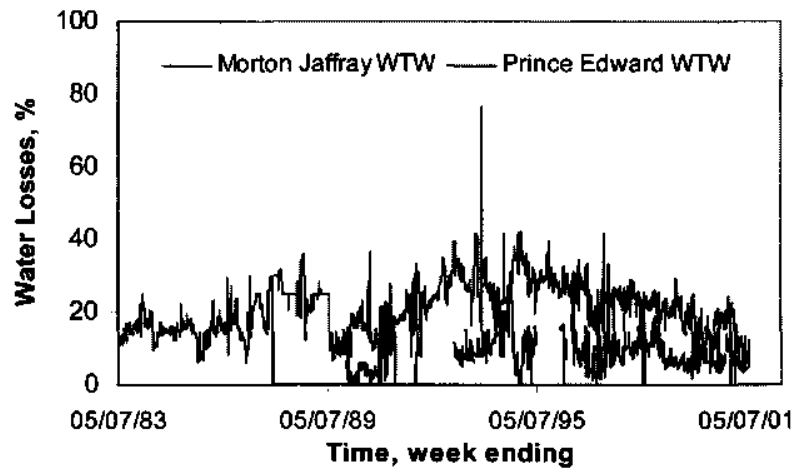

Fig 2.6: Treatment plant losses at Morton Jaffray and Prince Edward waterworks from 1983 to 2001 unaccounted for as percentage of inflow (Data source: City of Harare).

\section{Wastewater generation, collection and treatment}

Residential areas in Harare are classified into high, medium and low-density areas. High-density corresponds to low-income areas where the majority of the urban dwellers live on stands of about $\pm 300 \mathrm{~m}^{2}$, medium-density stands are around $1,000 \mathrm{~m}^{2}$ and low-density $>2,000 \mathrm{~m}^{2}$, and represent increasing household income levels. The wastewater production rates are 63 l/cap.d for high-density, $210 \mathrm{l} / \mathrm{cap} . \mathrm{d}$ for medium-density, and $315 \mathrm{l} / \mathrm{cap} . d$ for low-density residential areas (Table 2.2). About $17,000 \mathrm{~kg} / \mathrm{d}$ TN and $2,400 \mathrm{~kg} / \mathrm{d}$ TP are generated by a population of about $1,800,000$ and channelled to five wastewater treatment plants in Harare. An additional population of about 76,000 is served by septic tanks in low-density areas where about $750 \mathrm{~kg} / \mathrm{d}$ TN and $100 \mathrm{~kg} / \mathrm{d}$ TP are treated by septic tanks onsite. Domestic wastewater provides the bulk of the nutrients received at the five wastewater treatment plants, while industry generates about $17 \%$ of daily wastewater volume and only about $3 \%$ of the nutrient load. Some industries have pre-treatment facilities whilst others discharge into stormwater drains. 
Table 2.2: Estimated daily wastewater quantity and nutrient loads by landuse category and wastewater treatment works (modified from JICA, 1996)

\begin{tabular}{|c|c|c|c|c|c|c|}
\hline \multirow{2}{*}{$\begin{array}{c}\text { Wastewater } \\
\text { treatment works }\end{array}$} & \multirow{2}{*}{$\begin{array}{l}\text { Population } \\
\text { senved }\end{array}$} & \multirow{2}{*}{$\begin{array}{l}\text { Domestic flow } \\
\qquad \mathrm{m}^{3 / \mathrm{d}}\end{array}$} & Industrial flow & \multirow{2}{*}{$\begin{array}{l}\text { Commercial flow } \\
\qquad \mathrm{m}^{3 / d}\end{array}$} & \multirow{2}{*}{$\begin{array}{r}\text { Groundwater flow } \\
\text { (infittration) } \\
\mathrm{m}^{33} \mathrm{~d}\end{array}$} & \multirow{2}{*}{$\begin{array}{l}\text { Total } \\
\mathrm{m}^{3 / \mathrm{d}}\end{array}$} \\
\hline & & & $m^{3 / d}$ & & & \\
\hline Crowborough & 691,000 & 64,722 & 12,662 & 13,402 & 12,392 & 103,178 \\
\hline Firle & 892,000 & 81,162 & 37,932 & 48,227 & 3,502 & 170,823 \\
\hline Marlborough & 35,000 & 11,025 & & & 214 & 11,239 \\
\hline Donnybrook & 120,000 & 7,560 & & & 1,000 & 8,560 \\
\hline Hatcliffe & 48,000 & 3,024 & & & 252 & 3,276 \\
\hline Sub-total & $1,786,000$ & 167,493 & 50,594 & 61,629 & 17,360 & 297,076 \\
\hline \multicolumn{7}{|l|}{ Nutrient loads } \\
\hline & & Domestic & Industrial & Commercial & & Total \\
\hline$T N, \mathrm{~kg} / \mathrm{d}$ & & 15,063 & 338 & 1,389 & & 16,790 \\
\hline$T P, \mathrm{~kg} / \mathrm{d}$ & & 2,187 & 105 & 151 & & 2,443 \\
\hline
\end{tabular}

The two largest wastewater treatment plants in Harare (Firle and Crowborough) discharge their treated effluents into the Mukuvisi and Marimba rivers, respectively 5 and $8 \mathrm{~km}$ upstream of Lake Chivero. The major part of the industrial areas is also located in the sub-catchment of these two rivers. The Manyame River collects tertiary effluent from Chitungwiza, upstream of the lake.

The existing wastewater treatment plants in the Chivero catchment area were overloaded by about $30 \%$ (Table 2.3, based on measured flow data). Their total design capacity is 253,700 $\mathrm{m}^{3} / \mathrm{d}$ compared to the total current inflows of about $326,000 \mathrm{~m}^{3} / \mathrm{d}$. This has serious implications for downstream water quality. Chitungwiza commissioned a new biological nutrient removal (BNR) system (a modified version of activated sludge system) in the year 2000 and the town pumps about $50 \%$ of its effluent out of the catchment for irrigation on Imbwa Farm. The Hatcliffe plant discharges into the Chinyika River, a tributary of the Mazowe River, whilst Marlborough discharges into Gwebi River. Both Mazowe and Gwebi Rivers are outside the Chivero catchment area. The total amount of wastewater received at the treatment plants $(326,000$ $\mathrm{m}^{3} / \mathrm{d}$ ) is $60 \%$ of the total water abstracted $\left(544,000 \mathrm{~m}^{3} / \mathrm{d}\right)$, the difference being accounted for by water losses (treatment plant, distribution, and property level), outside washing and irrigation, and onsite disposal of wastewater. 
Table 2.3: Existing Wastewater Treatment Works in the greater Harare Area (JICA, 1996; City of Harare)

\begin{tabular}{|c|c|c|c|c|c|c|}
\hline $\begin{array}{l}\text { Wastewater } \\
\text { Treatment } \\
\text { Plant }\end{array}$ & $\begin{array}{l}\text { Population } \\
\text { Served }\end{array}$ & Treatment System & $\begin{array}{r}\text { Design } \\
\text { Capacity } \\
m^{3} / d\end{array}$ & $\begin{array}{r}\text { Year } 2002 \\
\text { Influent Flow } \\
\mathrm{m}^{3} / d\end{array}$ & $\begin{array}{r}\text { Discharged } \\
\text { to River, } \\
\mathrm{m}^{3} / d\end{array}$ & $\begin{array}{l}\text { Irrigation } \\
\text { Use, } \mathrm{m}^{3} / \mathrm{d}\end{array}$ \\
\hline \multirow[t]{2}{*}{ Crowborough } & 691,000 & Trickling filters & 36,000 & 87,000 & 35,300 & 51,700 \\
\hline & & Biological nutrient removal & 18,000 & 20,000 & 20,000 & \\
\hline \multirow[t]{2}{*}{ Firle } & 892,000 & Trickling filters & 36,000 & 72,800 & & 72,800 \\
\hline & & Biological nutrient removal & 108,000 & 79,800 & 10,800 & \\
\hline Hatcliffe & 48,000 & Extended aeration & 2,500 & 3,300 & 3,300 * & \\
\hline Marlborough & 35,000 & Waste stabilisation ponds & 2,000 & 11,200 & & 11,200 \\
\hline Donnybrook & 120,000 & Waste stabilisation ponds & 5,500 & 8,600 & 8,600 ** & \\
\hline Zengeza, & 465,000 & Biological nutrient removal & 20,000 & 20,000 & 20,000 & \\
\hline Chitungwiza & & Trickling filters & 20,000 & 18,000 & & $18,000^{\star * *}$ \\
\hline Ruwa & 20,000 & Waste stabilisation ponds & 5,300 & 5,300 & $5,300 * *$ & \\
\hline Total flows & & & 253,300 & 326,000 & 103,300 & 222,700 \\
\hline
\end{tabular}

\section{Wastewater disposal systems}

In Harare, pasture is irrigated with wastewater treatment plant effluent on three farms, namely Crowborough, Ingwe and Pension, which together cover 3,411 ha, of which 1,397 ha are irrigable and arable (McKendrick, 1982). Of this, Crowborough Farm has a total area of 594 ha of which only 305 ha are under irrigation (Manjonjo, 1999), suggesting that the area under irrigation could be increased. Effluent alone, or a mixture of effluent and sludge is used for irrigation and, on average, $112,000 \mathrm{~m}^{3} / \mathrm{d}$ of effluent/sludge mixture is pumped to the three farms. Kikuyu grass (Pennisetum clandestinum) and star grass (Cynodon plectostochus) are grown as pasture and flood-irrigated about once every three weeks. These pastures could produce enough to feed 13,000 head of cattle.

The disposal of effluent by pasture irrigation has a number of problems. Firstly, these pastures are an ideal incubator for all sorts of pests and diseases, and expensive control measures (dosing, dipping, and fumigation) are needed to keep the cattle in good health (McKendrick, 1982; Chimbari et al., 2004). Secondly, this practice is increasingly losing its capacity to remove nutrients (e.g. the phosphorus sorption capacity could be exhausted) and heavy metal are accumulating in the soil (Nyamangara and Mzezewa, 1999). There is a risk that some pollutants could enter the food chain. Another disadvantage is that this practice requires more land, a resource that is gradually becoming scarce and costly. In fact, some areas of suitable land between the wastewater treatment plants and the lake are now being converted into housing developments. The efficiency of the land treatment of effluent decreases in wet weather 
(McKendrick, 1982). During the dry season, the effluent is drained into the soil releasing its nutrients, mixing with the subsoil water and thus raising the water table forming springs and streams.

\section{Urban agriculture}

Urban agriculture is a notable economic activity in Harare. Bowyer-Bower et al. (1995) reported that by 1994 , an estimated area of 9,288 ha, or $34 \%$ of open spaces, was under cultivation in Harare. A rough estimate, based on an assessment of unpublished reports and newspapers, puts it at more than 16,000 ha by year 2003 . The cultivation of open spaces has been passively encouraged in Zimbabwean towns since the great drought of 1991-92 (Marongwe, 2003). It could also be related to economic hardships caused by an economic structural adjustment programme in the early 1990's (Mbiba, 1995). The crops that are grown are mainly maize, sweet potatoes, cassava, pumpkins, and sweet canes. On-plot cultivation is quite common for almost all residential areas. There are no institutions or mechanisms to control these practices and to ensure that appropriate conservation measures are taken to minimise nutrient runoff and soil loss (Masoka, 1997). Urban agriculture therefore poses a potential threat to water quality and this practice is likely to continue without regulation into the future (Zanamwe, 1997). Pesticides and fertiliser applications are thought to be generally higher than in normal farming (ENDA-Zimbabwe, 1996). This will result in cumulative fertiliser loading on the soils, leading to groundwater pollution and subsequent leaching into the lake.

\section{Surface water pollution}

River pollution. Studies on the water quality of the Mukuvisi River reported by Zaranyika (1997) and Kamudyariwa (2000) showed that it was significantly affected by human activities, especially wastewater discharges that adversely affected its water quality. Moyo and Worster (1997) also studied the effects of organic and other pollutants on the Mukuvisi River. They reported total nitrogen and total phosphorus concentrations of $15.2 \mathrm{mg} / \mathrm{l}$ and $6.6 \mathrm{mg} / \mathrm{l}$, respectively, in the river at Pension Farm, which is close to Lake Chivero, showing that the lake was receiving very high nutrient loads. Ammonia levels were low $\left(<0.5 \mathrm{mg} / / \mathrm{NH}_{4}-\mathrm{N}\right)$ at all the sites because the shallow stream is turbulent and well aerated. In other studies, Machena (1997) and Magadza (1997) recommended the management of rivers so that they become part of pollutant reduction systems through increased self-purification. There are a number of options to achieve this. Magadza (1997) suggests constructed wetlands and the control of activities that degrade streambeds and stream banks, such as landfills and urban agriculture on open spaces. The approach is to reduce flow velocity and increase biological and chemical activities. Algal growth raises the $\mathrm{pH}$ of the water and causes volatilisation of ammonia and the sedimentation of heavy metals and phosphates. 
The impact of effluent discharged from the Workington Industrial Area and of treated and partially treated wastewater from the Crowborough wastewater treatment plant on the quality of the Marimba River water was studied by Mathuthu et al. (1997). The levels of virtually all water quality variables monitored went up downstream of wastewater discharge points. Manjonjo (1999) also found that wastewater effluent, irrigation seepage and runoff were significantly increasing the concentrations of nutrients and heavy metals in the river. Partially treated trickling filter effluent from Crowborough wastewater treatment plant was the major polluter of the Marimba River (Nhapi and Tirivarombo, 2004).

Lake Pollution. Numerous hydro-biological investigations carried out in Lake Chivero in the 1970 's showed that the lake was eutrophic and that wastewater from the city of Harare was the major cause (Thornton, 1980; Jarvis et al., 1982; Watts, 1982; Mathuthu et al., 1997; Moyo, 1997). Robarts and Southall (1977) showed that nitrogen was the primary growth-limiting nutrient for phytoplankton. Besides some work reported in Moyo (1997), there appears to have been no comprehensive research programme in Lake Chivero in the 1990s and there is limited recent information on limnological aspects that might be useful in managing the lake's problems.

Problems related to water quality reported in Lake Chivero include extensive fish deaths that occurred in 1996 from the deoxygenation of the water compounded by ammonia and algae toxicity (Moyo and Mtetwa, 1999; Magadza, 1997). Most fish are sensitive to DO levels of below $3 \mathrm{mg} / \mathrm{l}$ (Mara, 1996; Welch and Lindell, 1980) and free ammonia could be toxic to fish at concentrations above $0.5 \mathrm{mg} / \mathrm{l}$ (Abesinghe et al., 1996). The growth of invasive water weeds like the water hyacinth (Eichhornia crassipes), and blue-green algae, principally Microcystis aeruginosa and Anabaena sp. (Marshall, 1997) is another example of water quality-related problems in the lake. Excessive amounts of algae and other organic matter seriously affect raw water abstraction and water treatment by requiring extra filtration measures and through the production of unpleasant tastes and odours, as well as the possible production of toxins (McKendrick, 1982; Moyo and Mtetwa, 1999). The high organic content often taints the water with a distinctive taste and affects $\mathrm{pH}$, making additional treatment necessary to make it potable. The lake is also losing its value as a recreational area (e.g. yachting, skiing, angling) and its aesthetic qualities have also deteriorated (Mbiba, 1995). 


\section{Discussion}

This study identifies three main factors which compromise the sustainability of the urban water management system in the Lake Chivero catchment. These are water scarcity, inadequate wastewater treatment, and surface water pollution. The Lake Chivero catchment receives a total of about $1.8 \times 10^{9} \mathrm{~m}^{3} / \mathrm{yr}$ of rainfall (about $750 \mathrm{~m}^{3} /$ cap.yr), of which $0.29 \times 10^{9} \mathrm{~m}^{3} / \mathrm{yr}(16 \%)$ flows into Lake Chivero. Some of the water is abstracted, treated and used in towns after which it returns to the lake as treated wastewater (Table 2.3). Only about $50 \%$ of the lake inflows are abstracted for urban uses. The rest either evaporates or flows downstream where some of it is abstracted for agricultural irrigation. Raw water is also abstracted from the immediately downstream Lake Manyame giving a combined storage volume for the two lakes of about $727,417,000 \mathrm{~m}^{3}$. At a projected water demand of 1,390,000 $\mathrm{m}^{3} / \mathrm{d}$ by 2012 (JICA, 1996), or $70 \%$ of current annual storage capacity, water scarcity is not an immediate problem, but it will be a problem in future. Abstraction levels are approaching the limit for Lake Chivero so the abstraction system needs to be optimised for Lake Manyame to avoid drawing down Lake Chivero. At current abstraction levels, the lake level is rapidly going down in the dry season.

The hydraulic overloading of wastewater treatment plants is an urgent problem in Harare and is related to high water consumption. A significant saving on investment requirements could be realised by reducing current wastewater production from 315 l/cap.d to 150 l/cap.d for lowdensity residential areas and from 210 l/cap.d to 135 l/cap.d for medium and mixed density residential areas. This could be achieved via demand management measures centred on cleaner production approaches (Gijzen 2001; Siebel and Gijzen, 2002). The measures include water saving measures at plant and distribution network, pollution prevention or reduction at household level, reuse and recycling of wastewater components, installation of water saving devices like low water use flush toilets, water saving faucets and showerheads. All these measures together could yield a reduction of about $33,700 \mathrm{~m}^{3} / \mathrm{d}$, or $20 \%$ of the current domestic hydraulic load, or $11 \%$ of the total wastewater produced in Harare (Table 2.2). Reduced water consumption of this magnitude could cancel the need for a new source of water supply, which is economically attractive as the construction of a BNR plant would cost US $\$ 254 / \mathrm{m}^{3}$ (Nhapi et al., 2002). If demand management is extended to commercial, industrial and other water consumers, even larger savings would result.

The lack of spillway outflows from the lake in the dry season when inflows are perennial (and increasingly contaminated) suggest that the lake could be acting as a sink for pollutants. This situation will worsen in low rainfall years. Although there is currently no published evidence on contamination from urban agriculture, it is likely that the applied fertilisers will eventually leach 
into the lake but this probably has little impact compared to nutrients contained in the urban effluents. The overloading and breakdowns of wastewater treatment plants are also detrimental to lake water quality. The last extensive water quality study in the Lake Chivero catchment was done by consultants in 1996 (JICA, 1996). Since that time, Zimbabwe has had extreme rainfall seasons (droughts and cyclones) and Harare has experienced high population growth due to rural-urban migration. A detailed assessment of water quality in the Chivero catchment is therefore necessary and is the subject of ongoing research work (Nhapi et al., 2004).

\section{In conclusion}

1. The rapid increase in population in the Chivero catchment ( $2.5 \%$ per annum) is putting increased pressure on available urban water infrastructure (water supply, wastewater treatment plants and disposal, rivers, and Lake Chivero) causing failures and overloading.

2. Water scarcity is not a problem now in Harare but it will be a major problem after year 2012.

3. Urbanisation and increased abstraction of water from Lake Chivero has resulted in changes in the lake inflow and outflow regimes meaning that the lake is receiving pollution throughout the year. Lake water outflows are reduced in the dry season and this could result in the accumulation of nutrients and other pollutants in the lake. An urgent investigation on water quality is therefore necessary.

4. The high water consumption in Harare is costly in terms of treatment infrastructure (both for water and wastewater) and needs to be reduced as a matter of urgency. There are good prospects for the application of cleaner production concepts (water conservation, pollution prevention and reuse) to urban water management in the Chivero catchment.

5. The presence of uncontrolled urban agriculture in the area is a potential threat to water quality in the long-term. On the other hand, when properly managed, urban agriculture offers a logical alternative for the reuse of nutrients in wastewater.

\section{References}

Abeysinghe, D.H., Shanableh, A. \& Rigden, B. (1996). Biofilters for Water Reuse in Aquaculture, in IAWQ Wat. Sci. Tech. Vol. 34(11), p253-260.

Bowyer-Bower, T.A.S., Mapure, I., and Drummond, R.B. (1996). Ecological Degradation of Cities: Impact of Urban Agriculture in Harare, Zimbabwe, in Joumal of Applied Science in Southem Africa (JASSA), Vol. 2(2), p53-67. 
Chidavaenzi, M (2001). A Rainfall-runoff Model for a Composite Micro-catchment Area and the Impact of Unban Agriculture on Storm Water Management. MSc Thesis, Harare, Zimbabwe: University of Zimbabwe.

Chimbari, M.J., Madyiwa, S., Mukaratiwa, S. and Musesengwa, R. (2004). Pollution Implications of Disposing Wastewater on Pasturelands, Final Project Report, Institute of Water and Sanitation Development, Harare, Zimbabwe.

City of Harare (1996). Leakage Control and System Rehabilitation Programme within the City of Harare, Department of Works, Harare, Zimbabwe.

CSO (Central Statistical Office) (2002). Census 2002: Zimbabwe, Preliminary Report, Central Census Office, Government of Zimbabwe, Harare, Zimbabwe.

Department of Water Development (1995). Assessment of Surface Water Resources in the Manyame Catchment - Zimbabwe; Streamflow Gauging and Conceptual Hydrological Modelling, SMHI Hydrology No. 60, 1995.

ENDA-Zimbabwe (1996). Uman Agriculture in Zimbabwe: Realities and Prospects. Proceedings of a workshop organised by ETC International and ENDA-Zimbabwe Mandel Training Centre, Harare, June 1996: Enda-Zimbabwe.

Engelman, R. and LeRoy (1993). Sustaining Water, Population and Future Water Supplies. Washington, USA: Population Action International.

Gardner-Outlaw, T. and Engelman, R. (1997). Sustaining Water, Easing Scarcity: A Second Update. Washington, USA: Population Action International.

Gijzen, H.J. (2001). Low Cost Wastewater Treatment and Potentials for Re-use: A Cleaner Production Approach to Wastewater Management, paper presented at the International Symposium on LowCost Wastewater Treatment and Re-use, NVA-WUR-EU-iHE, Cairo, Egypt, February 3 - 4, 2001.

Jarvis, M.J.F, Mitchell, D.S. and Thornton, J.A, (1982). Aquatic Macrophytes and Echhormia Crassipes, in Thornton, J.A. and Nduku, W.K. (Eds) Lake Mclwwaine - The Eutrophication and Recovery of a Tropical Man-made Lake, The Hague, The Netherlands, p137-144: Dr. W. Junk Publishers.

JICA Report (1996). The Study of Water Pollution Control in Upper Manyame River Basin in the Republic of Zimbabwe. Nippon Jogeduido Sekkei Co. Ltd., Nippon Koei Co. Ltd, September 1996: Ministry of Local Government and Public Construction, Zimbabwe.

Kamudyariwa, C. (2000). Seasonal Variation of Water Quality with Respect to Anthropogenic Activities Along Mukuvisi River, Harare, Zimbabwe. MSc. Thesis, IHE Delft, The Netherlands.

Machena, C. (1997). The Pollution and Self-Purification Capacity of the Mukuvisi River. In Moyo, N.A.G.

(Ed.) Lake Chivero: A Polluted Lake, Harare, Zimbabwe: University of Zimbabwe Publications.

Magadza C.H.D. (1997). Water Pollution and Catchment Management in Lake Chivero. In Moyo, N.A.G.

(Ed.) Lake Chivero: A Polluted Lake, Harare, Zimbabwe: University of Zimbabwe Publications.

Manjonjo, M (1999). Land Disposal of Sludge and Pond Effluent on Crowborough Farm: Its Efficiency and Influence on Marimba River, MSc WREM Thesis, University of Zimbabwe, Harare, Zimbabwe.

Marongwe, N. (2003). The Fast Track Resettlement and Urban Development Nexus: The Case for Harare, Paper Presented at the Symposium on Delivering Land and securing Rural Livelihoods: Post 
Independence Land Reform and Resettlement in Zimbabwe, Mont Clair, Nyanga, 26 - 28 March 2003.

Marshall, B.E. (1995). Changes in the Benthic Fauna of Lake Chivero, Zimbabwe, Over Thirty Years. Southem Africa Journal of Aquatic Science, Vol. 21(1/2), p22-28.

Marshall, B.E. (1997). Lake Chivero After Forty Years: The Impact of Eutrophication. In Moyo, N.A.G. (Ed.) Lake Chivero: A Polluted Lake, Harare, Zimbabwe: University of Zimbabwe Publications.

Masoka, M. (1997). The Potential role of Cultivators in Open Space Cultivation Reform in Harare, MA Dissertation, Department of Geography, University of Zimbabwe, Harare, Zimbabwe.

Mathuthu, A.S., Mwanga, K. and Simoro, A. (1997). Impact Assessment of Industrial and Sewage Effluents on Water Quality of the Receiving Marimba River in Harare. In Moyo, N.A.G. (Ed.) Lake Chivero: A Polluted Lake, Harare, Zimbabwe: University of Zimbabwe Publications.

Mawere, M (2001). Land Application of Sewage: The Role of Crowborough Pasture Irrigation in the Reduction of Nutrient Loads to Marimba River. MSc. Thesis, IHE Delft, The Netherlands.

Mbiba, B. (1995). Urban Agriculture in Zimbabwe - Implications for Urban Management and Poverty. Avebury, UK: Ashgate Publishing Ltd.

Mckendrick, J. (1982). Water Supply and Sewage Treatment in Relation to Water Quality in Lake Mcllwaine. In Thornton, J.A. and Nduku, W.K. (Eds) Lake Mcllwaine; The Eutrophication and Recovery of a Tropical African Man-Made Lake, The Hague, The Netherlands, p202-217: Dr W Junk Publishers.

McKendrick, J. and Williams, R.K. (1968). The Effects of Urban Drainage on Lake Mcllwaine, Rhodesia and Subsequent Water Purification Difficulties (Unpublished paper). Harare, Zimbabwe: Department of Biological Sciences, University of Zimbabwe.

Moyo, N.A.G. (Ed) (1997). Lake Chivero: A Polluted Lake. Harare, Zimbabwe: University of Zimbabwe Publications.

Moyo, N.A.G. and Mtetwa, S. (1999). Water Pollution Control, Paper presented at Seminar on Water Resources Management in Southern Africa: Enhancing Environmental Sustainability, Harare Zimbabwe: IUCN.

Moyo, N.A.G. and Worster, K. (1997). The Effects of Organic Pollution on the Mukuvisi River, Harare, Zimbabwe. In Moyo, N.A.G. (Ed) Lake Chivero: A Polluted Lake, Harare, Zimbabwe: University of Zimbabwe Publications.

Munro, J.L (1966). A Limnological Survey of Lake McLlwaine, Rhodesia, in Hydrobiologia, Vol. 28, p281308.

Nhapi, I., Siebel, M.A., and Gijzen, H.G. (2001). Dry Season Inflow and Export of Nutrients from Lake Chivero in Year 2000. Proceedings of the Zimbabwe Institution of Engineers, Vol. 2(1), p33 -41.

Nhapi, I., Hoko, Z., Siebel, M. and Gijzen, H.J. (2002). Assessment of major water and nutrient flows in the Chivero catchment area, Zimbabwe, Physics and Chemistry of the Earth, Vol. 27(11-22), p783792.

Nhapi, I., Siebel, M. and Gijzen, H.J. (2004). The Impact of Urbanisation on the Water Quality of Lake Chivero, Zimbabwe, Joumal of the Chartered Institute of Water and Environmental Management. Vol. 18(1), p44-49. 
Nhapi, I. and Tirivarombo, S. (2004). Sewage Discharges and Nutrient Levels in Marimba River, Zimbabwe, WaterSA, Vol. 30(1), p107-113.

Nyamangara, J. and Mzezewa J. (1999). The Effect of Long-term Sewage Sludge Application on $\mathrm{Zn}, \mathrm{Cu}$, $\mathrm{Ni}$ and $\mathrm{Pb}$ levels in a Clay Loam Soil under Pasture Grass in Zimbabwe. Agriculture, Ecosystems and Environment, Vol. 73, p199-204.

Pinkham, R. (1999). $21^{\text {St }}$ Century Water Systems : Scenarios, Visions and Drivers, Rocky Maintain Institute, Colorado, USA, Internet Site: http:/www.rmi.org/sitepages/pid123.php.

Robarts R.D. and Southall, G.C. (1977). Nutrient Limitation of Phytoplankton Growth in Seven Tropical Man-Made Lakes, with Specific Reference to Lake Mcliwaine, Rhodesia. Hydrobiologia. Vol. 79(1), p1-35.

Siebel, M.A. and Gijzen, H.J. (2002). Application of Cleaner Production Concepts in Urban Water Management, paper presented at the Environmental Technology and Management Seminar 2002, Bandug, Indonesia, January 9 - 10, 2002.

Taylor, P. and Mudege, N.R. (1997). Urban Sanitation in Zimbabwe and the Relation to Environmental Pollution. Harare, Zimbabwe: Institute of Water and sanitation Development.

Thornton, J.A. (1980). A Comparison of the Summer Phosphorous Loading to Three Zimbabwean WaterSupply Reservoirs of Varying Trophic States, WaterSA Vol. 64, p 163-170.

Watts, C.J. (1982). An Examination of Phytoplankton Nutrient Limitation in Lake Mcllwaine and Hunyani River System. In Thornton, J.A. and Nduku, W.K. (Eds) Lake Mcllwaine - The Eutrophication and Recovery of a Tropical Man-made Lake. The Hague, The Netherlands, p117-133: Dr. W. Junk Publishers.

Welch, E.B. and Lindell, T. (1980). Ecological Effects of Waste Water. London, UK: Cambridge University Press.

Wright, A.M. (1997). Toward a Strategic Sanitation Approach: Improving the Sustainability of Urban Sanitation in Developing Countries. Washington, USA: IBRD/The World Bank.

Zanamwe, L. (1997). Population Growth and Land Use in the Manyame Catchment Area. In Moyo, N.A.G. (Ed.) Lake Chivero: A Polluted Lake, Harare, Zimbabwe: University of Zimbabwe Publications.

Zaranyika, M.F. (1997). Sources and Levels of Pollution along Mukuvisi River: A Review. In Moyo, N.A.G. (Ed.) Lake Chivero: A Polluted Lake, Harare, Zimbabwe: University of Zimbabwe Publications. Zimbabwe Factbook (1998). Internet site http://www.odci.gov/cia/publications/factbook/zi.html. 


\section{Chapter 3}

\section{The Impact of Urbanisation on the Water Quality of Lake Chivero, Zimbabwe}

Parts of this Chapter were published as:

Nhapi, I., Siebel, M. and Gijzen, H.J. (2004) The Impact of Urbanisation on the Water Quality of Lake Chivero, Zimbabwe, Journal of the Chartered Institute of Water and Environmental Management, Vol. 18(1), p44-49.

Nhapi, I., Siebel, M. and Gijzen, H.J. (2001) Dry Season Inflow and Export of Nutrients from Lake Chivero; in Proceedings of the Zimbabwe Institution of Engineers, Vol. 2(1), p33-41. 


\title{
The Impact of Urbanisation on the Water Quality of Lake Chivero, Zimbabwe
}

\begin{abstract}
This study quantified major water, nitrogen and phosphorus flows in the Lake Chivero catchment area, Zimbabwe, through a water quality monitoring study. The results showed that wastewater effluent is the major source of nutrients in the lake, which averaged $2.0 \pm 1.3 \mathrm{mg} / \mathrm{l}$ total nitrogen and $0.6 \pm 0.3 \mathrm{mg} / \mathrm{l}$ total phosphorus. The lake is hypertrophic and it was concluded that the current situation is not sustainable. The lake is a major source of potable water supply for Harare and neighbouring towns and eutrophication would affect water treatment, aquatic life, and irrigation systems. The volumetric phosphorus loading agrees with the Vollenweider Model. The Model was used to predict acceptable lake inflow phosphorus levels to achieve oligotrophic conditions. The obtained value of $10 \mathrm{t} / \mathrm{yr}$ TP was considered unattainable under the current situation, as it is more than 90\% lower than that from non-point sources. A 1970's level of $75 \mathrm{tyr}$ TP is recommended as a preliminary target load as it excludes wastewater effluent influences. It is recommended for the long-term that a cleaner production approach (based on preventing pollution, reusing or recovery of used components) be adopted in combination with the recycling of nutrients in controlled urban agriculture.
\end{abstract}

Keywords: Eutrophication, Lake Chivero, mass balances, nutrients, pollution, wastewater

\section{Introduction}

Eutrophication of water bodies is undesirable because of deterioration of water quality, interference with most of the beneficial uses of water, and corresponding economic losses. Eutrophication may severely alter the recreational value of water bodies and impair related activities (swimming, fishing, etc). Its impact on drinking water supply may be serious, leading to reduced final quality (OECD, 1982). Furthermore, water treatment is made more difficult and costly (McKendrick, 1982). Eutrophic waters usually have to be extensively chlorinated during treatment and transportation in distribution networks. High levels of both chlorine and organic substances could lead to significant concentrations of organochlorinated compounds in drinking water. These substances are, on the long-term, considered potentially hazardous to human health (carcinogenic risk). Water for potable use should thus be protected from eutrophication through better control of nutrients. 
Serious water quality-related problems have been reported in the Lake Chivero catchment of Zimbabwe already for several decades (Munro, 1976; Nduku, 1976; Thornton, 1980; Thornton, 1982; JICA, 1996; Marshall, 1995; Nhapi et al., 2001). The catchment has a total population of about 2.4 million people, who are living in the towns of Harare (capital city of Zimbabwe), Chitungwiza, Epworth and Ruwa. These towns, together with Norton, draw about $77 \%$ of their potable water from the lake. The lake is located about $35 \mathrm{~km}$ downstream of Harare and receives the bulk of wastewater treatment plant effluent from Harare, Chitungwiza, and Ruwa via upstream rivers. Numerous hydro-biological investigations carried out in Lake Chivero in the 1970's showed that the lake was eutrophic and wastewater from the City of Harare was cited as the major cause (Robarts and Southall, 1977).

A number of water quality-related problems have been reported in Lake Chivero. In 1996 deoxygenation of water compounded by ammonia toxicity caused massive fish mortality (Magadza, 1997). Excessive amounts of algae and other organic matter in the lake have seriously impacted on raw water abstraction and water treatment (McKendrick, 1982'. Besides, the growth of water hyacinth (Eichhomia crassipes) and blue-green aigae, principally Microcystis aeruginosa and Anabaena sp., have been reported (Marshall, 1997).

There is no comprehensive research program that has taken place in the Lake Chivero catchment since 1996 to define the major sources of pollution and their impacts on the lake. The pollution situation has undoubtedly changed over the years because of population growth in Harare, Chitungwiza and Ruwa. The ageing of existing wastewater treatment works and the reported numerous breakdowns are also contributing factors. The current economic decline has affected the implementation of pollution control measures, including the rehabilitation and extension of wastewater treatment works, enforcement of legislation, and controlled urban agriculture. Zimbabwe has faced low rainfall years in the 1990s' and this pattern is likely to affect the nutrient balance of the lake. This Chapter reports on a study of the current status of pollution carried out from June 2000 to December 2001 through a monthly water quality monitoring program. The aim was to assess the water pollution situation in the Chivero catchment (rivers and lake) and to update water and nutrient (nitrogen and phosphorus) balances.

\section{Materials and Methods}

\section{Study area}

The study area is the Harare sub-catchment of Lake Chivero (Fig 3.1). This covers all areas drained by the Marimba and Mukuvisi Rivers. Only the lake entrance point of the Manyame 
River was monitored to get an idea of pollution from the towns of Chitungwiza and Ruwa. The lake receives its waters from the Manyame River (49\%) and the Mukuvisi (23\%) and Marimba (13\%) Rivers. Other small rivers that are not gauged and direct precipitation over the lake surface provide the remaining $15 \%$. The Mukuvisi and Marimba Rivers drain most parts of Harare. The catchment area of the Manyame River includes the town of Chitungwiza, Ruwa, the eastern parts of Harare, and part of Seke communal lands. The lake's total catchment is about $2,220 \mathrm{~km}^{2}$. Lake Chivero has a surface area of $26.449 \mathrm{~km}^{2}$ and a volume of $247,181,000 \mathrm{~m}^{3}$ at full capacity, and a mean depth of $9.3 \mathrm{~m}$ (Zimbabwe National Water Authority, ZINWA). It stratifies in summer and overturns in late February or March of each year (Marshall and Falconer, 1973; Thornton, 1982). The average precipitation in the catchment is $830 \mathrm{~mm} / \mathrm{annum}$ (range $450-1,250 \mathrm{~mm} / a n n u m$ ), most of it falling as high intensity storms from mid-November to April. Harare obtains its water from Lake Chivero $\left(416,000 \mathrm{~m}^{3} / \mathrm{d}\right)$, Lake Manyame $\left(84,000 \mathrm{~m}^{3} / \mathrm{d}\right)$, and Seke/Harava dams $\left(44,000 \mathrm{~m}^{3} / \mathrm{d}\right)$.

Two major wastewater treatment plants (WTP) in Harare are located within the studied area (Table 2.3, Chapter 2). These are Firle (design capacity $144,000 \mathrm{~m}^{3} / \mathrm{d}$ ), which discharges into the Mukuvisi River, and Crowborough (design capacity $54,000 \mathrm{~m}^{3} / \mathrm{d}$ ) which discharges into the Marimba River. These plants are currently overloaded, receiving about $170,000 \mathrm{~m}^{3} / \mathrm{d}$ and $103,000 \mathrm{~m}^{3} / \mathrm{d}$ respectively. They both use trickling filters (TF) and biological nutrient removal (BNR) systems. All trickling filter effluents $\left(160,000 \mathrm{~m}^{3} / \mathrm{d}\right)$ are mixed with primary and secondary sludge and used for pasture irrigation. About $68,000 \mathrm{~m}^{3} / \mathrm{d}$ of BNR effluent from Firle WTP is also used for pasture irrigation. The remaining BNR effluent $\left(11,000 \mathrm{~m}^{3} / \mathrm{d}\right)$ is discharged into rivers.

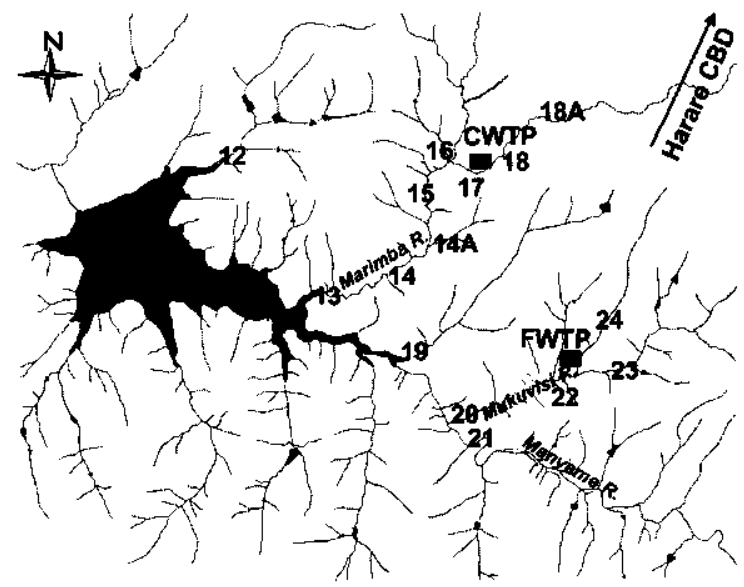

Figure 3.1: Site map for the study area showing numbered sampling locations

(CWTP = Crowborough wastewater treatment plant; FWTP = Firle wastewater treatment plant; for description of sampling points see text) 


\section{Data collection, sampling and analysis}

The study focused on total nitrogen (TN), total phosphorus (TP), and water flows in main rivers feeding into Lake Chivero. In addition, lake water was analysed for ortho-phosphates, and secchi disc measurements taken. A secchi disc is a round, flat disc with alternating black and white quadrants that is lowered into a lake to visually measure water clarity. The depth at which a secchi disc disappears provides an indication of the level of nutrients and algal growth in the lake. Other physical observations were also noted for purposes of data interpretation. River samples were collected upstream and downstream of WTP effluent discharge points (stations 15 - 18A on Marimba River, and 22, 23 on Mukuvisi River) and at continuous gauging stations just before discharge into Lake Chivero (12 - 14 19, 20, and 21) (Fig 3.1). River stretches 1616A and 18-18A were monitored for the influence of seepage and runoff from pasture irrigation on the Marimba River. Point 14A monitored a small stream that consists entirely of runoff and seepage from Ingwe Pasture Irrigation Farm. Six points, as indicated in Fig 3.1, were monitored in the lake (1 - 6). Samples from the lake were collected at depths of $0.5 \mathrm{~m}, 1 \mathrm{~m}, 2 \mathrm{~m}, 4 \mathrm{~m}, 10$ $\mathrm{m}$, and $1 \mathrm{~m}$ from the bottom. Samples were collected monthly from June 2000 to December 2001. Samples were collected in plastic containers that had been washed with phosphorousfree detergents, rinsed with distilled water and left to stand overnight in $1 \mathrm{M} \mathrm{HCL}$. Containers were rinsed again with distilled water and twice with sample water on site. Samples were stored in cooler boxes with ice blocks in the field after acid preservation, and later stored at about $4^{\circ} \mathrm{C}$ in the laboratory before analysis.

Samples were analysed according to standard procedures (Standard Methods, 1995). The TP was determined by digesting samples with concentrated sulphuric and nitric acids followed by the analysis of phosphate content using the vanado molybdophosphoric acid method. The lake algal-available phosphorus was estimated as the soluble ortho-phosphates as measured by the vanado molybdophosphoric acid procedure after the sample has been filtered on site through a $45 \mathrm{~mm}$ GFC filter. The tests for ortho-phosphates were done on the same day of collection. Nitrate was determined using the electrode screening method (WTW Microprocessor $\mathrm{pH} /$ ion meter pMX 300). Samples for TKN analysis were digested according to the micro-Kjeldahl method followed by distillation with sodium hydroxide and sodium thiosulphate solution. The released ammonia was collected in excess boric acid and determined by titration with $0.02 \mathrm{M}$ sulphuric acid. Flows for the Manyame, Marimba and Mukuvisi Rivers were obtained from gauging stations data from the ZINWA. Wastewater flows and raw water abstractions were determined from the continuous metering and pumping records of the City of Harare. The flow data were analysed statistically using the Microsoft Excel computer package. Sampling results were expressed as mean concentrations \pm standard deviations (SD). 
A water and nutrient balance for Lake Chivero was developed based on average annual flow data and sampling results of this study. In determining direct area runoff, an assumption was made that annual runoff from a sub-catchment area is about $8 \%$ of annual rainfall in that subcatchment (JICA, 1996). Precipitation was considered over the entire lake surface area assuming no water losses from rainfall falling directly on the lake surface area. An annual evaporation figure of $1,614 \mathrm{~mm}$ was used for calculating evaporation losses based on ZINWA data (Department of Water Development, 1995). Activities around the lake were not considered in the mass balances, as the population is negligibly small and, therefore, their impact was considered insignificant.

The amount of time needed for the lake's planktonic algal biomass to respond to reductions in available $\mathbf{P}$ load was estimated as three times the phosphorus residence time of the water column (Lee and Jones, 1986). This empirical determination does not directly include the lake internal P-cycle. The phosphorus residence time was defined as the average in-lake (water column) phosphorus mass divided by the annual phosphorus input load. Equation 3.1 (Thomann and Mueller; 1987) was used to check the concentration of phosphorous in the lake under steady state conditions. After validation of the equation, by getting figures close to observed concentrations of phosphorus in the lake, the same equation was used to assess alternative scenarios.

$$
[P]=\frac{W}{Q+V_{s} A}
$$

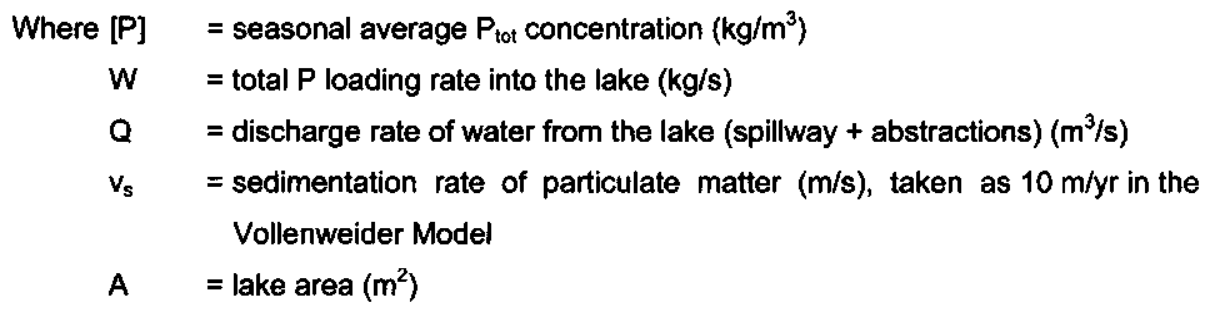

\section{Results}

\section{Nutrient concentrations of the rivers}

The nutrient levels in river stretches $18 \mathrm{~A}$ to 18 on the Marimba River and $16 \mathrm{~A}$ to 16 on Little Marimba River (Fig 3.2) increased downstream of the river. This reveals an influence from 
pasture irrigation. Runoff and seepage from Ingwe Pasture Irrigation Farm discharged into the Marimba River at point 14A did not allow the river to recover (through natural purification) from high nutrient loads until it discharged into Lake Chivero at point 13. Both TN and TP rose sharply after direct wastewater effluent discharge at point 17 for the Crowborough WTP. For the Firle WTP, the upstream sampling point (23) was more polluted than the downstream point (22) for TP. This was caused by the discharge of about $108,000 \mathrm{~m}^{3} / \mathrm{d}$ of good quality BNR effluent into the river, representing about $56 \%$ of the river flow (Fig 3.3). There were no significant nutrient changes $(p=0.04)$ from the point of effluent discharge (22) to the river entrance into Lake Chivero (20). It is likely that natural purification (via ammonia volatilisation, denitrification, sedimentation, and plant uptake) was taking place on this stretch of the river, but this was compensated for by additional non-point source flows from pasture irrigation and a large poultry farm on the other side of the river.

The nutrient levels in the Manyame River (21), although one of the lowest in Fig 3.2, show a high degree of contamination. This was attributed to sewer overflows in Chitungwiza and waste stabilisation pond effluents from Donnybrook and Ruwa wastewater treatment works. Station 12. which is on a small natural stream feeding directly into Lake Chivero (Fig 3.1), also had high values for TN $(4.1 \mathrm{mg} / \mathrm{l})$ and lower for TP $(0.3 \mathrm{mg} / \mathrm{l})$. This is reflective of agricultural influences from activities upstream of this point. The high TN and TP concentrations in Willowvale River (station 19) indicate influences of sewer overflows and effluent/sludge mixture discharges from Ingwe Pasture Irrigation Farm. The neighbouring dairy farm effluent was another likely source for high nutrient levels in the river.
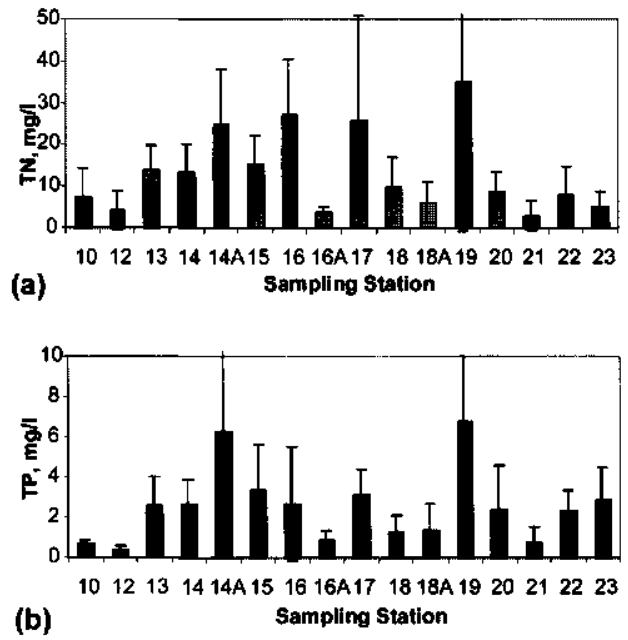

Figure 3.2: Average TN and TP sampling results for rivers based on monthly sampling from June 2000 to Dec. 2001 ( \pm SD) 
A correlation analysis of WTP effluent discharges and downstream river flows showed that (partially) treated wastewater constituted a major portion of total river flows in the Marimba and Mukuvisi Rivers (Fig 3.3). The Marimba River had a correlation coefficient of 0.58 and $50 \%$ of its flow was from WTP effluent. The Mukuvisi River had a better correlation coefficient of 0.79 and $56 \%$ of its flow was from WTP effluent. Physical observations (smell and colour) also support the notion that WTP effluent is the main portion of water in these rivers during the dry season. The relative contributions of the three major rivers in the catchment show that the Manyame River is now the largest contributor of both nutrients and water flows to the lake (Fig 3.4). It drains Chitungwiza, a rapidly expanding town.
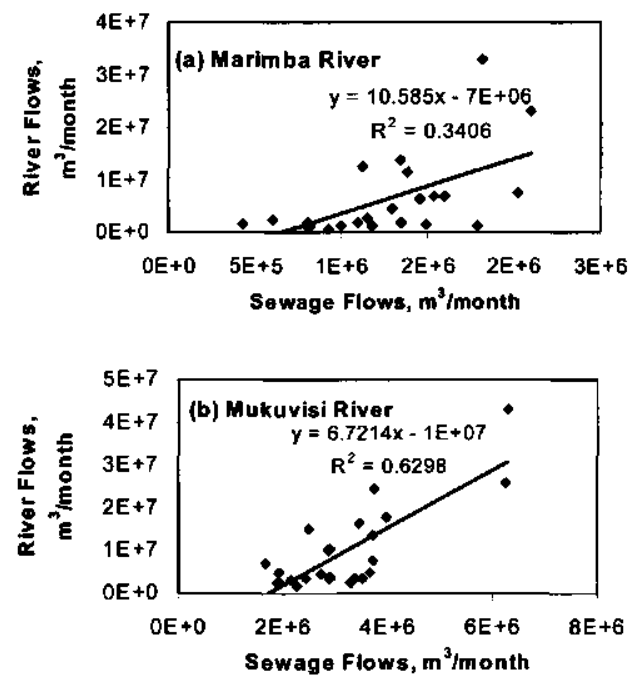

Figure 3.3: Correlation analysis of wastewater flows and river flows for the period March 1999 to February 2001 (a) Marimba River, and (b) Mukuvisi River

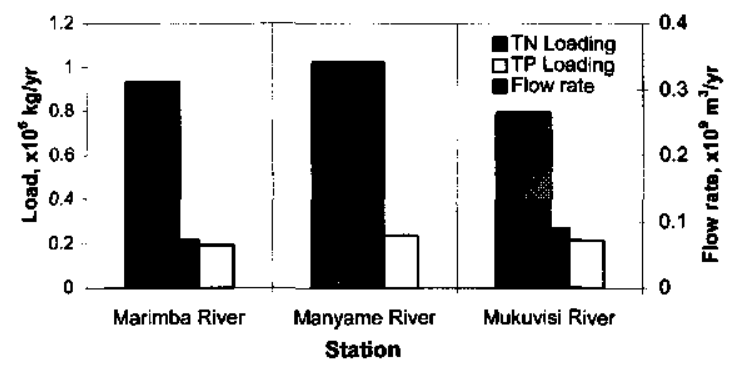

Figure 3.4: Average contributions of each river to the water and nutrient flows to Lake Chivero, June 2000 to December 2001 


\section{Nutrient concentrations in Lake Chivero}

Nutrient concentrations in Lake Chivero varied with seasons and also in space (Fig 3.5 and 3.6a). The average nutrient levels for the monitored period were $2.0 \pm 1.3 \mathrm{mg} / \mathrm{TN}$ and $0.6 \pm 0.3$ mg/l TP. During the predominantly dry period experienced from July 2000 to February 2001 nutrient levels in the lake were $2.4 \pm 0.7 \mathrm{mg} / \mathrm{TN}$ and $0.8 \pm 0.1 \mathrm{mg} / \mathrm{lP}$. After that period there were heavy rains in the Chivero catchment and nutrient levels monitored from May-December 2001 were $1.7 \pm 0.3 \mathrm{mg} / \mathrm{TN}$ and $0.5 \pm 0.1 \mathrm{mg} / \mathrm{TP}$.

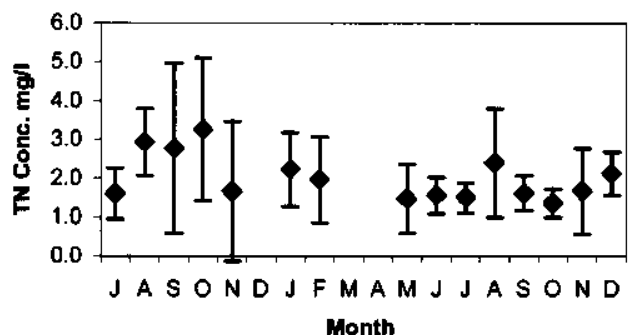

(a)

Month

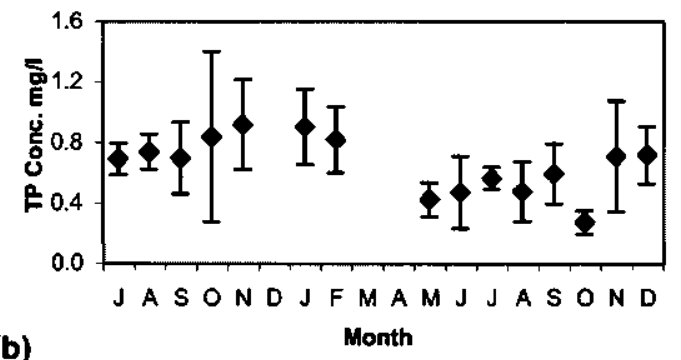

Figure 3.5: Average nutrient concentrations $( \pm S D$ ) in Lake Chivero for each month for the period July 2000 to December 2001 (a) nitrogen, and (b) phosphorus concentrations for the entire lake

The spatial variation of nitrogen and phosphorus for the period July 2000 to December 2001 is shown in Fig. 3.6a. The lake water is fairly mixed as evidenced by the fact that the sampling points are distributed wide apart (Fig 3.1) and depth samples were collected, but still have almost same levels of both nitrogen and phosphorus. Soluble ortho-phosphates were only analysed for the top water layer at depths of $0.5,1.0$ and $2.0 \mathrm{~m}$ (Fig 3.6b). From physical observations, this is where most algae are concentrated. The results gave a mean concentration of $0.4 \pm 0.2 \mathrm{mg} / \mathrm{l}$ as $\mathrm{P}$ (about $70 \%$ of the mean lake TP concentration). This means that most of the phosphorus is available as soluble $P$, which could trigger further water hyacinth 
and algal growth. Ortho-phosphates are mainly associated with domestic sewage contamination.
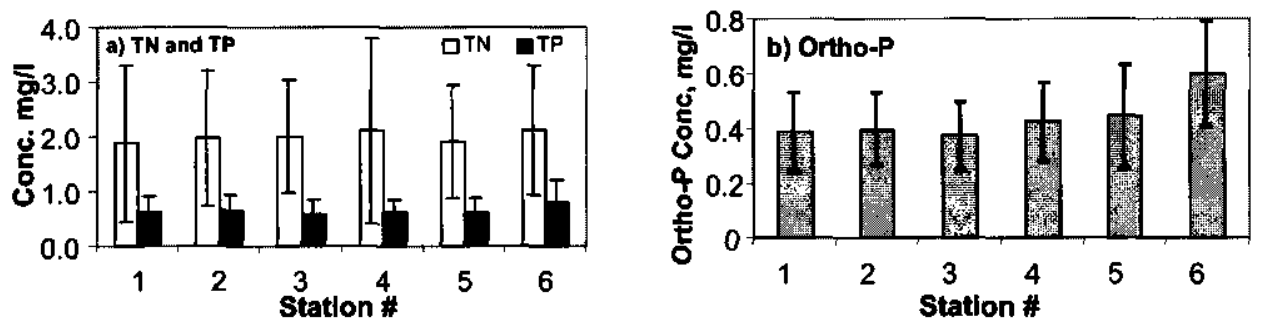

Figure 3.6: Average $( \pm S D)$ nutrient concentrations for each of the six sampling stations in Lake Chivero, July 2000 to December 2001. a) TN and TP, and (b) ortho-phosphates

Results for secchi disc measurements (Fig 3.7a) agree with physical observations that algal blooms are at their highest in July and October. This trend appears prone to distortions as the lake periodically receives inflows of poorly treated WTP effluent. An average secchi disc measurement value of $1.4 \pm 0.4 \mathrm{~m}$ was found. The lowest values were observed at station 3 because of wind and current effects that drift algae to the north-western parts of the lake.

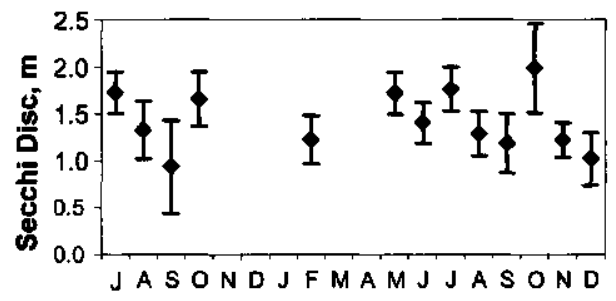

(a)

Month

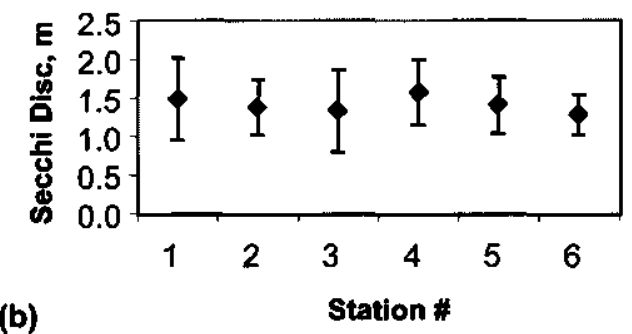

Figure 3.7: Average ( \pm SD) Secchi disc depths for the six sampling stations in Lake Chivero; July 2000 to December 2001 (a) monthly variation, entire lake, and (b) average for each station over sampled period 


\section{Water and nutrient balances}

Table 3.1 presents the water balance of Lake Chivero, consisting of inflow and outflow data. In the water balance, $11 \%$ of the inflows could not be accounted for. This error accounts for groundwater flows and errors of estimation and measurement. A nutrient mass balance analysis showed that $69 \%$ and $59 \%$ of the incoming TN and TP respectively are not being released via the lake spillway or through raw water abstractions. The $69 \% \mathrm{TN}$ gap is explained by possible denitrification and, to a lesser extent, by ammonia volatilisation. The TP gap reflects phosphorus losses to the sediments. The nutrients exported from the lake via groundwater infiltration and fish catches have not been quantified because of the absence of reliable data. An assessment of inflows and outflows from the lake for each year (Fig 3.8) showed that the average hydraulic retention time of the lake for rainfall years $1981 / 1982$ to1999/2000 is $1.6 \pm 1.0$ years. The low refreshment rate of the lake could affect phosphorus outflows. A retention time of six months only applies for a few years of extremely high rainfalls.

Table 3.1: Results of average water and nutrient budget for Lake Chivero based on water quantity and quality data collected during the period June'00 to Dec'01

\begin{tabular}{|c|c|c|c|c|c|c|c|}
\hline \multirow[b]{2}{*}{ Balance Component } & \multicolumn{2}{|c|}{ Area, Average Flow } & \multirow[t]{2}{*}{$\begin{array}{r}\text { Sampling } \\
\text { Station }\end{array}$} & \multicolumn{2}{|c|}{ Total Nitrogen } & \multicolumn{2}{|c|}{$\begin{array}{l}\text { Total } \\
\text { Phosphorus }\end{array}$} \\
\hline & $\mathrm{km}^{2}$ & $\mathrm{~m}^{3} /$ year & & $\mathrm{mg} / \mathrm{l}$ & $\overline{\mathrm{kg} / \mathrm{yr}}$ & $\mathbf{m g} / \mathbf{l}$ & $\overline{\mathrm{kg} / \mathrm{yr}}$ \\
\hline \multicolumn{8}{|l|}{ INFLOW } \\
\hline Marimba River & 189 & $70,980,000$ & 13 & 13.6 & 965,328 & 2.6 & 184,548 \\
\hline Manyame River & 1,510 & $341,529,474$ & 21 & 3.0 & $1,024,588$ & 0.7 & 239,071 \\
\hline Mukuvisi River & 231 & $89,440,667$ & 20 & 8.9 & 796,022 & 2.4 & 214,658 \\
\hline Direct Rainfall on lake & 26.5 & $20,793,939$ & & & & & \\
\hline Direct Area Runoff & 290 & $22,799,510$ & 12 & 4.1 & 93,478 & 0.3 & 6,840 \\
\hline Subtotal & & $545,543,590$ & & & $2,879,416$ & & 645,116 \\
\hline \multicolumn{8}{|l|}{ OUTFLOW } \\
\hline Evaporation & 26.5 & $42,688,686$ & & & & & \\
\hline Abstractions ** & & $151,999,570$ & 1 & 2.0 & 303,999 & 0.6 & 91,200 \\
\hline Discharge & 2,220 & $290,195,250$ & $\uparrow$ & 2.0 & 580,391 & 0.6 & 174,117 \\
\hline Subtotal & & $484,883,506$ & & & 884,390 & & 265,317 \\
\hline Discrepancy & & $-60,660,084$ & & & $-1,995,027$ & & $-379,799$ \\
\hline Discrepancy, \% of inflow & & $-11^{*}$ & & & $-69^{* *}$ & & $-59^{* * *}$ \\
\hline
\end{tabular}

* Explained by infiltration and error margins in data collection and estimation

** Explained by denitrification and ammonia volatilisation, groundwater flow, and fish catches

*** Explained by biological phosphorus removal and sedimentation, phosphorus release from sediments, groundwater flow, and fish catches 


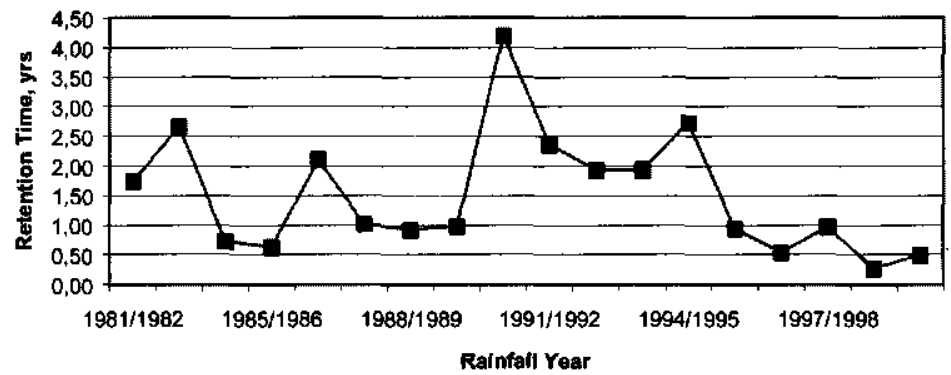

Figure 3.8: Hydraulic retention times of Lake Chivero for years 1981/1982 - 1999/2000

The average lake nutrient loadings were $2,879 \mathrm{t} \mathrm{TN} /$ year (i.e., $108.9 \mathrm{~g} / \mathrm{m}^{2}$ and $11.6 \mathrm{~g} / \mathrm{m}^{3}$ ) and $645 \mathrm{t} \mathrm{TP} /$ year (i.e., $24.4 \mathrm{~g} / \mathrm{m}^{2}$ and $2.6 \mathrm{~g} / \mathrm{m}^{3}$ ). A comparison with a nutrient balance derived from 1996 monitoring data shows that the lake inflow nutrient loads and lake concentrations have increased by a factor of about 4 in the past five years. This is attributed to poor maintenance of wastewater treatment plants due to economic hardships experience since 1997 and lack of plant expansions. Based on total phosphorus inflows and phosphorus stocks in the lake water column, a phosphorus residence time in Lake Chivero of about 0.4 years was calculated. This is of the same magnitude as the hydraulic retention time for the period June 2000 to December 2001. Consequently, an expected period of 1.2 years ( 3 times the P-residence time in water column) is expected before the lake will start to respond to reductions in phosphorus inflows. This empirical determination does not include phosphorous retained in the lake sediments in the calculation. However, the phosphorus already accumulated in the lake sediments is expected to play an important role in the recovery of Lake Chivero. The application of equation 3.1 to figures presented in Table 3.1 gives a mean phosphorus concentration [P] $=0.7 \mathrm{mg} /$. This compares well with the observed average figure of TP $=0.6 \pm 0.3 \mathrm{mg} /$. This equation, therefore, roughly describes the phosphorus loading and concentration of this lake.

\section{Discussion}

\section{Nutrient concentrations of the rivers}

Nutrient levels in the major inflow rivers of Lake Chivero have risen sharply over the past few years. In all rivers, TP was higher than the timit of $0.03 \mathrm{mg} / \mathrm{l}$ required for avoiding excess plant growth in rivers and streams (OME Guidelines, 1991). As for the Manyame River, JICA (1996) reported figures of $0.50 \mathrm{mg} / \mathrm{TN}$ and $0.08 \mathrm{mg} / \mathrm{TP}$ for a sampling point about $3 \mathrm{~km}$ upstream of sampling point 21 . Average values of $3.0 \mathrm{mg} / \mathrm{TN}$ and $0.7 \mathrm{mg} / \mathrm{TP}$ were found in this study. 
Magadza (1997) also noted that the phosphorus concentrations for the Manyame River had increased substantially between 1990-96. The rise is attributed to increased population and sewer overflows in the upstream town of Chitungwiza. About $50-60 \%$ of average flows in the Marimba and Mukuvisi Rivers is effluent from wastewater treatment plants (Fig 3.3) but the quality of this effluent is poor (Fig 3.2) as evidenced by nutrient concentrations immediately downstream of discharge points. It is crucial that wastewater be treated to standards of $<10 \mathrm{mg} / \mathrm{l}$ TN and $<0.5 \mathrm{mg} / \mathrm{TP}$ before river discharge according to the applicable Zimbabwean standards (Government of Zimbabwe, 2000).

\section{Nutrient concentrations of the lake}

The results on nutrient levels in Lake Chivero show a sharp deterioration in water quality compared to 1996 figures (JICA, 1996). The lake nutrient concentrations were far above the recommended levels of $0.3 \mathrm{mg} / \mathrm{TN}$ and $0.01 \mathrm{mg} / \mathrm{TP}$ for oligotrophic systems (Mandaville, 2000). The current lake nutrient values are also higher than the JICA (1996) findings of $0.5 \mathrm{mg} / \mathrm{l}$ TN (4 times) and $0.3 \mathrm{mg} / \mathrm{TP}$ ( 2 times). The phosphorus and part of the nitrogen increase is explained by increased wastewater inflows due to plant breakdowns and population increases. The other part of the nitrogen increase might be attributed to increased fertiliser usage in the catchment. Assuming an algal cell composition of $\mathrm{C}_{106} \mathrm{H}_{180} \mathrm{O}_{45} \mathrm{~N}_{16} \mathrm{P}$ (Lee and Jones, 1986; Polprasert, 1996), a stoichiometric N:P ratio of 7 can be derived. The N:P ratio in the lake is 3 , suggesting nitrogen is the limiting nutrient. However, it will be misleading to make concrete conclusions based on this ratio alone as both nutrients are present in abundance in the lake. Other factors in the pelagic environment like zooplankton grazing, light or micro-nutrients could be the limiting factor for algae or aquatic plant growth in the lake. Macrophytes were not included in the analyses but could also contain large amounts on $\mathrm{N}$ and $\mathrm{P}$ (internal cycle). The abundance of $P$ in the lake could also explain why the bulk of it is not contained in algae as would be normally expected for a productive lake. Lake Chivero is now hypertrophic according to the OECD Fixed Boundary System or Diagnostic Model (OECD, 1982) (TP $\geq 100 \mathrm{mg} / \mathrm{m}^{3}$; mean chlorophyll-a $\geq 25 \mathrm{mg} / \mathrm{m}^{3}$; mean secchi disc depth $\leq 1.5 \mathrm{~m}$ ).

The application of equation 3.1 to nutrient values from this study and also from JICA (1996) returned values similar to observed phosphorus concentrations in the lake. Magadza (1997) also reported similar findings. It can therefore be concluded that the Vollenweider Model accurately describes the Lake Chivero phosphorus regime and could therefore be used to predict lake responses to changes in phosphorus loadings. The inflow phosphorus load needs to be reduced from the current 645.1 tyear to about 10.0 tyear (a $98 \%$ reduction) in order to achieve the $0.02 \mathrm{mg} / \mathrm{TP}$ limit desirable for oligotrophic lakes (Mandaville, 2000). Achieving more stringent water quality objectives on a medium term is not considered realistic. For 
example, utilising the installed biological nutrient removal capacity in Harare to treat 126,000 $\mathrm{m}^{3} / \mathrm{d}$ to $0.5 \mathrm{mg} / \mathrm{TP}$ standard would still release $23.0 \mathrm{t} / \mathrm{yr}$ TP, only from wastewater treatment plant effluent. It is therefore recommended, as a first target, to reduce current phosphorus loadings to values reported in the 1970's of $75 \mathrm{t} \mathrm{P/yr}$ (Thornton, 1980). This would reduce the phosphorus concentration in the lake to about $0.14 \mathrm{mg} / \mathrm{l}$, which will be a remarkable achievement when compared to the current average of $0.6 \mathrm{mg} / \mathrm{lP}$. In the 1970's all wastewater effluent was being diverted away from the lake (to pasture irrigation) and river water quality was of acceptable standard (Thornton, 1980).

\section{Water and nutrient balances}

Table 3.1 supports the notion that phosphorus could be accumulating in the lake as only a small amount is flowing out $(59 \%)$. Part of the phosphorus could find its way to the sediments whilst some is locked up in plant biomass. In a similar study, Thornton (1980) reported phosphorus losses to sediments of $46 \%$. Hydraulic retention times shown in Fig 3.8 for the period 1981/1982 - 1999/2000 were above six months most of the time and this explains the high phosphorus losses to the sediments. However, a separate study on phosphorus levels in the sediments is required to better understand the current situation. A hydraulic retention time of less than six months is desirable for effective phosphorus flushing (Thornton, 1980). The phosphorus loadings from this study are higher than previously reported figures of $74.6 \mathrm{t} / \mathrm{year}, 2.8 \mathrm{~g} / \mathrm{m}^{2}$ and $0.3 \mathrm{~g} / \mathrm{m}^{3}$ (Thornton, 1980), which are loadings after effluent had been diverted to pasture irrigation. Before the diversion of municipal wastewater from the lake to pasture irrigation schemes implemented between 1970 and 1975, the TP loadings were respectively 288.1 t/year $11.0 \mathrm{~g} / \mathrm{m}^{2}$ and $1.2 \mathrm{~g} / \mathrm{m}^{3}$. These are about half of the current loadings, meaning that a lot now needs to be done to clean up the lake.

\section{Pollution prevention}

This paper emphasises on phosphorus control because controlling nitrogen inflows into the lake might stimulate nitrogen fixation by algae in the lake. For example, in Lake Kariba, Zimbabwe, nitrogen is the limiting nutrient and nitrogen fixation has been reported to be a major component of the nitrogen budget (Moyo, 1997). In lakes like Chivero that contain excessive amounts of phosphorus, planktonic algal biomass could respond to reductions in phosphorus load as was found by Lee and Jones (1986). The removal of phosphorus from municipal wastewater might be an effective strategy in controlling the eutrophication of Lake Chivero as this represents a major source of algal-available phosphorus. This could be effectively removed by chemical or biological methods. Onsite treatment of wastewater, wherever possible, could also present an effective way of preventing nutrients from entering surface waters and provide options for nutrient and effluent reuse. The banning of phosphorus detergents only (though a good starting 
point) will not result in noticeable impacts on lake water quality as these make up about $6 \%$ of the phosphorus from household wastewater in Harare (Gumbo and Savenije, 2001). Maki et al. (1984) found that a minimum reduction of lake phosphorus inflows of $20 \%$ is required to have noticeable impacts.

The exact contribution of urban agriculture to water quality deterioration in Lake Chivero is not known, but it is likely that part of the applied fertiliser will end up in the lake via runoff. A rational approach would be to recycle nutrients from wastewater to urban agriculture. Recycling the nutrients locally, combined with cleaner production approaches (pollution prevention and reuse) could yield important savings to the City in terms of chemicals for treating water to drinking standards, and energy and mechanical costs required to remove nitrogen at wastewater treatment plants. Cleaner production approaches involve source control of pollutants through avoidance/prevention, waste reduction, substitution, recycling and reuse. The control of nutrients in the Chivero catchment requires a cocktail of measures that could be integrated into a strategic approach for nutrient management. This needs to address the different categories of landuse in the catchment and should aim at reducing water and nutrient cycles to smallest possible levels.

\section{Conclusions}

The current pollution regime in the Chivero catchment is very critical and unsustainable. Specifically, the following were concluded from this study:

1. Nutrient concentrations in the major inflow rivers of Lake Chivero have risen sharply over the past few years and are at levels higher than the standard limits for avoiding excess plant growth in rivers and streams.

2. The Manyame River is now contributing significantly to pollution loads in Lake Chivero and the source of this pollution needs to be tackled.

3. Nutrient concentrations in Lake Chivero $(2.0 \pm 1.3 \mathrm{mg} / \mathrm{TN}$ and $0.6 \pm 0.3 \mathrm{mg} / \mathrm{TP})$ show a sharp deterioration in water quality compared to previous studies and are far above the recommended levels for oligotrophic systems.

4. Phosphorus in the lake is mostly in the form of soluble ortho-phosphates; a form most consistent with wastewater discharges.

5. Lake Chivero is now hypertrophic, or at least, in advanced stages of eutrophication.

6. The Vollenweider Model accurately describes the Lake Chivero phosphorus regime and can therefore be used to predict lake responses to changes in phosphorus loadings. 
Further studies are recommended to better understand the nutrient dynamics in Lake Chivero, especially the interactions with sediments.

\section{References}

Department of Water Development (1995) Assessment of Surface Water Resources in the Manyame Catchment - Zimbabwe; Streamflow Gauging and Conceptual Hydrological Modelling, SMHI (Swedish Meteorological and Hydrological Institute) Hydrology No. 60, Department of Water Development, Government of Zimbabwe, Harare, Zimbabwe.

Government Of Zimbabwe (2000) Statutory Instrument (S.I.) 274 of 2000, Water (Waste and Effluent Disposal) Regulations, Government Publications, Harare, Zimbabwe.

Gumbo, B. and Savenije, H.H.G. (2001) Inventory of Phosphorus Fluxes and Stocks in an Urban-shed: Options for Local Nutrient Recycling. Paper presented at the $1^{\text {st }}$ International Conference on Ecological Sanitation, Nanning, China, 5-8 November 2001. Extended abstract at http/www.wisechina.com/english/e39.html.

JICA Report (Japanese International Co-operation Agency) (1996) A Study of Water Pollution Control in Upper Manyame River Basin in the Republic of Zimbabwe. Nippon Jogeduido Sekkei Co. Ltd., Nippon Koei Co. Ltd, September 1996.

Lee, G.F., and Jones, R.A. (1986) Detergent Phosphate Bans and Eutrophication, Environ. Sci. Technol. Vol. 20(4), p330-341.

Magadza, C.H.D. (1997) Water Pollution and Catchment Management in Lake Chivero. In Lake Chivero: A Polluted Lake, edited by Moyo, N.A.G. University of Zimbabwe Publications, Harare, Zimbabwe, p13-26.

Maki, A.W., Porcella, D.B. and Wendt, R.H. (1984) The Impact of Detergent Phosphorus Bans on Receiving Water Quality. Water Res. Vol. 18(7), p893-903.

Mandaville, S.M. (2000) Lake Data of Relatively Undisturbed Lakes within Nova Scotia; Provincial Averages; CCME (Canadian Council of Ministers of the Environment), Health and Welfare Canada, and OME (Ontario Ministry of the Environment) Guidelines, Internet Site: http://www.chebucto.ns.ca/Science/SWCS/SWCS.html.

Marshall, B.E. and Falconer, A.C. (1973) Physio-chemical Aspects of Lake Mcllwaine (Rhodesia), a Eutrophic Tropical Impoundment. Hydrobiologia, Vol. 21(1/2), p22-28.

Marshall, B.E. (1995) Changes in the Benthic Fauna of Lake Chivero, Zimbabwe, Over Thirty Years. Southem Africa Joumal of Aquatic Science, Vol. 42, p15-62.

Marshall, B.E. (1997) Lake Chivero After Forty Years: The Impact of Eutrophication. In Lake Chivero: A Polluted Lake, edited by Moyo, N.A.G., University of Zimbabwe Publications, Harare, Zimbabwe, p112.

Mckendrick, J. (1982) Water Supply and Sewage Treatment in Relation to Water Quality in Lake Mcllwaine. In Lake Mcllwaine; The Eutrophication and Recovery of a Tropical African Man-Mado Lake, edited by Thornton, J.A. and Nduku, W.K. Dr W Junk Publishers, The Hague, The Netherlands, p202-217. 
Moyo, S.M. (1997) Contribution of Nitrogen Fixation to the Nitrogen Budget of Lake Kariba. In Advances in the Ecology of Lake Kariba, edited by Moreau, J., University of Zimbabwe Publications, Harare, Zimbabwe, p59-65.

Munro, J.L. (1996) A Limnological Survey of Lake McLIwaine, Rhodesia. Hydrobiologia, Vol. 28, p281308.

Nduku, W.K. (1976) The Distribution of Phosphorus, Nitrogen and Organic Carbon in the Sediments of Lake McLIwane, Rhodesia. Transactions of the Rhodesian Scientific Association, Vol.57(6), p45-60.

Nhapi, I., Siebel, M.A. and Gijzen, H.J. (2001) Dry Season Inflow and Export of Nutrients from Lake Chivero. Procedings of the Zimbabwe Institution of Engineers, Vol. 2(1), p33-41.

OECD (Organisation for Economic Co-operation and Development) (1982) Eutrophication of Waters: Monitoring, Assessment and Control. OECD Co-operative program on monitoring of inland waters (Eutrophication control), Environment Directorate, OECD, Paris, 154pp.

OME (Ontario Ministry of the Environment) (1991) Water Management: Provincial Water Quality Objectives and Guidelines. Internet site: $h$ ttp://www.ene.gov.on.ca/envision/gp.

Polprasert, C. (1996) Organic Waste Recycling; Technology and Management, John Wiley and Sons, Chichester, England.

Robarts, R.D. and Southall, G.C. (1977) Nutrient Limitation of Phytoplankton Growth in Seven Tropical Man-Made Lakes, with Specific Reference to Lake McLlwaine, Rhodesia. Hydrobiologia. Vol. 79(1), p1-35.

Standard Methods For The Examination Of Water And Wastewater, 19th edition (1995). American Public Health Association/American Water Works AssociationMater Environment Federation, Washington DC, USA.

Thomann, R.V. and Mueller, J.A. (1987) Principles of Surface Water Quality Modelling and Control, Harper and Row, New York, 644 pp.

Thomton, J A. (1980) A Comparison of the Summer Phosphorous Loading to Three Zimbabwean WaterSupply Reservoirs of Varying Trophic States. Water SA, Vol. 64, p163-170.

Thornton, J.A. (1982) Research Perspectives in Thornton, J.A. and Nduku, W.K. (editors). Lake MCL/waine - The Eutrophication and Recovery of a Tropical Man-made Lake. Dr. W. Junk Publishers, The Hague, The Netherlands, p227-231. 


\section{Chapter 4}

\section{A Strategic Framework for Managing Wastewater: A Case Study of Harare, Zimbabwe}

Parts of this Chapter were published as:

Nhapi, I., Siebel, M. and Gijzen, H.J. (2003) A Conceptual Framework for the Sustainable Management of Wastewater in Harare, Zimbabwe, IWA Wat. Sci. Tech. Vol. 47(7-8), p11-18.

Nhapi, I., Siebel, M. and Gijzen, H.J. (2003) A Strategic Framework for Managing Wastewater: A Case Study of Harare, Zimbabwe, Water International, journal of the International Water Resources Management. 


\title{
A Strategic Framework for Managing Wastewater: A Case Study of Harare, Zimbabwe
}

\begin{abstract}
Water quality is an urgent problem in Harare's main water supply source, Lake Chivero, whilst water scarcity would be a problem soon. This study focused on sustainable ways of urban water and nutrient (nitrogen and phosphorus) management in Harare, part of the Lake Chivero catchment. The Dublin Principles on water conservation, environmental protection, reuse, and economic utilisation of water were used as a basis for formulating innovative and responsive solutions. External and internal drivers for future evolution of wastewater approaches were identified. Water conservation, treatment and reuse strategies were developed starting from water-saving devices, regulation, leak detection and repair, to wastewater treatment and reuse. Three levels at which wastewater can be handled - onsite, decentralised, and centralised - were discussed and solutions formulated. Based on this, a strategic framework, the so-called "3-Step Strategic Approach", was then developed aimed at the sustainable use of water, nutrients, and other resources in the urban environment. This 3-Step Strategic Approach consists of pollution prevention and minimisation (step 1), reuse after treatment (step 2), and discharge into the environment with stimulation of self-purification capacity of the receiving environment (step 3 ). The 3-Step Strategic Approach was subsequently applied to the Lake Chivero catchment. It was demonstrated that these strategies could substantially reduce current water pollution and future water scarcity problems in Harare.
\end{abstract}

Keywords: (de-)centralised, onsite, reuse, 3-Step Strategic Approach, sustainability, (waste)water

\section{Introduction}

\section{The dilemma of Urban Water Management}

Urban Water Management (UWM) has quantitative and qualitative (hygienic) dimensions, both of which require careful planning if cities are to be managed efficiently in the future. Urban Water Management includes abstraction, treatment, storage, transmission and distribution to consumers, also water for city maintenance, rain-/stormwater management, water for ecological functions, and the subsequent collection and processing of the generated wastewater. Water scarcity is a critical problem in some countries (Engelman and LeRoy, 1993), but water quality seems to be the major problem in almost all developing countries (Moyo, 1997; Gijzen, 2001). Rapid urbanisation and recurrent water-borne diseases raise concerns about water quality 
deterioration in towns. Engineers have responded by constructing better facilities for treatment and developing 'cleaner' water resources (Gijzen, 2001). Often, these solutions are supplydriven and end-of-pipe technologies based on 'unlimited water resources' in terms of quality and quantity. Very sophisticated and expensive water and wastewater treatment technologies have been developed over the years to cater for deteriorated water quality. Many countries have enacted stricter effuent disposal regulations that are difficult to achieve because of the prohibitive cost of such 'end of pipe' interventions.

Huge investments in water supply have successfully reduced health-related problems in most cases. However, the continued expansion of cities means that future water needs would have to be developed further away from cities. The economic considerations (investment and cleaning up the environment) and limitations of water resources (in terms of quality and flow) raise questions regarding the sustainability of conventional approaches to UWM. In water management, sustainability amounts to maintaining the abundance and quality of water resources to sustain ecosystems and support future human needs while also meeting current household and commercial water requirements (Braden and Van lerland, 1999). Most researchers' questions relate to the quality needs for different ranges of water uses, and consumption levels in some cities (Otterpohl et al., 1997; Gijzen, 1998; Frijns and Janssen, 1996). High water consumption has serious implications on treatment and investment costs for the sanitation sub-sector. One litre of water consumed potentially translates into 0.5 - 0.85 litres of wastewater, which, after partial treatment, could potentially contaminate many litres of fresh water. Since the size and investment costs of a wastewater treatment plant (WTP) is related to volume of incoming wastewater, diluted wastewater actually makes the treatment less cost effective and more troublesome (Jeppson et al., 2002). The treatment of diluted wastewater requires more energy input for pumping and aeration and is less efficient for anaerobic treatment with methane recovery hindered by dissolution into the wastewater.

\section{The modern UWM Paradigm}

The functional and economic effectiveness of conventional water management methods in fulfilling environmental, quality of life, and other objectives is questionable (Pinkham, 1999; Gijzen, 1998). The conventional approach provides little solutions to problems such as water scarcity, environmental pollution, optimal resource utilisation, and waterborne diseases - serious issues in many urban areas (Otterpohl et al., 1998). An illustration of the current urban water management concept, characterised by high water consumption and large volumes of wastewater production is given in Fig 4.1. The main problem with this concept is that it is based on a wrong notion of unlimited water use via a long recycling loop. This "flush-through system" would only be able to operate sustainably if $100 \%$ treatment efficiency is achieved. This is, however, not affordable, especially in low and medium GNP countries. The solution to this partly 
lies in minimising or reducing water consumption, thereby leading to reduced wastewater production. In addition, local treatment and reuse of wastewater components would result in shorter cycles or loops.

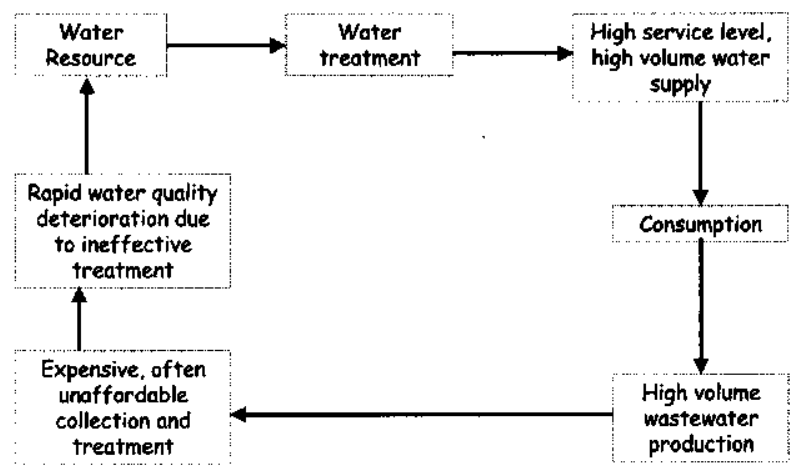

Figure 4.1: The current urban water management concept

The development of a new paradigm for urban water systems to fill in current gaps is therefore necessary. The greatest hindrance to appropriate solutions is that current systems have become the norm in society in terms of expectations in service, comfort, and perceived quality of life. In addition, huge investments have already been made in sewers and treatment infrastructure and there are strong commercial interests linked to these. Future solutions should be acceptable to intended beneficiaries. Water scarcity and urban food requirements encourage reuse of water and nutrients at the lowest possible level. Therefore, UWM should not only be an issue of 'end-of-pipe' or dry sanitation, but rather, managing both ends of the pipe. This implies managing both the supply side and the demand side. Sustainable UWM systems should always be affordable, have low environmental costs, be acceptable to local communities, and should optimise the utilisation of local resources.

\section{Vision and drivers}

The Dublin Statement and Agenda21 form a basis for more innovative and sustainable approaches to managing urban water and the environment. The Dublin Principles recognise freshwater as a finite (in terms of quantity, but not quality and flow) and vulnerable resource, essential to sustain life, economic development and the environment (ICWE, 1992; Cosgrove and Rijsberman, 2000). The effective management of water resources demands a holistic approach, linking social and economic development with the protection of natural ecosystems. They also recognise that water has an economic value in all its competing uses and should therefore be recognised as an economic good. The failure to recognise the economic value of water has led to wasteful and environmentally damaging uses of water. 
The implications of the Dublin recommendations on water conservation (industry, domestic and agriculture) and reuse are very important. Recycling and reuse could potentially reduce water consumption levels of many industries by $50 \%$ or more with additional benefits of reduced pollution (ICWE, 1992). The application of the 'polluter pays' principle and realistic water pricing would also encourage conservation and reuse. Better water management could reduce costly 'unaccounted for' water losses. These combined savings in agriculture, industry and domestic water supplies could significantly defer investment in costly new water resource development and have enormous impact on the sustainability of future systems.

Besides the Dublin Principles, there are emerging a number of external and internal drivers for the development of innovative water management systems. Over the past two decades, innovations have appeared in the water supply and sewerage collection systems e.g., low-cost pipes, small-bore sewers, vacuum sewers, integrated or hybrid treatment systems, packaged small treatment systems, and the use of sewers as part of the treatment system. These would compete favourably with current proposals for household-centred or non-waterborne sanitation (King, 2000). Fears of greenhouse effects related to conventional wastewater treatment methods (Pickin, 2002) would cause a shift from tertiary treatment followed by river discharge to more reuse-oriented natural or biological treatment systems. This in turn would require separate handling of industrial wastewater to avoid contamination. The increasing popular notion of 'environmental costing' would bring to the fore the rationality or otherwise of current urban water supply systems and their quality requirements. The cost to the environment of producing potable water is expected to discourage the use of potable water for non-potable purposes.

Frequent drought years and the increasing costs of developing new (and distant) sources of water supply would favour the water conservation route. The water reforms in many countries would result in proper pricing of water and this would send a message to users on its value and scarcity. Some water consumers would also find it increasingly difficult to pay for high water consumption because of economic problems. In developing countries, the absence of donor funds for capital projects could, in the long-term, be a driver for local engineers to be innovative and formulate affordable local solutions. A new vision for sustainable urban water systems is needed.

This paper presents a strategic framework for the effective management of water mainly focusing on reduction of water supply and wastewater volumes, recycling and the control of nutrient (nitrogen and phosphorus) discharges. A 3-Step Strategic Approach is proposed as a way to manage wastewater and to develop a sustainable urban water management system. 
Harare city in the Lake Chivero catchment in Zimbabwe is used as an example. Two previous studies in the Lake Chivero area (Nhapi et al., 2002a and 2003) form the main basis of data used in this Chapter.

\section{A 3-Step Strategic Approach to wastewater management}

An assessment of methods applied in solid waste management and industries for pollution prevention and control reveals a systematic approach that is also useful to urban wastewater management. In particular, three distinct steps are derived: 1) prevention (pollution prevention and waste minimisation, 2) treatment aimed at resource recovery and reuse, and 3) discharge with stimulation of self-purification capacity. The steps should be implemented in this order, and interventions under each step should be exhausted before moving on to the next step. This strategic approach will be referred to as the "3-Step Strategic Approach" to wastewater management and is illustrated in Fig 4.2. Under each step, there are several intervention options as elaborated further below.

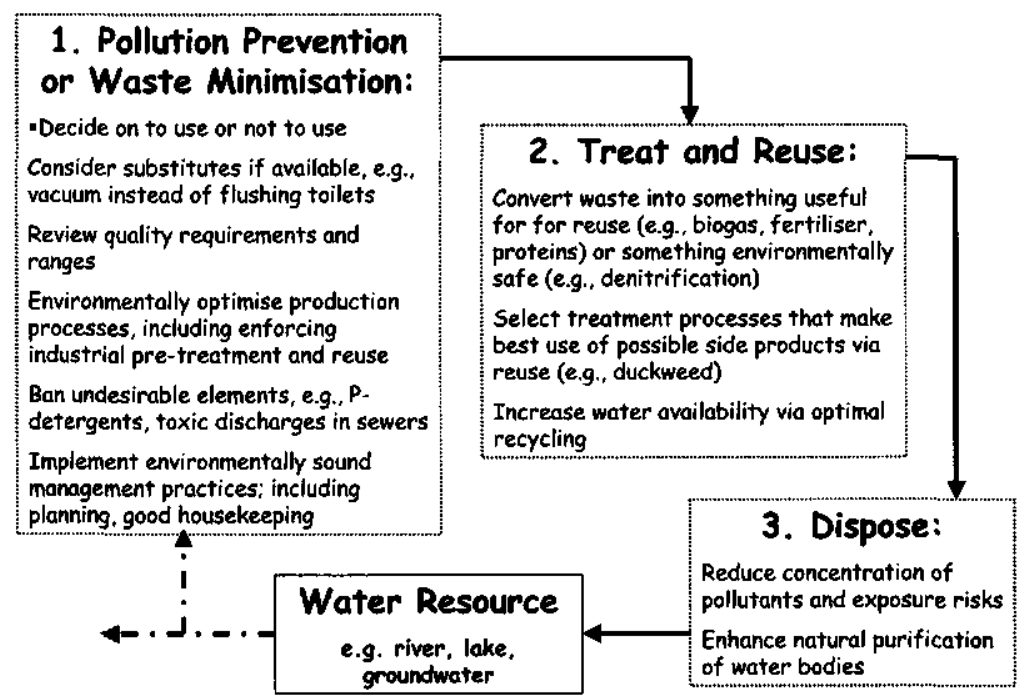

Figure 4.2: Illustration of the 3-Step Strategic Approach to wastewater management

Step 1: Prevent/reduce pollution generation: The basic principle under Step 1 is that intervention should start by controlling consumption. People should ask themselves whether some of the things they use are really necessary and safe to the environment and, if not, consider substitutes. The other question is whether people should really consume at current levels of inefficiency, e.g., use water, nitrogen and phosphorus only once? High water 
consumption has direct implications on the sizing of water and wastewater facilities and their efficiency. Reduction in wastewater generation is therefore necessary in view of the importance of conserving resources and energy, and optimising investments. Waste minimisation involves not only technology, but also planning, good housekeeping, and implementation of environmentally sound management practices (cleaner production). It also involves a special attitude of the users. The 'polluter pays' principle and discharge limitations are some of the instruments used to control user practices. Industries can also be compelled by legislation to strictly treat or pre-treat and reuse wastewater within their properties, wherever possible, and thus limit discharges to public sewers and streams. The reduction/elimination of industrial toxic waste(water) is an important aspect of pollution prevention. The successful implementation of step 1 could lead to smaller volumes of more concentrated wastewater reaching wastewater treatment facilities, making resource recovery from wastewater treatment more feasible (e.g. anaerobic pre-treatment).

Step 2: Treat and reuse: Municipal wastewater contains valuable resources and it is therefore irrational to treat it the conventional way with subsequent river discharge. Its components of water, organic matter (energy), and nutrients should be reused instead of removed at the expense of energy input. As part of the strategy, technologies are selected which aim at treating wastewater $\mathrm{n}$ the direction of reuse. Wastewater should be converted in the first instance to something useful for reuse (e.g. biogas, crops, and fish), or, if not possible, to something which is environmentally safe (e.g. denitrification). Secondary treatment could be combined with effective reuse of nutrients via aquatic plants (e.g., duckweed) and/or by irrigation of crops in agriculture and aquaculture. In some parts of the world, water itself is a scarce commodity and recycling wastewater would enhance water availability. Systems such as greywater separation offer opportunities for onsite reuse (after minimal treatment) at the point of generation for purposes such as car washing, toilet flushing, and on-plot irrigation. In some cases, urine could be separated and used directly (Larsen and Gujer, 1996).

Step 3: Dispose and stimulate natural self-purification: In some cases the above steps would still leave some residual wastes or reuse facilities might not be adequate, so the last option after treatment is disposal to surface waters. Here it is necessary to reduce pollutant concentrations and health risks through the enhancement of the natural purification capacity of the water bodies. The enhancement of the river self-purification could be achieved by online or offline river detention ponds that increases hydraulic residence time, thereby allowing more time for settlement and chemical and biological processes. Constructed wetlands could also be used for this purpose. Also, stream re-oxygenation could be increased by deliberately creating rapids and turbulence in streams. Other options include allowing rivers to flood in certain defined 
segments, and the introduction or stimulation of controlled algal development to stimulate oxygenation.

\section{Review of water management in Harare}

Harare is the capital city of Zimbabwe and is located in the Lake Chivero catchment area. It discharges WTP effluent into the main tributaries of Lake Chivero and also abstracts its raw water from the lake (Fig 4.3). Wastewater is treated at the two main WTPs of Crowborough (capacity $\left.54,000 \mathrm{~m}^{3} / \mathrm{d}\right)$ and Firle $\left(144,000 \mathrm{~m}^{3} / \mathrm{d}\right)$. These two plants treat about $60 \%$ of the raw wastewater by modified activated sludge systems, popularly referred to as biological nutrient removal (BNR) systems, whilst the rest $(40 \%)$ is treated by means of trickling filters (TF). The trickling filter effluent and primary and secondary sludge (after digestion for primary sludge only) are mixed and used for pasture irrigation. However, the two major WTPs are currently overloaded and often discharge partially treated effluent into the main tributaries of Lake Chivero (Kamudyariwa, 2000; Tirivarombo, 2001). As a result, river water quality has badly deteriorated in recent years, resulting in serious water quality problems in Lake Chivero (JICA, 1996; Moyo, 1997; Nhapi et al., 2001 and 2003). The discharge of partially treated wastewater into rivers is obviously not sustainable in the long-run as it could result in the further deterioration of water quality in Lake Chivero.

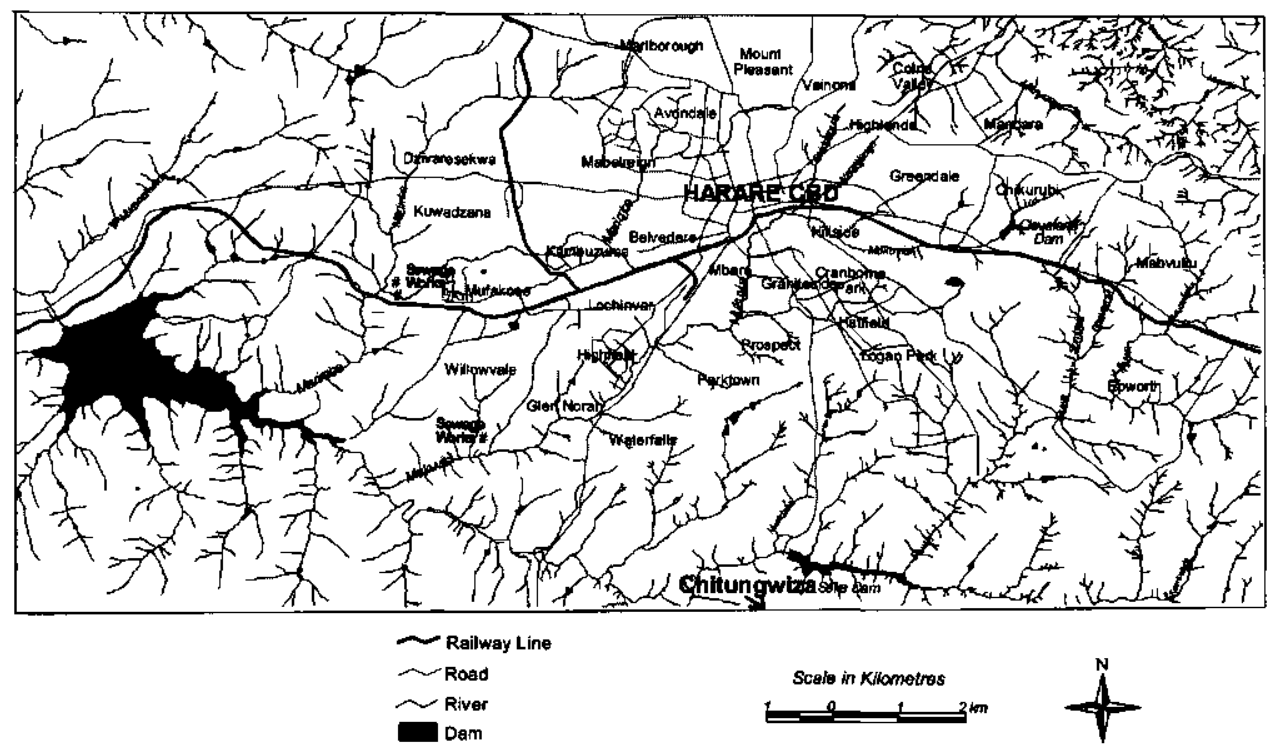

Figure 4.3: Map of study area showing the location of Lake Chivero in relation to Harare (CBD $=$ central business district) 
Previous studies on water quality in Lake Chivero show a disturbing trend of water quality deterioration. A study by JICA (1996) found average nutrient levels in the lake of $0.54 \mathrm{mg} / \mathrm{ltatal}$ nitrogen (TN) and $0.27 \mathrm{mg} /$ total phosphorus (TP). Since 1996, the phosphorus loads and water flows have changed substantialiy (Fig 4.4). Nhapi et al. (2003) reported average nutrient values ( \pm standard deviation) of $2.0 \pm 1.3 \mathrm{mg} / \mathrm{IN}$ and $0.6 \pm 0.3 \mathrm{mg} / \mathrm{lTP}$ based on more sampling points in the lake than those used in the JICA (1996) study. The high nutrient levels have resulted in periodic fish kills due to excessive ammonia levels and oxygen depletion. Other problems are water treatment difficulties and clogging of irrigation pipes due to high content of algae in the lake water (McKendrick, 1982). Excessive weed growth has also interfered with navigation.
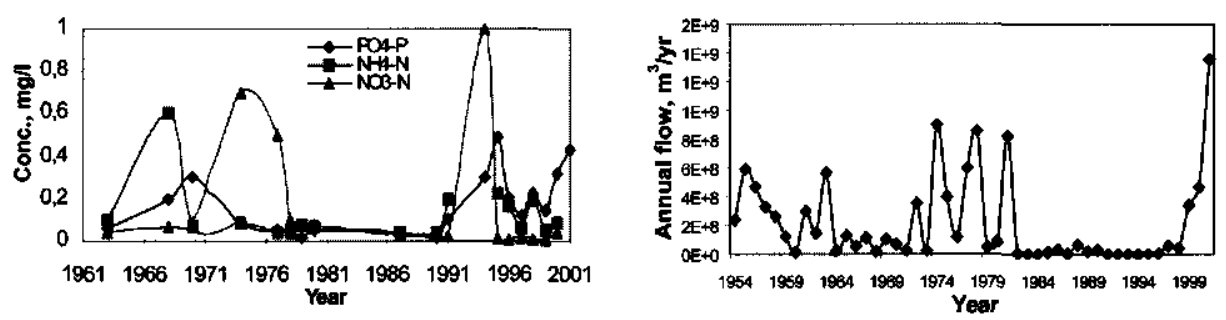

Figure 4.4: Nutrient and flow variations recorded in Lake Chivero (a) nutrient levels and (b) annual outflows at the spillway (Source: Marshall, 1997; Nhapi et al., 2003; City of Harare and Zimbabwe National Water Authority records)

A water balance of Lake Chivero shows that the lake can sustain a continued abstraction of $421,000 \mathrm{~m}^{3} / \mathrm{d}$ for urban water supply purposes at current inflow rates (Nhapi et al., 2002a). Current abstraction rates average $416,000 \mathrm{~m}^{3} / \mathrm{d}$ and as a contingency measure, Harare is looking for another source of water supply for itself and the neighbouring towns of Chitungwiza, Epworth, Norton and Ruwa. Except for the past five good rainfall seasons, Fig 4.4b shows that the city has been drawing down the water level in the lake resulting in little spillway discharges. This is compounded by excessive water consumption in residential areas. Reported water consumption figures are $630 \mathrm{l} / \mathrm{cap} . \mathrm{d}$ for low-density, $320 \mathrm{l} / \mathrm{cap} . \mathrm{d}$ for medium, and $80 \mathrm{l} / \mathrm{cap} . \mathrm{d}$ for high-density residential areas of Harare (JICA, 1996).

In summary, there are two basic challenges relating to urban water management in Harare. These are the long-term water scarcity problem (Nhapi et al., 2002a) and the immediate water quality problems in Lake Chivero (Nhapi et al., 2004). The current problems have been caused by rapid population growth after independence in 1980, inadequate maintenance of wastewater treatment plants, expensive technologies (TF and especially BNR), and a poor regulatory 
framework. Urban agriculture is also believed to be a major part of the problem in terms of washing off and leaching of nutrients, although there are no conclusive studies yet to quantify its impacts. This Chapter will propose the application of the 3-Step Strategic Approach with a view to simultaneously address the two problems identified.

\section{Application of the strategic approach to Harare}

\section{Wastewater generation in Harare}

A review of WW generation in Harare gives an insight into possible interventions. Urban landuse in Zimbabwe are generally classified as residential, commercial, and industrial areas. Residential areas are further categorised as high, medium and low-density. The affluent stay in low-density suburbs with stand areas of $>2,000 \mathrm{~m}^{2}$ up to about $8,000 \mathrm{~m}^{2}$, whilst medium-density areas have stand areas of around $1,000 \mathrm{~m}^{2}$. In some cases, the distinction between the two is blurred with noticeable overlaps. High-density areas have stand sizes of $150-300 \mathrm{~m}^{2}$ and this is where the poor stay. Commercial areas define shopping centres, mostly the central business district, suburban shopping centres and malls, service stations, institutional establishments, and warehouses.

Wastewater production by landuse category and the respective nitrogen and phosphorus productions are shown in Fig 4.5. These values were updated from JICA (1996) as reported by Nhapi et al. (2002a). About $304,000 \mathrm{~m}^{3} / \mathrm{d}$ of wastewater, $17,500 \mathrm{~kg} / \mathrm{d}$ TN and $2,600 \mathrm{~kg} / \mathrm{d}$ TP were produced in Harare (in 2002). The main source of household TN and TP is food, with phosphorus-containing detergents only contribute about $6 \%$ of household TP (Gumbo and Savenije, 2001). Some low-density areas are not sewered and use septic tanks.

(a)

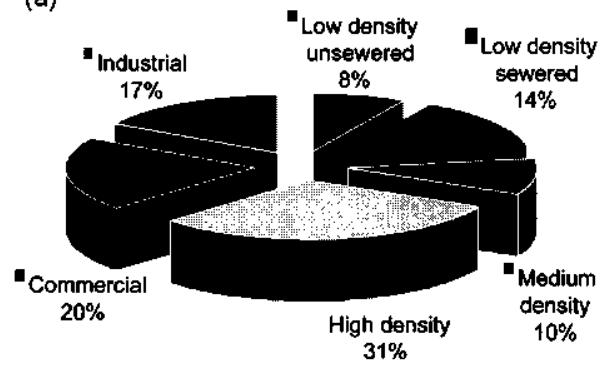

(b)

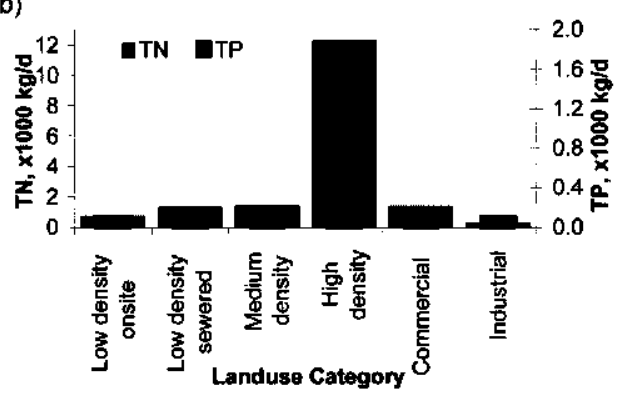

Figure 4.5: Wastewater production and nutrient generation in Harare for the year 2002 (a) Total wastewater production; $304,000 \mathrm{~m}^{3} / \mathrm{d}$, and (b) Nutrient generation; $17,500 \mathrm{~kg} / \mathrm{d} \mathrm{TN}, 2,600 \mathrm{~kg} / \mathrm{d}$ TP (updated from JICA, 1996) 
Low and medium-density residential and industrial stands offer opportunities for onsite management of wastewater because of space availability for treatment and disposal of effluent. Space and volume becomes a constraint for high-density residential and commercial areas and these produce substantial amounts of wastewater volumes and nutrients (Fig 4.5). In terms of future developments, the costs of urban sprawl (transportation, larger, longer and deep-laid pipes) could hamper the development of large stands and there would be more medium and high-density stands. The government's involvement in housing development is diminishing and more private developers, using open market capital, could increasingly find medium-density housing estates more attractive. These would buy private land within and on the periphery of the city. Decentralised wastewater treatment would, therefore, become more important in the technology mix of the City of Harare. Decentralised wastewater systems should provide specific wastewater management solutions for each housing estate or development.

\section{Step 1: Pollution prevention}

Household water conservation. Water consumption for medium and low-density areas of Harare is extremely high ( 320 and $630 \mathrm{l} /$ cap.d) compared to about $100-150 \mathrm{l} / \mathrm{cap} . \mathrm{d}$ in other countries (Metcalf and Eddy, 1991; Steen and Gijzen, 2003). As a result, the respective wastewater productions are $210 \mathrm{l} / \mathrm{cap}$.d for medium-density and $315 \mathrm{l} / \mathrm{cap} . \mathrm{d}$ for low-density residential areas (Fig 4.6). A large portion of household water consumption is used for gardening. The 'other' in Fig 4.6 includes water used for cleaning purposes and internal leaks. A combination of end-use efficiency, system efficiency, stormwater harvesting, storage innovations, and reuse strategies would greatly reduce current municipal water demand (Pinkham, 1999). The estimated proportion of water required for drinking and cooking is only $5-8 \%$, whereas $25-38 \%$ is wasted in toilet flushing in Harare. The high water usage for bathing and toilet flushing could be explained by installed water systems in homes. A great deal of reduction is feasible if water saving measures were to be employed. Education and community awareness campaigns could greatly reduce water consumption as reported in Bulawayo, Zimbabwe's second largest city, where reductions of more than $50 \%$ were reported $(B C C, 2002)$.

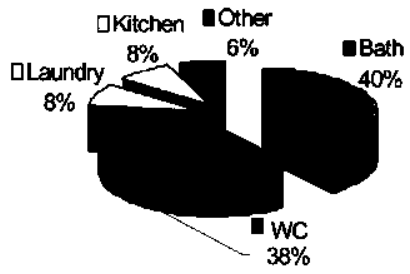

(a) High Density: 63 Vcap.d

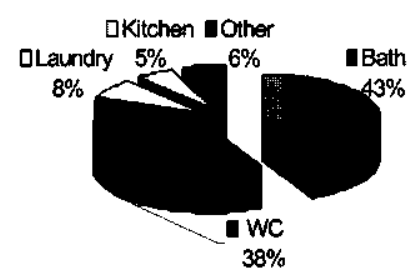

(b) Medium Density: 210 Vcap.d

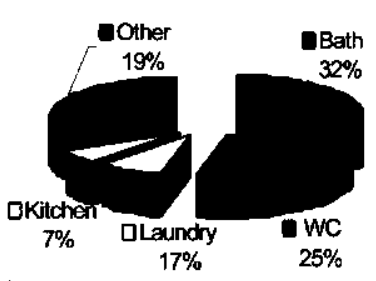

(c) Low Density: 315 Ucap.d

Figure 4.6: Household wastewater production in Harare (Source: Nhapi et al., 2002b)

(Captions below each graph relate to wastewater production, not water consumption) 
Water-saving devices are useful for water conservation in Harare and these include specific types of showerheads $(3-5 \mathrm{l} / \mathrm{min})$, smaller or dual flushing cisterns (6/3 $\mathrm{l} / \mathrm{flush})$, specialised toilet pans, and low water-usage faucets $(2 \mathrm{l} / \mathrm{min}$ ) (Chaplin, 1998). In low-density areas, borehole water could be used for supplementing municipal water supplies. This needs further investigation as an alternative source of water supply (because extracting from boreholes may have ecological or other negative effects). More efficient methods and devices for watering gardens can also be used, depending on costs, e.g., drip irrigation.

Using all the above methods, a potential reduction of about $33,700 \mathrm{~m}^{3} / \mathrm{d}$, or $20 \%$ of the current domestic hydraulic load, or $16 \%$ of the total wastewater production in Harare is feasible (Nhapi et al., 2002a). The reuse of wastewater, especially greywater (from laundry, kitchen and bathing), and rainwater harvesting, could greatly reduce water consumption by more than $50 \%$ (Chaplin, 1998; Lindstrom, 1998). Rainwater harvesting is another potential substitute of potable water supply. With an annual rainfall of $830 \mathrm{~mm} / a n n u m$ (ZINWA records), and assuming $50 \%$ losses, about $0.4 \mathrm{~m}^{3} / \mathrm{m}^{2}$.yr can be collected (depending on housing category, water consumption is $30-230 \mathrm{~m}^{3} / \mathrm{cap}$.yr). In certain parts of Hawaii, the Virgin Islands, Australia and Texas, rainwater collection systems provide the entire water supply for many homes (Chaplin, 1998). Progressively high water tariffs can also be used as a demand management tool since almost all properties in Harare have water meters. This is achieved by using an increasing block tariff structure with punitively high charges for high water consumers.

Water consenvation for commerce and industry. Commercial and industrial consumers produce about $62,000 \mathrm{~m}^{3} / \mathrm{d}(20 \%)$ and $52,000 \mathrm{~m}^{3} / \mathrm{d}(17 \%)$ respectively, of the wastewater produced in Harare (Fig 4.5). Literature shows that in some industries, water demand could be greatly reduced by using water saving devices in toilets and kitchens (ICWE, 1992). The application of cleaner production principles (pollution prevention and reuse) is the best way of controlling water use and pollution discharges from industries (Mlilo, 2002). Recycling should further reduce water consumption. The repair of teaks, especially in public places (toilets, parks, institutional) and water distribution systems, is a useful practice also in commercial and industrial areas. A number of Zimbabwean companies like Chibuku, Q-bic, and Afdis in Harare, Leopard Rock Hotel in Mutare, and Ziscosteel in Redcliff have successfully used recycled water over the years.

Utility-based measures. Utility-based measures available to urban water managers are many and offer important savings opportunities. These include leak detection and repair in water mains and lines, conservation price structures, watershed management activities to reduce 
storage losses from the siltation of reservoirs, and wastewater reclamation. The household phosphorus load could be reduced by about $6 \%$ (Gumbo and Savenije, 2001) through banning of phosphorus-containing detergents and further reductions should also be possible in industry and commerce.

\section{Step 2: Treat and reuse}

Onsite treatment and reuse of domestic wastewater. The prevalence of on-plot cultivation and large stand sizes in Harare offers an opportunity for onsite treatment and reuse of wastewater, especially for low-density and industrial areas and, to a limited extent, for medium-density areas. A typical scheme for residential areas is shown in Fig 4.7. Both urine/faeces and black/greywater separation is feasible with the other option being combined treatment of all wastewater streams. Source separation is advantageous in terms of low water usage and opportunities for localised direct reuse of waste components (urine, greywater) and a host of technologies are available for this (Lindstrom, 1998; Jeppsson et al., 2002). Greywater comes from laundry, bath, and kitchen and can be easily collected from waste pipes that lead into a gully trap. In most cases, greywater can be directly reused for gardening, or can undergo basic treatment (sedimentation, filtration) and its uses extended to include toilet flushing and car washing (under 'other' in Fig 4.7).

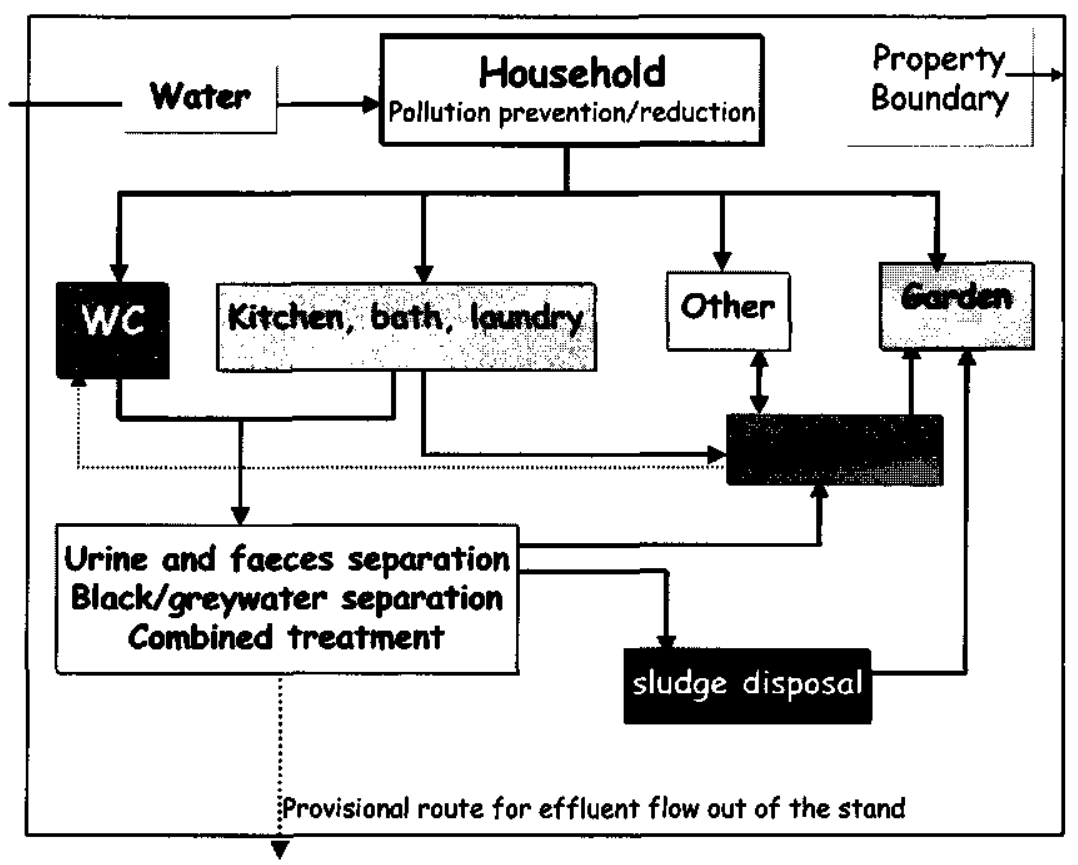

Figure 4.7: Options for household wastewater treatment and reuse 
Religious beliefs, fears and uncertainties related to safety are impediments to wastewater reuse (Marks et al., 2002). Extensive educational campaigns and effluent disinfection becomes important. UV radiation, chlorination and ozonation remain viable disinfection options based on practical experiences from countries that practice reuse (Asano and Levine, 1996). Disinfection can be reduced by using greywater or urine separately whilst faeces are composted. Urine is generally sterile and can be stored for some time before use (Lindstrom, 1998; Jeppson et al., 2002). Research is on-going in Zimbabwe on pathogen decay in composting toilets and preliminary results show that a hygienically safe product is obtainable after three months (Proudfoot, 2002). Watertight composting toilets are also a good option as they do not contaminate groundwater. The ultimate destination of both effluent and sludge is the garden. This is the shortest way of recycling both nutrients and water, resulting in reductions of nutrient flows into Lake Chivero.

Onsite treatment and reuse of industrial wastewater. Industrial wastewater is varied in composition depending on individual processes. It is therefore important, as a start, that process flows are not mixed. In terms of strategy, simple to high-tech methods of treatment could be employed to render the water suitable for reuse in or at another industry (waste trading). Primary and/or secondary treatment could be employed with effluent polishing outside the industry at decentralised or centralised levels. Wastewater could be treated to a degree conducive to the intended reuse, but not necessarily to a higher standard.

Decentralised and centralised treatment and reuse of wastewater. Where it is difficult to treat wastewater at property level a decision has to be made on how far from the source of generation the wastewater has to be handled. Central treatment is currently the norm but this would be expensive when trunk sewers are to be constructed over longer distances. About $60 \%$ of sanitation costs are usually for the collection component. Terrain might also limit gravity flow and expensive pumping has to be resorted to. Raw wastewater pumping is not popular in Zimbabwe because of cost considerations (capital and maintenance) and the unreliability of electricity supply. Transporting the wastewater far from sources of generation ignores local reuse possibilities and increases risks of failure (Venhuizen, 1998). An intermediate step - the decentralised concept - becomes more attractive as it gives better options for reuse. This addresses treatment and reuse within neighbourhoods, offering an opportunity of linking wastewater management to urban agriculture. Economic feasibility studies elsewhere have shown that the optimal number of households connected to decentralised systems is in the range 1,000 - 10,000 (Gray and Booker, 2003). Possible decentralised and centralised systems 
are shown in Fig 4.8. The dotted line indicates the return route of treated wastewater, directly or indirectly, to residential areas for non-potable uses.

(a)

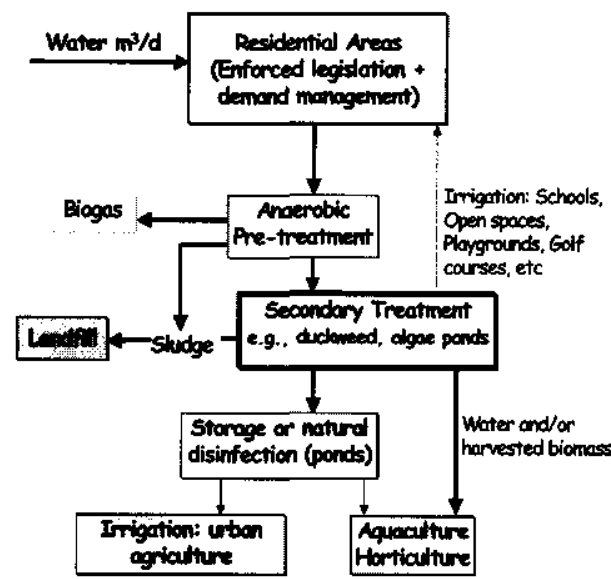

(b)

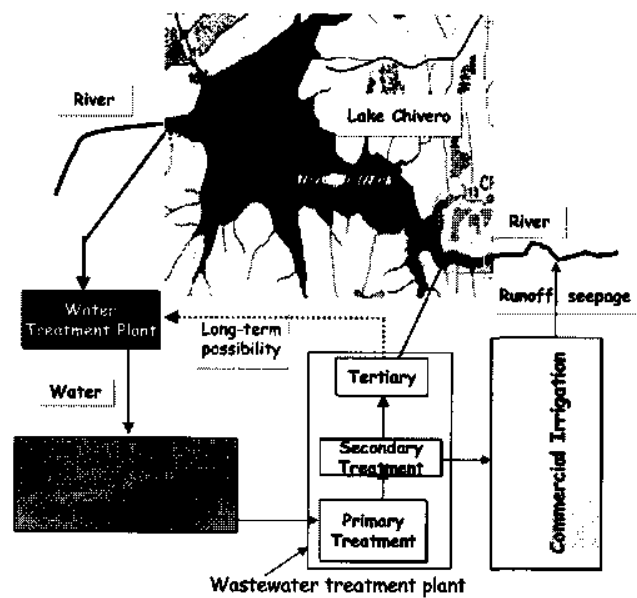

Figure 4.8: Options for offsite wastewater treatment: (a) a decentralised system, and (b) a centralised system

A schematic layout of a typical decentralised scheme is shown in Fig 4.8a. The source of wastewater coutd be new high and medium-density residential areas. Primary treatment would be mainly screening and grit removal followed by natural methods of secondary treatment. Locally available treatment technologies are waste stabilisation ponds, duckweed-based ponds, and constructed wetlands. These can be preceded by anaerobic wastewater treatment if water conservation strategies discussed above are implemented. Reduced water consumption would result in more concentrated wastewater, which makes anaerobic treatment methods more feasible, provided the produced biogas is collected as a source of renewable energy and to avoid greenhouse emissions (Pickin, 2002). Treatment technologies would be chosen depending on their ability to recover and reuse nutrients, reduce pathogens, and to use the final effluent for irrigation. The storage process involves disinfection, ideally by maturation ponds, ozonation or UV radiation. The effluent is used for local agriculture or aquaculture. This whole set-up requires the separation of (mainly) industrial effluents to avoid toxins, such as heavy metals, as these affect natural treatment, sludge disposal and reuse.

The centralised system shown in Fig $4.8 \mathrm{~b}$ is more or less the same as the existing systems in Harare but with some innovations and modifications. Firstly, the volume of wastewater to be 
handled could be lower (about 20\%) because of prevention measures (step 1) and the use of onsite systems for some landuse categories. The highly concentrated organic load could be reduced by increased aeration in the collector systems. Through policing discharges, only industrial effluent that does not contain toxic matter is allowed into the collection system. This means that the wastewater would require screening, grit removal, followed by organic load stabilisation through anaerobic treatment methods. Biogas collection becomes more attractive than for decentralised systems because of economies of scale gained by using larger treatment plants. The effluent can be used for commercial irrigation, industrial use, groundwater recharge, and surface water replenishment. Based on local crop preferences, irrigation schemes would include maize, tomato and potato production, instant turf production, barna or impala grass for cattle feed (previously used in Redcliff, Zimbabwe), gumtree plantations, and vineyards

In most cases, disinfection would be necessary. A provision has been made in Fig $4.8 \mathrm{~b}$ (dotted line) for possible tertiary treatment and subsequent treatment by such methods as ultra-filtration and reverse osmosis for potable purposes (Ramirez et al., 2002). Water reclamation and reuse can provide about $275,000 \mathrm{~m}^{3} / \mathrm{d}$ ( $52 \%$ of the current water demand) based on Crowborough and Firle WTPS only. The above proposals could result in marked improvements to the current system that uses biological nutrient removal and trickling filter systems. Sludge is currently mixed with trickling filter effluent and used for irrigation. The suggested scheme still needs stricter control of industrial effluents to avoid toxic components entering the food production system.

\section{Step 3: Disposal and stimulation of self-purification}

Land application is one option to achieve wastewater effluent polishing through using the selfpurification capacity of natural systems. The current disposal system for Harare involves using an effluent/sludge mixture for pasture irrigation, river discharge of tertiary effluent, and use of waste stabilisation pond effluent for commercial irrigation (grass, plantations). The latter is currently facing problems of land availability and has been abandoned resulting in poor quality effluent discharge into watercourses. Pasture irrigation is also being affected by land availability resulting in the overloading of the pastures (Mawere, 2001). The major wastewater treatment plants of Crowborough and Firle often discharge poorly treated effluent into the main tributaries of Lake Chivero. This is mainly due to treatment plant breakdowns and overloading.

A number of options can be used to improve the current systems. Firstly, sludge can be handled separately and disposed at the landfill. Controlling industrial and agricultural toxins could enhance disposal options, eventually making composting and reuse in agriculture feasible. The effluent can be used for commercial irrigation also outside the Chivero catchment. The impact of 
this on water availability in the catchment needs further study. Marimba and Mukuvisi rivers are well aerated because of rapids and shallow depths of below $1 \mathrm{~m}$. This is good for organic matter degradation and nitrification. Natural purification in these rivers could be enhanced further by constructing diversions with wetlands, which would increase the hydraulic retention time and increase the time available for biological and physical processes to take place. The waste stabilisation effluent might also be used for commercial irrigation within neighbourhoods.

\section{Discussion}

The strategies proposed in this Chapter have serious implications on the current institutional set-up. It would result in much more cumbersome management requirements than at present, necessitating well-organised and responsive institutions. Individual plot owners can manage onsite systems provided there are reductions in the cost of treatment and income generation from reuse. Several houses could also share a treatment facility. Private developers could participate at a decentralised level with incentives coming from the reduction of conveyance and treatment costs if appropriate technologies are selected. Economic benefits derived from reusing effluent water for commercial irrigation would also attract private investors, especialiy those involved in peri-urban farming. Technology selection, with emphasis on costs, recovery and profitable reuse of nutrients, is very important in the formulation of strategies. Preferably, technologies that achieve the above criteria and are backed by local expertise could be used as a starting point.

Different approaches and technologies would apply to different areas. The best way to achieve optimal results is by integrating the different approaches (onsite, decentralised, and centralised). A staged implementation is required with benefits to be realised over time. However, management solutions like banning phosphorus-containing detergents, trade effluent regulations, water tariffs, and new plumbing standards could be implemented soon. These could stimulate the implementation of concrete actions under each of the steps. Water pollution and possible future water scarcity problems in Harare could be solved by an integrated approach to wastewater management as proposed in this paper. A more creative approach is required. Such an approach starts with cleaner production approaches at onsite level, progressively reducing pollution loads at different levels of aggregation. Reuse needs to be optimised in each of the three steps.

Further work is required to model the pollution paths and reductions in order to quantify the actual impact on water quality of the downstream Lake Chivero. The details of options to be 
developed for each step in Harare require further analysis. This will be the subject of on-going studies.

\section{References}

Asano T. and Levine, A.D. (1996) Wastewater Reclamation, Recycling and Reuse: Past, Present and Future, in IAWQ Wat. Sci: Tech. Vol. 33(10-11) p1-14.

BCC (Bulawayo City Council) (2002) Study on Water Use, Water Consenvation and Affordability, May 2002, Department of Works, Bulawayo, Zimbabwe.

Braden, J.B. and van lerland, E.C. (1999) Balancing: The Economic Approach to Sustainable Water Management, in Wat. Sci. Tech. Vol. 39(5) p17-23.

Cosgrove, W.J. and Rijsberman, F.R. (2000) Wordd Water Vision: Making Water Everybody's Business, World Water Council, London, UK.

Chaplin, S. (1998) Water Efficiency: The Next Generation, Draft Report 5-9, Rocky Mountain Institute, Colorado, USA, Internet Site: http:/hww.rmi.org/sitepages.

Engelman, R. and Leroy (1993) Sustaining Water, Population and Future Water Supplies, Population Action International, Washington, USA.

Frijns, J. and Jansen, M. (1996) Institutional Requirements for Appropriate Wastewater Treatment Systems, in Proceeding of the Worksop on Sustainable Municipal Waste Water Treatment, Leusdan the Netherlands, 12-14 November 1996, pp54-66.

Gijzen, H.J. (1998) Sustainable Wastewater Management Via Reuse: Turning Waste into Wealth, in Proc. Aqua 98, Water and Sustainability, 1 - 4 June 1998, Cali, Colombia.

Gijzen, H.J (2001) Low Cost Wastewater Treatment and Potentials for Re-use: A Cleaner Production Approach to Wastewater Management, paper presented at the International Symposium on LowCost Wastewater Treatment and Re-use, NVA-WUR-EU-IHE, Cairo, Egypt, February 3-4, 2001.

Gray. S, and Booker, N. (2003) Wastewater Services for Small Communities, IWA Wat. Sci. Tech. Vol. 47(7-8), p65-71.

Gumbo B. and Savenije H.H.G., (2001), Inventory of phosphorus fluxes and stocks in an urban-shed: Options for local nutrient recycling. $1^{\text {st }}$ International Conference on Ecological Sanitation held on 5-8 November 2001. Nanning, China. Extended abstract at http/www.wise-china.com/english/e39.htm.

ICWE (International Conference on Water and the Environment) (1992) The Dublin Statement and Record of the Conference, World Meteorological Organisation, Geneva, Switzerland.

JICA (1996) The Study of Water Pollution Control in Upper Manyame River Basin in the Republic of Zimbabwe, MLGRUD, Nippon Jogeduido Sekkei Co. Ltd., Nippon Koei Co. Ltd, September 1996.

Jeppson, U., Hellström, D, Gruveberger, C., Baky, A., Malmem, L., Palm, O., Palmquest, It., And

Rydhagen, B. (2002) Framework for Analysis of Treatment Systems for Source-separated Wastewater and Organic Household Waste, in Proceedings of the IWA World Water Congress, Melbourne, Australia, 7 - 12 April 2002.

Kamudyariwa, C. (2000) Seasonal Variation of Water Quality with Respect to Anthropogenic Activities Along Mukuvisi River, Harare, Zimbabwe, MSc. Thesis, IHE Delft, The Netherlands 
King, N (2000) New Strategies for Environmental Sanitation, in Water21, Magazine of the International Water Association, April 2000, London, UK, p11-12.

Larsen, T.A. and Gujer, W. (1996) Separate Management of Anthropogenic Nutrient Solutions (human urine), Wat. Sci. Tech., Vol. 34, p87-94.

Lindstrom, C.R. (1998) Greywater, Cambridge, Website: http://greywater.com.

Marks, J., Cromar, N., Howard, F., Oemcke, D. and Zadoroznyj, M. (2002) Community Experience and Perceptions of Water Reuse, in Proceeding of IWA World Water Congress, Melbourne, Australia, April 7-12, 2002.

Marshall, B.E. (1997) Lake Chivero After Forty Years: The Impact of Eutrophication, in Moyo, N.A.G. (Ed.) Lake Chivero: A Polluted Lake, University of Zimbabwe Publications, Harare, Zimbabwe.

Mawere, M. (2001) Land Application of Sewage, The Role of Crowborough Pasture Irrigation in the Reduction of Nutrient Loads to Marimba River. MSc. Thesis, IHE Delft, The Netherlands.

Mckendrick, J. (1982) Water Supply and Sewage Treatment in Relation to Water Quality in Lake Mcllwaine in Thornton,J A and Nduku,W K (eds.) Lake Mcllwaine; The Eutrophication and Recovery of a Tropical African Man-Made Lake, Dr W Junk Publishers, The Hague, The Netherlands, p202217

Metcalf and Eddy (1991) Wastewater Engineering: Treatment, Disposal \& Reuse, McGraw - Hill, Inc, Singapore.

Mlilo, S.R. (2002) An Investigation into the Potential for Reducing Water Intake and Minimising Waste from the (i) Soft Drink Manufacturing (ii) Sugar Refining, and (iii) Wire Galvanising Industries in the City of Bulawayo, MSc Thesis, University of Zimbabwe, Harare, Zimbabwe.

Moyo, N.A.G. (Ed.) (1997) Lake Chivero: A Polluted Lake, University of Zimbabwe Publications, Harare, Zimbabwe.

Nhapi, I., Siebel, M. and Gijzen, H.J. (2002a) An inventory of the existing water management practices in Harare, Zimbabwe, paper submitted for publication in the Urban Water Journal.

Nhapi, I., Siebel, M. and Gijzen, H.J. (2002b) Options for the Onsite Management of Wastewater in Harare Zimbabwe, Proceedings of the IWA $5^{\text {th }}$ Specialised Conference on Small Water and Wastewater Treatment Systems, Istanbul, Turkey, 24 - 26 September, 2002.

Nhapi, I., Siebel, M. and Gijzen, H.J. (2004). The Impact of Urbanisation on the Water Quality of Lake Chivero, Zimbabwe, Joumal of the Chartered Institute of Water and Environmental Management, Vol. 18(1), p44-49.

Otterpohl, R., Grottker, M. and Lange, J (1997) Sustainable Water and Wastewater Management in Urban Areas, in IWAQ Wat. Sci. Tech., Vol. 35(9)

Otterpohl, R., Abold, A. and Oldenburg, M. (1998) Differentiating Management of Water Resources and Waste in Urban Areas - Proceedings of the internet Conference on Integrated Bio-Systems, Lübeck, Germany: Internet Site http://www.soc.titech.ac.jp/vem/waste/oldenburg.html.

Pickin, J. (2002) Greenhouse Gas Emissions from Waste: Outlook for the future in Proceedings of the IWA World Water Congress, Melbourne, Australia, 7-12 April 2002.

Pinkham, R. (1999) $21^{\text {St }}$ Century Water Systems: Scenarios, Visions and Drivers, Rocky Maintain Institute, Colorado, USA, Internet Site: http://www.rmi.org/sitepages/pid123.php. 
Proudfoot, D., Mguni, G., and Bhingu, D. (2002) Pathogen Destruction Study, Proceedings of the $3^{\text {rd }}$ WaterNetWARFSA Symposium in Dar Es Salaam, Tanzania, October 30-31, 2002, p505- 518.

Ramirez, J.A.L, Alonso, J.M.Q., Morquez, D.S. and Asano, T. (200). Indirect Potable Reuse and Reverse Osmosis: Challenging the course "New Water", in Water 21, Magazine of the international Water Association, June 2002.

Steen, P. van der and Gijzen, H.J. (2003) Duckweed-based Natural Systems for Wastewater Treatment and Resource Recovery, in Garcia, M. and Gijzen, H.J. (eds.) Memorias AGUA2003.

Tirivarombo, S (2001) Sewage Discharges and Nutrient Levels in Marimba River, Zimbabwe, MSc Thesis, University of Zimbabwe, Harare, Zimbabwe.

Venhuizen, D. (1997) The Decentralised Concept of Wastewater Management, Internet Site: http://www.geocities.com/RainForest/Vines/5240Nenh_ww.html. 


\section{Chapter 5}

\section{Options for Onsite Management of Wastewater in Harare, Zimbabwe}

\section{Submitted as:}

Nhapi, I., Siebel, M. and Gijzen, H.J. (2002) Options for Onsite Management of Wastewater in Harare Zimbabwe, Proceedings of the IWA $5^{\text {th }}$ Specialised Conference on Small Water and Wastewater Treatment Systems, Istanbul, Turkey, 24 - 26 September, 2002. 


\title{
Options for Onsite Management of Wastewater in Harare,
}

\section{Zimbabwe}

\begin{abstract}
This Chapter reviews options for onsite treatment of wastewater in Harare, Zimbabwe. It focuses on three objectives: a) quantification of wastewater that could be treated and reused onsite, b) identification of treatment and reuse options for different landuse categories, and c) prediction of the overall impact of these options, separately and integrated, on downstream water quality. An average of $304,000 \mathrm{~m}^{3} / \mathrm{d}$ of wastewater, containing $17,500 \mathrm{~kg} / \mathrm{d}$ of nitrogen and $2,600 \mathrm{~kg} / \mathrm{d}$ of phosphorus are produced in Harare and subsequently treated onsite ( $8 \%$ of total flow) or at five wastewater treatment plants. Of these amounts, $39 \%$ of flow, $14 \%$ of nitrogen, and $16 \%$ of phosphorus could potentially be handled onsite. Greywater separation was found to be the most effective measure in reducing (by $52 \%$ ) the current flows received at wastewater treatment plants. Urine separation would be an effective measure in nitrogen (52\%) and phosphorus (34\%) removal. Greywater separation and reuse will only remove $6 \%$ of nitrogen and $37 \%$ of phosphorus. It was concluded that high reductions in wastewater outflows from plots could be feasibly achieved, except for high-density areas where small plot sizes and high occupancy rates limit onsite effluent reuse options. A conceptual framework for onsite wastewater treatment and reuse in Harare was subsequently developed based on the so-called 3-step Strategic Approach.
\end{abstract}

Keywords: 3-Step Approach, cleaner production, onsite systems, pollution prevention, reuse, wastewater

\section{Introduction}

The sustainable management of water in rapidly expanding cities of developing countries is a big challenge in the twenty-first century. Changes in national economic patterns have pushed many people from rural areas to look for opportunities in urban areas. This has resulted in increased pressures on urban infrastructure and resources such as clean surface and groundwater to the extent that most cities are failing to cope with urban infrastructure provision. A common problem is serious water pollution in downstream water bodies. The conventional approach to this problem has been to develop very expensive and complicated "end-of-pipe" solutions based on advanced methods of wastewater treatment. The continued failure of these systems, in most cases, necessitates a drastic review of current pollution prevention approaches in terms of strategies and technologies used, regulatory frameworks, affordability and institutional settings. In Zimbabwe, serious problems related to wastewater management have been reported in Harare, the capital city (JICA, 1996; Moyo, 1997; Nhapi et al., 2001). 
In March 2000, the City of Harare announced the suspension of all new housing developments until solutions are found to wastewater treatment plant overloading and downstream pollution problems. Treatment efficiency has gone down and the downstream Lake Chivero, the city's main source of potable water supply, is under serious pollution stress (JICA, 1996; Moyo, 1997; Nhapi et al., 2004). The Nitrogen and phosphorus contamination of Lake Chivero is of major concern (Nhapi et al., 2001). Water hyacinth and algae infestations, and periodic fish kills due to low oxygen levels and ammonium poisoning, among others, have been reported (Magadza, 1997; Moyo and Mtetwa, 1999). On 14 February 2002, two Zimbabwean newspapers (The Herald and The Daily News) reported serious water shortages in some parts of Harare. The problem was attributed to low potable water production due to the need for frequent backwashing of sand filters as the water from Lake Chivero had high concentrations of algae. Because of numerous plant breakdowns, plant overloading or sewer overflows, untreated or partially treated wastewater is sometimes discharged into the major lake tributary rivers of Marimba and Mukuvisi (Taylor and Mudege, 1997; Kamudyariwa, 2000; Nhapi and Tirivarombo, 2004). Wastewater treatment in Harare is mostly by trickling filters and modified activated sludge systems (tertiary treatment). Tertiary effluent is discharged into rivers whilst all trickling filter effluent is mixed with primary and secondary sludge and used for pasture irrigation. All wastewater treatment plants (WWTP), including the existing system of pasture irrigation, suffer from overloading mainly due to population concentration in the area (Manjonjo, 1999; Nyamangara and Mzezewa, 1999; Mawere, 2001).

The current problems in Harare require a methodical approach to wastewater management. This Chapter evaluates options for managing wastewater at the onsite level only (household, institutional, commercial, or industrial), and addresses three objectives. The first was to assess the amount of wastewater in Harare that could be feasibly treated and reused onsite, taking into account the housing density, cost implications, physical, and environmental conditions. The second objective was to identify options for managing wastewater components (water, nitrogen and phosphorus) with emphasis on technologies that enable reuse of these components, and could be backed up by local expertise. The last objective was to estimate the potential reduction in wastewater pollution (nitrogen and phosphorus) likely to result from the onsite approach to wastewater management in Harare. The subject dealt with in this Chapter forms part of a broader study aimed at developing strategies for managing wastewater in Harare. The three main strategies considered are managing wastewater within the property boundary (onsite), within neighbourhoods (decentralised), and at a city-wide level (centralised). Whilst a combination of all levels are recommended for differentiated solutions, this Chapter deals with options that can be applied at the onsite level only. The other options for decentralised and 
centralised management of wastewater are dealt with separately (Nhapi et al., 2002a and 2003).

Onsite systems are generally shunned by affluent people as sub-standard. However, they remain the most attractive solution for scattered or large plots where conventional sewerage systems would be difficult and costly. In fact, they offer a number of economic and environmental benefits and could lead to rational use of valuable resources (water, biogas, and nutrients). Economic benefits relate to reduced capital costs for the construction of sewers and large-scale treatment facilities. With onsite systems, the user is directly confronted with his/her own costs (polluter pays). The smaller volumes of wastewater handled can be treated using simpler and cost effective methods which are specific to the type of wastewater generated. Environmental benefits result from reduced use of materials (pumps, pipes) and ground disturbances through excavations. The exposure risks from any mishaps are reduced and localised. The rational use of resources relate to possibilities for nutrient containment and direct beneficial re-use of both water and nutrients for food production. A new approach to onsite wastewater management is emerging, which is based on utilisation instead of disposal (Del Porto, 1999). At the extreme end of the scale are the zero-effluent discharge systems (King, 2000). Effective onsite wastewater systems are based on the three-part strategy of 1) conserve water, 2) separate/divert and pre-treat effluents at their source, and 3) recycle, reuse and utilise effluents (Davidavicius and Ramoskkiene, 1996; Del Porto, 1999).

\section{Methods}

\section{The study area}

The study area is the City of Harare, and its description has been extensively covered in previous Chapters. Harare has a population of approximately $\mathbf{1 . 9}$ million, the majority of whom are housed in $\mathbf{2 7}$ high-density residential areas. The locations of the five wastewater treatment works in Harare are shown in Fig 5.1. Over 95\% of inhabitants are connected to a sewer system, whilst the remainder is mainly accounted for by the use of septic tanks in some lowdensity areas. Two peri-urban settlements, locally termed "holding camps", have been in existence since 1994. Since the year 2000, a number of squatters have invaded some peripheral areas in a wave of national farm invasions. The majority of these squatters are developing thousands of plots close to Lake Chivero, potentially posing serious risks to the quality and uses of the water body. Peri-urban areas use composting toilets, urine separation toilets and pit latrines. Sewered systems discharge to five wastewater treatment plants, which have a combined capacity of $208,000 \mathrm{~m}^{3} / \mathrm{d}$. All the wastewater collected receives some form of 
treatment before discharge into rivers although plant breakdowns and overloading often compromise the final effluent quality.

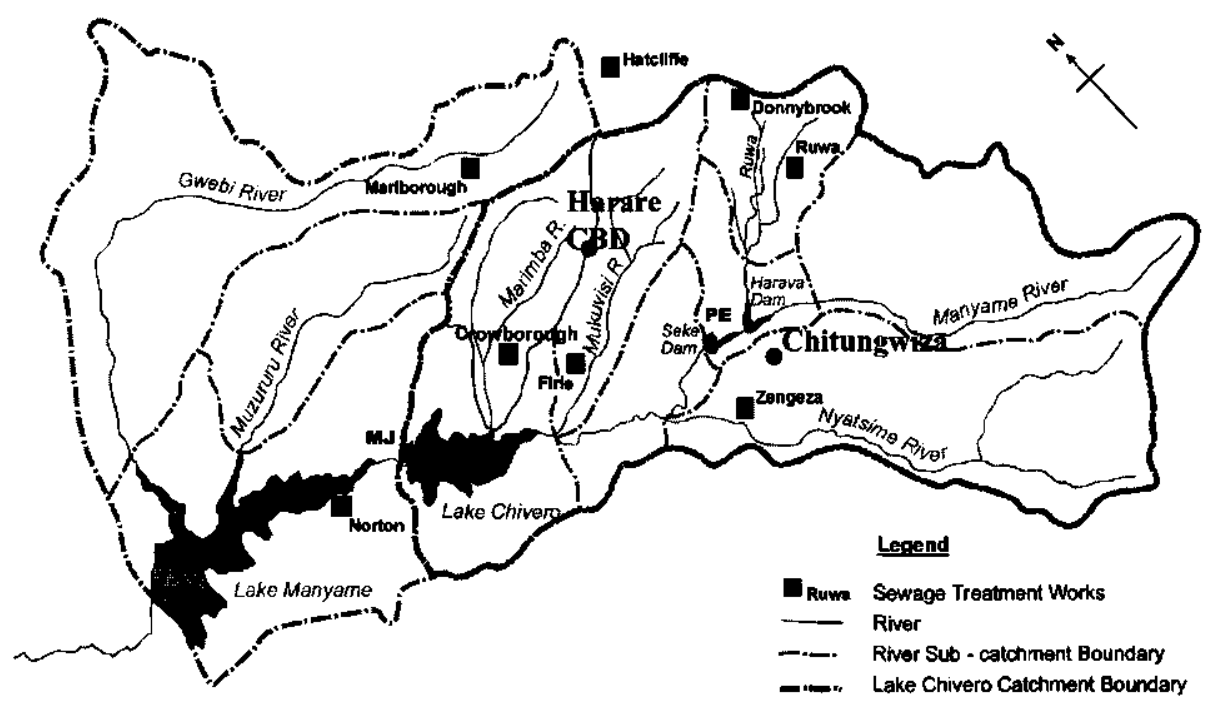

Figure 5.1: Map of the Chivero catchment area showing the location of Harare relative to Lake Chivero and the wastewater treatment plants in Harare and neighbouring farms.

\section{Approach}

Wastewater in Harare can be treated at onsite, decentralised, or centralised levels as described by Nhapi et al. (2002b). This Chapter deals only with onsite options for wastewater management, but forms part of an all-compassing strategic approach for urban water management referred to as the "3-step Strategic Approach" (Nhapi and Gijzen, 2003). The three steps seek to manage wastewater through (1) poliution prevention and reduction at the source, (2) treatment and reuse of wastewater components, and (3) disposal with stimulation of the natural purification capacity of the receiving water bodies. In operational terms, the study assessed wastewater, nitrogen and phosphorus generation in Harare from literature figures and from available reports and databases maintained by the City of Harare. The values available from databases were checked via a series of direct measurements. The population distribution and flow projections for different areas were originally done by JICA (1996) and these were updated based on preliminary results of the 2002 census. The amount of wastewater that could be feasibly handled onsite was estimated after considering population density, stand sizes, and income levels. The options proposed in this study were identified within the context of the ' 3 Step Strategic Approach' mentioned above. The potential impacts of each of the proposed onsite options on the pollution situation in the Lake Chivero catchment were considered based 
on "best available technology". These potential impacts were considered for the year 2002 and projected to the year 2015 .

\section{Data collection}

The data collected covered wastewater quality and quantity, housing categories, landuses and development standards, water consumption levels, and population distribution. The major sources of data were the City of Harare, the City of Bulawayo (complementary data not kept by Harare), Central Statistical Office, government departments, local standards and regulatory boards, and published/unpublished literature. Raw wastewater total nitrogen (TN) and total phosphorus (TP) concentrations were monitored monthly using Standard Methods (1995) for Crowborough and Firte wastewater treatment works. These two plants treat over $90 \%$ of the city's wastewater. The monitoring period was June 2000 to December 2001. For the other three STWs of Donnybrook, Hatcliffe and Marlborough, data from City of Harare were used. Wastewater flow data were obtained from the City of Harare. This information was processed using MS Excel data processing functions to estimate flows and pollution generation. Present and potential effluent quality and effects of innovations on the overall wastewater management strategy were assessed from a desk study.

\section{Results and discussion}

\section{Feasibility of onsite treatment}

Water consumption and wastewater generation. Typical landuse characteristics, household characteristics and water consumption and wastewater production figures are shown in Table 5.1. The per capita loads for nitrogen given by JICA (1996) were found to overstate the actual production. These were adjusted by dividing the measured daily nitrogen load by the population for those wastewater treatment plants that receive predominantly domestic wastewater. The obtained values agreed with those obtained by the Harare city council in a previous study (Department of Works, 2001). Table 5.1 shows that affluent people (low and medium-density areas) use a lot of water resulting in high volumes of wastewater. Normally low-density stands are on difficult terrain, are on poor quality soils (structurally), and have large gardens. The increasing differences in water consumption and wastewater generation, between high, medium and low-density areas, are due to differences in water uses, such as car washing, garden irrigation, and cleaning activities around the house, which are more likely to happen at lowdensity plots.

Nutrient loads to wastewater treatment plants were determined for each landuse category based on population data and unit poflution loads from Table 5.1. In Harare, it could be safely 
assumed that all wastewater produced is collected for treatment because this is a statutory requirement in Zimbabwe. The population was determined from JICA (1996) and the 2002 population census (CSO, 2002). It is evident from Table 5.2 that residential (domestic) areas play a major part in the pollution problems in Harare. High-density areas provide $31 \%$ of the total wastewater volume, and over $50 \%$ of both nitrogen and phosphorus contributions. The contribution from commercial sources is second highest for the three parameters. The high contribution of commercial activities to nutrient loads is attributed to toilet discharges by staff and use of phosphorus detergents (not yet banned in Zimbabwe). Most people spend the daytime at work, in town, or at school. The contribution of phosphorus detergents has been shown to be small at about $6 \%$ of the total phosphorus generated at household level (Gumbo and Savenije, 2001). The contributions from industries were much higher for phosphorus (15\%) compared to $6 \%$ for nitrogen. This is also attributed to the use of phosphorus detergents for cleaning in industries.

Table 5.1: Landuse categories, average income and wastewater production in Harare (Marks, 1993; JICA, 1996; Bulawayo City Council internal reports)

\begin{tabular}{|c|c|c|c|c|c|c|c|}
\hline $\begin{array}{l}\text { Landuse } \\
\text { (Housing } \\
\text { Category) }\end{array}$ & $\begin{array}{r}\text { Stand Size, } \\
m^{2}\end{array}$ & $\begin{array}{r}\text { Household } \\
\text { Size, } \\
\text { cap/stand }\end{array}$ & $\begin{array}{r}\text { Household } \\
\text { Income, } \\
\text { US\$/month }\end{array}$ & $\begin{array}{r}\text { Water } \\
\text { Use } \\
\text { Ucap.d }\end{array}$ & $\begin{array}{r}\text { Wastewater } \\
\text { Production, } \\
\text { Ucap.d }\end{array}$ & $\begin{array}{r}T N \\
\text { Production, } \\
\text { g/cap.d }\end{array}$ & $\begin{array}{r}\text { TP } \\
\text { Production, } \\
\text { g/cap.d }\end{array}$ \\
\hline High-density & $\leq 500$ & 13 & 75 & 80 & 63 & 8 & 1.2 \\
\hline Medium-density & $500-1,500$ & 11 & 263 & 320 & 210 & 9 & 1.3 \\
\hline Low-density & $>1500$ & 7 & 788 & 630 & 315 & 10 & 1.4 \\
\hline
\end{tabular}

N.B. The differences in water consumption are due to different uses such as garden irrigation, car wash, etc, which are not likely to be major factors in high-density residential areas.

Table 5.2: Wastewater generation and nutrient load estimation in Harare for the year 2002 (Source: JICA, 1996, Nhapi et al., 2002c; CSO, 2002)

\begin{tabular}{l|rrrr}
\hline Landuse & Population & Flow, $\mathrm{m}^{3} / \mathrm{d}$ & $\mathrm{TN}, \mathrm{kg} / \mathrm{d}$ & $\mathrm{TP}, \mathrm{kg} / \mathrm{d}$ \\
\hline Residential Areas & & & & \\
Low-density unsewered & 76.000 & 2,394 & 745 & 106 \\
Low-density sewered & 137,000 & 4,3155 & 1,336 & 191 \\
Medium-density & 164,000 & 30,783 & 1,476 & 213 \\
High-density & $1,485,000$ & 93,555 & 12,251 & 1,782 \\
& & & & \\
Commercial* Areas & & 61,629 & 1,389 & 151 \\
Industrial Areas & & 50,594 & 338 & 105 \\
Total & $1,862,000$ & 303,656 & 17,534 & 2,550 \\
\hline
\end{tabular}

* "Commercial" includes shops, wholesalers, warehouses, schools, hospitals and other institutional areas. 
As the data presented in Tables $\mathbf{5 . 1}$ and 5.2 are from unpublished reports, a check was done to compare estimated versus measured values. The data for the smaller wastewater treatment plants of Donnybrook, Hatcliffe and Marlborough were obtained from a regular water qualitymonitoring program of the City of Harare. The other data were measured in the present study. The nitrogen and phosphorus concentrations for June 2000 to December 2001 are shown in Fig 5.2a. The higher concentrations for Donnybrook and Hatcliffe reflect concentrated influents from high-density areas where water consumption is low (Table 5.1). The estimated nutrient and flow data correlated reasonably well with measured data. Estimates differed from measured influent values for the five wastewater treatment works by $+1 \%$ for flow, $-5 \%$ for $\mathrm{TN}$, and by $+15 \%$ for TP, and are considered to be within reasonable error margins. The TP estimates were particularly difficult for the Crowborough and Firle wastewater treatment works because almost all the industries in Harare are situated in their catchments. The discharge patterns of phosphorus from these industries are difficult to characterise. The over-estimation of nitrogen for the same two plants could be explained by the possibility of $\mathrm{N}$-losses via transformations (especially denitrification) in the long sewer lines.

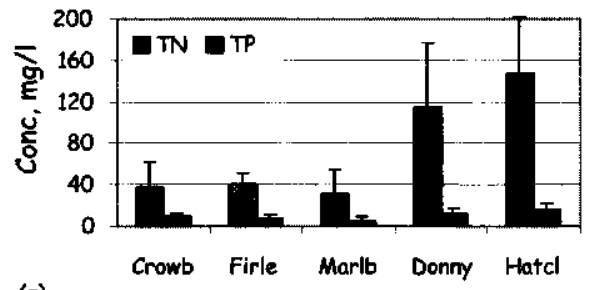

(a)

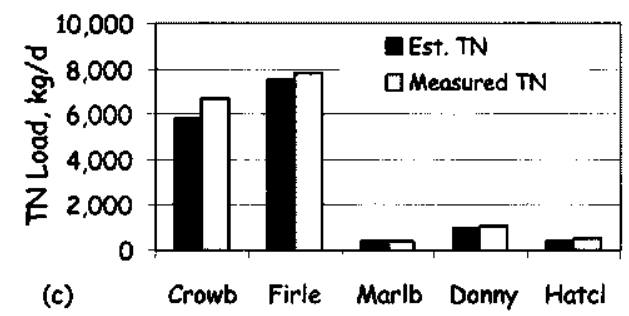

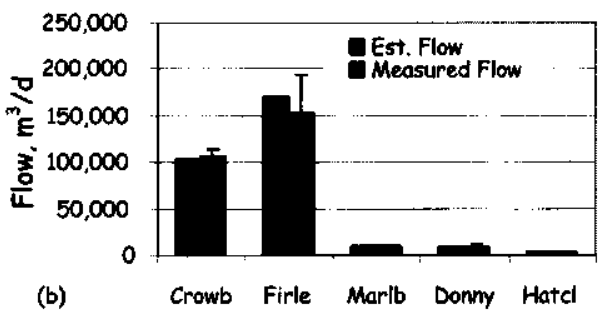

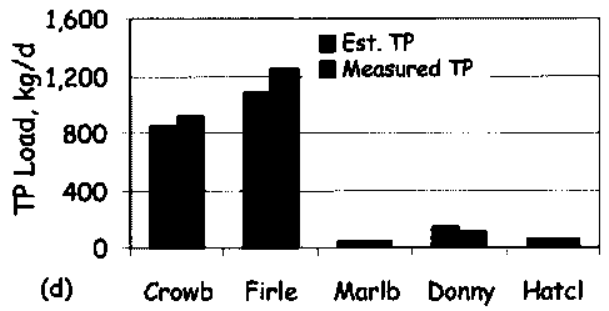

Figure 5.2: Results of the comparison between estimated and measured values of nutrients and flows at the five wastewater treatment works in Harare: (a) measured nutrient concentrations ( \pm standard deviation),(b) estimated (Est.) and measured flows, (c) TN load, and (d) TP load.

(Marlb = Mariborough STWs; Donny = Donnybrook STWs; Hatc $=$ Hatcliffe STWs)

Household water uses. Table 5.3 was developed from various sources and assumptions as given in the remarks column. The major domestic water uses considered are from washing 
(bath or shower), toilet flushing, laundry, kitchen, gardening and other (car washing, house cleaning, etc.). The per capita household water consumption in Harare is very high for medium and low-density residential areas when compared to international figures (Metcalf and Eddy, 1991; Steen and Gijzen, 2003). A culture of water conservation in the city is lacking whilst large garden areas account for a substantial portion of water consumption for irrigation.

Table 5.3: Sources of domestic wastewater for other studies and estimates for Harare

\begin{tabular}{|c|c|c|c|c|c|c|}
\hline \multirow[t]{3}{*}{ Usage } & \multirow{2}{*}{\multicolumn{2}{|c|}{$\begin{array}{l}\text { Typical } \\
\text { figures* }\end{array}$}} & \multicolumn{3}{|c|}{ Local estimates, Harare } & \multirow{3}{*}{ Remarks } \\
\hline & & & High & Med & Low & \\
\hline & //cap.d & $\%$ & /cap.d & I/cap.d & l/cap.d & \\
\hline Bath & 51 & 32 & 25 & 90 & 100 & $\begin{array}{l}\text { High-density residents use shower or bucket }(201) \text {. } \\
\text { Low and medium-density residents use geysers, } \\
\text { common size } 90-100 \text { litres and tubs; assuming } \\
\text { geyser almost emptied each time. }\end{array}$ \\
\hline wC & 54 & 34 & 24 & 80 & 80 & $\begin{array}{l}\text { High-density figure derived from Hoko (1999). For } \\
\text { low and medium-density a cistern capacity of } 20 \\
\text { litres and } 2 \text { urine and } 2 \text { faeces flushing per day } \\
\text { assumed }\end{array}$ \\
\hline Laundry & 25 & 16 & 5 & 16 & 52 & $\begin{array}{l}60 \text { litres per week per stand for high-density, } 180 \\
\text { and } 360 \text { litres per week per stand for medium and } \\
\text { low-density. Estimates based on Bulawayo City } \\
\text { Council water use surveys of } 2002\end{array}$ \\
\hline Kitchen & ** & $\star \star$ & 5 & 11 & 22 & $\begin{array}{l}\text { Based on dish-washing, food preparation, and hand } \\
\text { washing, } 3 \text { times per day: } 60 \text { litres/day for high, } 120 \\
\text { and } 150 \text { litres/day for medium and low-density areas }\end{array}$ \\
\hline Other & 28 & 18 & 4 & 13 & 61 & $\begin{array}{l}\text { Calculated as balance to achieve the total observed } \\
\text { figure. This figure includes water for gardening and } \\
\text { internal leaks. }\end{array}$ \\
\hline Total & 158 & 100 & 63 & 210 & 315 & Local figures from JICA (1996) \\
\hline Gre & vater l/ca & & 35 & 117 & 174 & \\
\hline & ywater \% & & 56 & 56 & 55 & \\
\hline
\end{tabular}

" Source: Metcalf and Eddy, 1991

** No figures given, amount assumed to be incorporated in 'other' uses

Areas suitable for onsite systems The application of the onsite option to wastewater management has limitations in Harare as it poses a number of problems in some areas. Firstly, high-density stands average only about $300 \mathrm{~m}^{2}$ with close to $70 \%$ of this area taken up by buildings. Secondly, the population density is high at about 13 persons/stand or 360 persons/hectare, reducing options for locally reusing the effluent (and nutrients) since gardening space is very small (Table 5.4). A higher number of people per stand takes more building 
space, whilst the wastewater volume and area required for a treatment facility increases. The current design of commercial stands averaging about $200 \mathrm{~m}^{2}$ with buildings taking up almost all the stand area makes it impossible to treat wastewater onsite if all water and nutrient components of wastewater have to be reused within the stand boundary. Table 5.4 shows that this can be achieved for low-density stands, some medium-density stands with areas $>1,000$ $\mathrm{m}^{2}$, and the majority of industrial stands, depending on specific activities and stand size. For medium and low-density areas, there is actually an opportunity for making money from utilising effluents as compared to paying municipal sewerage fees.

For some industries, systems for onsite suspended solids and BOD removal should be feasible when using high rate systems. However, onsite nitrogen and phosphorus reuse would be difficult, although specific solutions could be used depending on industrial processes. As an example, a brewery could send spent grains to farmers for cattle feeding, waste could be traded between industries, low water quality could be used for less sensitive tasks, etc. An extension of this approach could be used for high-density domestic waste using a two-stage treatment system (onsite + offsite). Onsite secondary treatment plus offsite reuse options should be possible and could significantly contribute to filtering out nutrients from effluents that currently trickle into Lake Chivero. As an example, a small onsite upflow anaerobic sludge blanket (UASB) reactor or a simple septic tank system could be used to enhance TSS and COD removal, followed by offsite sludge treatment and effluent reuse in urban agriculture, or irrigating open spaces.

The application of the measures described above would mean that about $118,000 \mathrm{~m}^{3} / \mathrm{d}(39 \%)$ of wastewater, $2,400 \mathrm{~kg} / \mathrm{d}(14 \%)$ of TN, and $400 \mathrm{~kg} / \mathrm{d}(16 \%)$ of TP generated in Harare would be practically handled onsite. These figures assume that all industrial effluents can be treated onsite. This will not be entirely the case (stand sizes and processes differ) and therefore the above statement slightly overstates the potential of the onsite strategy. In terms of residential areas, it is estimated that $11 \%$ of the population in Harare could potentially be served by onsite systems, inclusive of the $4 \%$ who are already using onsite systems (Table 5.2).

\section{Options for onsite treatment and reuse of wastewater}

An ideal onsite wastewater management scheme for residential areas, based on the 3-Step Strategic Approach (emphasising on pollution prevention/reduction, and treatment plus reuse), is shown in Fig 5.3. A major factor in this scheme is the control of waste volume and pollution loads at household level. This would reduce the amount of wastewater generated and treated (and the size of the treatment unit), and the produced effluent would be suitable for effective methods of treatment like anaerobic systems (Gijzen, 2001). In this scheme, black/greywater 
and urine/faeces separation systems are feasible with the other option being combined treatment of all wastewater streams but aimed at reuse close to the source of generation. Source separation is advantageous because it requires little or no water usage in the toilet. It also enhances opportunities for localised direct reuse of waste components (urine, greywater) and a host of technologies are available for this (Lindstrom, 1998; Jeppsson et al., 2002). Greywater comes from laundry, bath, and kitchen, and can be easily collected from waste down-pipes before they discharge into a gully trap. It constitutes about $55 \%$ of household wastewater in Harare (Table 5.3). In most cases, greywater could be directly reused for gardening, or it could undergo basic treatment and be used for toilet flushing and car washing.

Table 5.4: Values of water and nutrients from wastewater in Harare, based on irrigating a maize crop (staple food in Zimbabwe)

\begin{tabular}{|c|c|c|c|c|}
\hline \multirow[b]{3}{*}{ Value of wastewater } & \multirow[t]{3}{*}{ Unit } & \multicolumn{3}{|c|}{ Housing Density Category } \\
\hline & & \multirow[t]{2}{*}{ High } & \multirow[t]{2}{*}{ Medium } & \multirow[t]{2}{*}{ Low } \\
\hline & & & & \\
\hline Wastewater production & /cap.d & 63 & 210 & 315 \\
\hline Greywater, \% & $\%$ & 56 & 56 & 42 \\
\hline $\mathrm{N}$ production & g/cap.d & 8.3 & 9 & 9.8 \\
\hline P production & g/cap.d & 1.2 & 1.3 & 1.4 \\
\hline \# of people per stand & H'stand & 13 & 11 & 7 \\
\hline \multicolumn{5}{|l|}{ Irrigation area per household to utilise all water or nutrients, $3 \mathrm{crops} / \mathrm{yr}^{*}$} \\
\hline Area for cultivation based on Wastewater & $m^{2}$ & 125 & 352 & 336 \\
\hline Area for cultivation based on $\mathrm{N}^{* *}$ & $m^{2}$ & 750 & 688 & 477 \\
\hline Area for cultivation based on $\mathrm{P}^{\text {** }}$ & $m^{2}$ & 633 & 580 & 397 \\
\hline Typical house plinth area & $m^{2}$ & 100 & 150 & 250 \\
\hline Add $20 \%$ for other uses besides gardening & $m^{2}$ & 20 & 30 & 50 \\
\hline \multicolumn{5}{|l|}{ Total stand area requirements based on: } \\
\hline Water; total sewage & $m^{2}$ & 245 & 532 & 636 \\
\hline Water, greywater only & $m^{2}$ & 136 & 296 & 268 \\
\hline Nitrogen & $m^{2}$ & 870 & 868 & 777 \\
\hline Phosphorus & $m^{2}$ & 753 & 760 & 697 \\
\hline Actual average stand area for each housing category & $m^{2}$ & 300 & 1000 & 2000 \\
\hline \multicolumn{5}{|l|}{ Financial potential (maize at US\$158/tonne) } \\
\hline Amount of maize potentially cultivated at 7 tonnes/ha, 3 crops/yr & tonnes & & 1.82 & 1.63 \\
\hline Amount of money potentially realised per household @US\$158/tonne & US\$ & & 288 & 258 \\
\hline Wastewater fee currently paid to council per household per annum & US\$ & & 12 & 15 \\
\hline
\end{tabular}




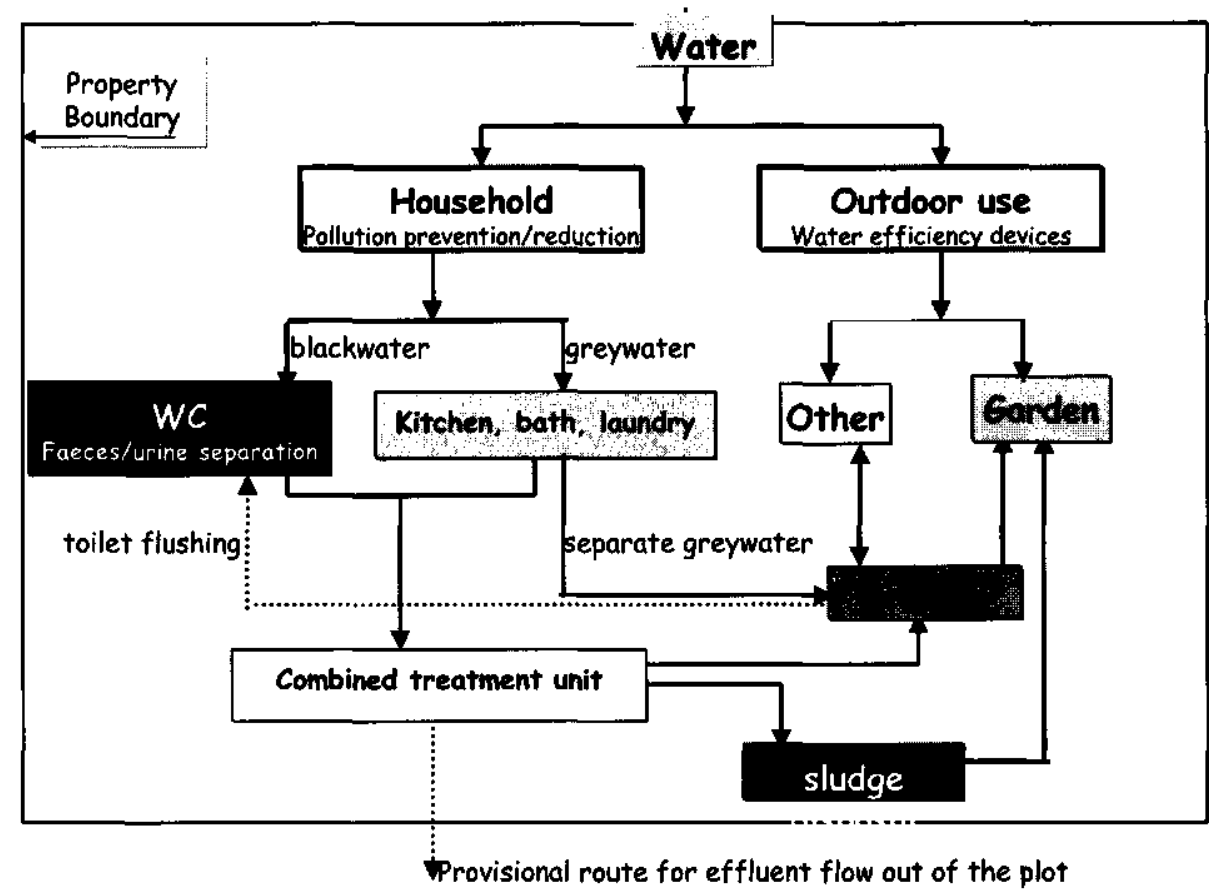

Figure 5.3: An illustration of various ways of managing wastewater onsite with possibilities for direct reuse and reuse after some treatment.

In Fig 5.3, waste from the toilet could be treated separately using anaerobic systems, drying beds, or co-composting with solid waste (Strauss, 1996). The same methods could be used for faeces only. Composting toilets are already in use in other parts of the world and also in periurban areas of Harare (Proudfoot, 2002). After stabilisation, the sludge can be applied as manure in gardening. Another option is to treat greywater and toilet waste (blackwater) together using septic tanks as is currently happening in some low-density areas of Harare. Greywater could also be reused directly for watering gardens. However, there are some potential threats to onsite reuse, e.g., growth impacting components encountered in food, medicine, etc. Hormones and other enzymatic stuff are threats to smaller recycling loops. The control of the discharge of these is crucial to making reuse safe.

\section{Strategy options and impacts}

Source control by users. The amount of wastewater produced in low and medium-density residential areas needs to be reduced through a combination of water-saving devices, heavy tariffs for high water consumption, water rationing, and user-education. The possible reductions and methods to achieve this objective are given in Table 5.5. Reducing wastewater production 
to $135 \mathrm{l} / \mathrm{cap} . \mathrm{d}$ for medium-density and to $150 \mathrm{l} /$ cap.d for low-density residential areas will result in $44,000 \mathrm{~m}^{3} / \mathrm{d}(23 \%)$ reduction in the domestic wastewater load. In terms of financial implications, the reductions in water use will result in annual savings US\$150/household for medium-density and US $\$ 210 /$ householdr for low-density residents.

Table 5.5: Modified wastewater production scheme for medium and low-density residential areas of Harare

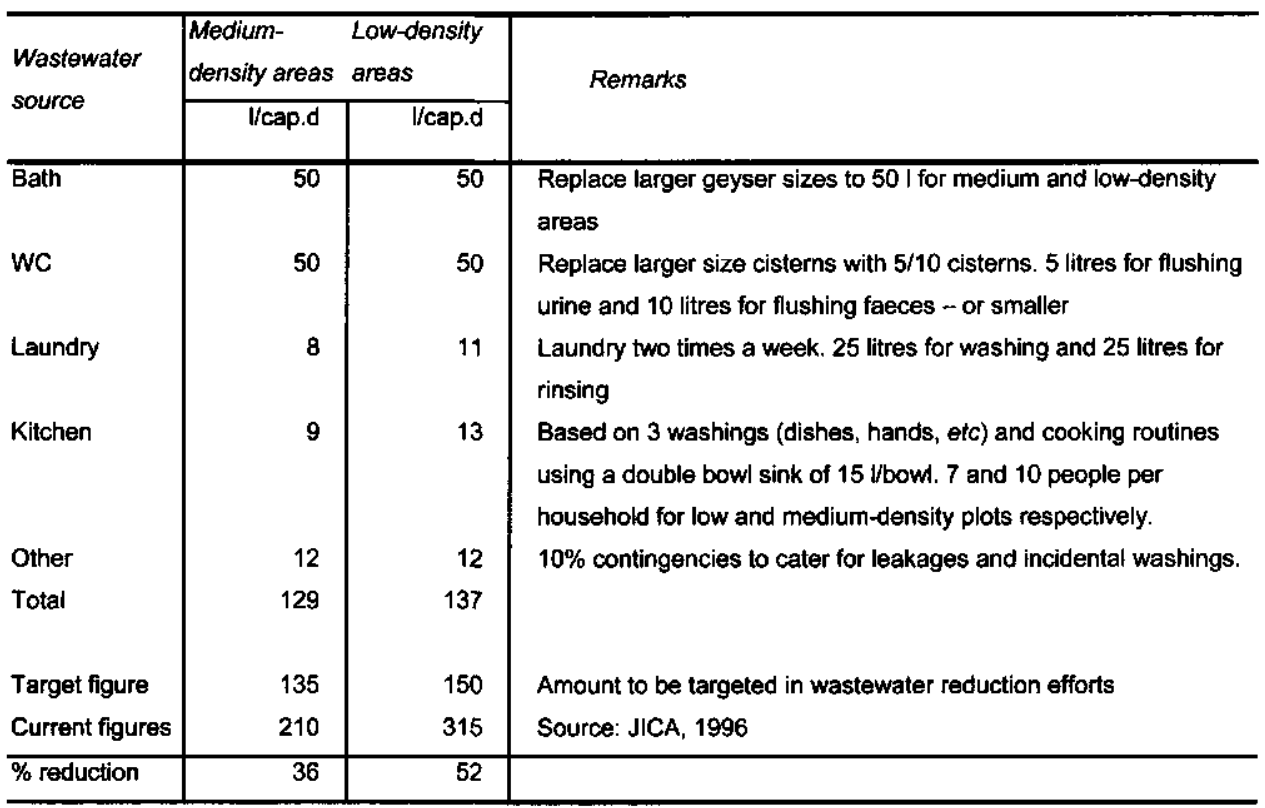

Table 5.5 suggests that a reduction in wastewater production is feasible without heavily compromising present comfort, convenience, and quality of life. The high wastewater volumes produced in medium and low-density areas are a direct result of installed systems in homes. For example, geysers in most affluent homes are as large as $200 \mathrm{I}$ and there is a tendency to empty the geyser each time a person takes a bath. A 50-litre geyser will still be adequate. Most of the toilet cisterns being sold in Zimbabwe have capacities of around $20 \mathrm{I}$ with no provision for separately controlling flushing volumes for urine and faeces, but the flushing of these two have different water demands. A $3 / 6$ cistern is used in Australia and other countries (Chaplin, 1998), with the $3 \mathrm{I}$ button used for flushing urine and the $6 \mathrm{I}$ for flushing faeces. Because of different development densities, a 5/10 cistern will still do for Zimbabwe and would realise substantial savings. There is a tendency for housemaids to do laundry everyday and this can be conveniently reduced to two times per week so that water usage is reduced. Double bowl sinks with volumes of $15 \mathrm{I}$ each can replace washing under a running tap in kitchens. 
Applying the above-mentioned changes and adding a $10 \%$ contingency level for leaks and other incidental washings shows that it would be feasible to reduce wastewater production from the current 210 l/cap.d to about 135 l/cap.d (a 36\% reduction) for medium-density residential areas. For low-density, the reduction would be from $315 \mathrm{l} /$ cap.d to $150 \mathrm{l} / \mathrm{cap}$.d, implying a $52 \%$ reduction in wastewater production. It is therefore concluded that source reduction of wastewater in Harare is technically feasible. Some of the measures described here for households could also be applied for commerce and industry. In addition to customer-based efficiency measures, utility-based measures available to water and wastewater system managers are many and offer important saving opportunities. These include leak detection and repair in water mains and lines, conservation pricing structures, watershed management activities to reduce storage losses, and water reclamation.

Greywater reuse potential. The greywater portion of wastewater is shown in Table 5.3 on a per capita basis. An assessment of greywater reuse potential was only done for residential areas, with population figures taken from Table 5.2. There are no published figures on greywater quality in Zimbabwe. However, literature shows that greywater contains about $10 \%$ of nitrogen and $50-70 \%$ of phosphorus contained in household wastewater (domestic sewage) (Larsen and Gujer, 1996; Hanæus et al., 1997). As shown in Table 5.2 about $304,000 \mathrm{~m}^{3} / \mathrm{d}$ of wastewater, $17,500 \mathrm{~kg} / \mathrm{d}$ of nitrogen and $2,600 \mathrm{~kg} / \mathrm{d}$ of phosphorus are produced and treated at five wastewater treatment plants in Harare. Of this, the daily domestic wastewater production amounts to about $191,000 \mathrm{~m}^{3} / \mathrm{d}$, containing $15,800 \mathrm{~kg}$ of TN and $2,300 \mathrm{~kg}$ of TP. Table 5.3 shows that greywater production is approximately $35 \mathrm{l} /$ cap.d for high-density areas, $117 \mathrm{l} / \mathrm{cap} . \mathrm{d}$ for medium-density, and 174 l/cap.d for low-density residential areas in Harare. Using population figures in Table 5.2, greywater in Harare amounts to about $107,000 \mathrm{~m}^{3} / \mathrm{d}$, or $56 \%$ of the total domestic wastewater generated. Assuming greywater contains $10 \%$ of $\mathrm{TN}$ and $50 \%$ of TP in domestic wastewater, greywater reuse for all domestic wastewater in Harare would reduce the export of $35 \%$ of total flow $\left(304,000 \mathrm{~m}^{3} / \mathrm{d}\right), 9 \%$ of TN, and $45 \%$ of TP based on all landuse categories. If greywater separation would be applied only for low-density residential areas, it would reduce the export of $12 \%$ of total flow, $1 \%$ of TN, and $6 \%$ of TP currently discharged from all landuse categories. The reuse of greywater, after applying water conservation measures, would result in cost savings on water bills of US $\$ 80-150$ per household per year.

Urine separation. There are no published Zimbabwean figures on nutrient concentrations in human urine. In other countries, urine is estimated to contribute about $80 \%$ to the nitrogen and $30-50 \%$ to the phosphorous found in ordinary household wastewater although it only forms 
$1 \%$ of the volume (Jönsson et al., 1998; DLG, 1998; Larsen and Udert, 1999). These literature values were adopted for calculations but it is noted that the composition could differ somewhat in practice depending on diets. The results revealed that urine potentially contributes 12,600 $\mathrm{kg} / \mathrm{d} \mathrm{TN}$, and $690 \mathrm{~kg} / \mathrm{d}$ TP to the total domestic nutrient load. For all landuse categories in Harare, urine separation would reduce the export of nutrients by $72 \%$ for TN, and $27 \%$ for TP. When applied for low-density residential areas only, urine separation would reduce the export of $9 \%$ of TN and $4 \%$ of TP from sources of generation. Urine separation is therefore more attractive compared to greywater reuse. The storage and use of urine is discussed by Larsen and Gujer (1996), Jönsson et al. (1998), Lindstrom (1998), Jeppsson et al. (2002), and includes storing it in tight containers and using it for orchard and garden irrigation. Retrofitting toilets for urine separation would cost about US $\$ 1,000$ as capital investments whilst annual water savings from flushing needs will be \pm US $\$ 80 /$ household.

Other onsite options. In Zimbabwe, there are other treatment methods in which expertise is still growing. These include composting toilets used in two peri-urban areas of Harare, constructed wetlands used for some small housing estates and large industrial complexes, and septic tanks in most low-density residential areas (Taylor and Mudege, 1997; Proudfoot, 2002). Upflow anaerobic sludge blanket (UASB) and small versions of activated sludge systems are also being used in industries. However, no water quality data of these plants are available to assess their performances. There is, however, new legislation that compels owners of such systems to periodically supply water quality data to the local environmental monitoring agency (Government of Zimbabwe, S.I. 274 of 2000).

There is also scope for hybrid systems such as septic tank (onsite) plus septage treatment and reuse (centralised), and simple UASB with biogas recovery onsite plus decentralised effluent management and reuse. It is also feasible to have combinations where part of the treatment is onsite and the further treatment and reuse (mostly of sludge) is centralised or decentralised. This would enormously amplify the efficiency of filtering out nutrients. Banning phosphorus detergents is also a viable option, resulting in $130 \mathrm{~kg} / \mathrm{d}(6 \%)$ reduction in the domestic phosphorus load.

Extrapolations to the future. The potential benefits of a re-organised wastewater collection and treatment system in Harare for the year 2015 are summarised in Table 5.6. All low-density sewered dwellings have been replaced with onsite systems. In developing this table, water consumption has been reduced via water saving measures like low-flush toilets, low-water showerheads and faucets, and also greywater reuse and rainwater harvesting. From this, total wastewater production could be reduced from $492,000 \mathrm{~m}^{3} / \mathrm{d}$ to $361,000 \mathrm{~m}^{3} / \mathrm{d}$ (a $26 \%$ saving). 
The savings on TN and TP will be $54 \%$ and $42 \%$ respectively, resulting in less loads being treated at wastewater treatment plants. As a result, a large investment in the construction of new treatment facilities could be postponed for up to 10 years. However, quite an investment is also needed to convert the present systems into low resources using systems. Table 5.6 was developed from population projections from JICA (1996). The phosphorus load has been reduced via banning of the use of P-detergents, treatment of all wastewater from low-density areas within the stand boundary, and greywater separation with local reuse. The substantial reduction in the nitrogen load is due mainly to urine separation and, to a lesser extent, greywater separation.

Table 5.6: Results of flow and nutrients projected to be received at offsite wastewater treatment plants in Harare for the year 2015 after selected interventions (2015 population, development data from JICA (1996))

\begin{tabular}{|c|c|c|c|c|c|c|}
\hline & \multicolumn{3}{|c|}{$\begin{array}{l}\text { Projections to } 2015 \text { without interventions } \\
\text { (business-as-usual) }\end{array}$} & \multicolumn{3}{|c|}{ Projections to 2015 with interventions } \\
\hline & Flow, $m^{3 / d}$ & $\mathrm{TN}, \mathrm{kg} / \mathrm{d}$ & $\mathrm{TP}, \mathrm{kg} / \mathrm{d}$ & Flow, $\mathrm{m}^{3 / d}$ & $\mathrm{TN}, \mathrm{kg} / \mathrm{d}$ & $\mathrm{TP}, \mathrm{kg} / \mathrm{d}$ \\
\hline Domestic & 285,720 & 34,323 & 3,739 & 199,977 & $6,490^{*}$ & 2,123 \\
\hline Industrial & 115,769 & 4,056 & 1,261 & 86,827 & 4,056 & 757 \\
\hline Commercial & 61,629 & 13,111 & 1,429 & 46,222 & 13,111 & 857 \\
\hline Groundwater & 28,450 & & & 28,450 & & \\
\hline Total & 491,568 & 51,490 & 6,429 & $361,476^{* *}$ & 23,657 & 3,737 \\
\hline \multicolumn{4}{|c|}{ \% savings realised in year 2015} & 26 & 54 & 42 \\
\hline
\end{tabular}

* The substantial reduction in domestic $\mathrm{N}$ discharge $(81 \%)$ is due to urine separation at all residential properties and the treatment of all wastewater from low-density areas at onsite level.

* Domestic flow reductions achieved by measures outlined in Table 5.5. Those for commercial and industrial areas achieved by water rationing first followed by using flow reduction devices plus a number of other cleaner production approaches.

\section{Conclusions}

1. Based on the current situation, up to $39 \%$ of the wastewater produced in Harare could potentially be managed onsite.

2. Greywater and urine separation appear attractive options in an onsite wastewater treatment strategy for Harare.

3. The onsite strategy shows that savings of $27 \%$ on flows, $54 \%$ on TN, and $42 \%$ on TP could be realised on loads that would otherwise be received at wastewater treatment plants in Harare in the year 2015. 


\section{References}

Del Porto, D. Zero Effluent-discharge Systems Prevent Pollution: Conserving, Separating and Using up Effluents on Site, paper presented at the International Ecological Engineering Society Conference, June 6, As, Norway, 1999. Internet Site: uww.ecological_engineering.com/zeroD.html.

Davidavicius E.S. and Ramoškiene, (1996) Eco-Policy and Market, in Staudemann, J, Schonborn, A and Etnier, C (Eds.) Recycling the Resource - Ecological Engineering for Wastewater Treatment, Transtec Publications Ltd, Switzerland, 1996.

Department of Works, Harare Sewerage Masterplan, Phase 2 Report, prepared by Safege Ingénieurs Conseils for the Department of Works, City of Harare, Zimbabwe, 2001.

Chaplin, S. Water Efficiency: The Next Generation, Draft Report 5-9, Rocky Mountain Institute, Colorado, USA, 1998. Intemet Site: http://www.rmi.org/sitepages.

CSO (Central Statistical Office) Census 2002: Zimbabwe, Preliminary Report, Central Census Office, Government of Zimbabwe, Harare, Zimbabwe, 2002.

Department of Water Development, Assessment of Surface Water Resources in the Manyame Catchment - Zimbabwe; Streamflow Gauging and Conceptual Hydrological Modelling, SMHI Hydrology No. 60, 1995.

Gijzen, H.J. Anaerobes, Aerobes and Phototrophs - A Winning Team for Wastewater Management, IWA Wat. Sci: Tech. Vol. 44(8), p121-132, 2001.

Government of Zimbabwe, Statutory instrument (S.I.) 274 of 2000, Water (Waste and Effluent Disposal) Regulations, Government Publications, Harare, 2000.

Gumbo B. and H.H.G. Savenije, Inventory of Phosphorus Fluxes and Stocks in an Urban-shed: Options for Local Nutrient Recycling, paper presented at the $1^{\text {st }}$ International Conference on Ecological Sanitation held on 5-8 November 2001, Nanning, China. Extended abstract at http/twww.wisechina.com/english/e39.htm.

Hanæus, J., D. Helistrom, and E. Johansson, A study of a Urine Separation System in an Ecological Village in Northern Sweden, Wat. Sci. Tech., 35(9), 153-160, 1997.

Hoko, Z., Innovative Sanitation for Harare, Zimbabwe (Case Study Mufakose Suburb), IHE MSc. Thesis, IHE Delft, Delft, The Netherlands, 1999.

Jeppsson, U., D. Hellström, C. Gruveberger, A. Baky, L. Maimem, O. Palm, I.T. Paimquest, and B. Rydhagen, Framework for Analysis of Treatment Systems for Source-separated Wastewater and Organic Household Waste, paper presented at the $3^{\text {rd }}$ IWA World Water Congress, Melbourne, Australia, 7 - 12 April March, 2002.

JICA Report, The Study of Water Pollution Control in Upper Manyame River Basin in the Republic of Zimbabwe, Nippon Jogeduido Sekkei Co. Ltd., Nippon Koei Co. Ltd, Japan, 1996.

Jönsson, H., Dalemo, M., Sonesson, V. and Vinneràs, B. Modelling the Sewage System - Evaluating Urine Separation as a Complimentary Function to the Conventional Sewage System, Paper presented at "Systems Engineering Models for Waste Management" International Workshop in Göteburg, Sweden, 25 - 26 February 1998. 
Kamudyariwa, C., Seasonal Variation of Water Quality with respect to Anthropogenic Activities Along Mukuvisi River, Harare, Zimbabwe, MSc Thesis, IHE Delft, Delft, The Netherlands, 2000.

King, N. New Strategies for Environmental Sanitation, in Water21, Magazine of the International Water Association, April 2000, London, UK, p11-12, 2000.

Larsen, T.A. and W. Gujer, Separate Management of Anthropogenic Nutrient Solutions (human urine), Wat. Sci. Tech., 34, 87-94, 1996.

Larsen, T.A. and K.M. Udert, Urine Separation - A way of Closing the Nutrient Cycles, 1999, Internet site: http:/www.blackwell.de/journale/wabo/9911inhalt.html.

Lindstrom, C.R., Greywater, Cambridge, 1998, Internet site: http://greywater.com.

Magadza C.H.D., Water Pollution and Catchment Management in Lake Chivero, in Lake Chivero: A Polluted Lake, edited by Moyo, N.A.G. University of Zimbabwe Publications, Harare, Zimbabwe, 1997.

Manjonjo, M. Land Disposal of Sludge and Pond Effluent on Crowborough Farm: Its Efficiency and influence on Marimba River, MSc WREM Thesis, University of Zimbabwe, Harare, Zimbabwe, 1999. Marks, R.F. Appropriate Sanitation Options for Southern Africa, IWA Wat. Sci. Tech., Vol. 27(1), 1993. Mawere, M., Land Application of Sewage, The Role of Crowborough Pasture Irrigation in the Reduction of Nutrient Loads to Marimba River. MSc. Thesis, IHE Delft, Delft, The Netherlands, 2001.

Metcalf \& Eddy, Wastewater Engineering: Treatment, Disposal \& Reuse, McGraw - Hill, Inc, Singapore, 1991.

Moyo, N.A.G., (editor) Lake Chivero: A Polluted Lake, University of Zimbabwe Publications, Harare, Zimbabwe, 1997.

Moyo, N.A.G. and S. Mtetwa, Water Pollution Control, paper presented at an IUCN Seminar on Water Resources Management in Southern Africa: Enhancing Environmental Sustainability, Harare, October 1999 .

Nhapi, I. and H.J. Gijzen, The 3-step Strategic Approach to Sustainable Wastewater Management, paper submitted to the Journal of the Chartered Institute of Water and Environmental Management, July 2003.

Nhapi, I., M.A. Siebel, and H.J. Gijzen, Dry Season Inflow and Export of Nutrients from Lake Chivero; Proceedings of the Zimbabwe Institution of Engineers, Vol. 2(1), 33-41, 2001.

Nhapi, I., Siebel, M. and Gijzen, H.J. Options for the Decentralised Management of Wastewater in Harare Zimbabwe, in Proceedings of the IWA Conference on Water and Wastewater Perspectives of Developing Countries, New Delhi, India, 11 - 13 December, 2002, p955 - 964, 2002(a).

Nhapi, I., Siebel, M. and Gijzen, H.J. A Strategic Framework for Managing Wastewater: A Case Study of Harare, Zimbabwe, paper submitted to Water International, journal of the International Water Resources Management, 2002(b).

Nhapi, I., Siebel, M.A. and Gijzen, H.J. An inventory of the existing water management practices in Harare, Zimbabwe, paper prepared for publication in the Urban Water joumal, 2002(c).

Nhapi, I., Siebel, M. and Gijzen, H.J. The Impact of Urbanisation on the Water Quality of Lake Chivero, Zimbabwe, Joumal of the Chartered Institute of Water and Environmental Management, Vol. 18(1), p44-49, 2004. 
Nhapi, I., Siebel, M. and Gijzen, H.J. Centralised Management of Wastewater in Harare, Zimbabwe: Current Practice and Future Options, paper submitted to IWA Water Research Journal, Dec. 2003.

Nhapi, I. and Tirivarombo, S. Sewage Discharges and Nutrient Levels in Marimba River WaterSA, Vol. 30(1), p107-113, 2004.

Nyamangara, J. and J. Mzezewa, The Effect of Long-term Sewage Sludge Application on $\mathrm{Zn}, \mathrm{Cu}, \mathrm{Ni}$ and $\mathrm{Pb}$ levels in a Clay Loam Soil under Pasture Grass in Zimbabwe, Agriculture, Ecosystems and Environment Vol. 73, p199-204, 1999

Proudfoot, D., Mguni, G., and Bhingu, D. Pathogen Destruction Study, Proceedings of the $3^{\text {rd }}$ WaterNetWARFSA Symposium in Dar Es Salaam, Tanzania, October $30-31,2002$, p505 - 518, 2002.

Standard Methods for the Examination of Water and Wastewater, 19th edition. American Public Health Association/American Water Works Association/Water Environment Federation, Washington DC, USA, 1995.

Strauss, M., Treatment of Sludges from Non-Sewered Sanitation Systems. Proceedings, of the International Workshop on Sustainable Municipal Wastewater Treatment Systems, Leusden NL, 12 14 November, 1996.

Taylor, P. and N.R. Mudege, Unban Sanitation in Zimbabwe and the Relation to Environmental Pollution, institute of Water and Sanitation Development, Harare, Zimbabwe, 1997. 


\section{Chapter 6}

\section{Options for the Decentralised Management of Wastewater in Harare, Zimbabwe}

Parts of this Chapter have been published as:

Nhapi, I., Siebel, M. and Gijzen, H.J. (2002) Options for the Decentralised Management of Wastewater in Harare Zimbabwe, in Proceedings of the IWA Conference on Water and Wastewater Perspectives of Developing Countries, New Delhi, India, 11 - 13 December, 2002, p955- 964 .

Nhapi, I., Dalu, J., Ndamba, J., Siebel, M.A. and Gijzen, H.J. (2002) An Evaluation of Duckweed-based Pond Systems as an Altemative Option for Decentralised Treatment and Reuse of Wastewater in Zimbabwe, IWA Wat. Sci. Tech. Vol. 48(2), p323-330. 


\title{
Options for the Decentralised Management of Wastewater in Harare, Zimbabwe
}

\begin{abstract}
This Chapter is based on a study conducted in Harare, the capital city of Zimbabwe, focusing on options for the decentralised management of wastewater. The city of Harare is currently facing pollution problems related to wastewater discharges into Lake Chivero. The lake is its major source of potable water. Previous studies have shown that nitrogen and phosphorous levels in the lake are increasing rapidly. The decentralised management of wastewater could provide a possible solution. This study focused on 1) the quantification of wastewater that could be handled at a decentralised level, 2) the formulation of a decentralised treatment strategy, and 3) assessing its potential impacts. Case studies of typical decentralised wastewater management using algae and duckweed-based pond systems are presented. The decentralised concept was found suitable for high and medium-density residential areas. For the year 2015 , wastewater generation could be reduced by $24 \%$ whilst the phosphorus load could be reduced by $5 \%$ through pollution prevention/reduction measures at source. After these measures, Harare would produce about $366,000 \mathrm{~m}^{3} / \mathrm{d}$ wastewater, containing $39,000 \mathrm{~kg} / \mathrm{d}$ of nitrogen and $4,000 \mathrm{~kg} / \mathrm{d}$ of phosphorus. If decentralised systems are fully adopted by this time, they would potentially handle about $55 \%$ of the hydraulic load, $84 \%$ of nitrogen and $80 \%$ of the phosphorus load. Through waste reduction/prevention measures at source and decentralised wastewater treatment, Harare would therefore greatly reduce wastewater treatment plant effluent discharges to Lake Chivero. It was concluded that a decentralised wastewater management strategy, utilising low-cost wastewater treatment methods, could be an effective component of an overall sustainable (waste-)water management plan for Harare.
\end{abstract}

Keywords: decentralised treatment, Lake Chivero, nutrients, strategic approach, wastewater reuse, water management

\section{Introduction}

The sustainable management of wastewater in developing countries is a major challenge in this century. Wastewater treatment plants tend to close soon after commissioning, health problems are enormous, and institutions to deal with this are too weak for the task (Rogers, 1993; Gunnerson and French, 1996; Marino and Boland, 1999; Nhapi and Gijzen, 2002). The prevalence of rural-to-urban migration, the high cost of sanitation provision, and the mushrooming of peri-urban squatter camps results in sanitation demands far outstripping supply (WHO, 2000). Besides cost factors (Kalbermatten ef al., 1982; Newton and Solt, 1994), other 
factors such as urban planning, choice of technology, and treatment objectives (Veenstra et al., 1997) contribute to the problem. In developing countries, frequent outbreaks of diseases due to unsanitary living conditions, poverty and the need to feed large urban populations are central problems. This leads to the question: "How can we plan our cities in such a way that we can feed all people whilst avoiding or at least minimizing environmental impacts?

The above-mentioned problems could be partly solved by rational wastewater management, with emphasis on resource recovery and reuse (water, biogas, and nutrients). However, in spite of the importance of reuse/recycling, etc., the real problem that the world is facing is that large funding agencies have set their minds on the most complex and expensive technologies for wastewater treatment and most of the world supports this, largely because the Westem countries can afford these technologies both financially and technologically. In many developing countries, it appears rational to link wastewater management to the prevalent urban and peri-urban agriculture, thus avoiding the current discharge of untreated or partially treated wastewater into rivers. At the same time, there is a need to address the health problems associated with effluent reuse through sound planning, responsive institutions, and regulations. The degree of treatment could be linked to intended reuse and waste transportation reduced by reusing the wastewater closer to sources of generation. Along these lines, a decentralised concept of wastewater management has been suggested (Venhuizen, 1998). Nhapi et al. (2003a) has looked into the practical implementation of the decentralised concept, and recommended the use of natural wastewater treatment methods for small urbanising areas in Zimbabwe.

The decentralised concept refers to an organizational paradigm for wastewater management that entails treating and beneficially reusing wastewater as close to where it is generated as practical, using technologies appropriate to the scale of the facilities (Venhuizen, 2003). A decentralised system may consist of individual on-site systems and/or cluster systems, either singly or in combination with more highly collectivised facilities. The degree of collectivisation at any stage of the treatment and reuse or dispersal processes will be determined by a variety of local circumstances, including topography, site and soil characteristics, development density, type of development, community desires with regard to landuse issues, and sites of potential reuse and/or sites where discharge would be allowable/beneficial.

This Chapter investigates the applicability and potential impacts of the decentralised concept of wastewater management in Harare, Zimbabwe, in the context of a 3-Step Strategic Approach to wastewater management described by Nhapi and Gijzen (2003). The decentralised concept is a treatment and reuse step in this approach. The study specifically focused on three objectives. The first was to quantity the amount of wastewater (flow, nitrogen, phosphorus) that could be 
feasibly treated and reused at a decentralised level. The second objective was to formulate a decentralised strategy for wastewater management in Harare. The strategy is based on waste minimisation, pollution prevention, direct and indirect reuse of wastewater components, and treatment and reuse within neighbourhoods. The third objective was to predict the overall impact of these intervention measures, separately and integrated, on the water pollution problems in the Lake Chivero catchment. The year 2015 was used for projection of impacts. Locally used treatment methods of duckweed ponds and waste stabilisation ponds were used as case studies.

\section{Materials and methods}

\section{The study area}

The study area is the City of Harare as explained in Nhapi et al. (2002b). Sewered systems in Harare account for over $93 \%$ of the wastewater flows whilst some low-density areas are served by septic tanks (Nhapi et al., 2002b). There are five wastewater treatment plants in Harare and all of them are overloaded. The plants use waste stabilisation ponds (WSP), trickling filters (TF), and modified activated sludge systems, generally called biological nutrient removal (BNR) systems. The trickling filter effluent is mixed with primary and secondary sludge and used for pasture irrigation whilst the rest is discharged into rivers. Residential landuse categories in Harare are classified into high-density (stand size $<500 \mathrm{~m}^{2}$ ), medium-density $\left(500-1,500 \mathrm{~m}^{2}\right.$ ), and low-density residential $\left(>1,500 \mathrm{~m}^{2}\right)$. Urban agriculture is prevalent in Harare (Bowyer-Bower et al., 1994) with most of the open spaces used for maize cultivation in summer. The impact of urban agriculture on the water quality in Lake Chivero (nutrient enrichment) has not been fully studied.

\section{Approach, data collection and analysis}

Wastewater can be managed either onsite, at a decentralised, or centralised level (Nhapi et al., 2003b). The current Chapter only deals with the decentralised strategy and mainly focuses on step 2 of the "3-Step Strategic Approach" (Nhapi and Gijzen, 2003). The three steps are: (1) pollution prevention and minimisation measures at source, (2) treatment and reuse of waste components (water, nutrients, and energy), and (3) disposal with stimulation of natural purification of receiving water bodies. In operational terms, the study assessed wastewater flows, total nitrogen (TN) and total phosphorus (TP) generation in Harare based on literature figures and from a recent water quality monitoring study of the Chivero catchment (Nhapi et al., 2003c). Raw wastewater nitrogen and phosphorus concentrations were monitored monthly using Standard Methods (1995) for Crowborough and Firle wastewater treatment plants (WTPs) in Harare, and Gutu and Nemanwa in Masvingo. For the other three WTPs of Donnybrook, Hatcliffe and Marlborough, data from City of 
Harare were used. The determination of the amount of wastewater that could be feasibly handled at decentralised level was based on population density, volume of wastewater produced, stand sizes, and income levels. The potential impacts of each option were considered based on current and projected influent data from JICA (1996) and City of Harare planning reports. These impacts were considered for the base year 2002 and then projected to the year 2015.

\section{The decentralised concept of wastewater management}

The concept of decentralised wastewater management goes beyond merely managing individual systems, filling in the gap between onsite systems and the conventional centralised systems. It enables wastewater management at the neighbourhood/community level; serving disaggregates of the larger urban areas and thus resulting in small-scale and low-cost facilities directly related to the reuse of valuable components in wastewater. Decentralised treatment systems should be as 'fail safe' as possible, i.e., should be stable due to biological diversity or have a physical configuration that ensures that mishaps or temporarily poor operating conditions would not routinely lead to bypasses of poorly treated water. Chosen technologies would suit site-specific conditions and financial resources of individual communities.

The decentralised concept has a number of advantages over conventional practices. The flows at any point would remain small, implying less environmental damage from any mishap. System construction would also result in less environmental disturbances as smaller collection pipes would be installed at shallow depths and these could be more flexibly routed. The system expansion would be afforded by adding new treatment centres rather than routing ever more flows to existing centres. Industrial waste would not be commingled with domestic wastes; as industrial wastewater generators could be legally compelled to implement treatment methods specific to their wastewater characteristics and reuse opportunities.

Financial advantages would result from the cost reduction of the collection system infrastructure (which can be over $60 \%$ of sanitation project costs), the use of small diameter sewers, and the choice of technologies that incur minimal maintenance costs. The effluent would be available throughout the service area, nearer to points of potential reuse, where it could be used for nonpotable demands such as urban agriculture, landscape irrigation and toilet flushing. Decentralised systems are easier to plan and finance, as each project is small compared to the typical conventional system expansion. The management needs of each new development are considered directly/individually and could be implemented independently. A range of management strategies could be employed in various parts of the service area, responding in 
the most financially efficient and environmentally responsible manner to each set of circumstances.

However, wastewater reuse potentially poses health risks and possibly contaminates groundwater with heavy metals and nitrates. The implementation of cleaner production principles (Siebel and Gijzen, 2002; Nhapi and Hoko, 2002) could reduce these risks. Health risks could also be reduced by disinfection (Asano and Levine, 1996), avoiding spray irrigation methods (aerosol effects) (Mara, 1996), boiling all food grown with WTP effluent (Cairncross and Feacham, 1983; Pescod, 1992). Adequate protective clothing and safe handling procedures for workers are also necessary (Khouri et al., 1994). The control or prevention of toxic materials (heavy metals and organics) from entering the sewer systems is a crucial part of reuse systems.

\section{Results}

\section{Quantification of wastewater suitable for decentralised treatment}

The suitability of the decentralised concept was considered for various landuses. A differentiated (different solutions for different areas) and integrated approach was assumed in which first preference was given to onsite treatment and reuse (Nhapi et al., 2002b) The second preference was to treat at a decentralised level what cannot be handled onsite. The third preference was to treat the remainder at a centralised level. Only industrial and low-density residential areas have adequate space for the onsite treatment and reuse of wastewater (Nhapi et al., 2002b). One of the major constraints to onsite wastewater management is the difficulty of utilising all the nutrients and water for crop irrigation within the plot boundary. As a result medium $\left(500-1,500 \mathrm{~m}^{2}\right)$ and high-density $\left(<500 \mathrm{~m}^{2}\right)$ residential plots are recommended for decentralised systems because they are normally developed as small housing estates and they produce more wastewater than they can utilise onsite. Decentralised systems would allow housing developments in isolated areas where sewer connection to existing areas would be difficult and expensive.

Commercial and industrial effluents are currently not suitable for natural treatment processes because they are likely to contain heavy metals and other toxic materials, which would also affect subsequent reuse options. The regulation of effluent quality from industry and commerce in Harare is desirable but could be difficult because of numerous informal traders, most of whose activities are not monitored by the authorities. Trade effluents are better treated at source and/or by central treatment systems that include effective sedimentation for the removal 
of undesirable components. The addition of flocculants might be required to aid sedimentation, but this might further complicate reuse options. To avoid this, process reconsiderations within industries are required. However, industries could (in future) be clustered in industrial parks where they could also apply decentralised treatment of wastewater by teaming up to develop joint wastewater treatment plants.

The population distribution and sources of wastewater in Harare are shown in Fig 6.1. Harare has a population of about 1.9 million people, producing about $304,000 \mathrm{~m}^{3} / \mathrm{d}$ of wastewater (CSO, 2002; Nhapi et al., 2002b). This wastewater contains about $17,500 \mathrm{~kg} / \mathrm{d}$ TN and 2,600 $\mathrm{kg} / \mathrm{d}$ TP. The majority $(80 \%)$ of people in Harare live in high-density residential areas and these areas account for the bulk of wastewater volume and nutrient loads (Fig 6.1 and 6.2). Commerce and industry contribute significantly only in terms of wastewater flows, but low in terms of nutrients. This is because they use a lot of water for cleaning purposes, processing and/or cooling. A decentralised strategy would channel/divert water and nutrients from high and medium-density residential areas to urban agriculture, thereby reducing nutrient flows to Lake Chivero. The reuse of wastewater in agriculture would replace artificial fertilisers, as currently some of the fertilisers, most likely, end up leaching into Lake Chivero. An important advantage of this is that reuse of WTP effluent would enhance food availability as crops could be grown throughout the year. Targeting high and medium-density areas for decentralised treatment and reuse of wastewater would be very attractive, accounting for $41 \%$ of the flow, $81 \%$ of the TN, and $78 \%$ of the TP produced in Harare as wastewater (Fig 6.1 and 6.2). If these amounts were successfully handled, small amounts of nutrients ( $<5 \%$ of total produced) would potentially reach Lake Chivero after centralised wastewater treatment, with positive results on water quality.

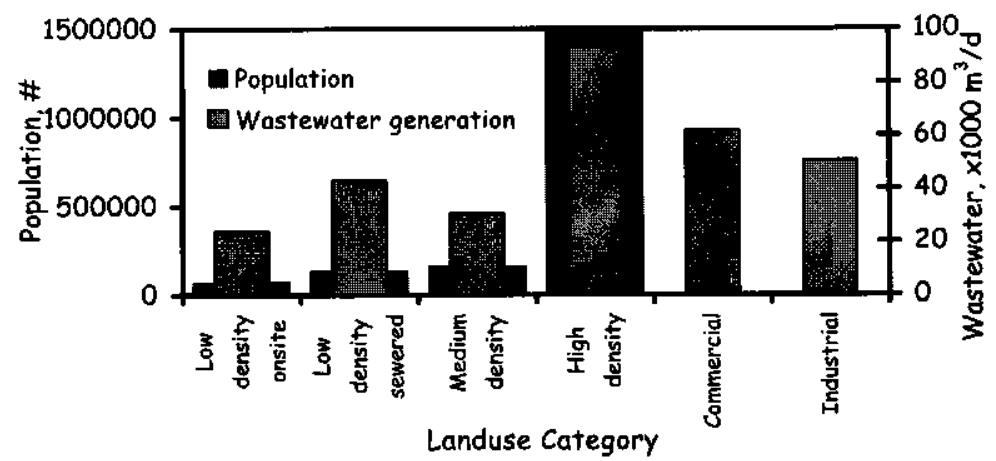

Flgure 6.1: Population distribution and wastewater generation in Harare, 2002 (Categories with density refer to residential areas) 


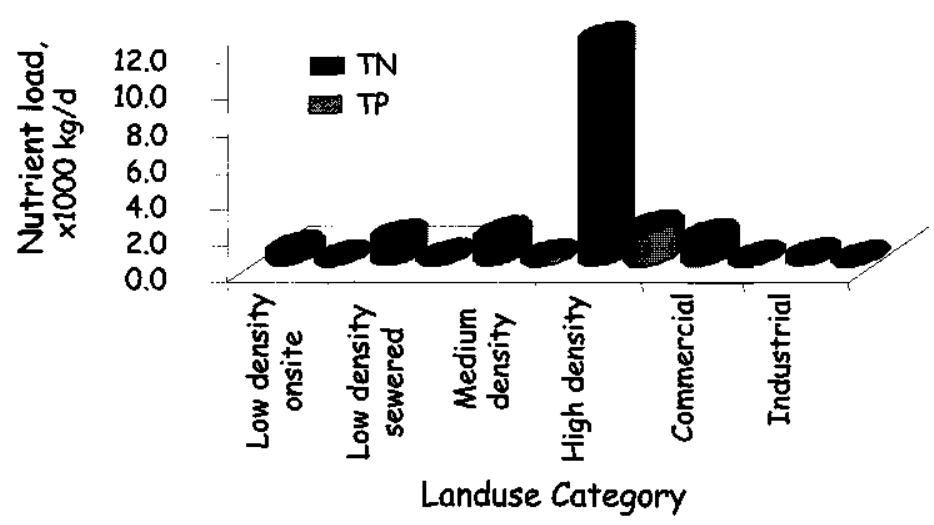

Figure 6.2: Sources of nitrogen and phosphorus in Harare, year 2002

\section{The decentralised treatment strategy}

A conceptual model of a decentralised scheme for wastewater treatment is shown in Fig 6.3. This scheme starts with water conservation and pollution prevention/reduction measures at source as covered in Chapter 5 . Reduced water consumption would result in more concentrated wastewater, which could be effectively treated by anaerobic methods with possible recovery of biogas. This scheme could accommodate both separated (greywater and urine handled separately) and combined wastewater flows. Treatment could be via three options. Option 1 is for less concentrated wastewater and uses natural treatment methods like algae and duckweedbased ponds, and constructed wetlands, with harvesting of protein biomass. The dotted line indicates the return route of the final effluent, directly or indirectly, to residential areas for on-plot and off-plot reuse. Option 2 is via anaerobic pre-treatment to allow for effective organic matter stabilisation and subsequent recovery of biogas and reduced quantities of sludge. The water is then directed to natural treatment systems as for Option 1. Option 3 is only different from Option 2 in that anaerobically treated effluent is reused after natural disinfection via maturation ponds. This route is not optimal but would suit very small systems of about 10 households. Less preferably, other methods like ozonation or UV radiation could be used depending on effluent quality. The use of chlorine should be discouraged because of possible formation of trihalomethanes and chlorine is not good for irrigation. In all cases, the final effluent could be used for local urban agriculture, open space and pasture irrigation, or aquaculture. This whole set-up requires the uncoupling of industrial and similar effluents, the major sources of heavy metals and other toxic compounds, as these affect treatment and sludge disposal, and sludge and water reuse. 


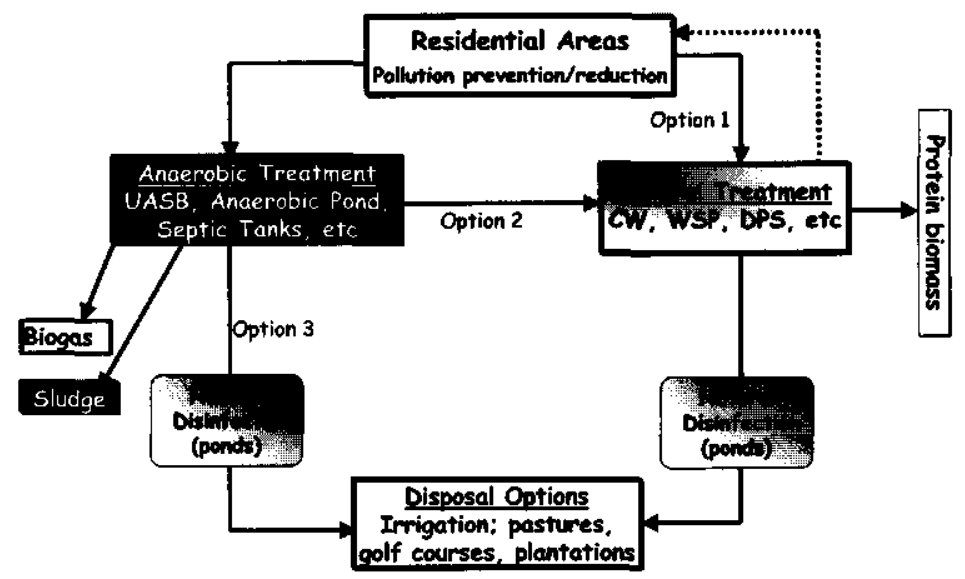

Figure 6.3: A conceptual model for the decentralised treatment of wastewater

(CW $=$ constructed wetlands; $W S P=$ waste stabilisation ponds; $D P S=$ duckweed-based pond systems $)$

\section{Potential impacts of the decentralised strategy}

An assessment of future developments and wastewater treatment requirements for the year 2015 was done by JICA (1996) and this was further updated by Nhapi et al. (2002b). Fig 6.4 shows the baseline wastewater production figures in Harare for the year 2002. In 2015, the flow would be about $487,000 \mathrm{~m}^{3} / \mathrm{d}$, containing some $30,000 \mathrm{~kg} / \mathrm{d}$ of TN and $4,000 \mathrm{~kg} / \mathrm{d}$ of TP (Fig 6.5). Figures 6.5 and 6.6 are based on possible re-organisation of wastewater flows and demonstrate that a great deal could be achieved through pollution prevention and reduction measures. Reducing household wastewater production from $315 \mathrm{~V} / \mathrm{cap}$.d to $150 \mathrm{l} / \mathrm{cap}$.d for lowdensity areas, and from $210 \mathrm{l} / \mathrm{cap} . \mathrm{d}$ to $135 \mathrm{l}$ /cap.d for medium-density areas (Nhapi et al., 2002c) would result in $14-24 \%$ reductions on overall flows. This could be achieved by using water conservation devices, leak detection and repairs, and other management measures like water rationing and punitive tariffs. The banning of phosphorus detergents is also necessary in Zimbabwe.

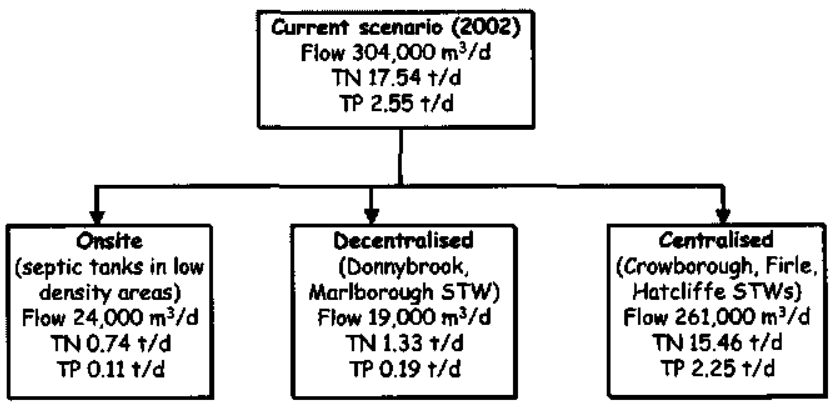

Figure 6.4: Baseline picture of wastewater treatment in Harare in the year 2002, showing water flows and nutrient loads 
Based on the 2002 scenario, treating all wastewater produced in low-density residential areas onsite would account for $15 \%$ of flow, and $12 \%$ of both TN and TP produced in Harare. Fig 6.6 shows the year 2015 scenario. Onsite treatment would account for $9 \%$ of flow, and $7 \%$ of both TN and TP. The decentralised systems would then account for $55 \%$ of flow, $81 \%$ of TN, and $80 \%$ of TP. The remaining wastewater from commerce and some industries could be treated the conventional way (centralised). A strategy for centralised treatment is also required to handle the remaining load and this is dealt with in the next Chapter. The current study shows that decentralised systems are the most effective method of diverting nutrients away from Lake Chivero. However, it is not feasible for Harare to transform overnight to this strategy. A staged (in time) and differentiated approach that includes onsite and centralised options should have the greatest impacts.

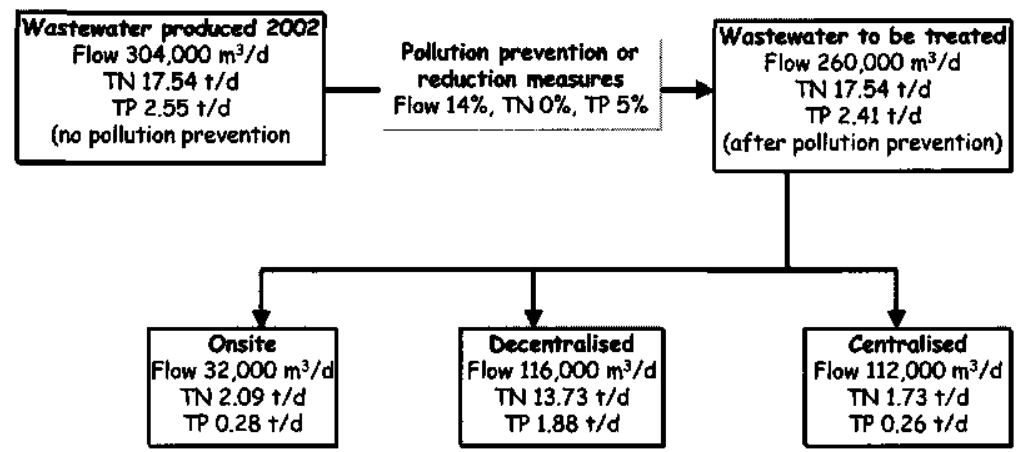

Figure 6.5: Re-organisation of wastewater treatment in Harare for the year 2002 showing resultant flows and nutrient loads; population 1.9 million people

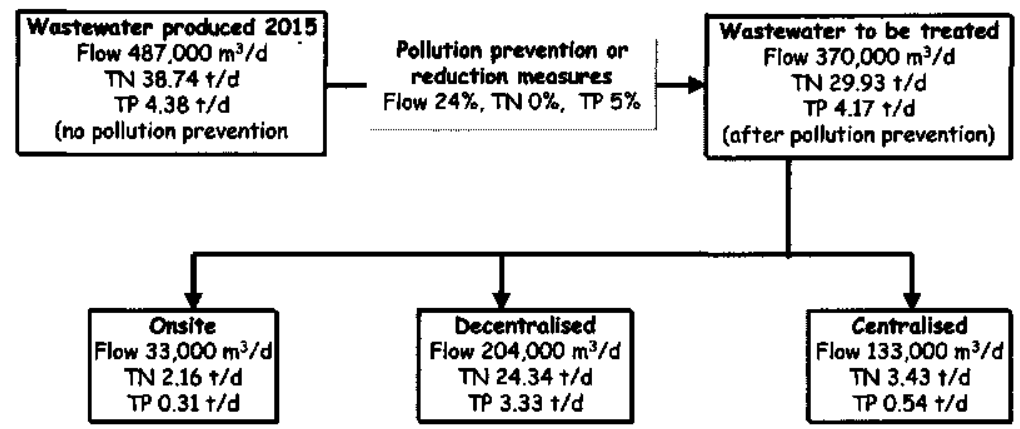

Figure 6.6: Re-organisation of wastewater treatment in Harare for year 2015 showing resultant flows and nutrient loads; population 3.1 million people 


\section{Zimbabwean case studies of the decentralised concept}

\section{Duckweed-based systems}

Nhapi et al. (2003a) reported on a study conducted in Zimbabwe to evaluate the performance of duckweed-based ponds as an option for treating and reusing wastewater in decentralised systems. The study focused on nitrogen and phosphorus removal, operational problems, and duckweed utilisation. Two full-scale trial plants at Nemanwa and Gutu-Mupandawana small urban centres were used (Fig 6.7). Water samples were collected and analysed according to Standard Methods (1995) on a monthly basis from September 2000 to August 2001 for $\mathrm{NO}_{3}-\mathrm{N}$, $\mathrm{NH}_{4}-\mathrm{N}^{-}, \mathrm{TKN}$, and TP. The duckweed was harvested daily and fed to chickens. The results (Fig 6.8 ) showed that both plants were not operating well with effluent concentrations above the respective Zimbabwean standards of $10 \mathrm{mg} / \mathrm{TN}$ and $0.5 \mathrm{mg} / \mathrm{l}$ TP (Government of Zimbabwe, S.I. 274 of 2000). This was attributed to inappropriate design especially pond depth $(\geq 1.5 \mathrm{~m})$ and short-circuiting. Harvesting was also not optimal at 80 - $190 \mathrm{~kg}$ fresh weight/ha.d (or 234 $555 \mathrm{~kg}$ dry weight/ha.yr) instead of $500-600 \mathrm{~kg}$ fresh weight/ha.d (Gijzen, 1997). The duckweed died off in the November to January period, this being attributed to excessive levels of ammonia.

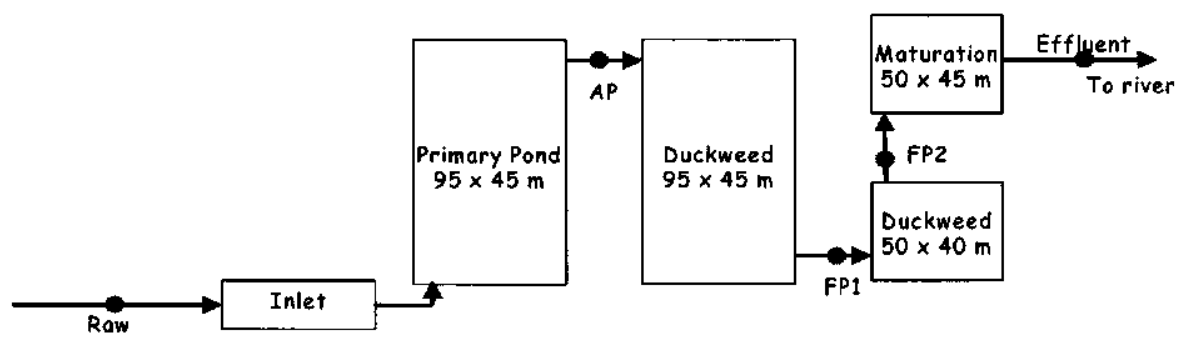

a) Gutu Plant

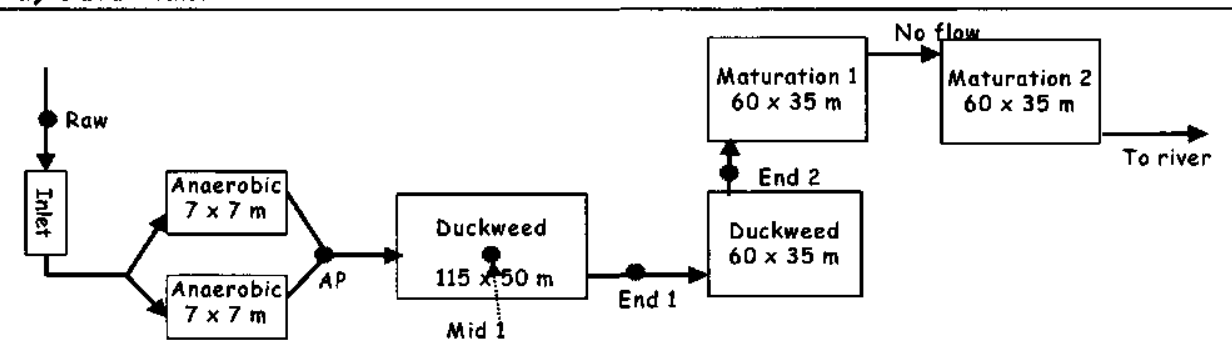

\section{b) Nemanwa Plant}

Figure 6.7: Layout and sampling points (with dots) for Nemanwa and Gutu duckweed-based pond systems 
The studied ponds could be improved by changing pond depth to about $1 \mathrm{~m}$, harvesting the duckweed at $500-600 \mathrm{~kg} / \mathrm{ha}$.d fresh weight, and ensuring $20-30$ days hydraulic retention time (FAO, 1999). Since less concentrated wastewater is related to medium and low-density residential areas, it would be rational to use duckweed ponds for such areas, consequently avoiding problems related to high nitrogen concentrations. Problems related to high ammonia concentrations could be solved by recycling final effluent within the treatment plant.

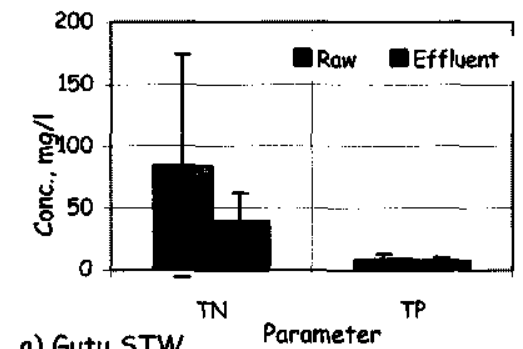

a) Gutu STW

Figure 6.8: Average nutrient concentrations ( \pm standard deviations) at Gutu and Nemanwa wastewater treatment plants, Sept 2000 to August 2001

The duckweed ponds studied offered an insight into possible use of natural wastewater treatment methods. The plants could be harvested for direct feed to animals (chickens, pigs) or for fish production (FAO, 1999). One person potentially produces about $9.5 \mathrm{~kg} / \mathrm{yr}$ duckweed on a dry matter basis, enough to feed 38 chickens as supplementary feed (Nhapi, 2004). The final effluent could be used for crop production. In addition, results by Dalu and Ndamba (2003), covering a wider spectrum of parameters, have confirmed the viability of duckweed systems for smaller treatment plants. Properly designed duckweed pond systems, therefore, offer a good alternative for managing and reusing wastewater at community level.

\section{Algae-based systems}

A second case study of typical decentralised wastewater management systems is on Donnybrook wastewater treatment system in Harare (Fig 6.9). This consists of four treatment lines of small algae-based waste stabilisation ponds scattered in the Mabvuku/Tafara highdensity area. The total treatment plant capacity is $5,500 \mathrm{~m}^{3} / \mathrm{d}$ serving a population of about 120,000 . All 4 plants are overloaded, receiving about $9,700 \mathrm{~m}^{3} / \mathrm{d}$ of wastewater. The treatment basically consists of primary treatment units (screening and grit removal), primary ponds (settling and anaerobic treatment), and secondary ponds (facultative and maturation). The effluent was originally meant for pasture and crop irrigation but is now being discharged into the river, as the irrigation system is no longer operational. 


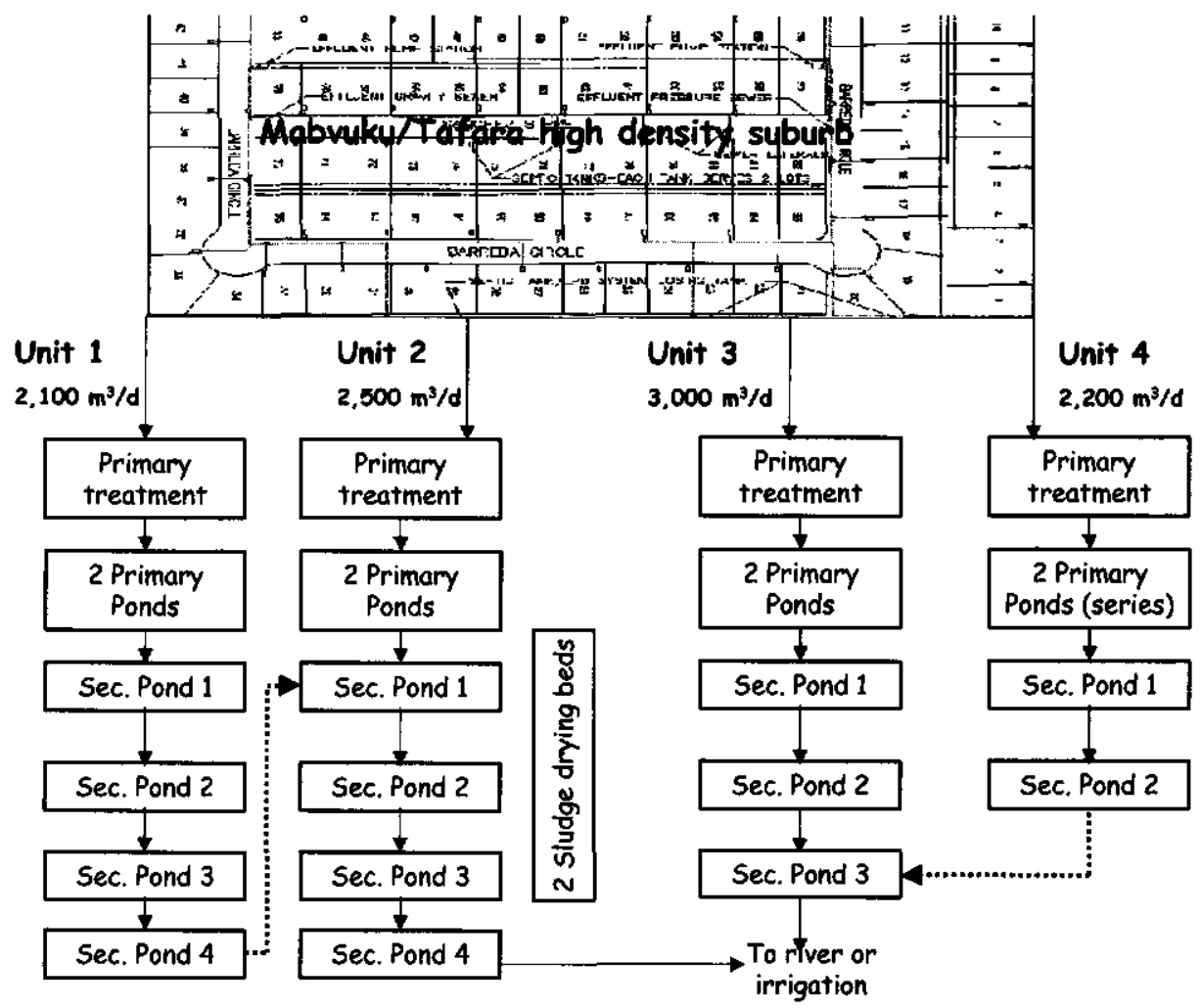

Figure 6.9: Layout of Donnybrook algae-based pond systems

Sampling results from the City of Harare for the period January 2000 to July 2002 were used to assess the performance of the Donnybrook system. The final effluent concentrations averaged $85 \pm 34 \mathrm{mg} / \mathrm{TN}$ and $12 \pm 4 \mathrm{mg} / \mathrm{TP}$ (Fig 6.10), meaning that the effluent is neither suitable for river discharge, nor for crop irrigation because of possibilities of $\mathrm{NH}_{3}$ toxicity to crops. The influent at Donnybrook is highly concentrated in terms of both nitrogen and phosphorus because of low water usage in the area due to perennial water shortages. The quality of the Donnybrook final effluent could be improved by final effluent re-circulation, and by deepening of the primary ponds to about $4 \mathrm{~m}$ to improve anaerobic processes. The final effuent, which will still be rich in nutrients, could then be used for protein production (duckweeds, constructed wetlands) and crop irrigation. Extra maturation ponds may be required to further polish the effluent and reduce pathogens. The treatment plants are located very close to residential areas making it cheaper to pipe effluent back to residential areas for open space and grounds irrigation. It could also be used for growing reeds for basket making, instant turf for lawns, and tomatoes or potatoes as in Australia (AWRC, 1991; Patterson and Chapman, 1998). 


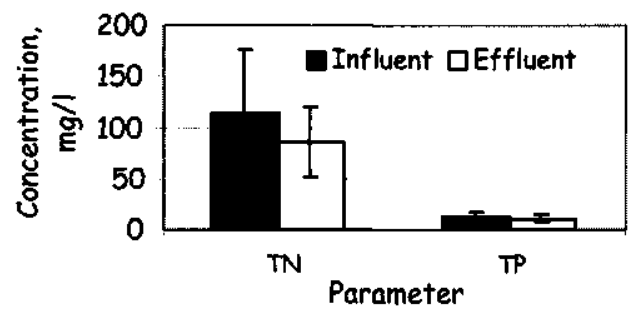

Figure 6.10: Average nutrient concentrations ( \pm standard deviations) at Donnybrook wastewater treatment works, Jan 2000 to July 2002

The Donnybrook ponds could be further enhanced for income generation by converting them to duckweed-based systems with poultry production or duckweed-fed aquaculture. If chickens are reared, about 4.6 miltion chickens could be kept per year with a market value of US\$14 million. The chicken droppings could be further applied as fertilizer in urban agriculture. There will, however, be other expenditures on extra feed as duckweed can only constitute about $10 \%$ of the chicken feed (Kusina ot al., 1999). For fish production, about $450,000 \mathrm{~kg} / \mathrm{yr}$ could be potentially harvested, realising an annual income of about US\$1.2 million. The possibility of realising some income from wastewater treatment is a strong incentive for this approach, and its cost/benefit assessment needs further study.

\section{Discussion}

The extent to which the decentralised concept is implemented in Harare would be determined by public acceptance, health and cost factors, and the availability of alternative water sources, rather than by technical barriers. Other contributing factors are regulations, convenience, and organisations necessary for users if they are to make correct use of wastewater systems, institutional willingness/acceptance, and organizational skill to make this happen. Public acceptance hinges on operational requirements and perceived safety of the system and this could be promoted through public awareness campaigns. A good example is the Bulawayo City Council which managed to reduce household water consumption to levels half those prevailing in Harare (JICA, 1996; BCC, 2002). The health aspects mainly relate to microbiological contamination and other toxic materials like heavy metals and chlorine derivatives. Pathogens could be destroyed by low-cost natural disinfection (maturation ponds), or costly physical/chemical disinfection methods like ozonation, nanofiltration, and reverse osmosis.

The cost aspect of decentralised systems is related to technologies used and the size of the population served. Technologies that use locally available resources (no foreign currency) and 
minimal mechanical inputs would be preferred. Such technologies should also have possibilities for cost recovery, e.g., duckweed for animal feed (Dalu and Ndamba, 2003), and crop irrigation for water and nutrient reuse (Mara and Cairncross, 1989). Besides natural systems for treatment, there are other intermediate high tech level systems that could very well serve the purpose of decentralised treatment. These include rotating biological filters, oxidation ditches, vegetated filter beds, intermittently decanted aerated lagoons, and oxidation beds. The availability and cost of alternative water systems (surface, groundwater, rainwater harvesting) would also affect the adoption of the decentralised strategy in Harare. Previous studies have shown that water availability in the Harare metropolitan area is greatly limited and this is worsened by recurrent years of drought. Groundwater exploitation could be another alternative.

The implementation of the decentralised concept in Harare would require a new and responsive institutional structure. Because treatment plants will be scattered around the city, it is best that these be run by local communities, special interest groups (youth, women, churches, nongovernmental organisations), or by private companies. The possibility of financial recovery from systems such as duckweed-based ponds would make them attractive for community management. The other advantage of community management is that it brings environmental management back to the polluters, making it easier for awareness campaigns. Private developers could also be asked to provide small treatment centres for each new housing subdivision and to manage such treatment centres. Private companies could be allowed to manage treatment plants and charge user fees for their services as in the French Model of privatisation of the water sector (Lobina and Hall, 1999). The council would act as a regulator, monitoring tariffs, standards and regulations.

The successful implementation of the decentralised strategy in Harare would require the revision of current Zimbabwean effluent standards (Statutory Instrument 274 of 2000) and health standards (Effluent (Public Health) Regulations of 1972). Areas that should be specifically addressed are agricultural applications, environmental health, and farmer protection. Agricultural regulations address the type of irrigation technology to be applied, applicable crop restrictions, and applicable loading rates to avoid ponding and minimise salination effects. Environmental health regulations address health standards for reuse and protection of groundwater resources, taking into consideration a limited areal zone where water may be affected. Farmer protection regulations address how farmers handle, manage and utilise wastewater effluents in agriculture in a way that health risks are minimal to the workers, their families and the consumers of effluent irrigated crops. 


\section{Conclusions and recommendations}

This study brings out some conclusions regarding the feasibility of decentralised wastewater systems in Harare.

1. Effective decentralised systems should be complemented by water use reduction and pollution prevention measures at source.

2. Areas that would suit decentralised systems are high and medium-density areas whilst low-density areas should use onsite systems because they have adequate space.

3. Effluents from commerce and industry should not be used as long as there is the risk of toxic waste flows.

4. Based on current and year 2015 wastewater flows, the decentralised concept would account for about $50 \%$ of flows, and about $80 \%$ of both TN and TP produced in Harare. It would result in the diversion of wastewater for reuse, leading to enormous reductions on wastewater discharges into Lake Chivero.

In terms of technology options, it is recommended that anaerobic systems be used for pretreatment with possible recovery of biogas, whilst sludge is used as manure. Natural (and any other low-cost) wastewater treatment methods could then be used to further polish the effluent with biomass harvesting and use as animal (fish, chickens, etc) feed, and effluent use for irrigation within neighbourhoods. Nutrients in effluent would replace artificial fertiliser use in urban agriculture. However, the success of the decentralised strategy would depend on socioeconomic, institutional, and health issues associated with wastewater reuse.

\section{References}

Asano T. and Levine, A.D. (1996) Wastewater Reclamation, Recycling and Reuse: Past, Present and Future, in IAWQ Wat. Sci: Tech. Vol. 33(10-11) p1-14.

AWRC (1991) Review of Effluent Disposal Practices, Australian Water Resources Council Water Management Series No. 20. Dept. of Primary Industries and Energy. Australian. Govt. Publications. Service. Canberra, Australia.

BCC (Bulawayo City Council) (2002) Study on Water Use, Water Conservation and Affordability, May 2002, Department of Works, Bulawayo, Zimbabwe.

Bowyer-Bower, T.A.S., Mapure, I., and Drummond, R.B. (1996) Ecological Degradation of Cities: Impact of Urban Agriculture in Harare, Zimbabwe, in Joumal of Applied Science in Southem Africa (JSSA), Vol. 2(2), p53-67.

Cairncross, S. and Feachem, R.G. (1983) Environmental Health Engineering in Tropics - An Introductory Text, John Wiley and Sons, Chichester, UK. 
CSO (Central Statistical Office) (2002) Census 2002: Zimbabwe, Preliminary Report, Central Census Office, Government of Zimbabwe, Harare, Zimbabwe.

Dalu, J.M. and Ndamba, J. (2003) Duckwe日d-based Wastewater Stabilisation Ponds for Wastewater Treatment (A Lowcost Technology for Small Urban Areas in Zimbabwe), Physics and Chemistry of the Earth, Vol. 28(20-27), p1147-1160.

FAO (1999) Duckweed - A Tiny Aquatic Plant with Enormous Potential for Agriculture and Environment, FAO Publications, Rome, Italy.

Gijzen, H. (1997) Scientific and Technical Validation of PRISM Duckweed Activities, PRISM Duckweed Project Report 0996, Dhaka, Bangladesh.

Government of Zimbabwe, (2000) Statutory instrument (S.I.) 274 of 2000, Water (Waste and Effluent Disposal) Regulations, Government Publications, Harare.

Gunnerson, C.G., French, J.A. (1996). Wastewater management for coastal cities - The ocean disposal option. Sringer Verlag, Berlin, Germany.

JICA (1996) The Study of Water Pollution Control in Upper Manyame River Basin in the Republic of Zimbabwe, MLGRUD, Nippon Jogeduido Sekkei Co. Ltd., Nippon Koei Co. Ltd, September 1996.

Kalbermatten, J.M., Julius, D.S., and Gunnerson, C.G. (1982) Appropriate Sanitation Altematives; A Technical and Economic Appraisal, International Bank for Reconstruction and Development, Washington, USA.

Khouri, N., Kalbermatten, J.M. and Bartone, C.R. (1994) Reuse of Wastewater in Agriculture: A Guide for Planners, UNB/WB Water and Sanitation Program, Washington, USA.

Kusina J, Mutisi C, Govere W, Mhona R, Murenga K., Ndamba J and Taylor P (1999) Evaluation of Duckweed (Lemna minor) as a Feed Ingredient in the Finisher Diets of Broiler Chickens. JASSA Vol. 5(1) p25-33.

Lobina, E. and Hall, D. (1999) Public Sector Alternatives to Water Supply and Sewerage Privatisation: Case Studies, International Journal of Water Resources Development, Vol. 16(1), p35-55, 2000. Also available on http://www.psiru.org/reports/9908-W-U-Pubalt.doc.

Mara, D (1996) Low-Cost Unan Sanitation, John Wiley and Sons Ltd, Chichester, UK.

Mara, D. and Cairncross, S. (1989) Guidelines for the Safe Use of Excrete in Agriculture and Aquaculture - Measures for Public Health Protection, World Health Organisation, Geneva, Switzerland.

Marino, M. and Boland, J. (1999) An Integrated Approach to Wastewater Management: Deciding Where, When, and How Much to Invest, The World Bank, Washington, D.C.

Mbiba, B. (1995) Urban Agriculture in Zimbabwe - Implications for Urban Management and Poverty, Ashgate Publishing Ltd, Avebury, UK.

Metcalf and Eddy (1991) Wastewater Engineering: Treatment, Disposal and Reuse, McGraw - Hill, Inc, Singapore.

Newton, D. and Solt, G. (1994) Water Use and Reuse, Institute of Chemical Engineers, UK.

Nhapi, I. and Gijzen, H.J. (2002) Wastewater Management in Zimbabwe, in Proceedings of the $28^{\text {th }}$ WEDC Conference held in Kolkota, india, November 2002, p181-184.

Nhapi, I., Siebel, M. and Gijzen, H.J. (2002a) An inventory of the existing water management practices in Harare, Zimbabwe, paper submitted for publication in the Urban Water Journal. 
Nhapi, I., Siebel, M. and Gijzen, H.J. (2002b) Options for the Onsite Management of Wastewater in Harare Zimbabwe, paper prepared for the IWA $5^{\text {th }}$ Specialised Conference on Small Water and Wastewater Treatment Systems, Instanbul, Turkey, 24 - 26 September, 2002.

Nhapi, I. And Hoko, Z. (2002) A Cleaner Production Approach to Unban Water Management: Potential for Application in Harare, Zimbabwe, Proceedings of the $3^{\text {th }}$ WaternetWARFSA Symposium in Dar Es Salaam, Tanzania, October $30-31,2002$, p573 - 583.

Nhapi, I. (2004) The Potential for the Use of Duckweed-based Pond Systems in Zimbabwe, WaterSA, Vol. 30(1), p115-120.

Nhapi, I. and Gijzen, H.J. (2003) The 3-step Strategic Approach to Sustainable Wastewater Management, paper submitted to the Journal of the Chartered Institute of Water and Environmental Management, October 2003.

Nhapi, I., Dalu, J., Ndamba, J., Siebel, M.A. and Gijzen, H.J. (2003a) An Evaluation of Duckweed-based Pond Systems as an Alternative Option for Decentralised Treatment and Reuse of Wastewater in Zimbabwe; IWA Wat. Sci. Tech. Vol. 48(2), p323-330.

Nhapi, 1., Siebel, M. and Gijzen, H.J. (2003b) A Conceptual Framework for the Sustainable Management Wastewater in Harare, Zimbabwe, IWA Wat. Sci. Tech. Vol. 47(7-8), p11-18.

Nhapi, I., Siebel, M. and Gijzen, H.J. (2003c) The Impact of Urbanisation on the Water Quality of Lake Chivero, Zimbabwe, Joumal of the Chartered institute of Water and Environmental Management, Vol. 18(1), p44-49.

Patterson, R.A. and Chapman, T.M. (1998) Environmental Indicators for Effective Effluent Re-use in Proceedings of WaterTECH Conference. Australian Water and Wastewater Association. Brisbane 27-28 April 1998. Also available on: http://www.lanfaxlabs.com.au/papers/P32-envir.PDF.

Pescod, M.B. (1992) Wastewater Treatment and Use in Agriculture, FAO, Rome, Italy

Pickin, J. (2002) Greenhouse Gas Emissions from Waste- Outlook for the future in Proceedings of the IWA World Water Congress, Melbourne, Australia, 7-12 April 2002.

Rogers, P. (1993) Integrated Urban Water Resources Management, Natural Resources Forum. Vol. 17(1): p33-42.

Siebel, M.A. and Gijzen, H.J. (2002) Application of Cleaner Production Concepts in Urban Water Management, paper presented at the Environmental Technology and Management Seminar 2002, Bandung, Indonesia, January 9-10, 2002.

Standard Methods for the Examination of Water and Wastewater, 19th edition, (1995) American Public Health Association/American Water Works AssociationMater Environment Federation, Washington DC, USA.

Veenstra S., Alaerts G., Bijlsma M. (1997) Technology Selection. In: Water Pollution Control. Eds. R Helmer and I. Hespanol. E\&FN Spon, London, UK.

Venhuizen, D. (1998) The Decentralised Concept of Wastewater Management, Internet Site: http://www.geocities.com/RainForest/Vines/5240Nenh_ww.html.

Venhuizen, D. (2003) The Decentralized Concept of "Waste" Water Management, available on Internet Site: http://www.venhuizen-ww.com/html/dcentral.html, May 2003. 
WHO (2000) Global Water Supply and Sanitation Assessment, 2000 Report, World Health Organisation, Geneva, Switzerland. 


\section{Chapter 7}

\section{Centralised Management of Wastewater in Harare, Zimbabwe: Current Practice and Future Options}

Parts of this Chapter were published as:

Nhapi, I., Hoko, Z., Siebel, M. and Gijzen, H.J. (2002) Assessment of Major Water and Nutrient Flows in the Chivero Catchment Area, Zimbabwe, Physics and Chemistry of the Earth, Vol. 27(11-22), p783-792.

Nhapi, I., Siebel, M. and Gijzen, H.J. (2002) Centralised Management of Wastewater in Harare, Zimbabwe: Current Practice and Future Options, IWA Water Research. 


\title{
Centralised Management of Wastewater in Harare, Zimbabwe: Current Practice and Future Options
}

\begin{abstract}
:
Wastewater can be managed at onsite, decentralised, and centralised levels. This Chapter investigates the performance of the current centralised system of managing wastewater in Harare, the capital city of Zimbabwe. The city is located in the Lake Chivero catchment. The lake is situated downstream of Harare and is the major water supply source for Harare. The Chapter focuses on water, nitrogen and phosphorus flows. A monthly water quality monitoring study was conducted from June 2000 to December 2001 covering two wastewater treatment works and the major wastewater treatment plant effluent receiving rivers, Marimba and Mukuvisi. The study showed that the nutrient removal efficiency for the two centralised wastewater treatment plants is poor. On average $24 \%$ for total nitrogen, and $8 \%$ for total phosphorus were removed. It was concluded that the current situation is not environmentally sustainable as it pollutes the Lake Chivero. A 3-Step Strategic Approach was applied in the formulation of sustainable solutions. These solutions include both short-term and medium to long-term measures. Proposed interventions include increased raw water abstractions from Lake Manyame instead of from Lake Chivero, the rehabilitation of the existing activated sludge systems, and increased effluent reuse within and outside the City of Harare boundary. It was demonstrated that the consistent application of interventions along the 3-Step Strategic Approach would greatly minimise pollution of the Lake Chivero.
\end{abstract}

Keywords: 3-Step Strategic Approach, centralised treatment, Lake Chivero, nutrient management, pollution control, wastewater management strategies

\section{Introduction}

The management of urban water in many developing countries is posing serious sustainability problems in view of rapid population growth and urbanisation. Of particular concern are the decreasing service coverage for water supply and sanitation (WHO, 2000). The Dublin Statement, Agenda21, and Vision21 are landmark developments in concerted efforts to find innovative and sustainable approaches to managing urban water and the environment. The 1992 International Conference on Water and the Environment (ICWE) in Dublin adopted the Dublin Statement, proposing concrete efforts to reverse over-consumption, pollution, and rising threats from drought and floods (ICWE, 1992; Consgrove and Rijsberman, 2000). In a follow-up meeting on Vision 21 at Bellagio, Italy, in 2000 , it was agreed that current waste management policies are abusive to human well-being, economically unaffordable, and environmentally unsustainable (King, 2000). Recent efforts to find sustainable solutions for developing countries 
are evidenced by numerous regional and international specialist group conferences on this topic. Whilst a lot of research has taken place on technological issues, the development of strategies for different circumstances still needs further improvement.

The Water Supply and Sanitation Decade of the 1980's improved water supply coverage in rural and some urban areas, but little gains were achieved in urban sanitation (WHO, 2000). This could be due to the high cost of sanitation provision compared to water supply (Gijzen, 2001; Gunnerson and French, 1996). Other researchers attribute this to problems in resource allocation, with water supply being treated as more prestigious and popular than sanitation (Franceys et al., 1992; Ali, 2002). However, some researchers believe this to be a result of the unsustainable strategies that are being copied from developed countries (Winbald, 1996, Otterpohl et al., 1997). This latter group believes that sustainable solutions should be based on resource recovery and reuse of useful wastewater components (water, nutrients, and biogas). In related discussions, three levels of wastewater management are considered, viz, onsite (within the plot boundary), decentralised (within neighbourhoods or at community level), and centralised or offsite management (Nhapi et al., 2003a).

Centralised systems are, in most cases, based on the Activated Sludge System, a technology known for huge energy consumption, and wasting of nutrients and water. However, huge investments have already been incurred worldwide on centralised wastewater treatment systems and a lot of resources are being channelled to improve their functioning. In fact, large groups of experts still believe that centralised systems are the most efficient way to handle urban wastewater (Bode et al., 2000). Centralised systems could provide satisfactory solutions in densely populated areas in high-income countries and will be in use for a long time to come. It is, therefore, necessary that strategies be developed to reduce capital and operational costs. and environmental risks posed by centralised systems particularly in poor countries.

This Chapter focuses on two distinct parts. The first is the performance evaluation of the current centralised wastewater management system in Harare, Zimbabwe, and identification of gaps. The second part deals with the formulation and assessment of possible solutions based on the so-called "3-Step Strategic Approach" to sustainable wastewater management (Gijzen, 2003; Nhapi and Gijzen, 2003). The Chapter considers solutions for the short to medium term (up to 10 years). It does not seek to glorify centralised wastewater management systems, but rather, to see how they could be integrated into a differentiated strategy for Harare - different solutions for different areas. However, a complete (overall) strategy for Harare is discussed in Chapter 9 , and would consider solutions for onsite, decentralised, and centralised treatment of wastewater. 
This means that the centralised strategy would only deal with the wastewater that could not be handled at onsite and decentralised levels.

\section{Materials and Methods}

\section{The study area}

The study area is the Harare sub-catchment area of Lake Chivero. Harare obtains its water from Lake Chivero $\left(416,000 \mathrm{~m}^{3} / \mathrm{d}\right)$, Lake Manyame $\left(84,000 \mathrm{~m}^{3} / \mathrm{d}\right)$, and Seke/Harava dams $(44,000$ $\mathrm{m}^{3} / \mathrm{d}$ ). Lake Manyame is situated immediately downstream of Lake Chivero and drains mainly agricultural areas and some northern parts of Harare. Seke and Harava dams are upstream of Lake Chivero on the Manyame River and drain the eastern parts of Harare and some rural areas. Harare City discharges wastewater treatment plant (WTP) effluent into the main tributaries of Lake Chivero but also abstracts its raw water from the lake. About $85 \%$ of the $304,000 \mathrm{~m}^{3} / \mathrm{d}$ of wastewater produced in Harare is treated at the two main WTPS of Crowborough (capacity $54,000 \mathrm{~m}^{3} / \mathrm{d}$ ) and Firle $\left(144,000 \mathrm{~m}^{3} / \mathrm{d}\right.$ ). These plants treat about $60 \%$ of their total influent wastewater by modified activated sludge systems incorporating biological nutrient removal (BNR), whilst the rest receives secondary treatment by means of trickling filters (TF). The TF effluent and sludge are mixed and used for pasture irrigation. The two major plants are currently overloaded and often discharge partially treated wastewater into the Lake Chivero.

\section{Data collection and analysis}

The study focused on total nitrogen (TN), total phosphorus (TP), and water flows at WTPs and in main rivers feeding into Lake Chivero. Samples were collected, preserved and analysed according to standard procedures (Standard Methods, 1995) on a monthly basis from June 2000 to December 2001. The sampling points are shown in Fig 7.1. River samples were collected upstream and downstream of WTP effluent discharge points (stations 15 to 18A on Marimba River, and 22, 23 on Mukuvisi River) and at continuous flow gauging stations, or just before river discharge into Lake Chivero (12, 13, 14, 19, 20, and 21) (Fig 7.2). In this study, water samples were collected only from Crowborough and Firle WTPs. River flows were obtained from gauging stations data from the Zimbabwe National Water Authority (ZINWA). Wastewater flows were determined from the continuous metering and pumping records of the City of Harare. The obtained data were analysed statistically using Microsoft Excel computer package. The sampling results in this Chapter are expressed as mean concentrations \pm standard deviations. The data from this study were checked against local and international standards in assessing wastewater, river, and lake water quality. Mass balance analyses and 
Vollenweider Model equations were used to check river and lake responses to changes in inflow nutrient loads.

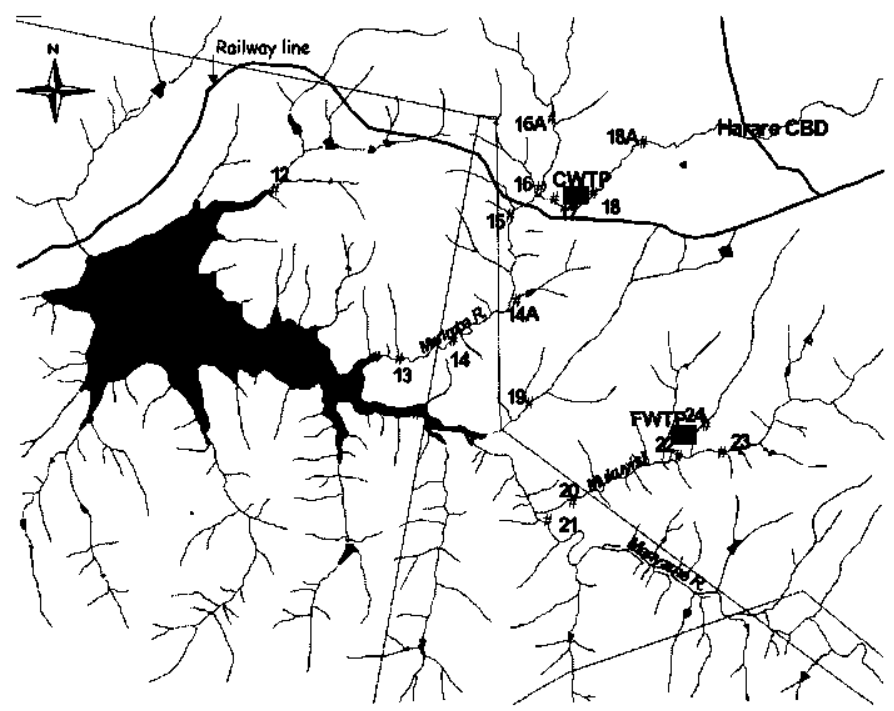

Figure 7.1: Site map for the study area showing sampling locations (CWTP = Crowborough wastewater treatment plant; FWTP = Firle wastewater treatment plant; for description of sampling points see text)

\section{Approach}

The 3-Step Strategic Approach to wastewater management was used to formulate sustainable solutions for wastewater management. The 3-Step Approach is based on three distinct steps of 1) prevention (pollution prevention and waste minimisation, 2) treatment for reuse, and 3) disposal of effluent and stimulation of the self-purification capacity of the receiving environment. This Chapter specifically focuses on the second and last steps because of their applicability at a centralised level. It looks at the current situation as it is and proposes solutions based on current loads. However, the potential reductions in wastewater volumes and loads proposed under step 1 are very important and these are dealt with separately (Chapter 5 - Nhapi et al., 2002a). The integration of the different approaches, including onsite, decentralised, and centralised management of wastewater, is dealt with in Chapter 9 (Nhapi et al., 2003b).

\section{Results}

\section{Wastewater and river nutrient levels}

The average nutrient concentrations for the Crowborough wastewater treatment plant and disposal system are shown in Figures 7.2 and 7.3. Except for TN at Crowborough, the BNR 
nutrient concentration had problems achieving the allowable limits of $10 \mathrm{mg} / \mathrm{TN}$ and $0.5 \mathrm{mg} / \mathrm{l}$ TP prescribed by Zimbabwean national standards for sensitive waters (Zimbabwe Government, SI 274 of 2000). This was in spite of the fact that BNR units are not overloaded. Any flows above BNR plant capacity are directed to trickling filter units and these units were often overloaded. The poor effluent quality of the BNR plants is attributed to poor operation and maintenance. The high nutrient levels recorded at station 14A originate from Ingwe Pasture Irrigation Farm. Pond 2 denotes the trickling filter effluent after passing through holding ponds. The holding pond outlets suffer from short-circuiting to varying degrees, resulting in different qualities from Pond 1 and Pond 2. The loss of water via evaporation and an internal nutrient cycle established by the recycling of sludge from humus tanks back to inlet works results in heavily concentrated effluent from ponds. Pond effluent (Pond 2) had high hydraulic flows and nutrient content, making it the major polluter of the Marimba River (Fig 7.3). It contributed 1,221 $\mathrm{kg} / \mathrm{d}$ TN $(46 \%$ of total load to river) and $286 \mathrm{~kg} / \mathrm{d}$ TP $(56 \%)$, with pasture irrigation also playing a significant role in polluting the Marimba River.

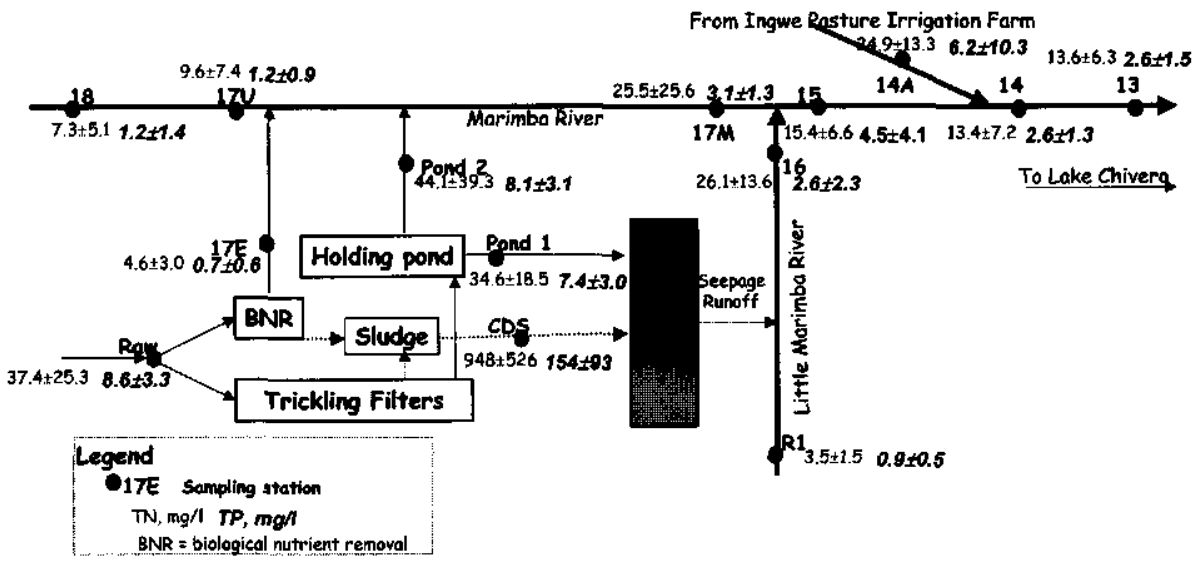

Figure 7.2: Schematic layout showing sampling points and average nutrient levels in $\mathrm{mgh}$ ( $n=15 ; \pm$ standard deviation) at Crowborough WTP and discharge points along Marimba and Little Marimba Rivers during the period June 2000 to December 2001 (dotted lines represent the sludge line).

The average nutrient concentrations for the Firle WTP and disposal system are shown in Figures 7.4 and 7.5. The zero values for flows and nutrients loads in Fig 7.5 are for stations that occasionally overflow due to plant breakdowns and peak loads. Averaging values for such stations do not make sense as the flows will be very small. Stations $20,21,22,23,24$, and inflow/outflow points at Firle wastewater treatment plant were monitored (Fig 7.6). There were no noticeable nutrient changes from the point of effluent discharge (22) to the river entrance point into Lake Chivero (20). It is likely that self-purification was taking place on this stretch of 
the river but there were additional non-point source flows from pasture irrigation and a large poultry farm (Crest Breeders International) on the other side of the river. The Firle Unit 4 plant was often not in operation, accounting for the high nutrient loads discharged into the Mukuvisi River (Fig 7.7). The Manyame River (21) had high TN and TP values attributed to sewer overflows in Chitungwiza and waste stabilisation pond effluents from Donnybrook and Ruwa wastewater works.

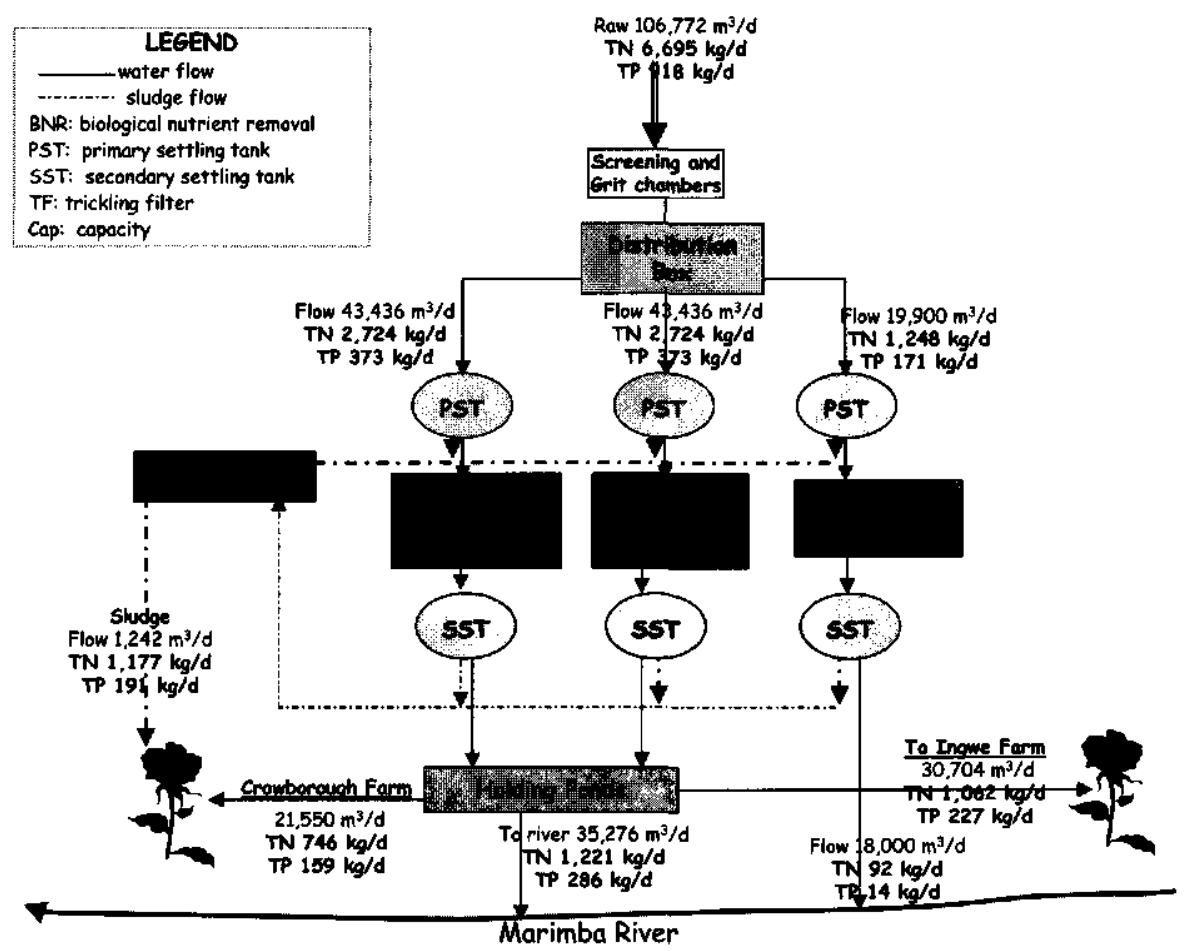

Figure 7.3: Average daily water and nutrient loads for the Crowborough wastewater treatment system during the period June 2000 to December 2001

The high levels of TKN and phosphorus recorded in Marimba, Mukuvisi, and Willowvale Rivers indicate contamination by organic matter, suggesting urban and industrial effluents. The unusually high TP concentrations in Willowvale River (station 19) indicate influences of sewer overflows and effluent/sludge mixture discharges from Ingwe Farm. The neighbouring dairy farm effluent probably also has an impact on nutrient levels in the river. In all cases, TP was higher than the limit of $0.03 \mathrm{mg} / \mathrm{l}$ required for preventing excess plant growth in rivers and streams (OME Guidelines, 1991). 


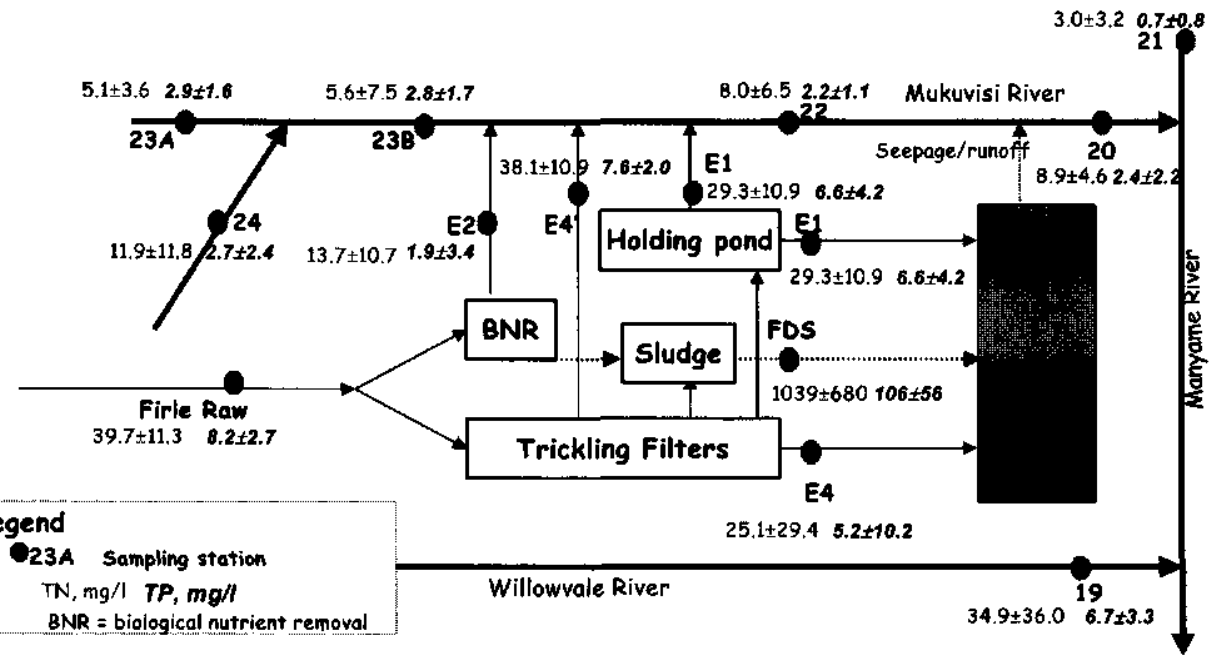

Figure 7.4: Schematic layout showing sampling points and average nutrient levels in $\mathrm{mg} / \mathrm{l}$ ( $\mathrm{standard}$ deviation) at Firle WTP and discharge points along Mukuvisi River in the period June 2000 to December 2001 (dotted lines represent the sludge line).

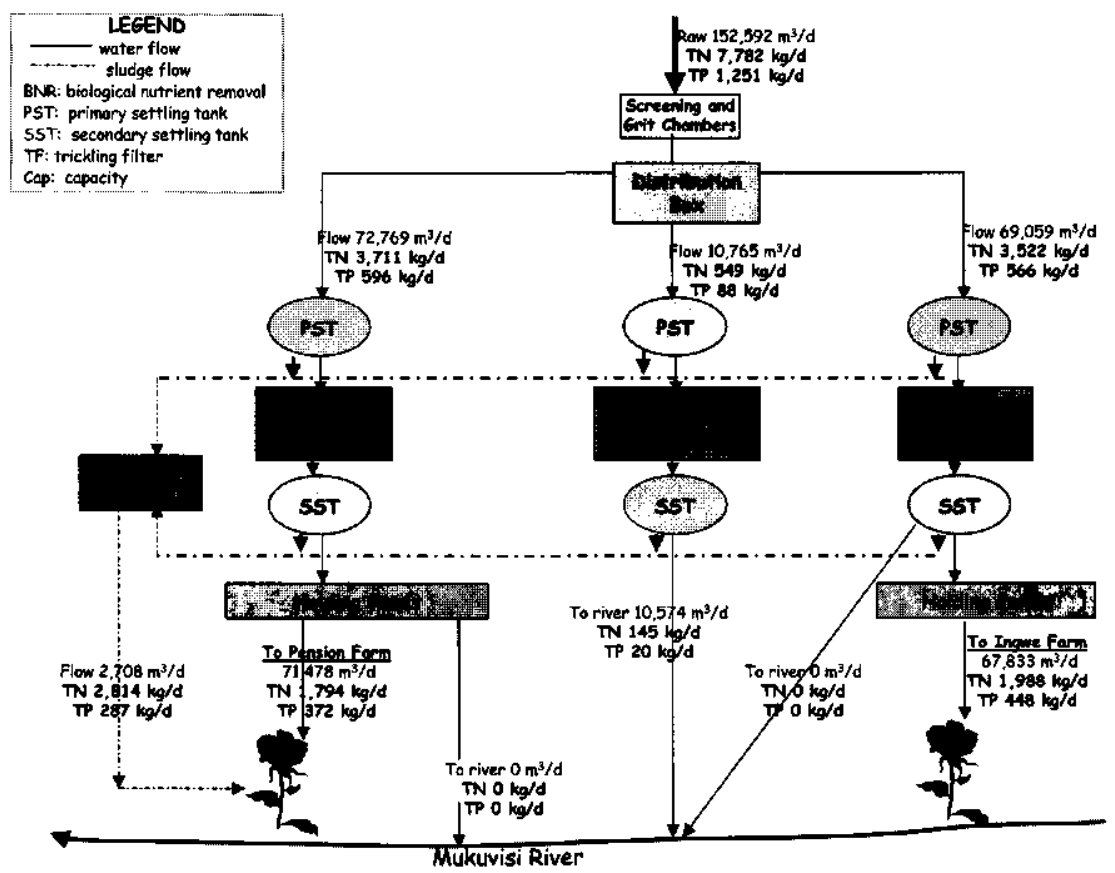

Figure 7.5: Resultant water and nutrient flow diagram for the Firle wastewater treatment system in the period June 2000 to December 2001 


\section{Efficiency of current system}

A mass balance analysis of nutrients was carried out on nutrient inflows and out flows (raw wastewater and final effluent + sludge) for all the five WTPs in Harare (Crowborough, Donnybrook, Firle, Hatcliffe, and Marlborough). It was observed that the average nitrogen removal efficiency for all the wastewater works in Harare was poor (about 24\%). Phosphorus removal efficiency was only $8 \%$. However, the poor performance of the treatment works is to some extent compensated for by pasture irrigation, which receives $80 \%$ of both TN and TP loads produced in Harare. The eventual loading of nutrients into Lake Chivero therefore mostly depends on the performance of the pasture irrigation system. A separate study on the performance of the pasture irrigation system is covered in Chapter 8.

\section{Discussion}

The way wastewater is currently managed in Harare is not sustainable as evidenced by high nutrient levels in rivers (Figs 7.2 and 7.4) and the lake itself (Chapter 3). A study on Crowborough pasture irrigation farm has revealed limitations because the land available for this purpose is very small (Nhapi et al., 2002b). The ultimate disposal of effluent into the main rivers feeding into Lake Chivero needs to be carefully controlled or avoided, because the lake is already hypertrophic, with nutrients concentrations of $2.0 \pm 1.3 \mathrm{mg} / \mathrm{l}$ and $0.6 \pm 0.3 \mathrm{mg} / \mathrm{lP}$ (Nhapi et al., 2004). A strategy is therefore considered for improving this situation in the context of the 3-Step Strategic Approach. According to this strategy, waste generation has to be drastically reduced (Step 1). For Crowborough and Firle WTPs a reduction of $41,000 \mathrm{~m}^{3} / \mathrm{d}(15 \%)$ could be achieved through waste avoidance and minimisation via technical and management measures as described in Chapter 5 . Step 2 is wastewater treatment with emphasis on resource recovery and reuse. In the context of the Chivero system, both recycling of water for urban needs and the recovery of nutrients for (urban) agriculture or aquaculture (e.g. duckweed-based treatment) have been identified as critical needs (Nhapi et al., 2002c). Step 3 deals with various strategies for safe disposal of effluent and sludge into the environment, and evaluates options for further stimulation of the natural self-purification capacity of water bodies. At a centralised level, steps 2 and 3 are important and these are discussed further in this Chapter. The impacts of implementing step 2 and 3 measures when applied for the whole of Harare and in combination with onsite (step 1) and decentralised wastewater management are discussed in Chapter 9.

\section{Step 2: Treatment and Reuse}

The general strategy proposed in this Chapter, based on the 3-Step Strategic Approach, discourages the use of BNR technology in favour of technologies geared towards resource 
recovery and reuse. Recycling the nutrients locally would reduce the costs of treating water from Lake Chivero, and energy and mechanical costs required to remove nitrogen at wastewater treatment plants. However, in view of the urgency of the pollution problems in Lake Chivero and due regard to the infrastructure already installed, the current BNR units should be optimised. This means that $126,000 \mathrm{~m}^{3} / \mathrm{d}$ of BNR effluent (current installed capacity) should be treated to effluent quality of $5 \mathrm{mg} / \mathrm{TN}$ and $0.5 \mathrm{mg} / \mathrm{TP}$ and discharged into Lake Chivero to enhance water availability. The $126,000 \mathrm{~m}^{3} / \mathrm{d}$ of BNR effluent constitute $16 \%$ of the current average daily inflows into Lake Chivero. Keeping all BNR units in top operating condition would result in substantial reductions in nutrient loads discharged into the Chivero system (Table 7.1). Because of the high risk of polluting Lake Chivero, a more stringent effluent standard of $5 \mathrm{mg} / \mathrm{l}$ $\mathrm{TN}$ and $0.5 \mathrm{mg} / \mathrm{TP}$ is suggested (current standards $10 \mathrm{mg} / \mathrm{TN}$ and $0.5 \mathrm{mg} / \mathrm{TP}$ ). This effluent quality is achieved at Crowborough WTP. Applying this new standard potentially results in reductions of $79 \%$ for TN and $90 \%$ for TP from current loads discharged into rivers by the two plants. Substantial investments in the rehabilitation and operation and maintenance improvements for these two plants are therefore justified.

Table 7.1: Potential reductions in pollution discharge levels due to improvements in BNR systems

\begin{tabular}{l|lrrrrr}
\hline Wastewater Treatment Works & Treatment Type & $\begin{array}{r}\text { Outflow, } \\
\mathrm{m}^{3} / d\end{array}$ & $\begin{array}{r}T N^{*} \\
m g / l\end{array}$ & $\begin{array}{r}T N \\
k g / d\end{array}$ & $\begin{array}{r}T P^{*} \\
m g / l\end{array}$ & $\begin{array}{r}T P \\
k g / d\end{array}$ \\
\hline Crowborough & BNR effluent to river & 18,000 & 5 & 83 & 0.5 & 9 \\
Firle & BNR discharge to river & 10,574 & 5 & 53 & 0.5 & 5 \\
& BNR-Pond to river, E1 & 0 & 5 & 0 & 0.5 & 0 \\
& BNR to river, E1 & 67,833 & 5 & 339 & 0.5 & 34 \\
\hline Total & & 96,407 & & 475 & & 48 \\
Reductions from current scenario** & & & & 1,740 & & 437 \\
\hline Reductions from current scenario, \% & & & & 79 & 90 \\
\hline
\end{tabular}

- Assumed TN is treated to $5 \mathrm{mg} / \mathrm{l}$, and TP to $0.5 \mathrm{mg} / \mathrm{l}$ at both Firle and Crowborough wastewater treatment plants

**In the current scenario $2,215 \mathrm{~kg} / \mathrm{d}$ TN and $480 \mathrm{~kg} / \mathrm{d}$ TP are being discharged

As a short-term measure, the existing trickling filter system could be rehabilitated and the effluent used for pasture irrigation. The current practice of separating sludge via primary and secondary settling tanks and mixing it again with final effluent has no relevance to nutrient reduction and needs to be revised. About $4,000 \mathrm{~m}^{3} / \mathrm{d}$ of sludge is produced at the two WTPs and should be processed separately and used as landfill in the short-term. In the medium-term, such sludge could be rendered environmentally safe by uncoupling industrial waste and the sludge could then be co-composted with household solid organics. The resultant compost could 
be used to replace chemical fertiliser, reducing nitrate contamination as nutrients in compost are slowly released. Natural wastewater treatment methods are not suitable for centralised treatment because of large land requirements of about $2-5 \mathrm{~m}^{2} / \mathrm{PE}$ (Metcalf and Eddy, 1991). For a population of about 1.9 million in Harare, this would imply an area of $380-950$ hectares only for the treatment plant whilst an extra amount will be required for effluent irrigation. However, natural treatment methods are good for nutrient recovery and could be used for some parts of the city in decentralised systems as discussed in Nhapi et al. (2003a). High-rate anaerobic pre-treatment is recommended for its effectiveness in COD reduction, reduced land requirements, and its effluent contains readily available forms of nitrogen and phosphorus.

The trickling filter effluent constitutes $163,000 \mathrm{~m}^{3} / \mathrm{d}$ of wastewater flow ( $58 \%$ of Harare total), $13,100 \mathrm{~kg} / \mathrm{d}$ of TN $(86 \%)$, and $1,750 \mathrm{~kg} / \mathrm{d}$ of TP $(73 \%)$. This effluent could be easily rendered suitable for irrigation purposes. The current total farming land in Harare is only 3,411 ha, of which 1,397 ha are irrigable and arable (McKendrick, 1982). Effluent irrigation outside the city boundaries therefore needs to be considered if full reuse of WTP effluents is to be achieved. In summary, the following steps are proposed:

i. In the short-term, all BNR effluent from Firle $\left(108,000 \mathrm{~m}^{3} / \mathrm{d}\right)$ and Crowborough $(18,000$ $\mathrm{m}^{3} / \mathrm{d}$ ) to be treated to $5 \mathrm{mg} / \mathrm{TN}$ and $0.5 \mathrm{mg} / \mathrm{IP}$ and discharged into rivers. This will utilise all the installed plant capacity.

ii. The trickling filter effluent from Firle WTP to be used to irrigate 1,320 ha of pastureland at Ingwe and Pension Farms. This could be changed to maize irrigation in the medium term, in order to achieve better nutrient removal, (Nhapi et al., 2002b).

iii. About $8,300 \mathrm{~m}^{3} / \mathrm{d}$ of trickling filter effluent from Crowborough WTP to be used to irrigate 305 ha currently under pasture irrigation at Crowborough Farm. Also changing to maize farming could be considered.

iv. The remaining trickling filter effluent from Crowborough WTP (about $80,400 \mathrm{~m}^{3} / \mathrm{d}$ ) to be used for commercial maize irrigation in neighbouring farms, closer to Lake Manyame.

v. The mixing of sludge and effluent to be discontinued in the short-term and sludge managed separately to avoid land contamination by heavy metals, excessive $N$ and $P$ and other pollutants.

\section{Step 3 Disposal with stimulation of self-purificatlon capacity}

Both the Marimba and Mukuvisi Rivers are heavily polluted (Figs 7.2 and 7.4). However, studies by Nhapi and Tirivarombo (2004) have shown substantial degrees of nutrient reductions along the river through self-purification (plant uptake, ammonia volatilisation, denitrification, and sedimentation). This ability to self-purify is related to the nutrient concentration of a particular river stretch, and needs to be enhanced. There are three ways of enhancing this self- 
purification: (1) controlling river pollution upstream of wastewater discharge so that oxygen supplied by re-aeration is utilised for the biodegradation of organic material, (2) ensuring that the discharged effluent quality is consistent with what the river can handle, and (3) introducing modifications in the river hydraulics and ecology (ecohydrological river engineering) to stimulate oxygenation, sedimentation, denitrification, and ammonia volatilisation. Actions 1 and 2 represent interventions under Steps 1 and 2 of the 3-Step Strategic Approach. Table 7.2 shows what would happen when WTP effluent quality and upstream nutrient levels have been controlled. In deriving this table, it was assumed that there would be negligible water losses from the point of WTP effluent discharge up to the point of discharge into Lake Chivero. An assessment of the current data shows that nitrogen losses do take place whilst phosphorus losses are negligible $(<1 \%)$. It was further assumed that the rate of nitrogen losses is the same for both Marimba and Mukuvisi rivers.

Table 7.2: Nutrient control upstream of and at wastewater treatment plants and resulting nutrient concentrations and loads downstream.

\begin{tabular}{l|llllll}
\hline & Flow, $\mathrm{m}^{3} / d$ & $T N, m g / l$ & $T N, k g / d$ & $T P, m g / l$ & $T P, k g / d$ \\
\hline
\end{tabular}

Current water quality just before river discharge into $L$. Chivero, based on stations actually monitored

\begin{tabular}{l|rrrrr} 
Marimba River & 194,466 & 13.6 & 2,645 & 2.6 & 506 \\
Mukuvisi River & 245,043 & 8.9 & 2,181 & 2.4 & 588
\end{tabular}

Upstream of wastewater discharge points

Assume river meets appropriate standards of $0.5 \mathrm{mg} / \mathrm{TN}$ and $0.04 \mathrm{mg} / \mathrm{TP}$

\begin{tabular}{|c|c|c|c|c|c|}
\hline Marimba River & 141,000 & 0.5 & 71 & 0.04 & 6 \\
\hline Mukuvisi River & 234,000 & 0.5 & 117 & 0.04 & 9 \\
\hline \multicolumn{6}{|c|}{ Wastewater Discharge } \\
\hline \multicolumn{6}{|c|}{ Assume good quality effluent, $5 \mathrm{mg} / \mathrm{TN}$ and $0.5 \mathrm{mg} / \mathrm{TP}$} \\
\hline Crowborough & 53,276 & 5.0 & 266 & 0.5 & 27 \\
\hline Firle & 10,574 & 5.0 & 53 & 0.5 & 5 \\
\hline \multicolumn{6}{|c|}{ Resulting downstream water quality, just after wastewater discharge point } \\
\hline Marimba River & 194,276 & 1.7 & 337 & 0.17 & 32 \\
\hline Mukuvisi River & 244,574 & 0.7 & 170 & 0.06 & 15 \\
\hline \multicolumn{6}{|c|}{ Resulting downstream water quality, just before river discharge into $L$. Chivero } \\
\hline Marimba River & 194,276 & 1.4 & 278 & 0.16 & 32 \\
\hline Mukuvisi River & 244,574 & 0.4 & 104 & 0.06 & 12 \\
\hline
\end{tabular}


Control of wastewater discharges. The BNR systems at Crowborough and Firle WTPs use similar modular units of $18,000 \mathrm{~m}^{3} / \mathrm{d}$ capacity. The BNR system at Crowborough achieved an effluent quality of about $5 \mathrm{mg} / \mathrm{TN}$ and $0.5 \mathrm{mg} / \mathrm{TP}$ (Fig 7.4). It can be assumed also that the BNR units at Firle are capable of achieving the same efficiency for more or less the same quality of influent. The results in Table 7.2 show that even after controlling upstream nutrient level, the downstream water quality will still not be of acceptable quality, especially for the Marimba River. The acceptable quality could only be achieved if wastewater is treated to unattainable high quality of $1 \mathrm{mg} / \mathrm{TN}$ and $0.1 \mathrm{mg} / \mathrm{TP}$; an almost $100 \%$ nutrient removal efficiency. It is therefore concluded that the nutrient inflows into Lake Chivero cannot be controlled from a wastewater treatment point of view only, as the best available technology BNR - cannot achieve the desired effluent standards. It is therefore necessary to control upstream and downstream river water quality in combination with tertiary effluent treatment. Supplying reduced quantities of raw wastewater to centralised treatment plants through source reduction measures and the decentralised treatment of part of the domestic waste load could enhance this tertiary treatment.

Control of upstream river water quality. Recent studies on the Willowvale River have shown that nutrient and heavy metals levels in the river are comparable to raw wastewater levels (Nhapi et al., 2001; Kandori, 2003). Another study further upstream of wastewater discharge points by Magombeyi (2003) found that storm flows from industrial areas and the central business district of Harare is the major source of point and non-point source pollution. The current study found that Marimba and Mukuvisi Rivers are already heavily polluted upstream of WTP effluent discharge points (Figures 7.2 and 7.4), and this requires appropriate interventions. Intervention measures should aim at bringing the water quality to acceptable levels for avoiding nuisance growth in rivers. For nutrients, these are $0.1-0.5 \mathrm{mg} / \mathrm{TN}$ and $0.01-0.04 \mathrm{mg} / \mathrm{TP}$ (OME Guidelines, 1991; Waikato Regional Council, 2003). The required interventions would include cleaner production approaches in industry/commerce and at household level, implementation of best management practices for all landuses, control of fertiliser runoff and sediment transport from urban agriculture, regular collection of municipal solid waste, and onsite/offsite stormwater treatment.

Control of downstream river water quality. The main thrust in controlling downstream river water quality is enhancing oxygenation and increasing the hydraulic residence time, thereby allowing more time for settlement and chemical/biological processes. Constructed wetlands could also be used for this purpose, or stream re-oxygenation could be increased by deliberately creating rapids and turbulence in streams. Other options include allowing rivers to flood in certain defined segments, and the introduction or stimulation of controlled algal development which 
increases oxygenation. In the short-term, the municipal water cycle could also be enlarged by abstracting raw water for Harare from Lake Manyame, which is located immediately downstream of Lake Chivero. This could be achieved by boosting pumping capacity from Lake Manyame. Theoretically this would give a much larger water body and therefore much more self-purification capacity.

\section{Overall impact on Lake Chivero water quality}

The relationship between average lake nutrient concentrations, nutrient inflow levels, and average lake water residence time can be expressed by Vollenweider's Model-based relationships - equations 7.1 and 7.2 (Vollenweider and Kerekes, 1982). Applying these equations to the 1996 scenario for Lake Chivero gave average concentrations of $0.7 \mathrm{mg} / \mathrm{TN}$ and $0.3 \mathrm{mg} / \mathrm{TP}$, as compared to measured values of $0.5 \mathrm{mg} / \mathrm{TN}$ and $0.3 \mathrm{mg} / \mathrm{TP}$ (JICA, 1996). For the current scenario, the estimates were $1.6 \mathrm{mg} / \mathrm{TN}$ and $0.6 \mathrm{mg} / \mathrm{TP}$, whilst measured average values were $2.0 \mathrm{mg} / \mathrm{l} \mathrm{TN}$ and $0.6 \mathrm{mg} / \mathrm{TP}$ (Nhapi et al., 2004).

(a) Nitrogen

$[\mathrm{N}]_{\mathrm{y}}=\frac{3.0}{\left\{[\mathrm{~N}]_{\mathrm{f}} /(1+\mathrm{SQRT} T(\mathrm{~W}))\right\}^{0.78}}$

$[\mathrm{N}]_{\mathrm{y}}=$ expected average lake nitrogen concentration, $\mathrm{mg} / \mathrm{m}^{3}$

$[\mathrm{N}] \mathrm{f}=$ average inflow nitrogen concentration, $\mathrm{mg} / \mathrm{m}^{3}$

$T(w)=$ average water residence time, years

(b) Phosphorus

$[P]_{y}=\frac{2.75}{\left\{[P]_{f} /(1+S Q R T T(w))\right\}^{0.82}}$

$[P]_{y}=$ expected average lake phosphorus concentration, $\mathrm{mg} / \mathrm{m}^{3}$

$[P] f=$ average inflow phosphorus concentration, $\mathrm{mg} / \mathrm{m}^{3}$

$T(w)=$ average water residence time, years

Since the Vollenweider Model accurately described the Lake Chivero nutrient regime, it was used to predict lake responses to changes in nutrient loadings. Two scenarios were analysed. In the first scenario, it was assumed that river water upstream of wastewater discharge is of acceptable quality for river ecological health $(0.5 \mathrm{mg} / \mathrm{TN}$ and $0.04 \mathrm{mg} / \mathrm{TP})$. The other assumptions were that BNR effluent discharges remain the same (quantity) but with quality of 5 $\mathrm{mg} / \mathrm{TN}$ and $0.5 \mathrm{mg} / \mathrm{TP}$, and that the rate of nitrogen losses after wastewater treatment plant 
discharge remains the same. Applying equations 7.1 and 7.2 , the resultant average nutrient concentrations in Lake Chivero will be $0.3 \mathrm{mg} / \mathrm{TN}$ and $0.06 \mathrm{mg} / \mathrm{TP}$, compared to $0.3 \mathrm{mg} / \mathrm{TN}$ and $0.01 \mathrm{mg} / \mathrm{l}$ TP required for oligotrophic systems (Mandaville, 2000).

Scenario 2 was considered based on the need to enhance water availability in the Chivero catchment and the need to fully utilise the existing BNR units. In this scenario, all the assumptions in Scenario 1 hold except that all BNR capacity $\left(126,000 \mathrm{~m}^{3} / \mathrm{d}\right)$ is utilised and the resulting BNR effluent discharged into rivers. The resultant average nutrient concentrations in Lake Chivero would be $0.4 \mathrm{mg} / \mathrm{TN}$ and $0.07 \mathrm{mg} / \mathrm{TP}$. The hydraulic residence time in the lake will be 0.4 years, which is below the maximum of 0.5 years required for flushing out phosphorus in lakes (Thornton, 1980). The results for both scenarios represent substantial improvements in water quality of the Lake Chivero. From this analysis, it is recommended that effluent and river water quality standards for the Chivero catchment be set accordingly. However, it would be too optimistic to say that Lake Chivero will realistically recover to these high levels of water quality. The proposed actions require huge investments whilst the extent of nutrient accumulations in the sediments is not known. There is a strong possibility of internal nutrient cycles, especially phosphorous. What is required now are concrete actions to reverse the current situation and long-term plans to sustain good water quality in the lake.

\section{Conclusions and recommendations}

The average nutrient removal efficiency for all wastewater treatment plants in Harare was poor at $24 \%$ for TN and $8 \%$ for TP. This will result in further deterioration of water quality in Lake Chivero. However, the poor performance of wastewater treatment plants is, to some extent, compensated for by pasture irrigation, which receives about $80 \%$ of both TN and TP loads produced in Harare. Runoff and seepage from the pastures eventually flow into the tributaries of Lake Chivero (Chapter 8). The following actions are therefore recommended at a central level:

1. The total installed BNR capacity of $126,000 \mathrm{~m}^{3} / \mathrm{d}$ should be utilised to achieve a final effluent quality of $5 \mathrm{mg} / \mathrm{TN}$ and $0.5 \mathrm{mg} / \mathrm{TP}$, the effluent being discharged into the rivers. This will reduce current discharges by about $80 \%$ for TN and $90 \%$ for TP, whilst enhancing water availability in Lake Chivero.

2. The trickling filter line should be improved to take care of the remaining inflow load. This involves increasing the treatment capacity, acquiring more land for effluent disposal, and separate disposal of effluent and sludge.

3. Modifications should be introduced to the river hydraulics and ecology in order to stimulate oxygenation, sedimentation, denitrification, and ammonia volatilisation. This 
should be complimented by stormwater treatment to reduce river pollution levels upstream of wastewater treatment plant effluent discharge points.

These proposed changes are envisaged to reduce nutrient concentrations in Lake Chivero closer to $0.3 \mathrm{mg} / \mathrm{TN}$ and $0.01 \mathrm{mg} / \mathrm{l}$ TP required for drinking water in lakes. Under a sustained reduction of nutrient inflows, the lake might not become oligotrophic in the medium term as nutrients have already accumulated in the lake and will establish an internal nutrient cycle. However, it should be given a chance to refresh itself over time. An integrated implementation plan that includes onsite, decentralised, and centralised treatment and reuse is discussed in Chapter 9.

\section{References}

Ali, A. (2002) Operational Problems of Wastewater Treatment Plants in Developing World, in Proceedings of the IWA Conference on Water and Wastewater Perspectives of Developing Countries, New Delhi, india, 11 - 13 December, 2002, p933 - 937.

Bode, H., Grünebaum, T., and Jardin, N. (2000) Selected Proceedings of the $8^{\text {th }}$ International Conference on Large Wastewater Treatment Plants, held in Budapest. Hungary, 6-9 September 1999, published as Wat. Sci. Tech. Vol. 41(9).

Cosgrove, W.J. and Rijsberman, F.R. (2000) World Water Vision: Making Water Everybody's Business, World Water Council, London, UK.

Department of Water Development (1995) Assessment of Surface Water Resources in the Manyame Catchment - Zimbabwe; Streamflow Gauging and Conceptual Hydrological Modelling, SMHi Hydrology No. 60, 1995.

Franz, A. and Kroiss, H. (eds) (1996) Selected Proceedings of the $7^{\text {th }}$ IAWQ Conference on Design and Operation of Large Wastewater Treatment Plants, held in Vienna, Austria, 27 August - 1 September 1995, published as Wat. Sci. Tech. Vol. 33(12).

Franceys, R., Pickford, J. and Reed, R. (1992) A Guide to the Development of Onsite Sanitation, WHO, Geneva, Switzerland.

Gijzen, H.J. (2001) Low Cost Wastewater Treatment and Potentials for Re-use: A Cleaner Production Approach to Wastewater Management, paper presented at the International Symposium on LowCost Wastewater Treatment and Re-use, NVA-WUR-EU-IHE, Cairo, Egypt, February 3-4, 2001.

Gijzen, H.J. (2003). A 3-Step Strategic Approach to Sewage Management for Sustainable Water Resources Protection. Proc: Asia WaterQual, Regional Conference on Water Quality, 19-23 October, 2003, Bangkok, Thailand.

Government of Zimbabwe, (2000) Statutory Instrument (S.I.) 274 of 2000, Water (Waste and Efluent Disposal) Regulations, Government Publications, Harare.

Gunnerson, C.G. and French, J.A. (1996). Wastewater Management for Coastal Cities - The Ocean Disposal Option. Sringer Verlag, Berlin, 340p. 
ICWE (International Conference on Water and Environment) (1992) The Dublin Statement and Recond of the Conference, World Meteorological Organisation, Geneva, Switzerland.

JICA Report (1996) The Study of Water Pollution Control in Upper Manyame River Basin in the Republic of Zimbabwe, MLGRUD, Nippon Jogeduido Sekkei Co. Ltd., Nippon Koei Co. Ltd, September 1996.

Kandori, C. (2003) Water Quality Assessment of the Glen View River, Harare, BSc Thesis, Department of Civil Engineering. University of Zimbabwe, Harare, Zimbabwe.

King, N. (2000) New Strategies for Environmental Sanitation, in Water21, Magazine of the International Water Association, April 2000, London, UK, p1 1-12.

Magombeyi, M. (2003) A Study on the Evaluation of Stormwater Drainage Quality in Harare City, Zimbabwe MSc WREM Thesis, Dept of Civil Engineering, University of Zimbabwe, Harare, Zimbabwe.

Mandaville, S.M. (2000) Lake Data of Relatively Undisturbed Lakes within Nova Scotia; Provincial Averages; CCME, Health \& Welfare Canada, and OME Guidelines, Internet Site: http://www.chebucto.ns.ca/Science/SWCS/SWCS.html.

Manjonjo, M (1999) Land Disposal of Siludge and Pond Effluent on Crowborough Farm: Its Efficiency and Influence on Marimba River, MSc WREM Thesis, University of Zimbabwe, Harare, Zimbabwe.

Mckendrick, J. (1982) Water Supply and Sewage Treatment in Relation to Water Quality in Lake Mcllwaine in Thornton, J.A. and Nduku, K. (eds.) Lake Mclwaine; The Eutrophication and Recovery of a Tropical African Man-Made Lake, Dr W Junk Publishers, The Hague, The Netherlands, p 202217.

Metcalf and Eddy (1991) Wastewater Engineering: Treatment, Disposal and Reuse, McGraw - Hill, Inc, Singapore.

Nhapi, I., Siebel, M. and Gijzen, H.J. (2001) Dry Season Inflow and Export of Nutrients from Lake Chivero; in Proceedings of the Zimbabwe Institution of Engineers, Vol. 2(1), p33-41.

Nhapi, I., Siebel, M. and Gijzen, H.J. (2002a) Options for the Onsite Management of Wastewater in Harare Zimbabwe, Proceedings of the IWA $5^{\text {th }}$ Specialised Conference on Small Water and Wastewater Treatment Systems, Istanbul, Turkey, 24 - 26 September, 2002.

Nhapi, I., Mawere, M., Veenstra, S.I. and Gijzen, H.J. (2002b) Effluent polishing via pasture irrigation in Harare, Zimbabwe; IWA Wat. Sci. Tech., Vol 46(9), p287-295.

Nhapi, I., Siebel, M.A. and Gijzen, H.J. (2002c) An Inventory of the Existing Water Management Practices in Harare, Zimbabwe, paper prepared for publication in the Urban Water journal.

Nhapi, I. and Gijzen, H.J. (2003) The 3-step Strategic Approach to Sustainable Wastewater Management; paper submitted to the Journal of the Chartered Institute of Water and Environmental Management, December 2003.

Nhapi, I., Siebel, M.A., and Gijzen, H.G (2003a) A Conceptual Framework for the Sustainable Management of Wastewater in Harare, Zimbabwe; IWA Wat. Sci. Tech., Vol 47(7-8), p11-18.

Nhapi, I., Siebel, M.A. and Gijzen, H.J. (2003b) A Proposal for Managing Wastewater in Harare, Zimbabwe , paper submitted to IWA Water Research journal, December 2003. 
Nhapi, I., Siebel, M. and Gijzen, H.J. (2004) The Impact of Urbanisation on the Water Quality of Lake Chivero, Zimbabwe, paper accepted for publication in the Journal of the Chartered institute of Water and Environmental Management, Vol. 18(1), p44-49.

Nhapi, I. and Tirivarombo, S. (2004) Sewage Discharges and Nutrient Levels in Marimba River, WaterSA, Vol. 30(1), p107-113.

OME (Ontario Ministry of the Environment) (1991) Water Management, Provincial Water Quality Objectives and Guidelines, Internet site: http://www.ene.gov.on.ca/envision/gp.

Otterpohl, R., Grottker, M. and Lange, J. (1997) Sustainable Water and Wastewater Management in Urban Areas, in IWA Wat. Sci. Tech., Vol. 35(9), p121-133.

Standard Methods for the Examination of Water and Wastewater (1995). 19th edn, American Public Health Association/American Water Works Association/Water Environment Federation, Washington DC, USA.

Thornton, J A (1980) A Comparison of the Summer Phosphorous Loading to Three Zimbabwean WaterSupply Reservoirs of Varying Trophic States, WaterSA Vol. 64, October 1980, p163-170.

Vollenweider, R.A. and Kerekes, J. (1982). Eutrophication of waters - Monitoring, assessment and control. Synthesis Report, OECD Paris, 154 pp.

Waikato Regional Council (2003) How Healthy are Our Rivers? Report available on Internet Site: http://www.ew.govt.nz/index.asp, Date Accessed: 1 August 2003

WHO (2000) Global Water Supply and Sanitation Assessment, 2000 Report, World Health Organisation, Geneva, Switzerland.

Winbald, U (1996) Towands an Ecological Approach to Sanitation, Speech delivered at the International Toilet Symposium, Tohama, Japan, October 1996 


\section{Chapter 8}

\section{Effluent Polishing via Pasture Irrigation in Harare, Zimbabwe}

Submitted as:

Nhapi, I., Mawere, M., Veenstra, S.I. and Gijzen, H.J. (2002) Effluent polishing via pasture irrigation in Harare, Zimbabwe; IWA Wat. Sci. Tech. Vol. 46(9) p287 - 295. 


\title{
Effluent Polishing via Pasture Irrigation in Harare, Zimbabwe
}

\begin{abstract}
Harare, the capital city of Zimbabwe, is experiencing eutrophication-related problems in its major potable water supply source of Lake Chivero. This is due mainly to poorly treated wastewater effluent encroachment into upstream rivers, especially the Marimba River. The Crowborough Pasture Irrigation farm is in the Marimba sub-catchment area and has 305 hectares of irrigated pastures. The pastures are flood-irrigated with trickling filter effluent and sludge mixture once every three weeks. Studies were conducted from July 2000 to February 2001 focusing on the pasture's management of nutrients (nitrogen and phosphorus) and their impact on the Marimba River. Water and nutrient balances were developed. Average nutrient reduction efficiencies for this pasture were found to be $84 \%$ for TN and $54 \%$ for TP. Both the Crowborough wastewater treatment works and the pastures are overloaded. Based on current Zimbabwean regulations for safe disposal of effluent on land, about 2,800 ha will be required for the effluent and sludge disposal. If effluent only is applied the land requirements will be about $2,100 \mathrm{ha}$, compared to the current 305 ha irrigated. It was recommended that additional treatment units be constructed at Crowborough wastewater treatment works to meet current flows. Moreover, pasture management needs substantial improvement. Nutrient recovery should be enhanced by regular harvesting of pasture grass and converting cow dung into an economic commodity as manure for neighbouring residents. Maize cultivation is also recommended to replace pasture grass as it is a local staple crop and has high nutrient uptake rates and commercial value.
\end{abstract}

Keywords: Closing water and nutrient cycles, digested sludge, effluent polishing, pasture irrigation, runoff, seepage

\section{Introduction}

Land application of wastewater is an attractive method of diverting nutrients from rivers, where these result in eutrophication, to agriculture where these are used as macro-nutrients for biomass production. In Zimbabwe, land application of wastewater has been practised near Harare since 1965. This practise was further stimulated since 1978 when serious eutrophication problems were observed in the receiving Lake Chivero. This lake together with the downstream Lake Manyame, supplies about $94 \%$ of Harare's potable water requirements. The lake has been eutrophic since the early 1970's and wastewater is considered the main source of pollution (Moyo, 1997). 
Marimba River contributes only $12 \%$ of the hydraulic load, but over $25 \%$ of the total nitrogen (TN) load and approximately $35 \%$ of the total phosphorus (TP) load into Lake Chivero (Nhapi et al., 2001). Following on from Chapter 7 , the current chapter specifically focussed on the disposal of effluent/sludge from the Crowborough Wastewater Treatment Plant (CWTP). The CWTP is situated in the Marimba sub-catchment area of Lake Chivero. The chapter aimed at evaluating the role of the Crowborough Pasture Irrigation (CPI) scheme in the removal of nitrogen and phosphorus from the mixed flow of primary and secondary sludge and trickling filter effluent of CWTP, and looks into possibilities to further improve the system. An assessment of the sustainability of the current system based on nutrient loading, removal and accumulation rates was carried out. A mass balance analysis of TN and TP enabled the formulation of specific intervention measures to enhance the performance of the system and contribute to improved water quality management of the Lake Chivero Basin. Pasture irrigation is an example of possible intervention measures in Harare under step 3 of the 3-Step Strategic Approach, explained by Nhapi et al. (2003).

\section{Background and operational aspects at Crowborough Farm}

\section{The study area}

Crowborough Pasture Irrigation Farm consists of 594 ha of which 305 ha are actively under irrigation. Trickling filter effluent and digested sludge from CWTP are mixed before being pumped to the pastures. A map of the study area is shown in Fig 8.1 together with the locations of sampling points for water quality assessment. The pasture is mainly drained towards Marimba River and Little Marimba River. The CWTP consists of an activated sludge system enhanced for Biological Nutrient Removal (BNR) and a Trickling Filter (TF) system (Fig 8.2). The BNR effluent is discharged into Marimba River, while the TF effluent (with its higher nutrient content) is mixed with digested primary and secondary sludge and released onto the pastures. This mixing practice is to 'fluidise' sludge so as to enable its transportation to and distribution onto the pastures. The CWTP are seriously overloaded, receiving $97,000 \mathrm{~m}^{3} / \mathrm{d}$ of raw wastewater, while its total design capacity is only $54,000 \mathrm{~m}^{3} / \mathrm{d}$. This overloading is allowed to occur only in the TF line with no overloading allowed in the BNR system. About one-third of the TF effluent is discharged onto the CPI system, one third is pumped to Ingwe Pasture Irrigation farm, while the remaining one-third overflows from a holding pond directly into Marimba River. 


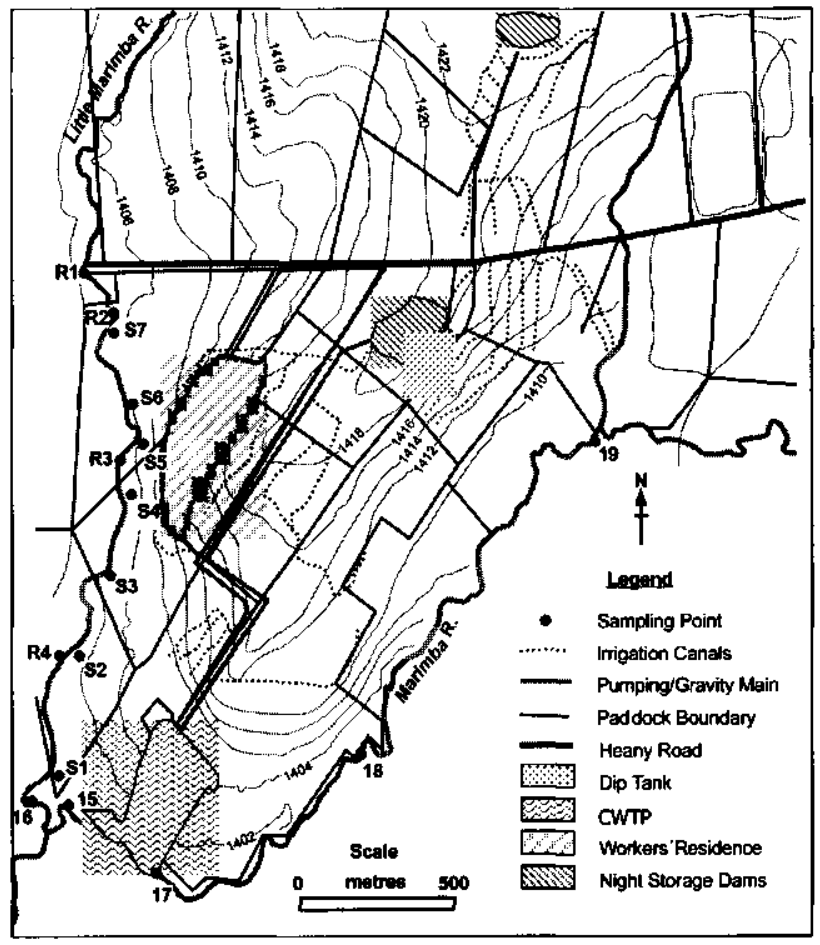

Figure 8.1: The layout of $\mathrm{CPI}$ and the location of water quality monitoring points

The CPI design was based on a dry weather hydraulic surface-loading rate of $100 \mathrm{~m}^{3} / \mathrm{ha} . \mathrm{d}$, allowing a safety factor of 1.5 times the average dry weather flow rate for wet periods. The pasture soils vary widely from clays derived from epidiorite in the north, through sandy clay loams from branded ironstone in the centre, to sandy loams and sands derived from granite in the south. Experiments on crop selection were reported back in 1968 and 1973 with maize, wheat, kikuyu grass (Pennisetum clandestinum) and star grass (Cynodon plectostochus) being considered the most appropriate (McKendrick and Wilson, 1968; Cormack, 1973). Whilst maize growing was the most ideal as a local staple food, it suffered from nitrogen deficiencies during wet seasons when it was not possible to apply the appropriate quantities of effluent. Star and kikuyu grasses were eventually selected because of their perennial demand for water and nutrients and their ability to take excessive irrigation loads or drought periods for long times. The added advantage of these grasses was their ability to absorb nitrogen from passing effluent through their leaves, and the limited costs of periodic land preparation. Cattle were allowed to graze on the pastures at a stocking density of $6-10$ livestock units per hectare (lu/ha), providing a good source of income. 


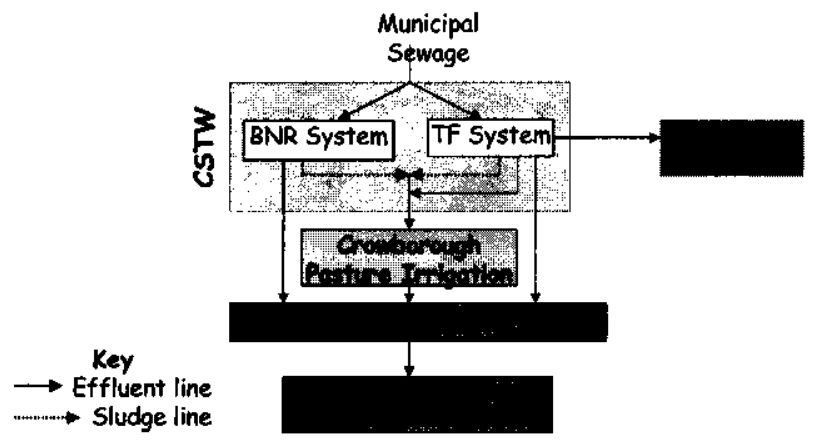

Figure 8.2: Crowborough wastewater treatment plant and its effluent disposal to the CPI

\section{Operational aspects}

A night storage dam with a volume of $13,200 \mathrm{~m}^{3}$ was provided based on 12-hour storage to cater for emergencies. The effluent/sludge mixture is supplied to the pastures daily regardless of crop water and nutrient requirements. Effluent is delivered to the pastures by three pumps with a combined capacity of $58,200 \mathrm{~m}^{3} / \mathrm{d}$. There is no worked out plan (nor infrastructure) for effluent distribution on the pastures. Designated drinking points for livestock were not provided, forcing cattle to drink from irrigation canals. The farm keeps a herd of 3,400 cattle, which is equivalent to a density of $11 \mathrm{lu} / \mathrm{ha}$ based on the actual 305 ha of irrigated land. The cattle have on average $450 \mathrm{~kg}$ live-weight after 2.5 years and about 670 livestock units (20\%) are sold each year, translating into a nutrient output. The mortality rate is 220 livestock units per year $(6 \%$ of the herd). A total of $46,100 \mathrm{~kg}$ ( $34 \% \mathrm{TN}$ and $0.5 \%$ TP content) livestock feed concentrates are consumed annually as supplementary animal feed. This translates into an extra nutrient input of $15,674 \mathrm{~kg}$ TN/yr and $230 \mathrm{~kg}$ TP/yr.

\section{Materials and methods}

\section{Water balance}

The CPI was assumed already saturated and the water balance defined as:

CWTP (effluent/sludge) + Precipitation = Evapotranspiration + Runoff + Seepage

The applied effluent /sludge mixture was determined from daily pumping records. Rainfall data recorded at CWTP were used to assess precipitation rates. Runoff was calculated using the SCS-SA method (Schulze et al., 1992). Seepage (or infiltration water) was estimated as the 
unknown factor in equation 8.1. Finally, evapotranspiration rates were estimated from equation 8.2:

$$
E T_{c}=K_{c} E T_{0}
$$

Where $E T_{c}=$ actual crop evapotranspiration $(\mathrm{mm} / \mathrm{d})$

$\mathrm{K}_{\mathrm{c}}=$ crop coefficient $( \pm 1$ for grass kept between $10-15 \mathrm{~cm}(\mathrm{FAO}, 1992))$

$E T_{0}=$ potential evapotranspiration ( $\left.=K_{\text {pan }} \times E_{\text {pan }}\right)$

$K_{\text {pan }}=0.75$ for Harare (Class A pan at wind speed $235 \mathrm{~km} / \mathrm{d}$ and humidity $64 \%$ )

\section{Nutrient balance}

A nutrient balance of the Crowborough pastures was developed based on the flow paths defined in the above water balance. Samples from locations shown in Fig 8.1 were collected to characterise effluent and sludge pumped to the pastures, seepage, and runoff. Besides these, other components of the balance studied are supplementary feed, grass nutrient uptake, cattle nutrient uptake, and annual beef export rates. Water samples were collected and analysed for TN $\left(\mathrm{NO}_{2}-\mathrm{N}+\mathrm{NO}_{3}-\mathrm{N}+\mathrm{TKN}\right)$ and TP according to Standard Methods (1995), from July 2000 to February 2001. A more intense fortnightly sampling programme concentrating on seepage was executed from October 2000 to January 2001. Runoff was only collected once because of the poor rainfall during the study time. The nutrient content of cattle feed was obtained from farm records and manufacturer's specifications. The grass nutrient uptake rates were obtained from literature (Feigin et al., 1990; Metcalf and Eddy, 1991) and nitrogen and phosphorus accumulation rates in cattie were obtained from Skerman (2000). Denitrification and volatilisation rates for nitrogen were assumed to be $55 \%$ of applied $\mathrm{N}$ (pH \pm 8 , average temperature of $25^{\circ} \mathrm{C}$, organic soils, moist conditions) (USEPA, 1981). The impacts of $N$ and $P$ exported as organic fertiliser and grass for planting as lawn were considered negligible. The applied nutrient loading rates to CPI pastures were evaluated in the context of the current legislation in Zimbabwe. Possible alternatives and their implications were explored to enhance the performance of the $\mathrm{CPI}$ system and so contribute to improved water quality management of the Lake Chivero basin.

\section{Results}

\section{Water balance}

Average quantities of $28,226 \mathrm{~m}^{3} / \mathrm{d}$ and $640 \mathrm{~m}^{3} / \mathrm{d}$ for effluent and sludge, respectively, were combined and pumped from CWTP to CPI. This resulted in an average crop water supply of 9.5 
$\mathrm{mm} / \mathrm{d}$ (ranging $0-14 \mathrm{~mm}$ ). The exact rate was difficult to assess due to regular electricity outages caused by national load shedding and pump failures. The highest application rates, unfortunately, coincided with periods of highest rainfall in November; suggesting an unbalanced application regime. During the period September 2000 to January 2001 only 18 rainfall days with a total of $416 \mathrm{~mm}$ rainfall were observed (10-year average for this period is $496 \mathrm{~mm}$ ). Average evapotranspiration rates of $5.8 \mathrm{~mm} / \mathrm{d}$ (September); $6.3 \mathrm{~m} / \mathrm{d}$ (October); $5.2 \mathrm{~mm} / \mathrm{d}$ November; $4.5 \mathrm{~mm} / \mathrm{d}$ (December); and $4.3 \mathrm{~mm} / \mathrm{d}$ (January) were used based on meteorological data from the Department of Water Development in Harare (Department of Water, 1995). A summary of the water balance is shown in Table 8.1. Although seepage was generally observed throughout the study period, there were some inconsistent periods of nil to low flows, varying from point to point and from time to time.

Table 8.1: Major water balance components for CPI over the research period Sept 2000 - Jan 2001

\begin{tabular}{l|rrrrr}
\hline Month & $\begin{array}{r}\text { Precipitation, } \\
m^{3}\end{array}$ & $\begin{array}{r}\text { Effluent/sludge } \\
\text { Mixture, } m^{3}\end{array}$ & $\begin{array}{r}\text { Evapotranspiration, } \\
m^{3}\end{array}$ & $\begin{array}{r}\text { Runoff, } \\
m^{3}\end{array}$ & $\begin{array}{r}\text { Seepage, } \\
m^{3}\end{array}$ \\
\hline Sept 2000 & 0 & 991,250 & 530,700 & 0 & 460,550 \\
Oct & 18,300 & $1,064,450$ & 595,665 & 0 & 487,085 \\
Nov & 480,375 & $1,143,750$ & 475,800 & 134,200 & $1,014,125$ \\
Dec & 343,125 & 704,550 & 425,475 & 61,000 & 561,200 \\
Jan 2001 & 305,000 & 256,200 & 406,565 & 54,900 & 99,735 \\
TOTAL & $1,146,800$ & $4,160,200$ & $2,434,205$ & 250,100 & $2,622,695$ \\
\hline
\end{tabular}

\section{Sampling results and fate of nutrients at $\mathrm{CPI}$}

A summary of the results for TN and TP analyses is presented in Table 8.2. The sludge from humus tanks (in the trickling filter system) formed an internal cycle in the system as it was continuously returned to the inlet works. This would have an effect on concentrations in subsequent units as an internal recycle is established. Points $R 1$ and 16 (Fig. 8.1) were respectively located before and after seepage discharges into Little Marimba while R2, R3 and R4 were intermediate points on this stretch. There was a significant build-up in nutrient levels along the river due to seepage intrusions and accidental discharges of effluent/sludge mixtures. Points 18 and $17 \mathrm{U}$ are respectively upstream and downstream of seepage discharge points into Marimba River itself. Nutrient concentrations increased between these two points. The average reduction efficiencies of CPI were found to be $84 \%$ for TN and $54 \%$ for TP. Reduction is here defined as that part of the nutrients that does not end up in the river-lake system. In this case, e.g., infiltration into groundwater is partial reduction. Table 8.3 was developed to show the fate of nutrients at CPI. 
Table 8.2: Summary of analytical results ( \pm standard deviations; for Station identification see Fig 8.1)

\begin{tabular}{l|rrr}
\hline Station & \# of Samples & $T \mathrm{~N}, \mathrm{mg} /$ & $T P, \mathrm{mg} /$ \\
\hline Raw wastewater & 7 & $31.7 \pm 19.0$ & $6.5 \pm 3.1$ \\
BNR Effluent & 7 & $4.3 \pm 3.5$ & $0.9 \pm 0.3$ \\
Trickling filter effluent & 10 & $33.3 \pm 28.8$ & $7.3 \pm 4.6$ \\
Digested sludge & 6 & $939.7 \pm 783.2$ & $152.4 \pm 52.3$ \\
Runoff & 4 & $28.8 \pm 12.9$ & $12.8 \pm 14.1$ \\
Seepage (S1-S7) & 30 & $12.0 \pm 3.1$ & $7.0 \pm 4.9$ \\
R1 & 6 & $3.1 \pm 1.3$ & $0.9 \pm 0.3$ \\
R2 & 6 & $4.0 \pm 1.3$ & $3.7 \pm 1.8$ \\
R3 & 6 & $7.1 \pm 2.6$ & $3.1 \pm 3.1$ \\
R4 & 6 & $9.1 \pm 3.3$ & $3.1 \pm 2.4$ \\
15 & 7 & $36.7 \pm 32.5$ & $3.1 \pm 1.2$ \\
16 & 7 & $8.9 \pm 0.6$ & $3.4 \pm 2.4$ \\
17 & 6 & $21.1 \pm 2.3$ & $1.2 \pm 0.3$ \\
18 & 8 & $7.9 \pm 5.7$ & $0.9 \pm 0.3$ \\
19 & 6 & $3.7 \pm 0.4$ & $0.9 \pm 0.3$ \\
\hline
\end{tabular}

Table 8.3: Nitrogen and phosphorus fluxes at CPI based on 305 ha irrigated land

\begin{tabular}{l|rr}
\hline FLUX & $T N, \mathrm{~kg} / \mathrm{d}$ & $T P, \mathrm{~kg} / \mathrm{d}$ \\
\hline INPUT & 940 & 206 \\
CWTP effluent & 601 & 98 \\
CWTP sludge & 43 & 1 \\
Imported cattle feed (46 100 kg annually; 34\% TN and 0.5\% TP) & 1584 & 305 \\
Total Input & & \\
OUTPUT & -206 & -120 \\
Seepage & -47 & -21 \\
Runoff & -21 & -6 \\
Beef export, 670 heads annually (figure reduced to daily) & -852 & - \\
Denitrification and ammonia volatilisation; 55\% of effluent sludge mixture & -1126 & -147 \\
Total Output & & - \\
INTERMEDIATE (transitional)* & -226 & - \\
Nitrogen plant uptake @ 270 kg N/ha.yr ** & - & -33 \\
Phosphorus plant uptake @ 40 kg P/ha.yr ** & -44 & - \\
Nitrogen animal uptake @ 0.013 kg live weight gain/livestock/day *** & - & -14 \\
Phosphorus animal uptake @ 0.004 kg live weight gain/livestock/day *** & 270 & 47 \\
Total intermediate & & \\
ACCUMULATION & -458 & -158 \\
Plant-soil matrix & -458 & -158 \\
Total Accumulation & & \\
\hline Plass and animal nutrient uptakes have been included in Table 8.3 only as intermediate or transitional fluxes \\
All livestock assumed to be of weight-gaining age & & \\
\hline
\end{tabular}


The amounts retained in the plant-soil matrix were determined as the unknown in the mass balances and amounted to $1.5 \mathrm{~kg} \mathrm{~N} / \mathrm{ha}$.d; much higher than rates up to $0.62 \mathrm{~kg} \mathrm{~N} / \mathrm{ha.d}$ reported by USEPA (1981). Different climatic and operating conditions would account for the difference. Up to $70 \%$ (average $25-30 \%$ ) of $\mathrm{NO}_{3}$ can be lost in the soil due to denitrification (Feigin et al., 1990; Skerman, 2000). There is a need for further research to establish the actual rates of denitrification in order to come out with a more accurate mass balance for CPI.

The results in Table 8.3 also show that about $52 \%$ phosphorus retention is being achieved in the plant-soil matrix. This does not support the assumption that the phosphorus sorption capacity of these soils has been far exceeded after years of continuous irrigation. Experiments on soil P-sorption capacity are required to confirm this. Seepage and accumulation in the plant/soil matrix were the major pathways for phosphorus. Of the influent nitrogen and phosphorus, about $29 \%$ and $48 \%$ respectively were accumulated in the pastures. Considering the hydraulic loading on the pastures, it is possible that they are now acting as a sludge drying bed, retaining the nutrients in the dry season and releasing them into the river in wet weather via runoff.

\section{Pollution loads to Marimba River}

The discharge of nutrients from the Crowborough wastewater treatment system into the Marimba River is shown in Fig 8.3.

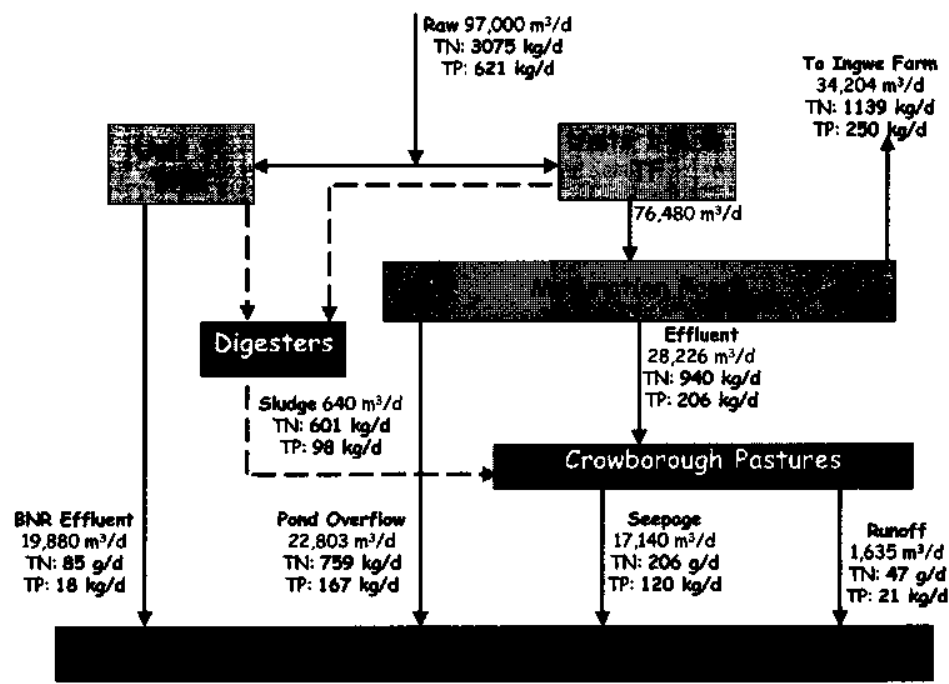

Figure 8.3: Daily nutrient flows into Marimba River in relation to wastewater treatment based on data for July 2000 - February 2001 (BNR = biological nutrient removal; TF = trickling filter) 
For the studied period, the current system allowed the following flows directly or indirectly to Marimba River: $1,097 \mathrm{~kg} / \mathrm{d}$ TN or $36 \%$ of the incoming TN, and $326 \mathrm{~kg} / \mathrm{d}$ TP or $52 \%$ of the incoming TP (Fig 8.3, derived from concentrations in Table 8.2). Seepage contributed $19 \%$ of the TN and $36 \%$ of the TP loads to Marimba River, whilst pond overflow appeared to be the major polluter of this river, contributing $69 \%$ of the TN and $51 \%$ of the TP loads. The pond overflows are due to the hydraulic overloading the Crowborough wastewater treatment plant was receiving, on average, $97,000 \mathrm{~m}^{3} / \mathrm{d}$ when its design capacity is only $54,000 \mathrm{~m}^{3} / \mathrm{d}$.

\section{Discussion}

\section{Regulatory constraints}

New effluent regulations were recently enacted in Zimbabwe (S.I. 274 of 2000; Water (Waste and Effluent Disposal) Regulations) requiring that councils apply for a permit before disposal of sludge onto land. These regulations and their implications on CPI are shown in Table 8.4. Column 3 gives the permissible nitrogen loading rates as per the new regulations. Column 4 gives the land requirements for current nitrogen discharges at CPI to remain within listed regulation categories. Column 5 gives the land that would be required to meet standards assuming that sludge is disposed off elsewhere. Permits classify słudge disposal practices onto land according to the risk level posed by application rates of nitrogen and cadmium.

Table 8.4: Zimbabwe effluent regulations on nitrogen loading on pastures and implications on CPI (Government of Zimbabwe, S.I. 274 of 2000)

\begin{tabular}{l|lrrr}
\hline Classification & Risk & $\begin{array}{r}\text { Permissible } \\
\text { Nitrogen Loading } \\
\text { Rate, kg Nha.yr }\end{array}$ & $\begin{array}{r}\text { Land Required to } \\
\text { Meet Standards: } \\
\text { Current Practice, ha }\end{array}$ & $\begin{array}{r}\text { Land Required to } \\
\text { Meet Standards: } \\
\text { Using Effluent Only } \\
\text { (Without Sludge), ha }\end{array}$ \\
\hline Blue & Safe & 300 & 2,798 & 2,067 \\
Green & Low hazard & 450 & 1,865 & 1,378 \\
Yellow & Medium hazard & 600 & 1,399 & 1,033 \\
Red & High hazard & $>600$ & $<1,399$ & $<1,033$ \\
\hline
\end{tabular}

The current loading rates at CPI are $1,844 \mathrm{~kg} \mathrm{~N} / \mathrm{ha} . \mathrm{yr}$ for the effluent/sludge mixture and would be $1,125 \mathrm{~kg} \mathrm{~N} / \mathrm{ha}$.yr if only effluent was being applied. The gross land available at CPI of $594 \mathrm{ha}$ is, therefore, not sufficient to meet safe loading rates prescribed by the regulations. The water quality in Little Marimba River before (R1) and after discharge of seepage (16) shows serious 
levels of contamination, necessitating stricter regulations in this catchment. In fact, the Lake Chivero basin is a very sensitive area and only the blue (safe) category of the regulations should be applied (Table 8.4).

\section{Improved management of CWTP}

The City of Harare has either to deal with the overloading (to improve nitrogen removal at CWTP), or it has to seek an extra 2,493 ha for safe effluent/sludge disposal (1,762 ha if effluent alone is used for irrigation). This is based on the assumption that no extra loads can be sent to Ingwe Farm and no pond overflow will be allowed. Two options could thus be followed in managing the CWTP. Firstly, the trickling filter system could be phased out and replaced by a BNR system of capacity of about $77,000 \mathrm{~m}^{3} / \mathrm{d}$ adjusted to a design period. Basing onty on this flow of $77,000 \mathrm{~m}^{3} / \mathrm{d}$ (about $770,000 \mathrm{PE}$ ) in the trickling filter line, and unit cost of US\$32/PE (average of 7 recently constructed BNR systems in Zimbabwe, Nhapi et al., 2002), this option would require an investment of US $\$ 25$ million or ZWD105 billion (1 US $\$=4,200 \mathrm{ZWD}$, March 2004). Assuming similar performance as the current BNR system, the current loads to Marimba River would be reduced from $1,097 \mathrm{~kg} / \mathrm{d}$ to $417 \mathrm{~kg} / \mathrm{d}(62 \%)$ for TN and from $107 \mathrm{~kg} / \mathrm{d}$ to $29 \mathrm{~kg} / \mathrm{d}$ $(73 \%)$ for TP. The sludge would have to be handled separately and disposed off as landfill. This option, however, defeats the objective of nutrient recovery, as sludge is very rich in nutrients (but contains a variety of toxins).

The trickling filter system has not been operating well because of frequent breakdowns and overloading. The second option will be to rehabilitate this system and achieve a better $B O D_{5}$ effluent quality and use only the effluent for irrigation. This would require purchasing additional land at a cost of US $\$ 100,000$ (ZWD420m) at current urban land costs. The cost of land in Harare is very high and suitable land might be difficult to find within the boundaries of Harare. Trickling filter systems could reduce $\mathrm{BOD}_{5}$ by 40 up to $95 \%$ depending on the rating and staging but are poor at TN and TP removal (Metcalf and Eddy, 1991). The overland treatment portion would, however, achieve $75-90 \%$ TN and $50-70 \%$ TP removal efficiencies. With proper irrigation management, this would mean that only $225-508 \mathrm{~kg} / \mathrm{d}$ TN and $43-67 \mathrm{~kg} / \mathrm{d}$ TP would reach Marimba River compared to current figures of $1,097 \mathrm{~kg} / \mathrm{d}$ TN and $107 \mathrm{~kg} / \mathrm{d}$ TP. The desirability of land-intensive systems like pasture irrigation is becoming more questionable because of urbanisation land pressures. In the long-term, the city would be compelled to look for irrigation options further downstream, and far out of the current urban boundaries. The current practice should also be discouraged from an environmental perspective as sludge could be heavily contaminating the soils with heavy metals (Manjonjo, 1999; Chimbari et al., 2004). The continued use of land application of wastewater should be complemented by concerted efforts 
to control the dumping of toxic materials into the sewer system, uncoupling industries, and educating domestic water users.

\section{Optimisation of operations at CPI}

The CPI could be optimised via increased plant nutrient uptake, optimum cattle density, or nutrient exports through cow dung vending. Table 8.3 shows that plant uptake could potentially contribute significantly to nutrient outflows from the pastures, especially if the grass is harvested regularly. Beef production removes only $2 \%$ TN and $12 \%$ TP but produces a gross revenue of about US $\$ 335,000$ annually, assuming a selling price of US\$500/livestock unit. The economic viability of beef production needs a separate study. The mortality rate of 220 livestock units per year (6\% of the herd) is also high compared to the 670 heads sold annually. A separate (dedicated) feedlot system would reduce the risks of diseases associated with effluent irrigated pastures. The pastures have been found to be an ideal incubator for all sorts of pests, diseases, etc, and expensive control measures are needed to keep the cattle in good health (McKendrick, 1982; Chimbari et al., 2004). Although the pastures do not show visible signs of strain, the present stocking density of 11 livestock units per hectare is on the high side; Cormack (1973) recommended 6 - 10 livestock per hectare.

Encouraging organised vending of cow dung by neighbouring residents could also enhance the export of nutrients from CPI. Urban residents cultivate all the surrounding areas of the CPI. Whilst these might have objections to direct use of treated wastewater, at least they could reduce the use of artificial fertilisers by substituting it with cow dung. This can be composted by mixing with pasture grass and the product sold as organic manure.

\section{Irrigation distribution and grazing scheme}

It was observed that some secondary irrigation canals at CPI were completely clogged. This affected uniform water distribution, leading to water-logging and short-circuiting or preferred pathways. This could potentially contribute to variations in seepage quality and could increase runoff. The application of the effluent/sludge mixture should ideally rotate over the pastures to allow dry periods for pathogen die-off. Dedicated cattle drinking points are required to avoid cattle drinking from irrigation waters. The pastures were originally designed with $3-4$ weeks break periods between the application of irrigation water and the onset of cattle grazing (Cormack, 1973). With the current hydraulic overloading of the system, a rotational system will result in excessive runoff. 


\begin{abstract}
Alternative crops
Maize is the staple crop in Zimbabwe and its cultivation in effluent-irrigated farms could be an attractive option. According to Bowyer-Bower et al. (1996), by 1994 about 9,288 ha were under (maize) cultivation in Harare and this figure is now more than double. Using fertiliser application rates of $175 \mathrm{~kg} / \mathrm{ha} \mathrm{N}$ and $30 \mathrm{~kg} / \mathrm{ha} P$ (Veeberk, personal communications) as local figures to produce $7,000 \mathrm{~kg} / \mathrm{ha}$ maize grain, 1,182 ha would be required to take up all the nitrogen currently being sent to the pastures as effluent and to Marimba River as pond overflow (based on three crops per year). For this area, $20.6 \mathrm{t}$ of TP would still be required which could be imported to the catchment to make up for the required $35.4 \mathrm{t}$ of $\mathrm{P}$. The maize can be sold for ZWD7.45 billion per annum (US $\$ 1.77$ million), which is much more than the current income from beef sales of US $\$ 335,000$. Maize cultivation could be done in conjunction with neighbouring plot holders to obtain the required acreage. Further studies are required to fully establish the cost/benefit of growing maize versus the current pasture irrigation system.
\end{abstract}

\title{
Conclusions and recommendations
}

The land application of wastewater at Crowborough is contributing significantly to the pollution of the Marimba River. Removal efficiencies for CPI are significant for TN at $84 \%$ but fairly good for TP at $54 \%$, but the loads are still too high. Denitrification and ammonia volatilisation were considered the main removal mechanism for nitrogen whilst soil phosphorus removal showed some limitations, probably due to reduced phosphorus sorption capacity of the pastureland soils. The allowable cattle stocking density has been exceeded, affecting proper management of the irrigation scheme. The supplying wastewater treatment works are also overloaded, delivering poor quality effluent to $\mathrm{CPI}$, and are now in urgent need of upgrading. Harare City Council must also improve resource recovery by harvesting the pasture grass and selling the cow dung to neighbouring residents.

The mixing of effluent and sludge after treatment is irrational and should be stopped as sludge contains a host of pollutants that should be disposed of separately and safely. From a nutrient management point of view, the importation of nutrients as supplementary feed for cattle is also not desirable.

The role of denitrification and volatilisation of ammonia from the pastures, the sorption capacity of the soils, and the economic viability of beef production against other attractive options like maize growing, need further investigation. 


\section{References}

Bowyer-Bower, T.A.S., Mapaure, I. and Drummond, R.B. (1996) Ecological Degradation in Cities: Impact of Urban Agriculture in Harare, Zimbabwe, JASSA Vol. 2 (2), p53 - 67.

Chimbari, M.J., Madyiwa, S., Mukaratirwa, S. and Musesengwa, R. (2004). Pollution Implications of Disposing Wastewater on Pasturelands, Final Project Report, Institute of Water and Sanitation Development, Harare, Zimbabwe.

Cormack, R. (1973) Farming Aspects of Pollution Control, Internal Report, City Engineer's Department, Harare, Zimbabwe.

Department of Water (1995) Assessment of Surface Water Resources in the Manyame Catchment Zimbabwe; Streamflow Gauging and Conceptual Hydrological Modelling, Government of Zimbabwe, Department of Water, SMHI Hydrology No. 60, 1995.

FAO (1992) Irrigation and Drainage Paper 24: Crop Water Requirements, Food and Agricultural Organisation Publications, Rome, Italy.

Feigin, A., Ravina, I., and Shalhevet, J. (1990) Imigation with Treated Sewage Effluent: Management for Environmental Protection. Advanced Series in Agricultural Sciences, Vol. 17.

Government of Zimbabwe, (2000) Statutory instrument (S.I.) 274 of 2000, Water (Waste and Effluent Disposal) Regulations, Government Publications, Harare.

Manjonjo, M (1999) Impact of Land Disposal of wastewater Sludge and Effluent on Surface Water - A Case Study of the Impact of Crowborough Farm on Marimba River in Harare, Zimbabwe, MSc WREM Thesis, University of Zimbabwe, Harare, Zimbabwe.

McKendrick, J and Williams, R.K. (1968) The Effects of Urban Drainage on Lake Mcllwaine, Rhodesia and Subsequent Water Purification Difficulties (Unpublished paper) - Bulawayo 23-24 July 1968, p13. Mckendrick, J. (1982) Water Supply and Sewage Treatment in Relation to Water Quality in Lake Mcllwaine. In Lake Mcllwaine; The Eutrophication and Recovery of a Tropical African Man-Made Lake, edited by Thornton, J.A. and Nduku, W.K. Dr W Junk Publishers, The Hague, The Netherlands, p202-217.

Metcalf and Eddy (1991) Wastewater Engineering: Treatment, Disposal and Reuse, McGraw - Hill, Inc, Singapore.

Moyo, N.A.G. (1997) Causes of Massive Fish Deaths in Lake Chivero, in Moyo, N.A.G. (Ed.) Lake Chivero: A Polluted Lake, University of Zimbabwe Publications, Harare, Zimbabwe.

Nhapi, I., Siebel, M.A., and Gijzen, H.G (2001) Dry Season Inflow and Export of Nutrients from Lake Chivero in Year 2000; in Proceedings of the Zimbabwe Institution of Engineers, Vol. 2(1), p33-41.

Nhapi, I., Hoko, Z., Siebel, M. and Gijzen, H.J. (2002) Assessment of Major Water and Nutrient Flows in the Chivero Catchment Area, Zimbabwe, Physics and Chemistry of the Earth, Vol. 27(11-22), p783792.

Nhapi, I., Siebel, M.A., and Gijzen, H.G (2003) A Conceptual Framework for the Sustainable Management of Wastewater in Harare, Zimbabwe; IWA Wat. Sci. Tech., Vol. 47(7-8), p11-18.

Schulze, R., Schimdt, E.J., and Smithers, J.C. (1992) SCS-SA User Manual: PC-based SCS Design Flood Estimates for Small Catchments in Southem Africa, IHE Lecturenotes, Delft, The Netherlands. 
Skerman, A. (2000) Department of Primary Industries: Intensive Livestock Environmental Management Services in Quensland, Australia, Internet site: http://www.dpi.qld.gov.au/ilems.

Standard Methods for the Examination of Water and Wastewater (1995). 19th edn, American Public Health Association/American Water Works Association/Water Environment Federation, Washington DC, USA.

USEPA (1981) Process Design Manual: Land Disposal of Municipal Wastewater, EPA 625/1-81 0.13, Washington, USA. 


\section{Chapter 9}

\section{A Proposal for the Sustainable Management of Wastewater in Harare, Zimbabwe}

Submitted as:

Nhapi, I., Siebel, M.A. and Gijzen, H.J. (2002) A Proposal for the Sustainable Management of Wastewater in Harare, Zimbabwe, IWA Water Research. 


\title{
A Proposal for the Sustainable Management of Wastewater in Harare, Zimbabwe
}

\begin{abstract}
The management of wastewater should aim at pollution prevention first, followed by pollution control aimed at resource recovery and reuse. This approach offers great potential to enhance water availability and to protect water resources from pollution. This Chapter deals with wastewater management in Harare, the capital city of Zimbabwe, which is located upstream in the Lake Chivero catchment area. The Chapter aimed at developing a sustainable system for managing water and nutrients (nitrogen and phosphorus) with particular emphasis on wastewater. Data from previous studies and findings from a water quality monitoring study of June 2000 - December 2001 were used. A so-called "3-Step Strategic Approach" to urban (waste)water management was used as a basis for formulating solutions. Under each of the three steps, short-term, medium-term, and long-term solutions were considered. The short-term solutions include reduction of wastewater volume through cleaner production approaches and process reengineering in industries, with the overall objectives of enhancing water availability and controlling pollution. The medium-term solutions involve treating wastewater to high standards, introducing or improving resource recovery and reuse options, and controlling upstream point and non-point sources of pollution. A long-term solution was suggested based on pollution prevention and direct reuse, treatment at onsite and decentralised levels followed by reuse, and minimal disposal of remaining effluents combined with the stimulation of the self-purification capacity of the receiving rivers. Short-term measures would reduce wastewater flows by $24 \%$ and TP by $5 \%$. It is predicted, through modelling, that respective lake TN and TP would be reduced to $0.4 \mathrm{mg} / \mathrm{l}$ and $0.07 \mathrm{mg} / \mathrm{l}$ via measures proposed for the medium-term. The long-term measures would aim at sustaining this lake water quality under increased urbanisation conditions. It was concluded that it is feasible to reduce pollution levels in the catchment by applying these phased developments.
\end{abstract}

Keywords: 3-Step Strategic Approach, integrated water management proposal, Lake Chivero, pollution prevention, wastewater management strategies, staged approach

\section{Introduction}

The sustainability of urban water management poses serious challenges in the face of rapid urbanisation taking place in most developing countries. In these countries, extreme climatic conditions of drought and cyclones coupled with rapid population growth result in significant financial resources being channelled into the provision of clean drinking water and sanitation 
services. In many cases, these resources are scarce and only applied in a reactive manner to mitigate effects of droughts and to combat disease outbreaks. The planning authorities are rarely given enough time and space to properly plan decent settlements with sustainable and adequate water and sanitation facilities.

Recent initiatives, notably the Dublin Principles (ICWE, 1992) and Vision21 (Cosgrove and Rijsberman, 2000), acknowledge the shortcomings of current approaches to water services management and seek concerted efforts to find lasting solutions (King, 2000). The importance of improved water supply and sanitation provision was again emphasised in the Millennium Development Goals (UN, 2003). The Environmental Resources Department at the UNESCOIHE Institute for Water Education has, in line with Vision 21 and the Bellagio statement, proposed a cleaner production approach to urban water management (Siebel and Gijzen 2002; Gijzen 2001, 2002, 2003). This involves pollution prevention/minimisation, and resource recovery, reuse and recycling at all levels (household, on site, decentralised and centralised) and in all sectors (domestic, commerce, industries).

Goal 7 of the Millennium Development Goals (MDGs) seeks to ensure environmental sustainability by drastically reducing the proportion of people without adequate access to safe drinking water and appropriate sanitation by 2015. If this goal is to be realised, both technical and engineering solutions are required, whilst changes are also required in managerial, institutional, and regulatory areas. Most of the solutions being suggested emphasise on full-cost recovery management of water and sanitation services, resource recovery and reuse, and the use of simple, low-cost treatment methods. Innovative sewerage systems such as vacuum sewers, small-bore sewers, and intermediate (settled) sewerage are essential for managing reduced volumes of wastewater proposed in new approaches. In fact, a paradigm shift is required as current mainstream technologies for urban water and sanitation services are too costly, not rational and ineffective. The two goals suggested in the MDGs are conflicting: more water supply coverage will cause more wastewater generation which needs treatment again. There is a substantial risk that especially the sanitation targets will yet again not be met. Although sanitation does not necessarily include wastewater treatment, these are placed under the goal 'sustainable environment' which suggests that wastewater and nutrient management are very high on the agenda.

The capital city of Zimbabwe, Harare, is one of the towns that are facing serious urban water management problems. Harare is located in the Lake Chivero sub-catchment area, draining into Lake Chivero whilst also collecting its potable water supply from the same reservoir. In this way, the lake serves as a sink for pollutants that were not effectively removed via wastewater 
treatment or reuse. Wastewater is believed to be the major direct and indirect source of pollution in Lake Chivero (Moyo, 1997; Nhapi et al., 2001).

This Chapter is based on results of a monthly water quality monitoring study in Harare, covering wastewater treatment plant (WTP) effluent, pasture irrigation runoff and seepage, and river and lake water quality, conducted from June 2000 to December 2001. The monitoring part focused on water flows, nitrogen and phosphorus concentrations. Possible solutions for limiting nutrient inflows into Lake Chivero are discussed. The solutions include pollution prevention and minimisation at sources of generation, resource recovery (nutrients, biogas and water) and reuse, and effluent/sludge disposal options. A 3-Step Strategic Approach (Nhapi et al., 2002a; Gijzen, 2003) is used in formulating solutions. Fig 9.1 places this Chapter into context.

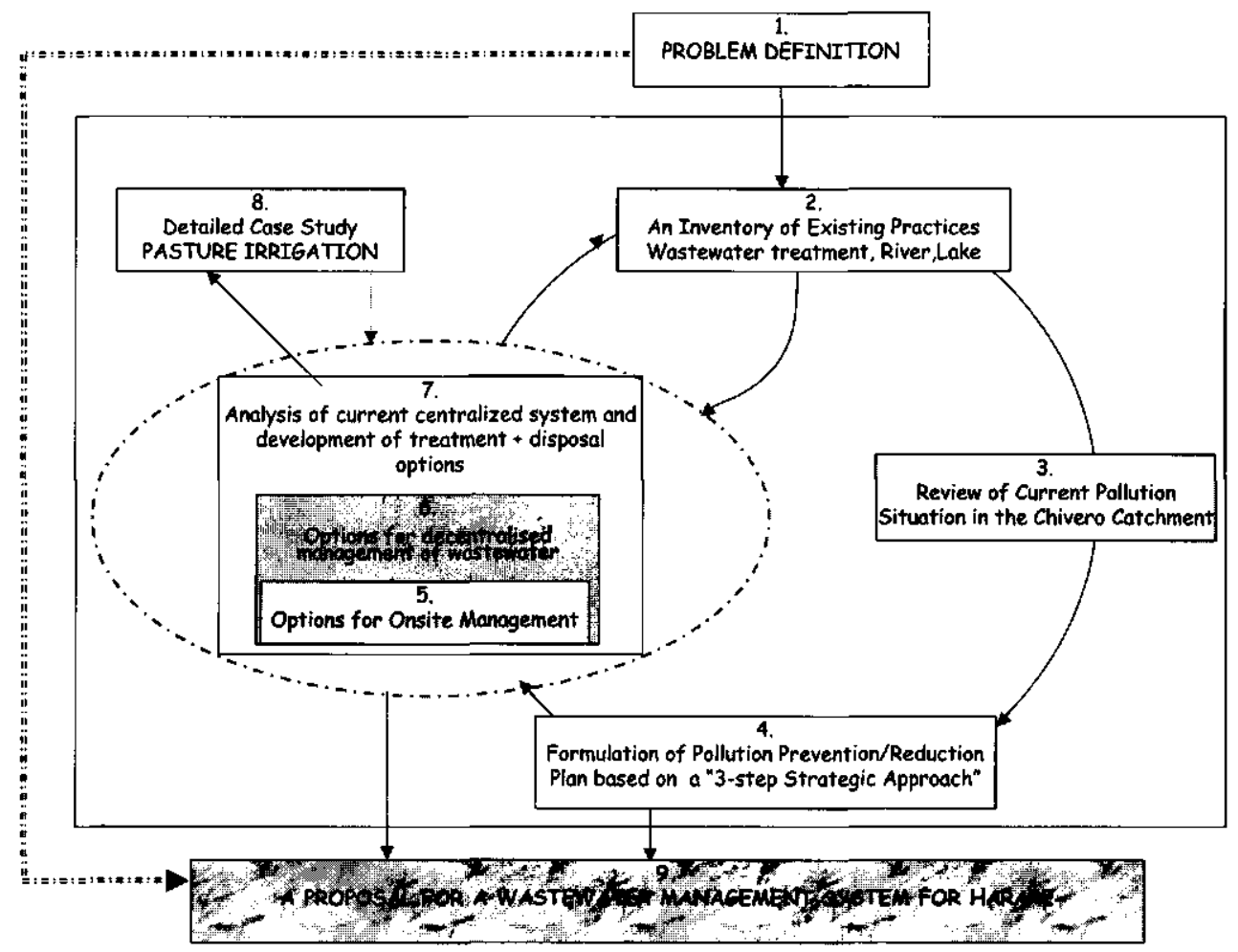

Figure 9.1: The structure of the overall study on wastewater management in Harare (the numbers in caption refer to the sequence of chapters/papers produced in the course of the study)

The individual numbers in Fig 9.1 represent chapters/papers covered in separate publications and these form the building blocks in an overall strategy for the sustainable management of wastewater in Harare. The chapters/papers covered the introduction and problem definition (No. 
1), an inventory of the existing wastewater management practices (No. 2, Nhapi et al., 2002b) and a detailed monitoring of the pollution situation in the Chivero catchment (No. 3, Nhapi et al., 2004). An overall framework based on the 3-Step Strategic Approach was then formulated (No. 4; Nhapi et al., 2002a). Subsequent chapters/papers (No. 5, Nhapi et al., 2002c; No. 6, Nhapi et al., 2002d; and No. 7, Nhapi et al., 2003) looked in detail into options for managing wastewater at various stages of onsite, decentralised and centralised levels, within the context of the 3-Step Strategic Approach. A detailed case study on reuse via pasture irrigation was carried out (No. 8 , Nhapi et al., 2002e). The current chapter/paper (No. 9 in Fig 9.1) synthesises all previous findings and develops a composite solution for the sustainable use of water and nutrients in the Lake Chivero catchment. The overall strategy consists of three important components a) a 3Step Strategic Approach (this shows how to approach the problem), b) a differentiated approach (this shows where to do what: residential, commercial, and industrial areas), and c) a staged approach (this shows when to do what; that is the short, medium and long term action plan). The 3 steps are covered as follows: No. 5 - step 1; No. 6 and 7 - step 2; and No. 7 and 8 - step 3. Although these chapters/papers dealt mainly with one step for each paper, there are of course clear interactions and therefore overlaps especially for steps 2 and 3.

\section{Current water management problems in Harare}

\section{Wastewater generation}

Harare has problems relating to high water consumption in low and medium-density residential areas. Studies have shown that the respective water consumption figures are about 630 Vcap.d and $320 \mathrm{l} / \mathrm{cap} . d$ (JICA, 1996). In these areas $20 \%$ of the total population of Harare accounts for $32 \%$ of the total domestic water consumption. The water consumption figure for high-density areas is reasonably low at 80 l/cap.d (JICA, 1996; Hoko, 1999). Here $80 \%$ of the population uses only $31 \%$ of the total water consumption, in other words the rich $20 \%$ uses about the same quantity of water as the $80 \%$ poor. In comparison, the average water consumption in the second largest city of Zimbabwe, Bulawayo is $36 \mathrm{l} /$ cap.d for high-density and $75 \mathrm{l} /$ cap.d for low-density residential areas (BCC, 2001). The sources of wastewater in Harare for the year 2002 are shown in Table 9.1. High-density areas produce the bulk of the nutrients ( $70 \%$ of total) because of the high population number. An estimated $304,000 \mathrm{~m}^{3} / \mathrm{d}$ of wastewater was produced in Harare in the year 2002. A big challenge in Harare is what to do with the increasing volume of wastewater produced, and especially the discharge of nutrients. 
Table 9.1: Estimated sources of wastewater in Harare, year 2002 (JICA, 1996; Nhapi et al., 2002b)

\begin{tabular}{l|rrrr}
\hline Landuse & Population & Flow $\mathrm{m}^{3} / \mathrm{d}$ & $\mathrm{TN}, \mathrm{kg} / \mathrm{d}$ & $\mathrm{TP}, \mathrm{kg} / \mathrm{d}$ \\
\hline Low-density unsewered & 76000 & 24,000 & 990 & 110 \\
Low-density sewered & 137,000 & 43,000 & 1,340 & 190 \\
Medium-density & 164,000 & 31,000 & 1,480 & 210 \\
High-density & $1,485,000$ & 94,000 & 12,290 & 1,780 \\
Commercial & & 62,000 & 1,390 & 150 \\
Industrial & & 51,000 & 340 & 110 \\
Total & $1,862,000$ & 304,000 & 17,810 & 2,550 \\
\hline
\end{tabular}

\section{Wastewater treatment}

Problems relating to wastewater treatment in Harare have been discussed by McKendrick (1982), Manjonjo (1999), Kamudyariwa (2000), Mawere (2001), Tirivarombo (2001), and Nhapi et al. (2003). The wastewater treatment plants (WTP) are overloaded due to rapid population growth and a halt in new construction of treatment plants since 1996. Frequent breakdowns also contribute to untreated or partially treated wastewater discharges into receiving rivers. The treatment technologies and capacities of the five wastewater treatment plants in Harare are shown in Table 9.2. From the table it is clear that $55 \%$ of the wastewater is 'treated' in systems that are heavily overloaded (i.e. more than $36 \%$ over the design capacity). The treatment plants have a combined nutrient removal efficiency of $24 \%$ for total nitrogen (TN), and $8 \%$ for total phosphorus (TP) (Nhapi et al., 2003).

The estimated total wastewater flows slightly differ from the average measured figures by $6 \%$ (Tables 9.1 and 9.2), and this is attributed to malfunctioning meters and estimation errors. (The estimates were used to validate the per capita wastewater production figures that were used in making future projections.) Infiltration also plays a significant role in water inflows at wastewater treatment plants (6\%) (Nhapi et al., 2002b) The trickling effluent and primary/secondary sludge are mixed and pumped to pasture irrigation farms. The effluent from activated sludge plants modified for biological nutrient removal (often referred to as BNR plants) is discharged into rivers whilst waste stabilisation pond (WSP) effluent is supposed to be pumped to farms for irrigation. Plant failures and insufficient land for irrigation, however, have resulted in the WSP effluent being discharged straight into rivers. 
Table 9.2: Overview of technologies, capacities and loading condition of existing wastewater treatment plants in Harare, year 2002 scenrio (BNR = biological nutrient removal)

\begin{tabular}{l|lrrrr}
\hline Wastewater & Treatment Type & Capacity, & \multicolumn{3}{c}{ Inflow, Overioading, Overioading, } \\
Treatment Plant & & $\mathrm{m}^{3} / d$ & $\mathrm{~m}^{3 / d}$ & $\mathrm{~m}^{3} / d$ & $\%$ \\
\hline Crowborough & BNR + trickling filter & 54,000 & 107,000 & 53,000 & 98 \\
Firle & BNR + trickling filter & 144,000 & 153,000 & 9,000 & 6 \\
Marlborough & Waste stabilisation ponds & 2,000 & 11,000 & 9,000 & 450 \\
Donnybrook & Waste stabilisation ponds & 5,500 & 9,000 & 3,500 & 64 \\
Hatcliffe & Extended aeration & 2,500 & 4,000 & 1,500 & 60 \\
Total & & 208,000 & 284,000 & 76,000 & 36 \\
\hline
\end{tabular}

\section{Wastewater disposal}

The disposal of wastewater effluent and sludge in Harare poses serious problems. According to Nhapi et al. (2003), the BNR effluent at Crowborough is often of good quality in terms of nutrient concentration $(4.6 \pm 3.0 \mathrm{mg} / \mathrm{TN}, 0.7 \pm 0.6 \mathrm{mg} / \mathrm{TP})$. On the other hand, the BNR effluent from Firle is poor $(13.7 \pm 10.7 \mathrm{mg} / \mathrm{TN}, 1.9 \pm 3.4 \mathrm{mg} / \mathrm{TP})$, mainly due to plant breakdowns and poor maintenance. The applicable Zimbabwean limits for effluents discharged into sensitive waters are $10 \mathrm{mg} / \mathrm{l} \mathrm{TN}$ and $0.5 \mathrm{mg} / \mathrm{TP}$ (Government of Zimbabwe S.I. 274 of 2000). The bulk of the BNR effluent from Firle WTP $(87 \%)$ is used for pasture irrigation whilst the remainder is discharged into the Mukuvisi River. All BNR effluent at Crowborough WTP is discharged into the Marimba River. About $4,000 \mathrm{~m}^{3} / \mathrm{d}$ of sludge from Crowborough and Firle is used for pasture irrigation. This practice is questionable, since it allows previously separated nutrients and other contaminants to enter again into the Lake Chivero catchment via seepage and runoff from pastures. It is better to manage sludge in other ways - such as landfilling and the production of useful materials like bricks and roofing tiles.

The current land area reserved for pasture irrigation is very small compared with the effluent and sludge quantities pumped to the pastures (Nhapi et al., 2003). Only about 1,400 ha are available for pasture irrigation compared to about 6,730 ha required for handling the current irrigation load of about $196,000 \mathrm{~m}^{3} / \mathrm{d}$ of effluent. Extra land has to be acquired beyond the city boundaries. Because of overloading, nutrient removal efficiency via pasture irrigation has dropped to $84 \%$ for TN and $54 \%$ for TP (Nhapi et al., 2002e) resulting in increased nutrient inflows into Lake Chivero. The practice of pasture irrigation fits into the 3-Step Approach (step 2 and 3) but it needs to be managed within the capacity range of the available land in terms of water and nutrient requirements. Also, when using cattle, improved management of supplementary feed and manure collection could significantly improve the situation. High value 
crops with high nutrient uptake rates like maize could be used instead of pasture grass (kikuyu grass (Pennisetum clandestinum) and star grass (Cynodon plectostochus)). On the other hand, significant improvements to current BNR units would enable the safe discharge of part of the effluent into rivers, thereby reducing the overloading via land irrigation.

\section{Receiving water quality}

The water quality in the major effluent receiving rivers of Marimba and Mukuvisi has been deteriorating over the years (Thorntorn, 1980; JICA, 1996; Nhapi et al., 2003). The flows in these rivers have become perennial, meaning that the lake is receiving pollution throughout the year (Nhapi et al., 2002b). Although wastewater appears to be the major polluter of these rivers, it has also been observed that nutrient levels upstream of WTP effluent discharge points mostly exceed allowable levels for rivers (Nhapi et al., 2003). This is due to non-point source pollution especially from stormwater and some illegal point source discharges. Recent studies by Mvungi (2002) and Magombeyi (2003) showed that small formal and informal industries and poor garbage collection are major causes of pollution upstream of WTP effluent discharge points. Fig 9.2 shows water and nutrient flows for the Harare sub-catchment area and the Lake Chivero. It can be deduced from Fig 9.2 that the maximum allowable limits of $0.1 \mathrm{mg} / \mathrm{TN}$ and $0.03 \mathrm{mg} / \mathrm{TP}$ for avoiding excess plant growth in rivers (OME Guidelines, 1991) are being exceeded. Moreover, the allowable limits of $0.3 \mathrm{mg} / \mathrm{TN}$ and $0.01 \mathrm{mg} / \mathrm{AP}$ for drinking water in lakes (Mandaville, 2000) are also exceeded. Lake Chivero is now hypertrophic and Nhapi et al. (2004) has established that nutrients are accumulating in the lake. About $59 \%$ of the incoming TP were retained in the lake and this could lead to further eutrophication problems for some time even after phosphorus inflows have been stopped. This situation is very dangerous for a major water supply source of over 2 million people. It could result in serious fish kills, loss of beneficial uses of the lake (fishing, boating), water treatment difficulties, clogging of irrigation pipes, and health problems (e.g., gastro enteritis).

\section{Application of the 3-Step Strategic Approach in Harare}

The 3-Step Strategic Approach to wastewater management is adopted in this study to develop sustainable solutions in a structured way. This approach is based on three distinct steps of 1) prevention (pollution prevention and waste minimisation), 2) treatment for reuse, and 3) disposal of WTP effluent and sludge in combination with the stimulation of self-purification capacity of receiving water bodies. Constructed wetlands, in-river cascade aeration, and the creation of impoundments to increase hydraulic retention time in river systems (eco-hydrology concepts) are some of the measures that could be used to increase natural purification processes. This 


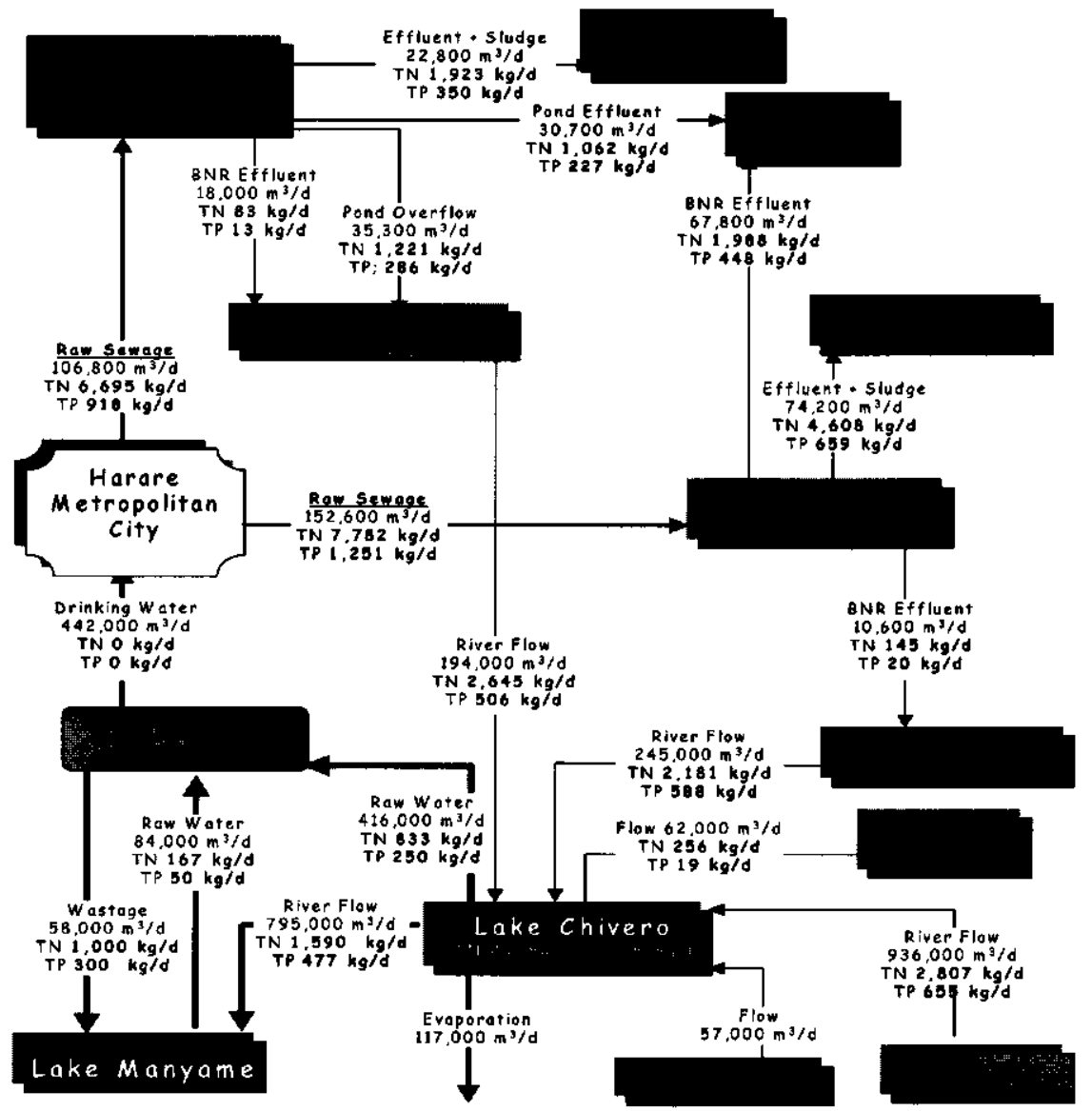

Figure 9.2: Diagram showing current water and nutrient flows for the Chivero Catchment, based on water quantity and quality data collected from June'00 to Dec'01 (updated from Nhapi et al., $2002 f$ ).

approach encompasses modern thinking in wastewater management, which includes the application of cleaner production principles (Gijzen, 2002; Siebel and Gijzen, 2002), householdcentred approaches (King, 2000), treatment methods geared to resource recovery (e.g., duckweed, aquaculture), up to safe disposal of sludge and effluent, and eco-hydrology principles to river and lake systems. In the Harare context, the bulk of wastewater emanates from domestic sources, so methods that reduce, treat, and reuse wastewater within residential areas will significantly reduce pollution loads entering Lake Chivero. The decentralised or onsite handling of wastewater opens opportunities for simpler methods of wastewater treatment (especially natural methods) and encourages wastewater reuse closer to sources of generation. Effluent discharged into the water resource (in this case Lake Chivero) in step 3 could also be recycled through a longer loop back to step 1 . This means running the municipal water cycle not only over Lake Chivero but also over Lake Manyame, abstracting raw water from the latter. 


\section{Phased implementation}

The formulation of a sustainable strategy for managing wastewater in Harare needs to recognise two important limitations. Firstly, Harare has an existing extensive infrastructure that has been operational for some years and which represents an enormous capital investment. Therefore, this cannot be phased out overnight and a gradual approach is required. In terms of drinking water supply and sanitation provision, Harare boasts of over $90 \%$ service coverage for individual plots (WHO, 2000). Very few residential areas use communal water and sanitation facilities. Secondly, landuse patterns in Harare exhibit vastly different characteristics so much that it would be irrational to adopt a single solution for all areas. Lifestyles and water use characteristics for low, medium and high-density residential areas are quite different. A differentiated approach is therefore required. This is illustrated in Table 9.3 where possible solutions for Harare have been categorised into short-term ( $<5$ years), medium-term $(5-10$ years), and long-term (over 10 years). The proposed measures take into account the respective landuses. Table 9.3 represents extreme cases whilst, in practice, a mixture of these would overcome physical and financial constraints. If these suggestions would be fully implemented, a sustainable situation could be achieved, with substantially reduced loads of nitrogen and phosphorus finding their way into Lake Chivero and thus allowing the lake to recover over time. Water availability from the lake would also be enhanced.

\section{Strategy Implications on the Chivero system}

\section{Scenario 1: Short-term solutions}

To avoid plant overloading in Harare (Table 9.1), both the hydraulic and pollutant loads have to be drastically reduced. The starting point is the source reduction of wastewater (cleaner production) and the banning of phosphorus detergents. This would reduce hydraulic and phosphorus loading of plants by $17 \%$ and $3 \%$, respectively, according to Nhapi et al. (2002c). Industries need to be legally enforced to pre-treat their effluents before discharging into municipal sewers, or, preferably, to avoid discharge altogether by using onsite treatment and recycling of effluents. Concerted efforts are required, through formal and informal educational campaigns, posters and pamphlets, and print and electronic media, to encourage low and medium-density residents to reduce water consumption. Similar measures have been successfully implemented in Bulawayo, Zimbabwe's second largest city, where over $50 \%$ reduction in water consumption has been achieved (BCC, 2001). 
Table 9.3: Proposed differentiated and phased improvement of wastewater management in Harare

\begin{tabular}{|c|c|}
\hline Scen & $n$ \\
\hline $\begin{array}{l}\text { Main goal: Water } \\
\text { saving measures } \\
\text { and pollution } \\
\text { prevention and } \\
\text { control }\end{array}$ & 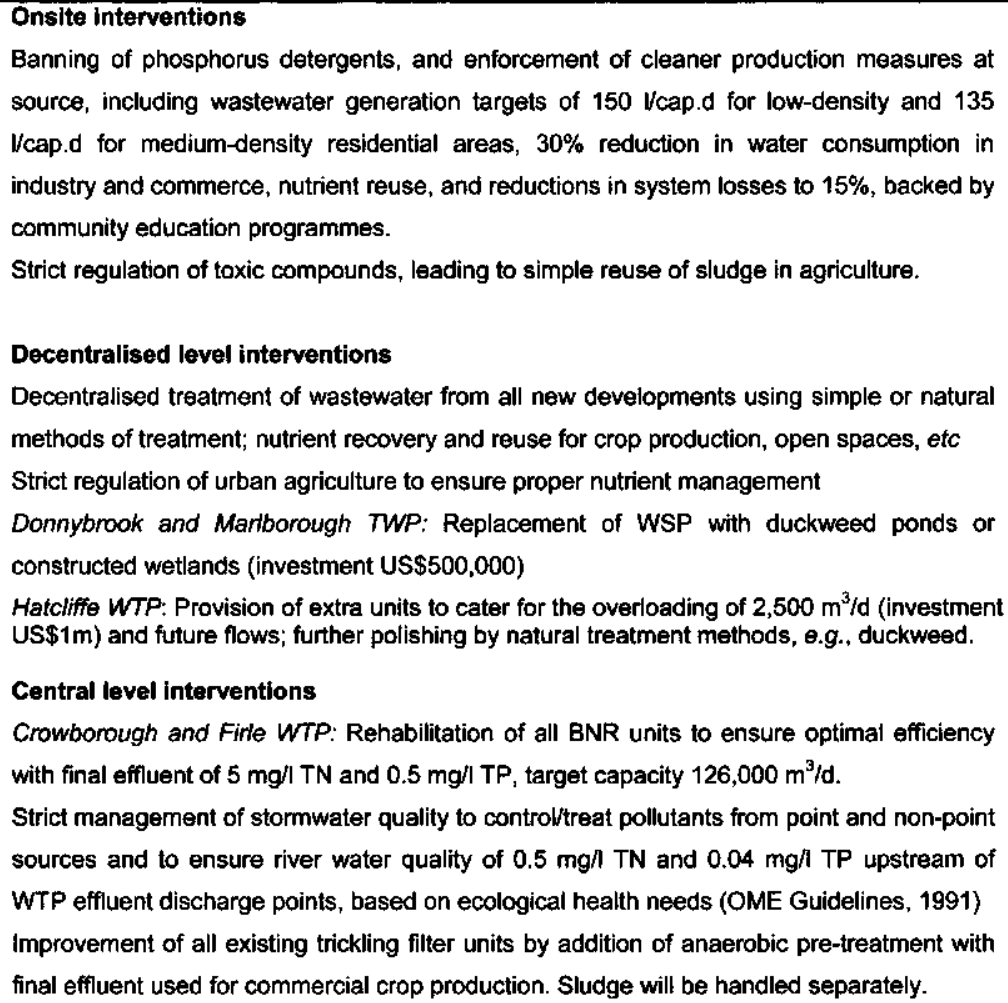 \\
\hline $\begin{array}{l}\text { Main goal: Pollution } \\
\text { control }\end{array}$ & $\begin{array}{l}\text { Onsite interventions } \\
\text { Enforcement of cleaner production measures at source - wastewater target <100 l/cap.d } \\
\text { All low and medium-density residential areas to be served by onsite sanitation systems } \\
\text { Use of alternative sources of water supply, e.g., rainwater harvesting, boreholes } \\
\text { Uncoupling and on site treatment (and reuse where possible) of industrial wastewater } \\
\text { Decentralised level interventions } \\
\text { Decentralised treatment of wastewater from all new developments using low-cost methods } \\
\text { of treatment; nutrients to be recovered and reused for crop production, open spaces, etc. } \\
\text { Central level interventions } \\
\text { Stormwater control and treatment. BNR treatment capacity increased to } 133,000 \mathrm{~m}^{3} / \mathrm{d} \text {. }\end{array}$ \\
\hline Long-term & G \\
\hline $\begin{array}{l}\text { Main goal: } \\
\text { Increased resource } \\
\text { recovery and reuse }\end{array}$ & $\begin{array}{l}\text { Further enforcement of cleaner production measures at source } \\
\text { Decentralised level interventions } \\
\text { Decentralised treatment and reuse of wastewater from all new developments; including } \\
\text { current loads treated by trickling filters. No more expansions for centralised treatment. }\end{array}$ \\
\hline
\end{tabular}


Considering the current economic and political climate in Zimbabwe, the effectiveness of these approaches raises a lot of doubt, especially in the short-term. It is recommended that cleaner production measures be implemented together with the rehabilitation of current BNR systems (total capacity $126,000 \mathrm{~m}^{3} / \mathrm{d}$, or $30 \%$ of daily lake abstractions) for the urgent protection of Lake Chivero and the enhancement of water availability.

\section{Phase 2: Medium term solutions}

For the medium term, all trickling filter units at Crowborough and Firle WTPs should be preceded by anaerobic pre-treatment to reduce organic loads. The final effluent is used for crop irrigation in commercial farms. The farms are managed in such a way that nutrient uptake is maximised with sludge being handled separately. A similar hybrid system has been successfully used in Gweru, Zimbabwe (Broome et al., 2002). Assuming steps are taken to uncouple industrial effluents from the system, the sludge could be safely applied on land or disposed of as landfill. The sludge could be managed such that some cost recovery is achieved, e.g., composting and replacing inorganic fertiliser. This would additionally contribute to reducing the nitrogen and phosphorus loads in the catchment. Table 9.4 shows the resultant nutrient and water flows into and out of Lake Chivero. This is followed by Fig 9.3 showing the Chivero system covering only Crowborough and Firle WTPs. In Fig 9.3, all the sludge is handled separately and centrally disposed of as landfill to avoid groundwater contamination. All the BNR capacity is used to treat effluent to stricter standards of $5 \mathrm{mg} / \mathrm{TN}$ and $0.5 \mathrm{mg} / \mathrm{TP}$.

The lake nutrient figures in Table 9.4 were obtained from mass balance analyses and the Vollenweider Model-based equations explained in detail in Nhapi et al. (2003). The application of the Vollenweider Model to the new regime revealed significant improvements to nitrogen levels $(0.4 \mathrm{mg} / \mathrm{l}$ compared to current $2.0 \pm 1.3 \mathrm{mg} / \mathrm{l} \mathrm{TN})$ and phosphorus levels $(0.07 \mathrm{mg} / \mathrm{l}$ compared to current $0.6 \pm 0.3 \mathrm{mg} / \mathrm{TP}$ ). In addition, the hydraulic retention time in the lake changed to an average of 0.4 years (current $1.56 \pm 1.05$ years), due to the addition of extra water from BNR effluents. A hydraulic retention time shorter than 0.6 years would improve the flushing of phosphorus over time (Thornton, 1980). More importantly, the raw water availability in Lake Chivero is increased from $421,000 \mathrm{~m}^{3} / \mathrm{d}$ to $644,000 \mathrm{~m}^{3} / \mathrm{d}$. It is therefore concluded that, barring the current condition of nutrients of in the lake sediments, Phase 1 and 2 measures would significantly improve water quality in the lake and would improve water availability for Harare. This strategy hinges on the reduction of direct and indirect pollution discharges upstream of wastewater treatment works (Nhapi et al., 2003; Magombeyi, 2003). Strict legislation on both wastewater and stormwater quality are required and regular monitoring should be enforced. 
Similar efforts are also necessary for the Manyame River whose main sources of pollution are the towns of Ruwa and Chitungwiza.

Table 9.4: Modified water and nutrient budget for Lake Chivero when all BNR treatment capacity is fully utilised and effuent discharged into Marimba and Mukuvisi Rivers as presented under medium term actions.

\begin{tabular}{|c|c|c|c|c|c|c|c|}
\hline \multirow{2}{*}{ Balance Component } & \multirow[t]{2}{*}{ Area } & \multirow{2}{*}{$\begin{array}{l}\text { Refenence; source of } \\
\text { data or calculation } \\
\text { method }\end{array}$} & \multirow{2}{*}{$\begin{array}{l}\text { Average Flow } \\
\mathrm{m}^{3} / \text { year }\end{array}$} & \multicolumn{2}{|c|}{ Total Nitrogen } & \multicolumn{2}{|c|}{$\begin{array}{l}\text { Total } \\
\text { Phosphorus }\end{array}$} \\
\hline & & & & $\mathrm{mg} / \mathrm{l}$ & $\mathrm{kg} / \mathrm{yr}$ & $\mathrm{mg} / \mathrm{l}$ & $\overline{\mathrm{kg} / \mathrm{yr}}$ \\
\hline \multicolumn{8}{|l|}{ INFLOW } \\
\hline Marimba River & 189 & $\mathrm{C} 24$ & $58,035,000$ & 0.8 & 48,355 & 0.09 & 5,284 \\
\hline Manyame River & 1510 & $\mathrm{C} 21$ & $341,529,474$ & 0.5 & 170,765 & 0.04 & 13,661 \\
\hline Mukuvisi River & 231 & $\mathrm{C} 22$ & $124,830,000$ & 1.2 & 147,453 & 0.18 & 23,044 \\
\hline Lake precipitation & 26,5 & Lake area x Rainfall & $20,793,939$ & & & & \\
\hline Direct Area Runoff & 290 & & $22,799,510$ & 4.1 & 93,478 & 0.3 & 6,840 \\
\hline Subtotal & & & $567,987,923$ & & 460,051 & & 48,829 \\
\hline \multicolumn{8}{|l|}{ OUTFLOW } \\
\hline Evaporation & 26,5 & Met. Data & $42,688,686$ & & & & \\
\hline Abstractions & & City of Harare & $151,999,570$ & 0.4 & 57,010 & 0.07 & 10,639 \\
\hline Discharge & 2220 & $\mathrm{C} 17$ & $290,195,250$ & 0.4 & 108,842 & 0.07 & 20,312 \\
\hline Subtotal & & & $484,883,506$ & & 165,851 & & 30,952 \\
\hline \multicolumn{2}{|l|}{ Outflows less inflows } & & $-83,104,417$ & & $-294,200$ & & $-17,877$ \\
\hline \multicolumn{2}{|c|}{ Discrepancy, $\%$ of inflow } & & $-15^{*}$ & & -64 & & -37 \\
\hline
\end{tabular}

* Partly explained by errors in measurement and estimation.

\section{Phase 3: Long-term solutions}

The long-term measures (Table 9.3) are aimed at sustaining the situation shown in Table 9.4 and Fig 9.3. They are based on onsite systems for all low-density residential stands and decentralised systems for all new high and medium-density residential stands. This follows from an assessment of future developments and wastewater treatment requirements in Harare for the year 2015 done by JICA (1996). The projections were further updated by Nhapi et al. (2002c). Without any intervention measures, Harare was expected to produce about 304,000 $\mathrm{m}^{3} / \mathrm{d}$ of wastewater in the year 2002, and $487,000 \mathrm{~m}^{3} / \mathrm{d}$ in the year 2015 (Nhapi et al., 2002c). In year 2015, the wastewater would contain about $39,000 \mathrm{~kg} / \mathrm{d}$ of TN and $4,000 \mathrm{~kg} / \mathrm{d}$ of TP. 


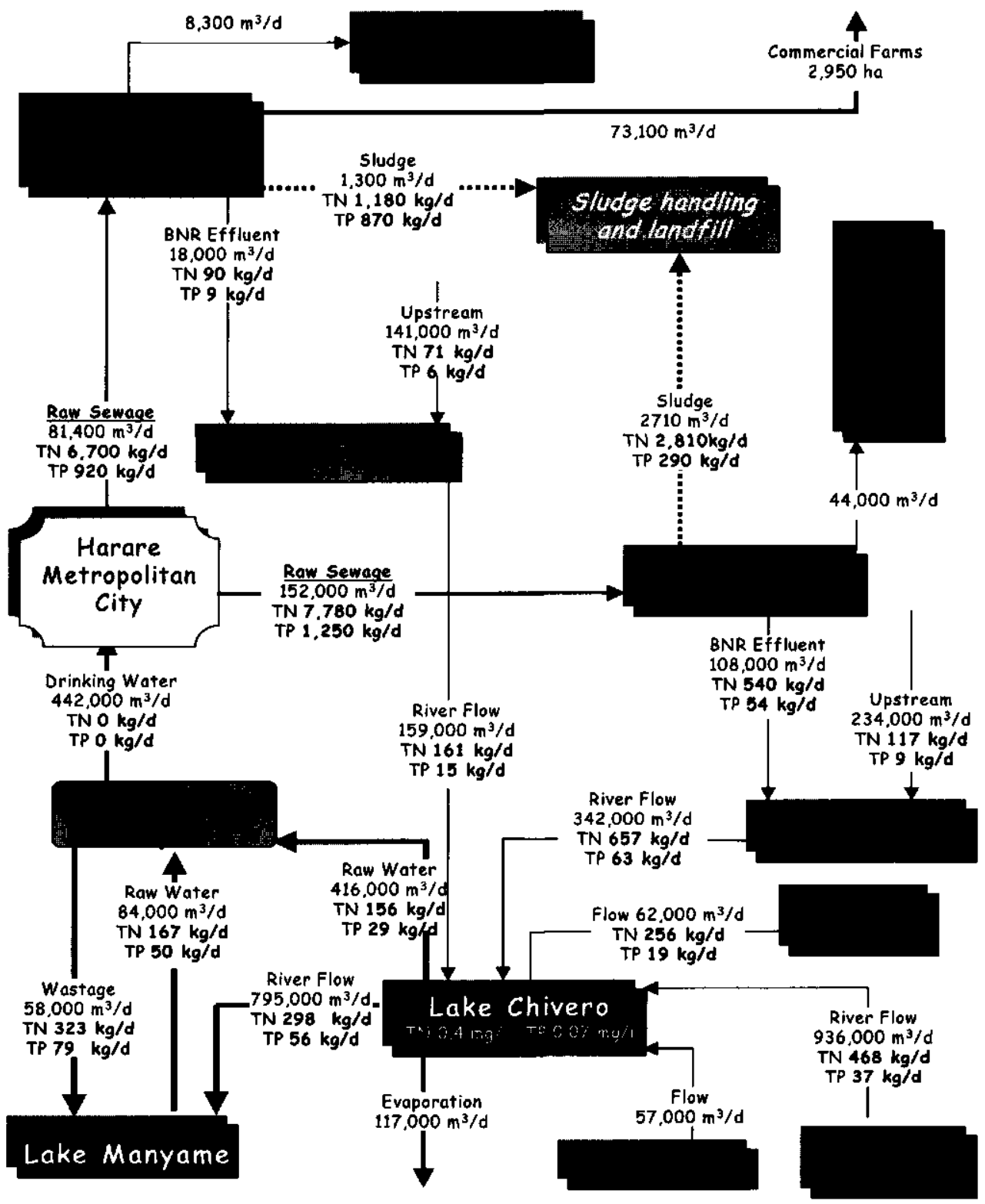

Figure 9.3: A modified water and nutrient flow diagram for the Chivero Catchment based on successful implementation of proposed short and medium term intervention measures

Fig 9.4 shows the year 2015 situation and shows that a great deal could be achieved through pollution prevention and reduction measures. The projected wastewater production is reduced to $370,000 \mathrm{~m}^{3} / \mathrm{d}(24 \%)$ through pollution prevention and reduction measures. The reduced flows 
could then be conveniently apportioned between onsite, decentralised, and centralised treatment depending on landuse characteristics and amounts of wastewater generated. Onsite treatment of wastewater could be applied for all low-density residential areas, accounting for $12 \%$ of flow, and $7 \%$ of both TN and TP. Decentralised systems could be applied for all high and medium-density residential areas, accounting for $55 \%$ of flow, $84 \%$ of TN, and $80 \%$ of TP. The rest, from commerce and industry, could then be treated in a centralised system using the current BNR units at Crowborough and Firle WTPs. Decentralised systems would be the most effective method of wastewater reuse and diverting nutrients away from Lake Chivero and to food production (Nhapi et al., 2002d).

The last box in Fig 9.4 shows that the wastewater loads to be treated at a centralised level are very low $\left(133,000 \mathrm{~m}^{3} / \mathrm{d}\right)$. The current BNR capacity of $126,000 \mathrm{~m}^{3} / \mathrm{d}$ could easily accommodate an extra capacity through slight modifications. Assuming effluent quality of $5 \mathrm{mg} / \mathrm{TN}$ and 0.5 $\mathrm{mg} / \mathrm{l} \mathrm{TP}$, the eventual nutrient amounts directly discharged into Lake Chivero from centralised plants will be $0.7 \mathrm{t} / \mathrm{d}$ TN and $0.1 \mathrm{t} / \mathrm{d}$ TP. The current loads directly discharged into Lake Chivero tributaries are $2.6 \mathrm{t} / \mathrm{d} \mathrm{TN}$ and $0.5 \mathrm{t} / \mathrm{d}$ TP. This means that $74 \%$ and $86 \%$ reductions in TN and TP loads respectively could be achieved. As these projections are for year 2015, and if other steps are taken to reduce nutrient discharges upstream of WTP effluent discharge points, water quality improvements in Lake Chivero could be sustained. However, it is not possible for Harare to transform overnight to this strategy as huge investments are required. A staged and differentiated approach, which includes onsite and centralised options, will have the greatest impacts.

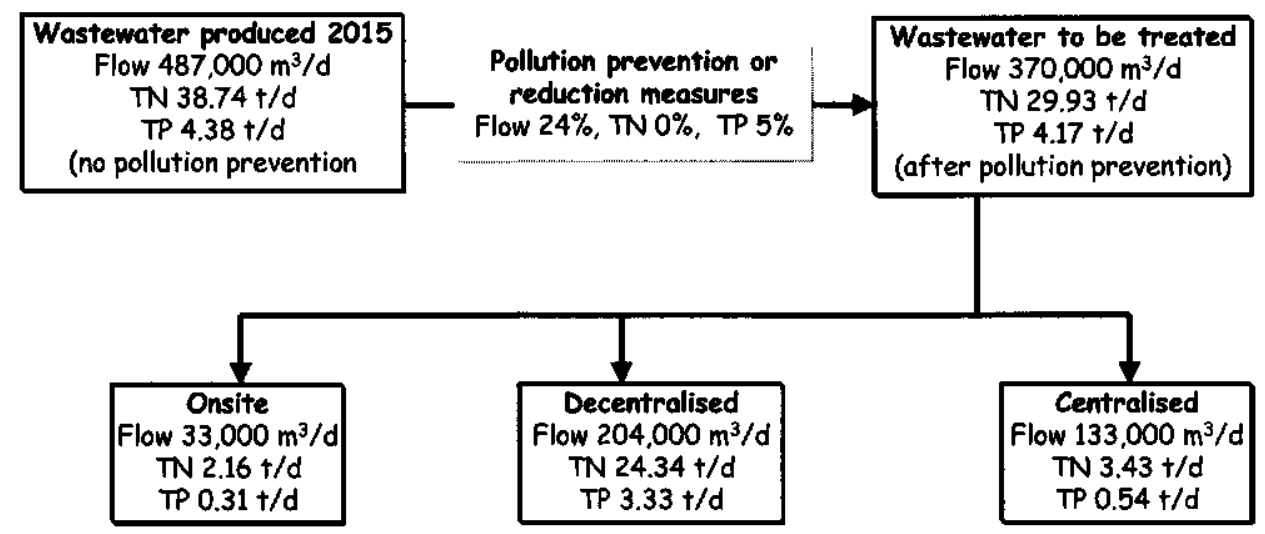

Figure 9.4: Long term approach: re-organisation of wastewater treatment in Harare for the year 2015, showing resultant flows and nutrient loads (Source: Nhapi et al., 2002d) 


\section{Discussion}

This Chapter has summarised most of the wastewater-related pollution issues in the Chivero catchment. The main problems are the immediate water pollution in Lake Chivero and its tributaries, and the long-term water scarcity due to increased raw water abstractions (related to high water consumption in households) and frequent drought years. The two problems are interlinked since water scarcity will contribute to the pollutant sink effect in Lake Chivero and consequently will worsen the water quality problem. The current results show that pollution prevention efforts could give a substantial relief on the stressed situation arising. The two main rivers of Marimba and Mukuvisi show high pollution levels upstream of wastewater discharge points, and pollution loads remain high downstream due to non point sources, including seepage and runoff from effluent irrigated pastures. Sewer overflows and blockages plus illegal discharges from formal and informal industries need to be monitored upstream of wastewater discharge points.

Table 9.4 and Fig 9.3 show that the Manyame River provides the largest flow into Lake Chivero. This river, which drains Chitungwiza (population 322,000) and Ruwa (population 22,000), among other areas, was only monitored at its entry point into Lake Chivero. The rationale for its exclusion from the current analysis was that a modern nutrient removal plant had been constructed (in year 2000) in Chitungwiza and JICA (1996) studies had reported low levels of nutrients in the Manyame River. The current study shows that a lot of effort is required to urgently arrest pollution increases in this river. These efforts include cleaner production approaches at plot or household level, diversion and reuse of industrial effluents, improvement of the new WTP to achieve design pollutant removal efficiencies, good agricuitural practices (both urban and rural), and control of sewer overflows.

The flow and water quality data obtained from the City of Harare and the Zimbabwe National Water Authority (ZINWA) showed some wide variations and inconsistencies, resulting in discrepancies in the mass balances. The mass balances in this report used data for the water quality-monitoring period of June 2000 to December 2001. Heavy rains were experienced in the 2000/1-rainfall season and this tended to overplay the long-term role of rainfall runoff in rivers. Towards the end of this research period, most flow meters had gone out of use as maintenance deteriorated due to severe economic hardships. As a result, Figures 9.2 and 9.3 , and Table 9.4 hide an important aspect that wastewater actually plays a significant role in terms of water flows in the Marimba and Mukuvisi Rivers. This was confirmed by Nhapi et al. (2004) using flow data for the period March 1999 - February 2001. The effect of nutrients accumulated in the lake sediments was not captured in this study but could upset the predicted recovery of the lake. 


\section{Conclusions and recommendations}

This study shows that water quality and quantity improvements in Lake Chivero are feasible in the medium to long-term. This could be achieved through source control by users (pollution prevention/reduction and reuse), better management of wastewater treatment, and efforts to control direct and indirect river discharges upstream and downstream of wastewater treatment plants. A gradual implementation plan has been suggested, focusing on immediate options for pollution control, up to long-term efforts for pollution prevention and nutrient reuse. The longterm part involves differentiated solutions for onsite, decentralised, and centralised management of wastewater with appropriate regulations and institutions for each case.

\section{References}

BCC (Bulawayo City Council) (2001) Bulawayo Water Conservation and Sector Services Upgrading Project, Final Report, Volume 1, Engineering Services Department, Bulawayo, Zimbabwe.

Broome, J.M., Morris, P.M., and Nanthambwe, J. (2002) Hybrid Treatment Systems - Anaerobic Ponds and Trickling Filters in Zimbabwe; in Proceedings of the $5^{\text {th }}$ IWA Specialist Conference on Waste Stabilisation Ponds held in Auckland, New Zealand, April 2 - 5, 2002, 477-484

Cosgrove, W.J. and Rijsberman, F.R. (2000) World Water Vision: Making Water Everybody's Business, World Water Council, London, UK.

Department of Water Development (1995) Potentials and Limitations of Groundwater Use in Zimbabwe, Final Report, December 1995, Ministry of Lands and Water resources, Harare, Zimbabwe.

Gijzen, H.J. (2001) Low Cost Wastewater Treatment and Potentials for Re-use: A Cleaner Production Approach to Wastewater Management, paper presented at the International Symposium on LowCost Wastewater Treatment and Re-use, NVA-WUR-EU-IHE, Cairo, Egypt, February 3-4, 2001.

Gijzen, H.J. (2002) Anaerobes, Aerobes and Phototrophs - A Winning Team for Wastewater Management, IWA Wat. Sci: Tech. Vol. 44(8), p121-132.

Gijzen H.J. (2003). A 3-Step Strategic Approach to Sewage Management for Sustainable Water Resources Protection. IWA Conference Asia WaterQual, Bangkok, 19-23 October, 2003.

Government of Zimbabwe, (2000) Statutory Instrument (S.I.) 274 of 2000, Water (Waste and Effluent Disposal) Regulations, Government Publications, Harare.

Hoko, Z. (1999) Innovative Sanitation for Harare, Zimbabwe (Case Study Mufakose Suburb), IHE MSc Thesis, IHE Delft, The Netherlands.

ICWE (International Conference on Water and Environment) (1992) The Dublin Statement and Record of the Conference, World Meteorological Organisation, Geneva, Switzerland.

JICA Report (1996) The Study of Water Pollution Control in Upper Manyame River Basin in the Republic of Zimbabwe, MLGRUD, Nippon Jogeduido Sekkei Co. Ltd., Nippon Koei Co. Ltd, September 1996. Kamudyariwa, C. (2000) Seasonal Variation of Water Quality with Respect to Anthropogenic Activities Along Mukuvisi River, Harare, Zimbabwe, MSc. Thesis, IHE Delft, The Netherlands. 
King, N. (2000) New Strategies for Environmental Sanitation, in Water21, Magazine of the International Water Association, April 2000, London, UK, p11-12.

Magombeyi, M. (2003) A Study on the Evaluation of Stormwater Drainage Quality in Harare City, Zimbabwe MSc WREM Thesis, Dept of Civil Engineering. University of Zimbabwe, Harare, Zimbabwe.

Mandaville, S.M. (2000) Lake Data of Relatively Undistunbed Lakes within Nova Scotia; Provincial Averages; CCME, Health \& Welfare Canada, and OME Guidelines, Internet Site: http://www.chebucto.ns.ca/Science/SWCS/SWCS.html.

Manjonjo, M (1999) Land Disposal of Sludge and Pond Effluent on Crowborough Farm: Its Efficiency and Influence on Marimba River, MSc WREM Thesis, Department of Civil Engineering, University of Zimbabwe, Harare, Zimbabwe.

Mawere, M (2001) Land Application of Sewage, The Role of Crowborough Pasture Irrigation in the Reduction of Nutrient Loads to Marimba River. MSc. Thesis, IHE Delft, The Netherlands.

Mckendrick, J. (1982) Water Supply and Sewage Treatment in Relation to Water Quality in Lake Mcllwaine in Thornton, J.A. and Nduku, K. (eds.) Lake Mcllwaine; The Eutrophication and Recovery of a Tropical African Man-Made Lake, Dr W Junk Publishers, The Hague, The Netherlands, p 202217.

Metcalf and Eddy (1991) Wastewater Engineering: Treatment, Disposal and Reuse, McGraw - Hill, Inc, Singapore.

Moyo, N.A.G. (Ed.) (1997) Lake Chivero: A Polluted Lake, University of Zimbabwe Publications, Harare, Zimbabwe.

Mvungi, A.F. (2002) The Study of the Impact of High Density Urban Environment on the Water Quality of Marimba River with Particular Reference to Home Industries, MSc Thesis, Department of Civil Engineering, University of Zimbabwe, Harare, Zimbabwe.

Nhapi, I., Siebel, M. and Gijzen, H.J. (2001) Dry Season Inflow and Export of Nutrients from Lake Chivero; in Proceedings of the Zimbabwe Institution of Engineers, Vol. 2(1), p33-41.

Nhapi, I., Siebel, M. and Gijzen, H.J. (2002a) A Strategic Framework for Managing Wastewater in Harare, Zimbabwe, paper submitted to Water International, journal of IWRM, October 2002.

Nhapi, I., Siebel, M.A. and Gijzen, H.J. (2002b) An Inventory of the Existing Water Management Practices in Harare, Zimbabwe, paper submitted for publication in the Urban Water Journal, September 2002.

Nhapi, I., Siebel, M. and Gijzen, H.J. (2002c) Options for the Onsite Management of Wastewater in Harare Zimbabwe, paper prepared for the IWA $5^{\text {th }}$ Specialised Conference on Small Water and Wastewater Treatment Systems, Istanbul, Turkey, 24-26 September, 2002.

Nhapi, I., Siebel, M. and Gijzen, H.J. (2002d) Options for the Decentralised Management of Wastewater in Harare Zimbabwe, in Proceedings of the IWA Conference on Water and Wastewater Perspectives of Developing Countries, New Delhi, India, 11 - 13 December, 2002, p955 - 964.

Nhapi, I., Mawere, M., Veenstra, S.I. and Gijzen, H.J. (2002e) Effluent Polishing via Pasture Irrigation in Harare, Zimbabwe; IWA Wat. Sci. Tech. Vol. 46(9), p287-295. 
Nhapi, I., Hoko, Z., Siebel, M. and Gijzen, H.J. (2002f) Assessment of Major Water and Nutrient Flows in the Chivero Catchment Area, Zimbabwe, Physics and Chemistry of the Earth, Vol. 27 (11-22), p783792.

Nhapi, I. and Gijzen, H.J. (2003) The 3-step Strategic Approach to Sustainable Wastewater Management; paper submitted to the Journal of the Chartered Institute of Water and Environmental Management, December 2003.

Nhapi, I., Siebel, M. and Gijzen, H.J. (2004) The Impact of Urbanisation on the Water Quality of Lake Chivero, Zimbabwe, Journal of the Chartered Institute of Water and Environmental Management, Vol. 18(1), p44-49.

Nhapi, I., Siebel, M. and Gijzen, H.J. (2003) Centralised Management of Wastewater in Harare, Zimbabwe: Current Practice and Future Options, paper submitted to IWA Wat. Res., December 2003.

OME (Ontario Ministry of the Environment) (1991) Water Management, Provincial Water Quality Objectives and Guidelines, Internet site: http://www.ene.gov.on.ca/envision/gp.

Siebel, M.A. and Gijzen, H.J. (2002) Application of Cleaner Production Concepts in Urban Water Management, paper presented at the Environmental Technology and Management Seminar 2002, Bandug, Indonesia, January 9-10, 2002.

Thornton, J A (1980) A Comparison of the Summer Phosphorous Loading to Three Zimbabwean WaterSupply Reservoirs of Varying Trophic States, WaterSA Vol. 64, October 1980 p 163-170.

Tirivarombo, $S$ (2001) Sewage Discharges and Nutrient Levels in Marimba River, Zimbabwe, MSc Thesis, Department of Civil Engineering, University of Zimbabwe, Harare, Zimbabwe.

United Nations (2003) Millennium Indicator Database, Department of Economic and Social Affairs, Internet Site: http://unstats.un.org/unsd/mi/mi_goals.asp, Accessed: July 2003.

WHO (2000) Global Water Supply and Sanitation Assessment, 2000 Report, World Health Organisation, Geneva, Switzerland. 


\section{Summary}

Urban sanitation is an important component of the water and nutrient cycles, and its efficient management is crucial for sustainable water resources and pollution management. A new school of thinking believes that the conventional sanitation approach is very inefficient and expensive in terms of money, resources and energy. Its proponents call for radical changes in urban water management, focusing increasingly on pollution prevention, resource recovery (nutrients, biogas, and water) and reuse. The emerging approaches emphasize the household as the first target unit for pollution prevention and reduction measures, and recycling and reuse. This results in shorter nutrient cycles, thus avoiding the accumulation of nutrients in water bodies. A holistic analysis of water and nutrient cycles would therefore lead to the development of specific intervention measures appropriate at each stage of these cycles. This thesis takes this approach further and uses Harare, the capital city of Zimbabwe, as a case study. Harare discharges wastewater into the Lake Chivero, also its main source of water supply.

The general objectives of this thesis were to assess the contribution of wastewater from Harare to the nitrogen and phosphorous inflows into Lake Chivero and, based on this assessment, to formulate feasible intervention measures. The research specifically targeted nutrients because these are the major problem parameters, since $B O D$ is largely taken care of via current wastewater treatment and river self-purification processes. The general strategy was to intervene at various levels; i.e., property or onsite, decentralised and centralised levels, with various options aimed at limiting waste production and reusing or recycling water and nutrients. This strategy would reduce nitrogen and phosphorous flows entering into the Lake, and increase water availability.

A main description of the study area and background to the research problem, objectives and approach are given in Chapter 1. The Lake Chivero catchment was the main study area of which Harare city is the main influence, although also some other towns in the catchment are considered. The Chivero catchment area has an estimated population of 2.4 million people and is about $2,220 \mathrm{~km}^{2}$ in extent. The Lake is located about $35 \mathrm{~km}$ south-west and downstream of Harare. The Lake supplies more than $70 \%$ of the catchment's potable water requirements. Lake Chivero receives water from the following major rivers: Manyame, Mukuvisi and Marimba. The Marimba and Mukuvisi Rivers drain most parts of Harare. Five wastewater treatment plants (WTP) and two drinking water treatment works (Prince Edward, Morton Jaffray) are found in the Chivero catchment. Wastewater treatment is by activated sludge systems modified for biological 
nutrient removal (BNR), trickling filters (TF), and waste stabilisation ponds (WSP). The wastewater treatment plants are Crowborough (BNR + TF), Donnybrook (WSP), Firle (BNR + TF), Hatcliffe (extended aeration), and Marlborough (WSP). Trickling filter effluent from Firle and Crowborough is mixed with sludge and used for pasture irrigation.

Chapter 2 looks at the sustainability of key components of the Harare urban water cycle in relation to water quantity and quality management in the Chivero catchment. Data on population, water supply, water and wastewater treatment and river flows were obtained from urban councils and government departments. The data were used to assess water consumption, wastewater generation, treatment and disposal practices, river flow trends, raw water abstractions, and water demand patterns. The results showed that the current situation is not sustainable. The rapid increase in population in the Chivero catchment ( $2.5 \%$ per annum) is putting increased pressure on available urban water infrastructure (water supply, wastewater treatment plants and disposal, rivers, and Lake Chivero) causing failures, overloading, and polfution. However, water scarcity is not a problem now in the area, but it may be expected to be a major problem by year 2010 and onward.

The ever-increasing abstraction of water from Lake Chivero has altered the Lake flow regime, resulting in the Lake receiving pollution throughout the year. Lake water outflows are reduced in the dry season, resulting in possible accumulation of nutrients and other pollutants in the Lake. The prevalence of uncontrolled urban agriculture in Harare is also a potential threat to water quality in the long-term. However, properly managed urban agriculture could offer a logical alternative for the reuse of nutrients in wastewater. The high water consumption pattern in Harare is costly in terms of treatment infrastructure (both for water and wastewater) and needs to be urgently reduced. There are good prospects for the application of cleaner production concepts (water conservation, pollution prevention/reduction and reuse) to urban water management in the Chivero catchment area. Water and nutrient management strategies, which include water use efficiency, wastewater treatment and water recycling, and nutrient reuse in controlled urban agriculture are recommended.

Chapter 3 quantifies major water, nitrogen and phosphorus flows in the Lake Chivero catchment area through a water quality monitoring study conducted from June 2000 to December 2001. The results show that wastewater is a major source of nutrients in Lake Chivero and that the general pollution regime in the catchment is critical and unsustainable. The Manyame River is currently contributing significantly to pollution loads in Lake Chivero due to pollution flows from Chitungwiza town. Nutrient concentrations in Lake Chivero of $2.0 \pm 1.3 \mathrm{mg} / \mathrm{l}$ $\mathrm{TN}$ and $0.6 \pm 0.3 \mathrm{mg} / \mathrm{lP}$ ( \pm standard deviation) show a sharp deterioration in water quality 
compared to previous studies and the levels are far above those recommended for oligotrophic systems. Phosphorus in the Lake is mostly present in the form of soluble ortho-phosphates; a form readily available for algal growth, and indicative of wastewater discharges. The N:P ratio in the Lake water column is 3 but both nitrogen and phosphorus are already in abundance in the Lake. The Lake has become hypertrophic and eutrophication is already affecting water treatment, aquatic life, and irrigation systems. The volumetric phosphorus loading agrees with the Vollenweider Model. The Model was used to predict acceptable Lake inflow phosphorus levels to achieve oligotrophic conditions. The obtained value of $10.0 \mathrm{t} / \mathrm{yr}$ TP was considered unattainable under the current situation, as it is lower than that from non-point sources. A 1970 's level of $75.0 \mathrm{t} / \mathrm{yr}$ TP is recommended as a preliminary target load as it excludes wastewater effluent influences. For the long-term, it is recommended that a cleaner production approach (pollution prevention/reduction and reuse) be adopted in combination with the recycling of nutrients in controlled urban agriculture.

Chapter 4 focuses on sustainable ways of urban water and nutrient (nitrogen and phosphorus) management in Harare based the Dublin Principles and later initiatives. Three levels at which wastewater could be handled - onsite, decentralised, and centralised - were discussed and typical frameworks presented. Based on this, a "3-Step Strategic Approach" was suggested, and this aimed at the sustainable use of water, nutrients, and other resources in the urban environment. The approach consists of pollution prevention and minimisation (step 1), treatment using methods geared towards reuse (step 2), and discharge into the environment with stimulation of the self-purification capacity of the receiving environment (step 3 ). It is demonstrated that the proposed approach could substantially reduce current water pollution and future water scarcity problems in Harare. Different approaches and technologies would apply to different areas. The best way to achieve optimal results is by integrating the different options for onsite, decentralised, and centralised wastewater management. A staged implementation (in time) is required with benefits to be realised over time. However, management solutions like banning phosphorus-containing detergents, trade effluent regulations, rising block water tariffs, and new plumbing standards could be implemented in the short-term. Conventional approaches to the water quality and water quantity problems of Lake Chivero will be too expensive, and will not be able to achieve required reductions in consumption and pollution. A more creative approach is therefore required. Such an approach starts with pollution prevention/reduction and reuse at onsite level, progressively filtering out nutrient flows to decentralised and centralised levels. This ensures that only a small fraction of nutrients reach centralised level treatment and are possibly discharged into Lake Chivero. 
A detailed look at options for a differentiated approach, based on the 3-Step Strategic Approach, is covered in Chapters 5 - 7. Chapter 5 reviews options for onsite treatment of wastewater in Harare. It focuses on three objectives: a) quantification of wastewater that could be treated and reused onsite, b) identification of treatment and reuse options for different landuse categories, and c) prediction of the overall impact of these options on downstream water quality. About $304,000 \mathrm{~m}^{3} / \mathrm{d}$ of wastewater, $17,500 \mathrm{~kg} / \mathrm{d}$ of nitrogen and $2,600 \mathrm{~kg} / \mathrm{d}$ of phosphorus are produced in Harare and subsequently treated onsite ( $8 \%$ of total flow) or at five offsite wastewater treatment plants $(92 \%)$. Of these amounts, $39 \%$ of flow, $14 \%$ of nitrogen, and $16 \%$ of phosphorus could potentially be handled onsite. Greywater separation was found to be the most effective measure in reducing the current flows received at wastewater treatment plants by $52 \%$. Urine separation would be an effective measure in nitrogen $(52 \%$ of all produced) and phosphorus (34\%) removal. Greywater separation and reuse will only remove $6 \%$ of nitrogen and $37 \%$ of phosphorus. The onsite treatment and reuse strategy shows that savings of $27 \%$ on flows, $54 \%$ on TN, and $42 \%$ on TP could be realised, by year 2015 , on loads that would otherwise be received at wastewater treatment plants in Harare. It was concluded that high reductions in wastewater outflows from residential stands could be feasibly achieved, except for high-density areas where small plot sizes and high occupancy rates limit onsite effluent reuse options.

Chapter 6 deals with options for the decentralised management of wastewater in Harare. It focuses on 1) the quantification of wastewater that could be handled at a decentralised level, 2) the formulation of a decentralised treatment and reuse strategy, and 3) the assessment of the potential impacts of the decentralised strategy in Harare. Case studies of typical decentralised wastewater management using algae and duckweed-based pond systems are presented. The decentralised concept was found suitable for high and medium-density residential areas. It was estimated that after reduction of water consumption and nutrient generation at source, Harare would produce about $366,000 \mathrm{~m}^{3} / \mathrm{d}$ of wastewater, containing $39,000 \mathrm{~kg} / \mathrm{d}$ of nitrogen and 4,000 $\mathrm{kg} / \mathrm{d}$ of phosphorus by the year 2015. Decentralised systems were estimated to be able to handle about $55 \%$ of the hydraulic load, $84 \%$ of the nitrogen and $80 \%$ of the phosphorus load. By combining waste reduction/prevention measures at source and decentralised wastewater treatment, Harare could reduce wastewater treatment plant effluent discharges to Lake Chivero by over $90 \%$. It was concluded that a decentralised approach, utilising natural wastewater treatment methods (or other low-cost methods), could be an effective component of an overall sustainable (waste)water management strategy for Harare. However, the success of the decentralised strategy would strongly depend on socio-economic, institutional, and health issues associated with wastewater reuse. 
Chapter 7 describes the performance of the current centralised system in Harare and offers options for improvements. It is based on a monthly water quality monitoring study conducted from June 2000 to December 2001 which covered five wastewater treatment works and the major WTP effluent receiving rivers of Marimba and Mukuvisi. The study showed that the nutrient removal efficiency for all the wastewater treatment plants was poor. On average $24 \%$ for total nitrogen, and $8 \%$ for total phosphorus were removed. It was concluded that the current situation was not environmentally sustainable as it polluted the Lake Chivero. The 3-Step Strategic Approach was applied and this process resulted in the following actions being recommended for improving the current wastewater management system in Harare:

i. Replacement of the existing trickling filter units at Crowborough and Firle with a system that uses primary treatment + anaerobic treatment + effluent + effluent irrigation in commercial farms.

ii. Rehabilitation and addition of new treatment steps to the current BNR systems at Crowborough and Firle (total capacity $126,000 \mathrm{~m}^{3} / \mathrm{d}$ ) to achieve a very good quality effluent (BOD $<20 \mathrm{mg} / \mathrm{l}, \mathrm{TN}<5 \mathrm{mg} / \mathrm{h}$, TP $<0.5 \mathrm{mg} /$ ), which could be discharged into Lake Chivero. Sludge is separated and processed for final disposal as landfill.

iii. Enlargement of the urban water cycle by drawing all raw water for urban supplies from Lake Manyame which is immediately downstream of Lake Chivero.

Chapter $\mathbf{8}$ is based on a detailed performance evaluation of the Crowborough Pasture Irrigation system. The farm is in the Marimba sub-catchment area and has 305 hectares of irrigated pastures. The pastures are flood-irrigated with trickling filter effluent and sludge mixture from Crowborough WTP once every three weeks. Studies were conducted from July 2000 to February 2001 focusing on the pasture's management of nutrients (nitrogen and phosphorous) and their impact on the Marimba River. Water and nutrient balances were developed. Average nutrient reduction efficiencies for this pasture were found to be $84 \%$ for TN and $54 \%$ for TP. Both the Crowborough WTP and the pastures were overloaded. Based on current Zimbabwean regulations for safe disposal of effluent on land, about 2,800 ha will be required for the effluent and sludge disposal. If effluent only would be applied, the land requirements amount to about 2,100 ha, compared to the current 305 ha irrigated. The required cattle stocking density has been exceeded, affecting proper management of the irrigation scheme. The supplying wastewater treatment works are also overloaded, supplying poor quality effluent to the farm. Resource recovery could be improved by harvesting the pasture grass and selling the cow dung to neighbouring residents. Maize production is another possibly more attractive alternative. The mixing of effluent and sludge after treatment should be stopped as sludge contains a host of pollutants that could be disposed of separately and safely. From a nutrient management point of view, the importation of nutrients as supplementary feed for cattle is not desirable. 
Chapter 9 integrates findings from previous chapters and describes a wastewater management plan for Harare based on the "3-step Strategic Approach". Three implementation phases were considered based on short-term ( $<5$ years), medium-term ( $5-10$ years), and long-term $>10$ years) solutions. Of these, short-term measures would have marginal impacts as these would reduce wastewater flows by $24 \%$ and TP by $5 \%$. The short-term solutions include reduction of wastewater volume through cleaner production approaches and process changes in industries, banning of phosphorus-based detergents, and nutrient reuse, with an overall objective of enhancing water availability and controlling pollution. Further measures are proposed for the medium term and it is predicted, through modelling, that Lake TN and TP would be reduced to $0.4 \mathrm{mg} / \mathrm{l}$ and $0.07 \mathrm{mg} / \mathrm{l}$ respectively via these measures. However, this prediction could be affected (delayed) by internal nutrient loading, especially phosphorus from sediments. With the current eutrophic status of the Lake, anoxia would be expected and exchanges of phosphorus from sediments would be a common occurrence. The medium-term solutions include the decentralised treatment of wastewater from all new developments, utilising the current BNR capacity to treat wastewater to high standards, and the regulation/control of stormwater quality and urban agriculture. A long-term solution was suggested based on pollution prevention and direct reuse, treatment at onsite and decentralised levels followed by reuse, and minimal disposal of remaining effluents combined with stimulation of the self-purification capacity of the receiving rivers. Chapter 9 showed that water quality improvements in Lake Chivero are technically feasible over time. 


\section{Samenvatting}

Stedelijke sanitatie is een belangrijke component van de water- en nutriëntenkringlopen. Het efficiënte beheer ervan is cruciaal voor een duurzame watervoorziening en het beheersen van vervuiling. Er is een nieuwe stroming die gelooft dat de traditionele of conventionele benadering van sanitatie erg inefficiënt en duur is in termen van geld, grondstoffen en energie. De voorstanders ervan roepen om radicale veranderingen in het stedelijke waterbeheer met een toenemende focus op het voorkomen van vervuiling en het terugwinnen van grondstoffen (nutriënten, biogas en water). Deze stroming benadrukt het huishouden als het eerste doelwit voor afvalreductie methoden middels het 'pollution prevention' concept en dringt aan op behandeling-gerichte terugwinning en hergebruik van grondstoffen. Dit resulteert in kortere water- en nutriëntenkringlopen in tegenstelling tot de lineaire grondstoffenstromen in de traditionele benadering die bekend staan om de accumulatie van nutriënten in waterlichamen. Een holistische analyse van water- en nutriëntenkringlopen zou bovendien leiden tot de ontwikkeling van specifieke interventiemaatregelen, aangepast aan het specifieke onderdeel van de kringloop. Deze thesis volgt dezelfde benadering en is gebaseerd op stedelijk waterbeheer in Harare, hoofdstad van Zimbabwe.

Het studiegebied, de achtergrond van het onderzoek, de doelstellingen en de benadering van het onderzoek zijn gegeven in Hoofdstuk 1. Het stroomgebied van het Chivero meer is het belangrijkste studiegebied waarop Harare stad de belangrijkste invloed heeft alhoewel er ook enige andere steden in het stroomgebied worden meegenomen in de studie. Het Chivero stroomgebied heeft een geschatte bevolking van 2.4 miljoen en is ongeveer $2,220 \mathrm{~km}^{2}$ groot. Het meer bevindt zich ongeveer $35 \mathrm{~km}$ ten zuidwesten en stroomafwaarts van Harare. Het meer levert meer dan $70 \%$ van de drinkwaterbehoefte in het stroomgebied. Het Chivero meer ontvangt water van de volgende grote rivieren: Manyame, Mukuvisi and Marimba. De rivieren Mukuvisi and Marimba ontwateren het grootste deel van Harare. Vijf afvalwaterbehandelingsinrichtingen ( $\mathrm{ABI}$ ), te weten Crowborough, Donnybrook, Firle, Hatcliffe, Malborough, en twee drinkwaterbehandelingsinstallaties (Prince Edward, Morton Jaffray) bevinden zich in de Chivero stroomgebied. Afvalwaterbehandeling is middels actiefslib systemen aangepast voor biologische nutriëntenverwijdering, oxidatiebedden en afvalwaterstabilisatie vijvers. Het effluent van de oxidatiebedden van Firle en Crowborough wordt gemengd met slib en gebruikt voor de irrigatie van grasland.

De doelstellingen van deze thesis waren te bepalen wat de bijdrage aan stikstof en fosfor was in het afvalwater van Harare dat in het Chivero meer stroomt en, hierop gebaseerd, geschikte interventiemaatregelen te formuleren. Het onderzoek was specifiek gericht op nutriënten omdat 
deze de belangrijkste probleemparameters vormen en omdat BOD grotendeels verwijderd wordt in de huidige afvalwaterbehandeling- en zelfreinigingprocessen in de rivier. De strategie was te interveniëren op verschillende niveaus, i.e. op eigen terrein ("onsite"), gedecentraliseerd en gecentraliseerd niveau met verschillende opties gericht op het beperken van afvalproductie en het hergebruik van water en nutriënten. Deze strategie was erop gericht stikstof- en fosforstromen te verminderen in het Chivero meer en water meer beschikbaar te maken.

Hoofdstuk 2 kijkt naar de duurzaamheid van belangrijke onderdelen van de Harare stedelijke waterkringloop in relatie tot het beheer van de waterkwantiteit en -kwaliteit in het stroomgebied van de Chivero rivier. Gegevens over bevolking, drinkwatervoorziening, water- en afvalwaterbehandeling werden verkregen van stedelijke overheden en de centrale overheid. De gegevens werden gebruikt om het watergebruik, afvalwaterproductie, - behandeling en - lozing, trends in de rivierafvoer, waterwinning, en patronen in de vraag naar water in te schatten. De resultaten toonden aan dat de huidige situatie niet duurzaam kan zijn. De snelle bevolkingstoename in het stroomgebied van de Chivero $(2.5 \%$ per jaar) zorgt voor een toenemende druk op de stedelijke waterinfrastructuur (drinkwatervoorziening, afvalwater behandelingsinrichtingen, effluent lozing, rivieren en het Chivero meer) met onderbrekingen in service, overbelasting en vervuiling als gevolg. Echter, op dit ogenblik is er geen watertekort in het gebied maar een probleem van deze aard kan vanaf het jaar 2010 worden verwacht.

De verstedelijking en de toegenomen wateronttrekking uit het Chivero meer heeft de watertoevoer naar en - afvoer uit het meer verandert met als resultaat dat het meer nu vervuiling ontvangt gedurende het gehele jaar. De afvoer uit het meer is verminderd in het droge seizoen, en dit zou kunnen resulteren in de accumulatie van nutriënten en andere pollmutanten in het meer. Het veelvuldig voorkomen van ongecontroleerde stedelijke landbouw in Harare is ook een potentiële bedreiging van de waterkwaliteit op de lange termijn. Echter, in goede banen geleide stedelijke landbouw zou een logisch optie kunnen zijn voor het hergebruik van nutriënten in afvalwater. Het hoge drinkwatergebruik in Harare is duur in termen van behandelingsinfrastructuur (zowel voor water als voor afvalwater) en moet dringend worden verminderd. Er zijn goede vooruitzichten voor de toepassing van het concept van schone technologie (water besparing, het voorkomen/verminderen van vervuiling en hergebruik) op het beheer van stedelijk water in het stroomgebied van de Chivero rivier. Strategieen voor het beheer van water en nutriënten zoals efficiënt water gebruik, afvalwaterbehandeling en water hergebruik, en hergebruik van nutriënten in gecontroleerde urbane landbouw zijn aanbevolen.

Hoofdstuk 3 kwantificeert de belangrijkste water-, stikstof- en fosforstromen in het stroomgebied van het Chivero meer middels een studie naar de waterkwaliteit uitgevoerd van 
juni 2000 tot december 2001. De resultaten laten zien dat afvalwater de belangrijkste bron van nutriënten in het Chivero meer is en dat het patroon van vervuiling van het stroomgebied zich in een kritiek stadium bevindt en onhoudbaar is op de lange termijn. De Manyame rivier draagt in belangrijke mate bij aan de vervuilingbelasting van het Chivero meer dank zij de lozing van de stad Chitungwiza. Nutriënt concentraties in het Chivero meer van $2.0 \pm 1.3 \mathrm{mg} / \mathrm{l}$ Totale Stikstof (TS) en $0.6 \pm 0.3 \mathrm{mg} / \mathrm{l}$ Totale Fosfor (TF) ( \pm standaard afwijking) tonen een duidelijke verslechtering aan van de waterkwaliteit vergeleken met vorige studies en de niveaus zijn ver boven die welke worden aanbevolen voor oligotrofe systemen. Fosfor in het meer is voornamelijk aanwezig in de vorm van oplosbare ortho-fosfaten, een vorm die direct beschikbaar is voor algengroei en duidt op afvalwaterlozing. Het meer is hypertroof geworden en eutrofiering drukt al zijn stempel op waterbehandeling, het aquatische leven en irrigatiesystemen. De volumetrische belasting met fosfor is in lijn met het Vollenweider Model. Het model werd gebruikt om de inkomende fosforbelasting te bepalen zodanig dat oligotrofe condities konden worden gehandhaafd. De verkregen waarde van 10.0 t/jaar TF wordt geacht onhaalbaar te zijn in de huidige omstandigheden omdat dit niveau lager is dan dat welke alleen al via de diffuse bronnen het meer bereikt. Een 1970 niveau van 75.0 tjaar wordt aanbevolen als een voorlopige doelstelling omdat het de invloed van afvalwatereffluent uitsluit. Op de lange termijn is het aanbevolen dat een schone technologie benadering (het voorkomen/verminderen van vervuiling en hergebruik) wordt aangenomen met het hergebruik van nutriënten in gecontroleerde stedelijke landbouw.

Hoofdstuk 4 richt de aandacht op manieren voor het duurzame beheer van water en nutriënten (stikstof en fosfor) in Harare. De Dublin principes over waterbesparing, milieubescherming, hergebruik, en economisch gebruik van water werden gebruikt als basis voor de formulering van innovatieve oplossingen. Waterbesparings-, waterbehandelings- en waterhergebruik strategieën werden ontwikkeld, van waterbesparende voorzieningen in het huishouden, regulering, lekdetectie en - reparatie, tot afvalwaterbehandeling en - hergebruik. Drie niveaus waarop afvalwater zou kunnen worden behandeld - 'op eigen terrein', gedecentraliseerd en gecentraliseerd - werden besproken en oplossingen gepresenteerd. Hiermee gerelateerd wordt een "3-Staps-Benadering voorgesteld gericht op het duurzame gebruik van water en andere grondstoffen in het stedelijke milieu. Deze benadering bestaat uit het voorkomen of minimaliseren van vervuiling (stap 1), hergebruik na behandeling (stap 2), en lozing in het milieu met de stimulering van de zelfreinigende capaciteit van het ontvangende milieu (stap 3). Het is aangetoond dat de voorgestelde benadering de huidige waterverontreiniging en toekomstige waterschaarste problemen in Harare substantieel zou kunnen verminderen.

De strategieën die worden voorgesteld in hoofdstuk 4 zouden kunnen resulteren in een veel omslachtiger pakket van eisen aan het beheer dan momenteel het geval is. Dit zou goed 
georganiseerde en adequaat reagerende instituties vereisen. Technologiekeuze, met nadruk op het verhalen van de kosten en winstgevend hergebruik van nutriënten is ook cruciaal. Technologieën die voldoen aan bovenstaande eisen en worden ondersteund door lokale kennis zouden een beginpunt kunnen zijn. Verschillende benaderingen en technologieën zouden kunnen worden toegepast in verschillende gebieden. De beste manier om optimale resultaten te bereiken is door middel van het integreren van verschillende opties voor 'op eigen terrein', gedecentraliseerd en gecentraliseerd afvalwaterbeheer. Een gefaseerde implementatie is nodig waarbij de voordelen in de tijd kunnen worden gerealiseerd. Echter, beheersoplossingen zoals het bannen van fosfor-bevattende wasmiddelen, standaarden voor de lozing van industrieel effluent, progressieve watertarieven en nieuwe voorschriften voor sanitaire voorzieningen zouden op korte termijn kunnen worden geïmplementeerd. Dit zou de implementatie van concrete acties stimuleren. Water vervuiling and mogelijke toekomstige waterschaarste problemen in Harare zouden kunnen worden opgelost door middel van een geïntegreerde benadering van het afvalwaterbeheer zoals in dit hoofdstuk voorgesteld. Het traditioneel benaderen van de waterkwantiteits- en - kwaliteitsproblemen van het Chivero meer is te duur en zal niet in staat zijn de vereiste reductie in gebruik en vervuiling te bewerkstelligen. Een meer creatieve benadering is daarom vereist. Zo'n benadering begint met het voorkomen/verminderen van vervuiling en het hergebruik op het 'eigen terrein' niveau, leidend tot het geleidelijk aan uitfilteren van nutriënten naar het gedecentraliseerde en gecentraliseerde niveau. Dit zal ervoor zorgen dat slechts een kleine fractie van de nutriënten de centrale zuivering zal bereiken en mogelijkerwijs zal worden geloosd in het Chivero meer.

Een gedetailleerde beschouwing van opties voor de gedifferentieerde benadering, gebaseerd op de 3-Staps-Benadering, wordt gegeven in de hoofdstukken $5-7$.

Hoofdstuk 5 geeft een overzicht van de opties voor de 'op eigen terrein' behandeling van afvalwater in Harare. Het concentreert op drie doelstellingen: a) de kwantificering van afvalwater dat zou kunnen worden behandeld en hergebruikt 'op eigen terrein', b) de identificatie van behandelings- en hergebruikopties voor verschillende categorieën van landgebruik, en c) het voorspellen van het totale effect van deze opties op de benedenstroomse waterkwaliteit. Ongeveer $304,000 \mathrm{~m}^{3} / \mathrm{d}$ afvalwater, $17,500 \mathrm{~kg} / \mathrm{d}$ stikstof en $2,600 \mathrm{~kg} / \mathrm{d}$ fosfor worden geproduceerd in Harare en vervolgens 'op eigen terrein' behandeld ( $8 \%$ van de totale stroom) of in vijf afvalwaterbehandelings inrichtingen $(92 \%)$. Van deze hoeveelheden zou in principe $39 \%$ van het debiet, $14 \%$ van de stikstof en $16 \%$ van de fosfor 'op eigen terrein' kunnen worden behandeid. Grijswaterscheiding bleek de meeste effectieve maatregel voor de reductie met $52 \%$ van de huidige debieten die de afvalwaterbehandeling inrichtingen bereiken, maar zou slechts $6 \%$ stikstof en $37 \%$ fosfor verwijderen. Urinescheiding zou een effectieve maatregel kunnen zijn voor de verwijdering van $52 \%$ stikstof en $34 \%$ fosfor. 
De 'op eigen terrein' behandeling- en hergebruikstrategie zou besparingen van $27 \%$ op het debiet, van 54\% op het TS en van 42\% op het TF mogelijk maken bij het jaar 2015 van een belasting welke anders naar de afvalwaterbehandeling inrichtingen van Harare zou gaan. $\mathrm{Er}$ kan worden geconcludeerd dat grote reducties mogelijk zijn in afvalwaterdebieten van woningen behalve in stadsgebieden met hoge bevoikingsdichtheid waar kleine grondoppervlakken op eigen terrein' hergebruikopties onmogelijk maken.

Hoofdstuk 6 behandelt opties voor het gedecentraliseerde beheer van afvalwater in Harare. Dit hoofdstuk concentreert op 1) de kwantificering van afvalwater dat zou kunnen worden behandeld op het decentrale niveau, 2) de formulering van een strategie voor decentrale behandeling en hergebruik, en 3) de inschatting van het potentiële effect van een strategie voor decentrale behandeling en hergebruik in Harare. Case studies worden gepresenteerd van gedecentraliseerd afvalwaterbeheer dat gebruik maakt van algen en eendekroos vijvers. Het concept van gedecentraliseerd afvalwaterbeheer bleek geschikt voor residentiele gebieden met een hoge en middelhoge bevolkingsdichtheid. Het is geschat dat, na vermindering van het watergebruik en de nutriëntenlozing op het niveau van het huishouden, Harare in het jaar 2015 een productie zou hebben van $366,000 \mathrm{~m}^{3} / \mathrm{d}$ afvalwater, die $39,000 \mathrm{~kg} / \mathrm{d}$ TS en $4,000 \mathrm{~kg} / \mathrm{d}$ TF zou bevatten. Gedecentraliseerde systemen zouden in staat zijn ongeveer $55 \%$ van het debiet, $\mathbf{8 4} \%$ van de TS en $80 \%$ van de TF te verwerken. Door het combineren van maatregelen ter vermindering of voorkoming van afvalwater bij de bron, zou Harare de afwatering naar het Chivero meer van effluent van afvalwaterbehandeling inrichtingen kunnen verminderen met meer dan $90 \%$. Derhalve werd geconcludeerd dat een benadering van decentralisatie, met gebruikmaking van natuurlijke afvalwaterbehandeling methoden (of andere 'low-cost' methoden), een effectieve component zou kunnen zijn van een strategie voor het duurzame beheer van (afval-)water voor Harare. Echter, het succes van zo'n strategie zou sterk afhangen van de socio-economische, institutionele en gezondheid-gerelateerde aspecten die samenhangen met hergebruik van afvalwater.

Hoofdstuk 7 beschrijft de prestatie van het huidige gecentraliseerde systeem voor het beheer van afvalwater in Harare en suggereert mogelijkheden voor de verbetering hiervan. Het is gebaseerd op een studie die maandelijks de waterkwaliteit controleerde in de periode juni 2000 tot december 2001 in een gebied met daarin vijf afvalwaterbehandeling inrichtingen naast de Marimba en Mukuvisi rivieren die het belangrijkste deel van het effluent van afvalwaterbehandeling inrichtingen ontvangen. De studie toonde aan dat van alle afvalwaterbehandeling inrichtingen, de efficiëntie voor de verwijdering van nutriënten slecht was. Gemiddeld werd $24 \%$ TS en $8 \%$ TF verwijderd. Hieruit kon worden geconcludeerd dat de huidige situatie, in milieutechnisch opzicht, niet duurzaam is omdat het Chivero meer wordt 
vervuild. De 3-Staps-Benadering werd toegepast en dit resulteerde in aanbeveling van de volgende acties voor de verbetering van het huidige systeem voor afvalwaterbeheer in Harare.

I Vervanging van de bestaande oxidatiebedden in Crowborough en Firle welke geen redelijke verwijderingspercentages gaven voor nutriënten en organisch materiaal. In deze optie moet primaire behandeling worden gevolgd door anaërobe behandeling en het effluent hiervan moet worden gepompt naar opslagvijvers van waar het gaat naar commerciële boerderijen voor irrigatie.

II Verbetering van het huidige systeem van biologisch nutriënt verwijdering op Crowborough en Firle (totale capaciteit $126,000 \mathrm{~m}^{3} / \mathrm{d}$ ) door rehabilitatie en uitbreiding met behandelingsunits. Een zeer hoge kwaliteit kan worden bereikt (BOD $<20 \mathrm{mg} / \mathrm{l}$, TS $<5$ $\mathrm{mg} / \mathrm{l}, \mathrm{TF}<0.5 \mathrm{mg} / \mathrm{l})$, welke dan zou kunnen worden geloosd in het Chivero meer. Omdat het water in het Chivero meer minder verontreinigd zal zijn, zal drinkwaterbehandeling gemakkelijker worden en een duurzame waterkringloop kan in ere worden hersteld. In alle gevallen moet slib apart worden gehouden en geschikt gemaakt voor het storten.

III Vergroting van de stedelijke waterkringloop door al het water voor stedelijk gebruik te onttrekken aan het Manyama meer hetgeen direct stroomafwaarts van het Chivero meer is gelegen. Dit zou de waterlichamen meer tijd en capaciteit geven om zich te herstellen.

Hoofdstuk 8 is gebaseerd op een gedetailleerde evaluatie van het Crowborough weideirrigatiesysteem. De boerderij ligt in het deelstroomgebied van de Marimba rivier en heeft 355 hectaren geïrrigeerd gebied. De weiden worden eens per 3 weken geïnundeerd met een combinatie van effluent van het oxidatiebed en slib afkomstig van de Croborough afvalwaterbehandelinginrichting. Studies werden uitgevoerd van juli 2000 tot februari 2001 op het gebied van het nutriëntenbeheer (stikstof en fosfor) van de weidegebieden en de invloed daarvan op de Marimba rivier. Water- en nutriëntenbalansen werden ontwikkelend. Gemiddelde verwijderings efficiencies voor nutriënten voor deze weidegebieden bleken $84 \%$ voor TS en $54 \%$ voor PF te zijn. Zowel de Crowborough afvalwaterbehandeling inrichting als de weidegebieden bleken overbelast te zijn. Op basis van huidige Zimbabwaanse richtlijnen voor het veilig lozen van effluent op land, is ongeveer 2800 ha vereist voor effluent- en sliblozing. Indien alleen effluent zou worden toegepast, zou een landoppervlak van 2100 ha nodig zijn, vergeleken met de huidige 305 ha die wordt geïrrigeerd.

Denitrificatie en ammonia volatilisatie worden gezien als de belangrijkste verwijderingsmechanismen voor stikstof terwijl de capaciteit van de bodem beperkt is voor de absorptie van fosfor. De vereiste veegraasdichtheid is overschreden hetgeen een nadelige invloed heeft op het beheer van het irrigatiegebied. De aanleverende afvalwaterbehandeling inrichtingen zijn overbelast en leveren daardoor mindere kwaliteit effluent aan de boerderij. De installatie is urgent toe aan een renovatie. Het gemeentebestuur van Harare zou het terugwinnen van 
grondstoffen kunnen bevorderen door het gras van het weidegebied te oogsten en het verkopen van de koeienmest aan bewoners in de buurt. Mais productie is een andere, mogelijk meer aantrekkelijk alternatief. Het mengen van het effluent en het slib na het behandelingsproces moet worden gestopt daar slib een scala aan pollutanten bevat die apart en veilig kunnen worden geloosd. Vanuit het oogpunt van het beheer van nutriënten is de invoer van nutriënten als supplementair veevoer niet wenselijk.

Hoofdstuk 9 beschrift een afvalwaterbeheersplan voor Harare dat de resultaten van de vorige hoofdstukken integreren. Weer werd de 3-Stappen-Benadering gebruikt. Drie implementatiefasen werden beschouwd gebaseerd op korte termijn ( $<5$ jaar), middellange termijn $(5-10$ jaar), en lange termijn (>10 jaar) oplossingen. Hiervan zouden korte termijn maatregelen de afvalwaterstroom verminderen met $24 \%$ TS en $5 \%$ TF. Middels modellering wordt voorspeld dat de TS en TF concentraties in het meer zullen dalen tot respectievelijk $0.4 \mathrm{mg} / \mathrm{l}$ and $0.07 \mathrm{mg} / \mathrm{l}$ door maatregelen voor de middellange termijn. Er kon worden geconcludeerd dat het inderdaad mogelijk is om vervuilingniveaus te verminderen in het stroomgebied door middel van het gefaseerd implementeren van maatregelen. De korte termijn oplossingen behelzen de vermindering van de afvalwaterstroom middels schone technologie benaderingen en proces modificaties in de industrie, het bannen van fosfor bevattende detergenten, en het hergebruik van nutriënten, met als overall doelstelling het verbeteren van de waterbeschikbaarheid en het onder controle brengen van vervuiling. De middellange term oplossingen zijn o.a. de decentrale behandeling van afvalwater van alle nieuwe woongebieden, het gebruiken van de huidige capaciteit van de biologische nutriënten verwijderingsinstallaties om het afvalwater tot hogere standaarden te behandelen, en de regulering/controle van regenwaterkwaliteit en stedelijke landbouw. Een lange termijn oplossing is gesuggereerd op basis van het voorkomen van vervuiling en direct hergebruik, behandeling 'op eigen gebied' en decentrale niveaus gevolgd door hergebruik, en de minimale lozing van het overblijvende effluent in combinatie met het stimuleren van de zelfreinigende capaciteit van de ontvangende rivieren. Hoofdstuk 9 laat zien dat waterkwaliteitsverbeteringen in het Chivero meer mogelijk zijn. 


\section{Curriculum Vitae}

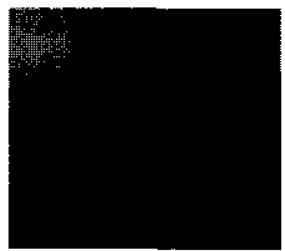

Innocent Nhapi was born on 11 December 1966 in the Chegutu District of Zimbabwe. He finished his advanced level education at Allan Wilson School in November 1985. In March 1986 he joined the University of Zimbabwe from where he obtained a Bachelor of Technology degree in Civil Engineering in November 1990. From that time up to the end of December 1998 he worked for Redcliff Municipality in Zimbabwe as a municipal engineer in various capacities. During that time, he obtained a postgraduate diploma in Project Planning and Management from the University of Zimbabwe (November 1993) and a masters degree in water engineering from the University of Technology, Sydney, Australia (July 1997). He also studied by distance learning and obtained Diploma in Business Administration from the Zimbabwe Institute of Management.

In January 1999 he joined the University of Zimbabwe as a Staff Development Fellow and pursued PhD studies with the UNESCO-IHE Institute for Water Education under a regional Capacity Building Project funded by the SAIL Project of the Netherlands. The research was carried out in Zimbabwe and focused on wastewater management in Harare.

Innocent's address in Zimbabwe is:

P.O. Box 5946

Harare

Zimbabwe

Tel. 263 (0)23 414529

Fax. $263(0) 4303288$

Email: inhapi@eng.uz.ac.zw 